Marcel Ayres de Araújo

Metodologia Baseada em Medidas Dispersas de Tensão e Árvores de Decisão para Localização de Faltas em Sistemas de Distribuição

Modernos 

Marcel Ayres de Araújo

\section{Metodologia Baseada em Medidas Dispersas de Tensão e Árvores de Decisão para Localização de Faltas em Sistemas de Distribuição Modernos}

Tese apresentada a Escola de Engenharia de São Carlos, Universidade de São Paulo, como parte dos requisitos para obtenção do Título de Doutor em Ciências, Programa de Engenharia Elétrica, área de concentração em Sistemas Dinâmicos.

Orientador: Prof. Dr. Rogério Andrade Flauzino

São Carlos 2017 


\section{AUTORIZO A REPRODUÇÃO TOTAL OU PARCIAL DESTE TRABALHO, POR QUALQUER MEIO ÇONVENCIONAL OU ELETRÔNICO, PARA FINS DE ESTUDO E PESQUISA, DESDE QUE CITADA A FONTE.}

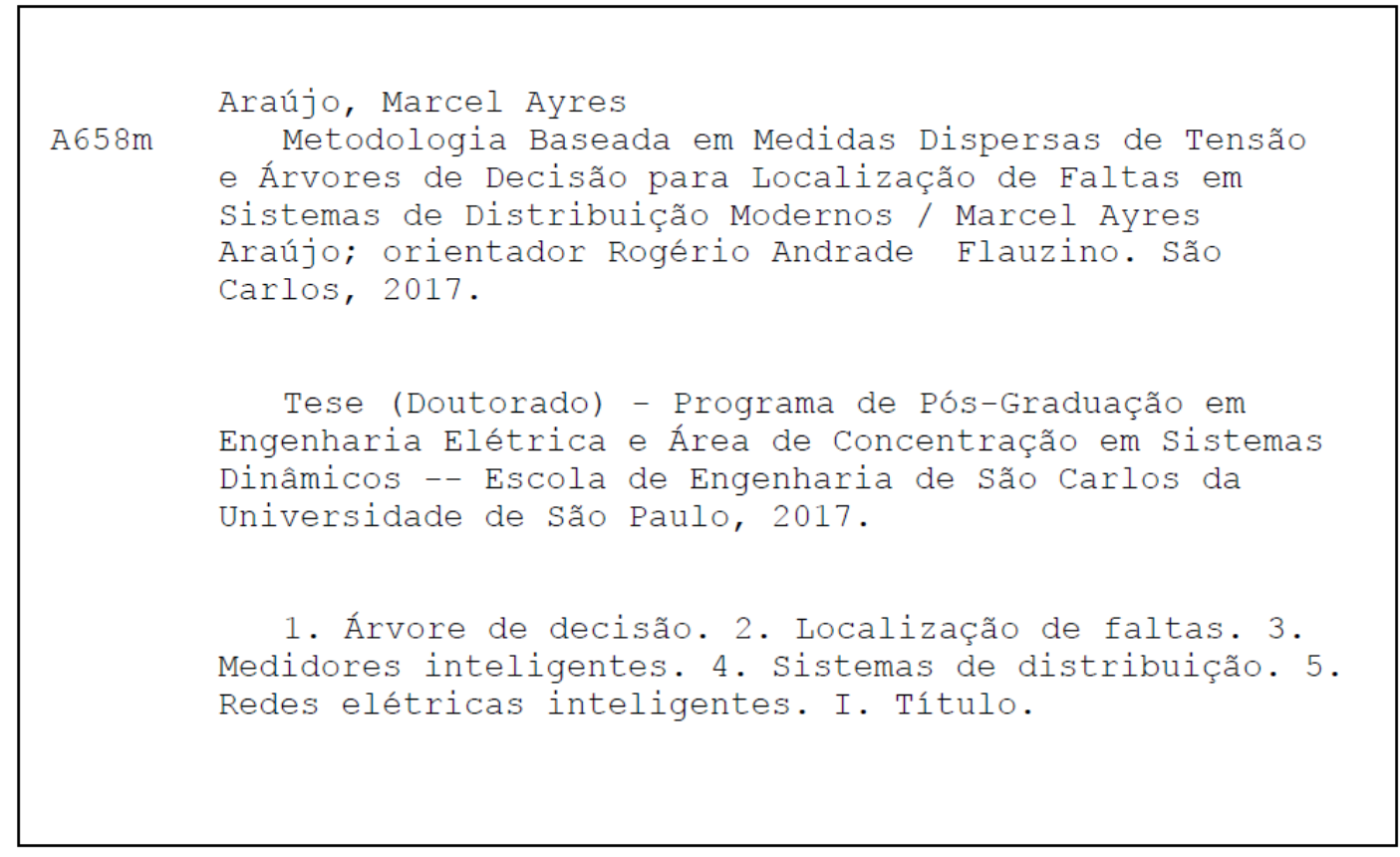




\section{FOLHA DE JULGAMENTO}

Candidato: Engenheiro MARCEL AYRES DE ARAUJO.

Título da tese: "Metodologia baseada em medidas dispersas de tensão e árvores de decisão para localização de faltas em sistemas de distribuição modernos".

Data da defesa: 06/10/2017.

Comissão Julgadora:

\section{Resultado:}

Prof. Associado Rogério Andrade Flauzino (Orientador)

(Escola de Engenharia de São Carlos/EESC)

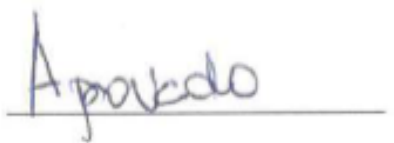

Prof. Associado Ivan Nunes da Silva

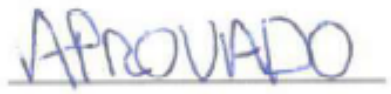

(Escola de Engenharia de São Carlos/EESC)

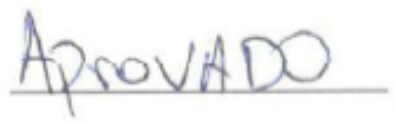

Prof. Dr. Renato Machado Monaro

(Escola Politécnica/EP-USP)

Prof. Dr. Fábio Bertequini Leão

ApROVADO (Universidade Estadual Paulista "Júlio de Mesquita Filho"/UNESP-Ilha Solteira)

Prof. Dr. Madson Cortes de Almeida

(Universidade Estadual de Campinas/UNICAMP)

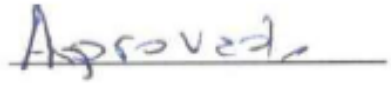

Coordenador do Programa de Pós-Graduação em Engenharia Elétrica: Prof. Associudo Luís Fernando Costa Alberto

Presidente da Comissão de Pós-Graduação:

Prof. Associado Luís Fernando Costa Alberto 



\section{DEDICATÓRIA}

Aos meus

familiares e amigos. 



\section{AGRADECIMENTOS}

Gostaria de fazer um agradecimento especial ao meu orientador Rogério Andrade Flauzino pela oportunidade concedida, orientação, incentivo e confiança depositada para realização desta pesquisa.

Ao professor José Carlos de Melo Vieira Júnior, primeiro orientador em minha vida acadêmica, pelas orientações, incentivo, amizade e atenção sempre prestada a mim.

A todos os professores da Escola de Engenharia de São Carlos que contribuíram para minha graduação e pós-graduação em Engenharia Elétrica pela Universidade de São Paulo.

A todos os funcionários do Departamento de Engenharia Elétrica e de Computação EESC-USP que colaboraram com o desenvolvimento desta pesquisa.

Aos amigos de pós-graduação Cesar Martins, Fabbio Borges, Lucas Moraes, Luisa Liboni, Sergio Yoneda e Oureste Batista pelas contribuições e trabalhos em conjunto. 



\section{RESUMO}

Araújo, M. A. (2017). Metodologia Baseada em Medidas Dispersas de Tensão e Árvores de Decisão para Localização de Faltas em Sistemas de Distribuição Modernos. Tese de Doutorado apresentada à Escola de Engenharia de São Carlos, Universidade de São Paulo, São Carlos, 2017.

Nos sistemas de distribuição, a grande ramificação, radialidade, heterogeneidade, dinâmica das cargas e demais particularidades, impõem dificuldades à localização de faltas, representando um desafio permanente na busca por melhores indicadores de continuidade e confiabilidade no fornecimento de energia elétrica. A regulação incisiva dos órgãos do setor, a penetração de geração distribuída e a tendência de modernização trazida pelas redes inteligentes, demandam detalhados estudos para readequação dos sistemas elétricos a conjuntura atual. Neste contexto, esta tese propõe o desenvolvimento de uma metodologia para localização de faltas em sistemas de distribuição empregando a capacidade dos medidores inteligentes de monitoramento e de aquisição de tensão em diferentes pontos da rede elétrica. A abordagem proposta baseia-se na estimação, por ferramentas de aprendizado de máquina, das impedâncias de sequência zero e positiva entre os pontos de alocação dos medidores inteligentes e de ocorrência de falta, e do estado de sensibilização destes medidores frente a correntes de falta. Assim, calculando-se as respectivas distâncias elétricas em função das impedâncias estimadas e definidas as direções das mesmas em relação a topologia da rede, busca-se identificar o ponto ou área com maior sobreposição de distâncias elétricas como o local ou a região de maior probabilidade da falta em relação aos medidores inteligentes. Para tanto, faz-se uso combinado de ferramentas convencionais e inteligentes pela aplicação dos conceitos de análise de sistemas elétricos, diagnóstico dos desvios de tensão, e classificação de padrões por meio da técnica de aprendizado de máquina denominada Árvore de Decisão. Os resultados obtidos pela aplicação desta metodologia demonstram que o uso de informações redundantes fornecidas pelos medidores inteligentes minimiza os erros de estimação. Além disso, para a maior parte dos casos testados o erro absoluto máximo de localização da falta se concentra entre $200 \mathrm{~m}$ e $1000 \mathrm{~m}$, o que reduz a busca pelo local de ocorrência da falta pelas equipes de manutenção da rede elétrica.

Palavras-chave: Árvore de decisão, Localização de faltas, Medidores inteligentes, Sistemas de distribuição, Redes elétricas inteligentes. 



\section{ABSTRACT}

Araujo, M. A. (2017). Methodology Based on Dispersed Voltage Measures and Decision Trees for Fault Location in Modern Distribution Systems. Thesis Doctorate Degree presented to the São Carlos School of Engineering, University of São Paulo, São Carlos, 2017.

In distribution systems, the dense branching, radial pattern, heterogeneity, dynamic of the loads, and other characteristics create several difficulties in defining the fault location, representing a great challenge in the search for better continuity and reliability indicators of the electrical energy supply. The intense government regulations, the increasing use of distributed generation, and the trend towards modernization via smart grids require a detailed study in order to upgrade the current systems. In this context, this thesis proposes a methodology development for fault location in distribution systems with the use of smart meters monitors and the acquisition of voltage at different points in the electrical network. The proposed method is based on the estimation, using machine learning, of the state of awareness of smart meters across the fault currents and of the zero and positive sequence impedance between the location of these meters and of the fault occurrence. Therefore, by calculating the electrical distances as a function of the estimated impedances and defining its the direction in relation to the network topology, the point/region with the biggest superposition of the electrical distances can be assigned as the point/region with the highest probability of fault occurrence in relation to the smart probes. For this purpose, a machine learning technique named decision tree is used to apply concept analyses to the electrical systems, diagnosis of voltage deviations, and pattern recognition of the electrical systems. The results obtained by the application of this methodology demonstrate that the use of redundant information provided by the smart meters minimizes estimation errors. In addition, for most of the cases tested, the maximum absolute error of the fault location is concentrated between $200 \mathrm{~m}$ and $1000 \mathrm{~m}$, which reduces the search for the fault location by the maintenance teams of the electrical network.

Keywords: Decision tree, Fault location, Distribution systems, Smart grid, Smart meters. 



\section{LISTA DE SIGLAS E ABREVIATURAS}

$\checkmark$ AD - Árvore de Decisão

$\checkmark$ ABDI - Agência Brasileira de Desenvolvimento Industrial

$\checkmark$ AM - Aprendizado de Máquina

$\checkmark$ AMI-Advanced Metering Infrastructure

$\checkmark$ AMM-Advanced Meter Management

$\checkmark$ AMR-Automated Meter Reading

$\checkmark$ ANEEL - Agência Nacional de Energia Elétrica

$\checkmark$ CCM - Centro de Controle de Medição

$\checkmark$ CGEE - Centro de Gestão e Estudos Estratégicos

$\checkmark$ DFR - Digital Fault Recorders

$\checkmark$ DOE-Department of Energy

$\checkmark$ DSP - Digital Signal Processing

$\checkmark$ EPRI-Electric Power Research Institute

$\checkmark$ GD - Geração Distribuída

$\checkmark$ GPRS - General Packet Radio Services

$\checkmark$ GPS - Sistema de Posicionamento Global

$\checkmark$ IED - Intelligent Electronic Devices

$\checkmark$ KDD-Knowledge Discovery in Databases

$\checkmark$ MCTI - Ministério da Ciência, Tecnologia e Inovação

$\checkmark$ MDM-Meter Data Management

$\checkmark$ NIST - National Institute of Standards and Technology

$\checkmark$ PMC - Perceptron Multicamadas

$\checkmark$ PRODIST - Procedimentos de Distribuição de Energia Elétrica no Sistema Elétrico Nacional

$\checkmark$ QEE - Qualidade da Energia Elétrica

$\checkmark$ RBF - Função de Base Radial

$\checkmark$ REI - Rede Elétrica Inteligente

$\checkmark$ RFE-Recursive Feature Elimination

$\checkmark$ RNA - Rede Neural Artificial

$\checkmark$ SCADA - Supervisory Control and Data Acquisition

$\checkmark$ SEP - Sistema Elétrico de Potência

$\checkmark$ WEKA - Waikato Environment for Knowledge Analysis 



\section{LISTA DE FIGURAS}

Figura 2-1: Diagrama de blocos da constituição dos SEPs. ................................................. 15

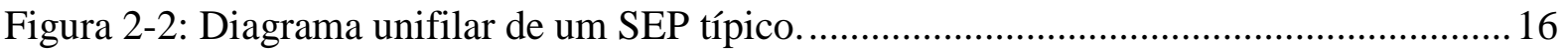

Figura 2-3: Representação de uma Rede Elétrica Inteligente................................................ 20

Figura 2-4: Representação básica da Infraestrutura de Medição Avançada............................26

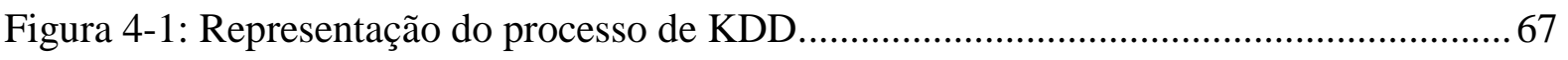

Figura 4-2: Etapas do processo de classificação de padrões. .................................................. 73

Figura 4-3: Árvore de decisão para diagnostico da saúde de um paciente.............................. 77

Figura 4-4: Processo de classificação de duas classes utilizando a estratégia de "dividir para conquistar" das AD: (a) obtenção da primeira fronteira de decisão; (b) segunda fronteira de decisão 80

Figura 4-5: Nó raiz para a Árvore de Decisão. .86

Figura 4-6: Combinação do atributo "Umidade" com atributo dia por meio da aresta "Ensolarado". . .87

Figura 4-7: Árvore de Decisão para o estudo de caso dos dados exemplo .88

Figura 4-8: Árvore de Decisão não compacta antes da Poda. ................................................91

Figura 4-9: Árvore de Decisão não compacta após a Poda. .................................................... 92

Figura 5-1: Ilustração representativa dos princípios básicos do método proposto................. 101

Figura 5-2: Representação da sensibilização e medição de impedâncias dos medidores em relação ao ponto de falta.

Figura 5-3: Representação da sensibilização e medição das distâncias elétricas dos medidores em relação ao ponto de falta. 105

Figura 5-4: Disposição geográfica da rede primária do alimentador de distribuição real..... 108 Figura 5-5: Diagrama de blocos da modelagem no MATLAB/Simulink do alimentador piloto.

Figura 5-6: Tensões normalizadas: (a) Fase A; (b) Fase B. ................................................ 111

Figura 5-7: Tensões normalizadas: (a) Fase C; (b) entre Fases A e B. ................................ 112

Figura 5-8: Tensões normalizadas: (a) entre Fases B e C; (b) entre Fases C e A. ................ 112 Figura 5-9: Tensões normalizadas: (a) componente de sequência zero; (b) componente de

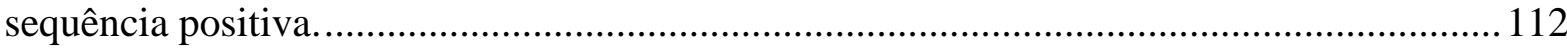

Figura 5-10: Tensões normalizadas: componente de sequência negativa. ........................... 113 
Figura 5-11: Tensões normalizadas: (a) componente real da Fase B; (b) componente imaginária da Fase B.

Figura 5-12: Tensões normalizadas: (a) componente real da Fase C; (b) componente imaginária da Fase C.

Figura 5-13: Tensões normalizadas: (a) componente real da Fase AB; (b) componente imaginária da Fase AB.

Figura 5-14: Tensões normalizadas: (a) componente real da Fase BC; (b) componente imaginária da Fase BC.

Figura 5-15: Tensões normalizadas: (a) componente real da Fase CA; (b) componente imaginária da Fase CA.

Figura 5-16: Tensões normalizadas: (a) componente real de $\mathrm{V}_{0}$; (b) componente imaginária de $\mathrm{V}_{0}$.

Figura 5-17: Tensões normalizadas: (a) componente real de $\mathrm{V}_{1}$; (b) componente imaginária de $\mathrm{V}_{1}$. 115

Figura 5-18: Tensões normalizadas: (a) componente real de $\mathrm{V}_{2}$; (b) componente imaginária de $\mathrm{V}_{2}$.

Figura 5-19: Número de ocorrência de sensibilização ou não por correntes de falta dos medidores inteligentes. 116

Figura 5-20: Impedâncias normalizadas: (a) sequência zero; (b) sequência positiva........... 116

Figura 6-1: Taxa de acerto dos classificadores da impedância $\mathrm{Z}_{0}$.

Figura 6-2: Taxa de acerto dos classificadores da impedância $Z_{1}$.

Figura 6-3: Quantidade de dados utilizada pelos classificadores da impedância $Z_{0} \ldots \ldots \ldots \ldots . . . .125$

Figura 6-4: Quantidade de dados utilizada pelos classificadores da impedância $Z_{1}$............ 125

Figura 6-5: Tamanho das ADs induzidas por classes e agrupamentos das impedâncias para $\mathrm{Z}_{0}$.

Figura 6-6: Tempo de construção das ADs induzidas por classes e agrupamentos das impedâncias para $\mathrm{Z}_{0}$.

Figura 6-7: Tamanho das ADs induzidas por classes e agrupamentos das impedâncias para $\mathrm{Z}_{1}$.

Figura 6-8: Tempo de construção das ADs induzidas por classes e agrupamentos das impedâncias para $\mathrm{Z}_{1}$.

Figura 6-9: Índices da Estatística Kappa para os classificadores da impedância $Z_{0}$.

Figura 6-10: Índices da Estatística Kappa para os classificadores da impedância $Z_{1}$.

Figura 6-11: Taxa de erro absoluto médio para os classificadores da impedância $\mathrm{Z}_{0}$. 
Figura 6-12: Taxa de erro absoluto médio para os classificadores da impedância $Z_{1} \ldots \ldots \ldots . . .130$

Figura 6-13: Taxa de erro relativo absoluto para os classificadores da impedância $Z_{0}$....... 131

Figura 6-14: Taxa de erro relativo absoluto para os classificadores da impedância $Z_{1}$........131

Figura 6-15: Taxa da raiz do erro médio quadrático para os classificadores da impedância $\mathrm{Z}_{0}$.

Figura 6-16: Taxa da raiz do erro médio quadrático para os classificadores da impedância $\mathrm{Z}_{1}$.

Figura 6-17: Taxa da raiz do erro relativo quadrático para os classificadores da impedância $\mathrm{Z}_{0}$.

Figura 6-18: Taxa da raiz do erro relativo quadrático para os classificadores da impedância $Z_{1}$.

Figura 6-19: Comparativo entre valores estimados e reais da impedância $Z_{0}$ para o conjunto de dados de validação. 140

Figura 6-20: Erro de estimação da impedância $Z_{0}$ para o conjunto de dados de validação. . 140 Figura 6-21: Comparativo entre valores estimados e reais para a distância da falta em função da impedância $\mathrm{Z}_{0}$ para o conjunto de dados de validação.

Figura 6-22: Erro de estimação da distância da falta em função da impedância $Z_{0}$ para o conjunto de dados de validação. 142

Figura 6-23: Comparativo entre valores estimados e reais da impedância $Z_{1}$ para o conjunto de dados de validação.

Figura 6-24: Erro de estimação da impedância $Z_{1}$ para o conjunto de dados de validação. . 144 Figura 6-25: Comparativo entre valores estimados e reais para a distância da falta em função da impedância $Z_{1}$ para o conjunto de dados de validação. 145

Figura 6-26: Erro de estimação da distância da falta em função da impedância $Z_{1}$ para o conjunto de dados de validação. 146

Figura 6-27: Número de ocorrência de sensibilização ou não por correntes de falta dos medidores inteligentes para o conjunto de dados de validação

Figura 6-28: Indicação do ponto de falta na barra 462 e da estimação do estado de sensibilização dos medidores inteligentes a passagem de corrente de falta.

Figura 6-29: Indicação do ponto de falta na barra 462 e das estimações das distâncias $\mathrm{d}_{0} \ldots 151$ Figura 6-30: Indicação do ponto de falta na barra 462 e das estimações das distâncias $d_{1} \ldots 152$ Figura 6-31: Indicação do ponto de falta na barra 1421 e da estimação do estado de sensibilização dos medidores inteligentes a passagem de corrente de falta. 155 Figura 6-32: Indicação do ponto de falta na barra 1421 e das estimações das distâncias do. 156 
Figura 6-33: Indicação do ponto de falta na barra 1421, das estimações das distâncias do e da região com maior concentração de estimações.

Figura 6-34: Indicação do ponto de falta na barra 1421 e das estimações das distâncias d 1. $_{1} 158$ Figura 6-35: Indicação do ponto de falta na barra 1421, das estimações das distâncias d $\mathrm{d}_{1}$ e da região com maior concentração de estimações.

Figura 6-36: Erro absoluto máximo de localização para os testes das simulações do conjunto de validação 162 


\section{LISTA DE TABELAS}

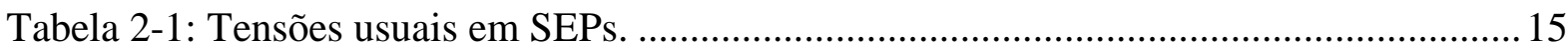

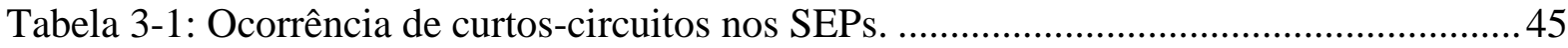

Tabela 3-2: Ocorrência de curtos-circuitos permanentes e temporários nos SEPs. ................ 45

Tabela 3-3: Principais agentes causadores de faltas em sistemas de distribuição................... 47

Tabela 3-4: Probabilidade de ocorrência para cada tipo de falta em sistemas de distribuição.

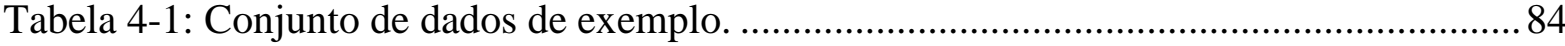

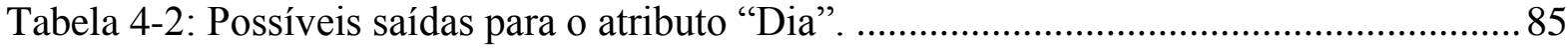

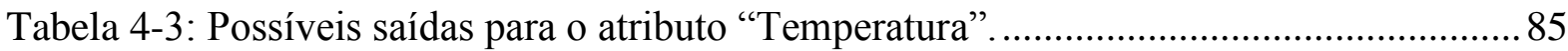

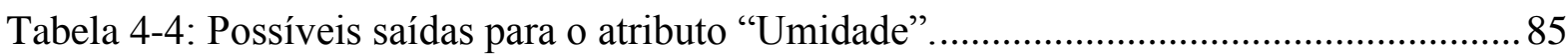

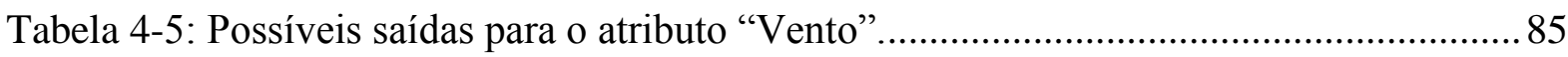

Tabela 4-6: Relacionamento da aresta "Ensolarado" com o atributo "Temperatura".............86

Tabela 4-7: Relacionamento da aresta "Ensolarado" com o atributo "Umidade"...................87

Tabela 4-8: Relacionamento da aresta "Ensolarado" com o atributo "Vento".......................87

Tabela 4-9: Relacionamento da aresta "Chuvoso" com o atributo "Temperatura"................ 88

Tabela 4-10: Relacionamento da aresta "Chuvoso" com o atributo "Vento". ........................8 88

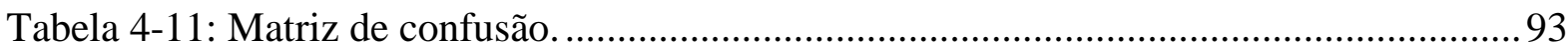

Tabela 4-12: Interpretação da Estatística Kappa. ............................................................ 95

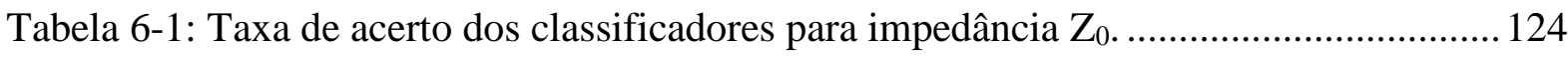

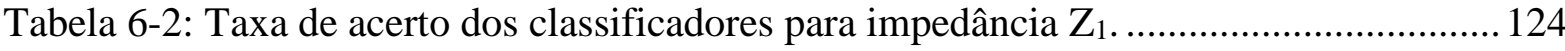

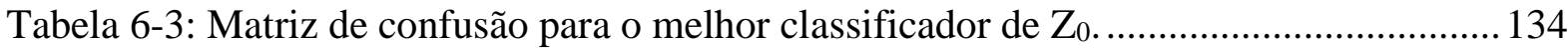

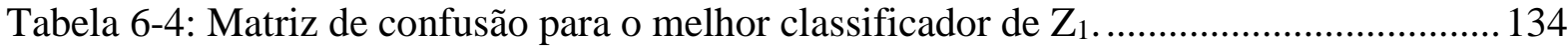

Tabela 6-5: Desempenho do classificador de $Z_{0}$ em relação aos parâmetros "confidenceFactor" e "minNumObj" do algoritmo J48. 135

Tabela 6-6: Desempenho do classificador de $Z_{1}$ em relação aos parâmetros "confidenceFactor" e "minNumObj" do algoritmo J48.

Tabela 6-7: Desempenho do classificador de sensibilização dos medidores inteligentes em relação aos parâmetros "confidenceFactor" e "minNumObj” do algoritmo J48. 138

Tabela 6-8: Erros do processo de localização de faltas para as simulações do teste de validação. 



\section{SUMÁRIO}

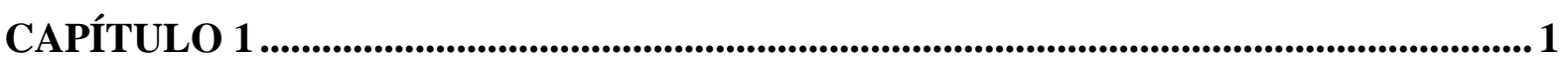

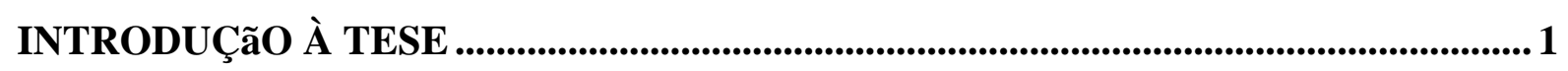

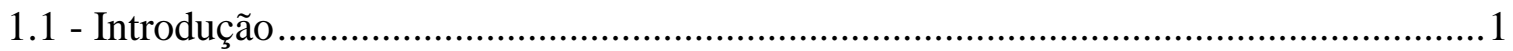

1.2 - Justificativa e Motivação da Tese ...........................................................................

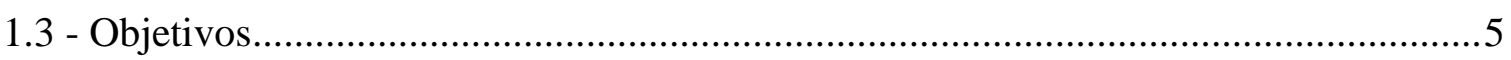

1.4 - Contribuições Originais da Tese …………………………………....................

1.5 - Atividades de Divulgação Científica............................................................................

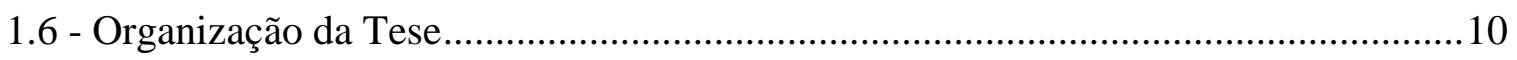

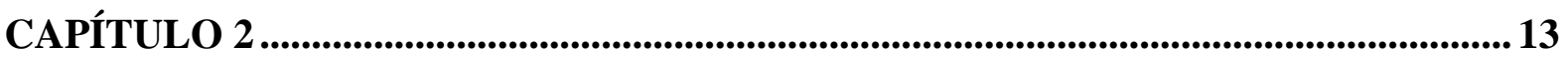

ASPECTOS RELACIONADOS AOS SISTEMAS DE DISTRIBUIÇÃO DE ENERGIA

ELÉTRICA E ÀS REDES ELÉTRICAS INTELIGENTES..............................................13

2.1 - Composição Básica dos Sistemas Elétricos de Potência ..............................................13

2.2 - Redes Elétricas Inteligentes..............................................................................17

2.3 - Características, Funcionalidades, Benefícios e Desafios das REIs ……………….....20

2.4 - Infraestrutura de Medição Inteligente ..................................................................2

2.4.1 - Infraestrutura de Medição Avançada ................................................................24

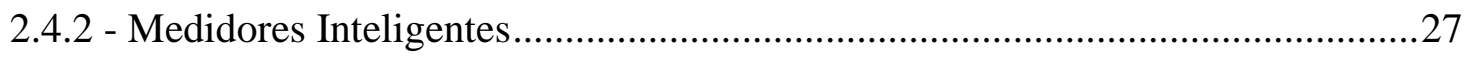

2.5 - Panorama de Desenvolvimento e Implantação das REIs ............................................28

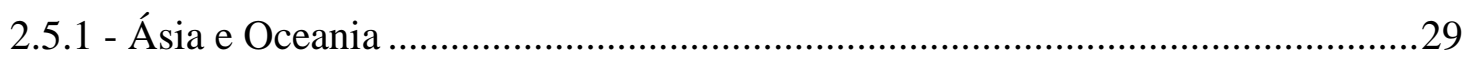

2.5.2 - Estados Unidos ............................................................................................

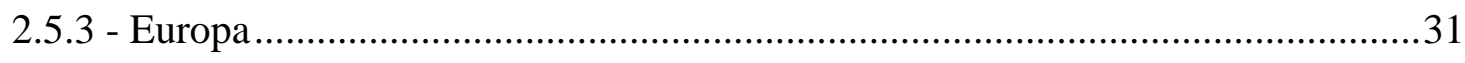

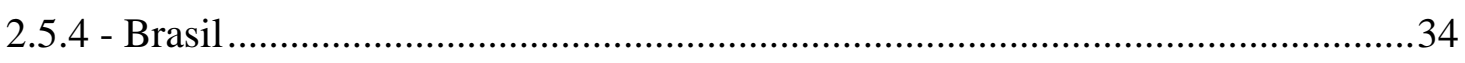

2.6 - Considerações Parciais sobre Sistemas de Distribuição de Energia Elétrica e as Redes

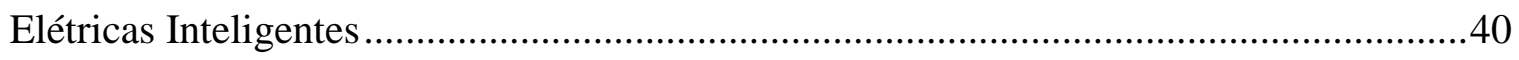

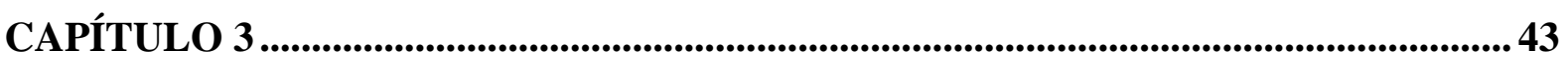

ASPECTOS RELACIONADOS À LOCALIZAÇÃO DE FALTAS EM SISTEMA DE DISTRIBUIÇÃO DE ENERGIA ELÉTRICA .................................................................... 43

3.1 - Principais Conceitos Relativos às Faltas nos Sistemas Elétricos de Potência............43

3.2 - Particularidades das Faltas nos Sistemas de Distribuição .............................................46

3.3 - Tópicos Fundamentais sobre a Localização de Faltas nos Sistemas de Distribuição48 
3.4 - Revisão Bibliográfica e Histórica dos Métodos de Localização de Faltas 50

3.5 - Considerações Parciais sobre Localização de Faltas nos Sistemas de Distribuição. 63 CAPÍTULO 4..

ASPECTOS RELACIONADOS AO APRENDIZADO DE MÁQUINA E ÀS ÁRVORES

DE DECISÃO . .65

4.1 - Conceitos Básicos sobre Extração de Conhecimento de Dados ............................... 65

4.2 - Principais Aspectos Relativos ao Aprendizado de Máquina ......................................6 68

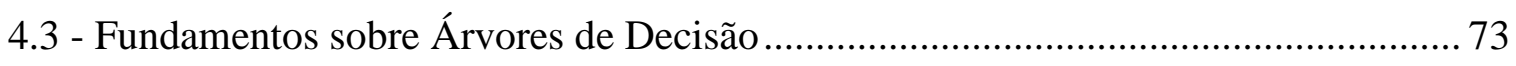

4.3.1 - Etapas do Processo de Construção de Árvores de Decisão................................. 77

4.3.2 - Exemplo de Construção de uma Árvores de Decisão ....................................... 83

4.3.3 - Métricas do classificador da Árvores de Decisão ............................................ 92

4.4 - Considerações Parciais sobre Aspectos Relacionados ao Aprendizado de Máquina e às

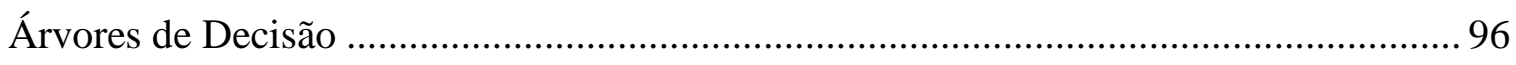

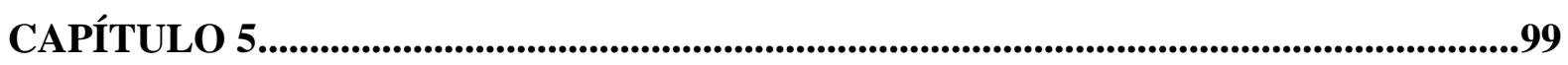

METODOLOGIA PROPOSTA PARA LOCALIZAÇÃO DE FALTAS..........................99

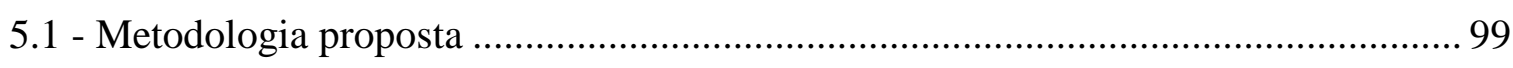

5.1.1 - Descrição das etapas da metodologia proposta ............................................ 101

5.2 - Modelagem do Sistema Elétrico sob Estudo......................................................... 106

5.2.1 - Resultados das Simulações do Sistema Elétrico sob Estudo.......................... 110

5.3 - Considerações Parciais sobre a Metodologia Proposta para Localização de Faltas 117

CAPÍTULO 6

APLICAÇÃO DA METOdOLOGIA PARA LOCALIZAÇÃo DE FALTAS EM

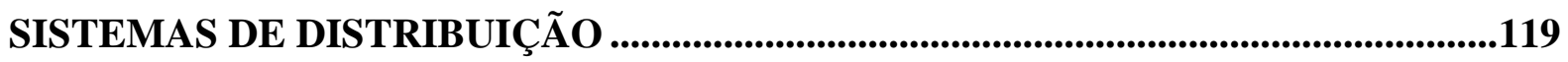

6.1 - Implementação dos Sistemas Inteligentes.......................................................... 119

6.1.1 - Definição dos Parâmetros do Algoritmo J48 para implementação das Árvores de

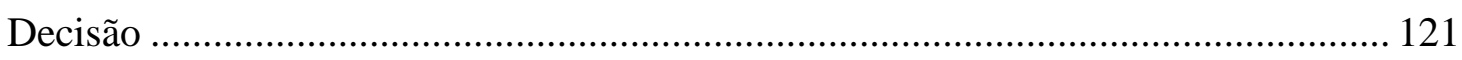

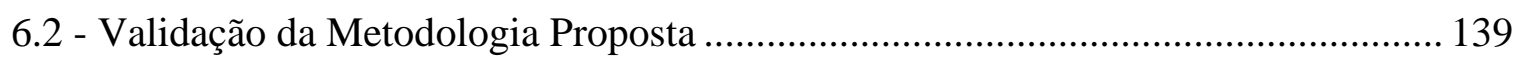

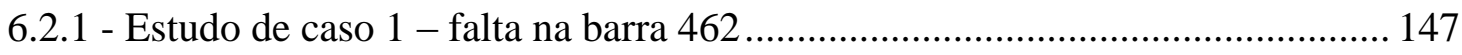

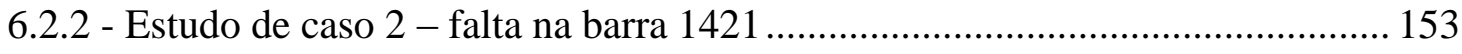

6.2.3 - Resultados da Localização de Faltas para os Casos de Validação da Metodologia Proposta

6.3 - Considerações Parciais sobre a Aplicação da Metodologia para Localização de Faltas em Sistemas de Distribuição 


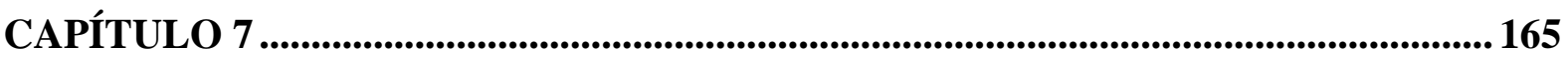

CONCLUSÕES E TRABALHOS FUTUROS............................................................... 165

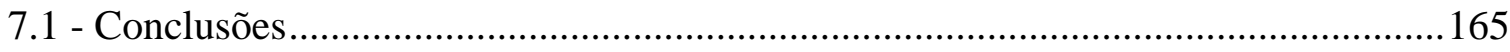

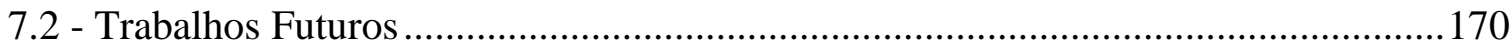

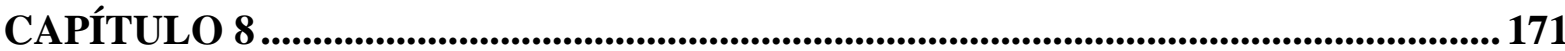

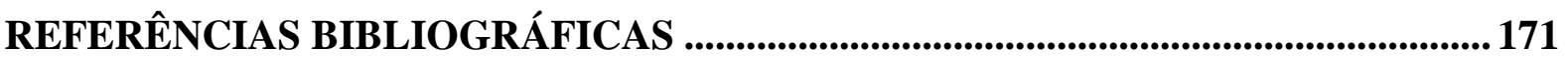





\section{CAPÍTULO 1}

\section{INTRODUÇÃO À TESE}

\section{1 - Introdução}

O crescente e contínuo desenvolvimento tecnológico e econômico atrelado ao aumento do consumo de energia elétrica vem impulsionando a permanente ampliação e modernização dos Sistemas Elétricos de Potência (SEP). A expansão dos SEPs traz novos desafios para adequação de suas cinco áreas correlatas: comercialização, regulação, geração, transmissão e distribuição. Assim, pretende-se ajustá-los as necessidades de suprimento de demanda de energia elétrica de um número cada vez maior de consumidores. Além de uma maior demanda de energia, exige-se também melhor qualidade do serviço e do produto oferecidos aos consumidores (DUGAN, 2003; KAGAN; ROBBA; SCHMIDT, 2009).

Simultaneamente, observa-se o aumento da complexidade dos SEPs decorrente da inserção de novas tecnologias para sua reestruturação, mais exigências do mercado consumidor, inserção de novas fontes de geração, ampliação e interligação dos sistemas elétricos existentes, e maior regulação, entre outros. Desse modo, frente a estes desafios, grandes investimentos no aprimoramento de técnicas e procedimentos para expansão, operação e manutenção dos SEPs têm sido realizados, levando ao desenvolvimento de equipamentos, serviços, ferramentas e metodologias inovadoras.

Em meio às soluções em desenvolvimento a de maior destaque é a aplicação dos conceitos e tecnologias provenientes da implantação das Redes Elétricas Inteligentes (REIs), em inglês smart grids, as quais preconizam fornecer energia com altos índices de confiabilidade, continuidade e segurança. Para tanto, por meio das mesmas busca-se desenvolver e implantar nas redes elétricas ferramentas de comunicação, informação, monitoramento, controle e medição, a fim de integrar toda rede para viabilizar serviços e informações em tempo real tanto para os consumidores quanto para as concessionárias, 
compondo os chamados sistemas de distribuição modernos (FANG et al., 2012; DUTRA et al., 2013; KAGAN et al., 2013).

Neste contexto, os medidores inteligentes (Smart Meters) vêm recebendo destaque, pois além da medição de energia e do registro de valores de tensão e corrente, podem possuir funções para identificação de harmônicos, controle e capacidade de se comunicar com os centros de operações das concessionárias. Essas características, associadas a novos desenvolvimentos, podem possibilitar o emprego destes medidores de forma eficiente no diagnóstico de faltas, controle de demanda, tarifação em tempo real, análise da qualidade de energia e identificação de cargas e geradores distribuídos conectados à rede (DEPURE; WANG; DEVABHAKTUNI, 2011; FANG et al., 2012; YAN et al., 2012). Ressalta-se que estas novas tecnologias estão em processo de desenvolvimento e demandam estudos amplos e detalhados para elaboração e conformação de seus sistemas de monitoramento, controle, comunicação e proteção, os quais sejam coerentes com as atuais e futuras necessidades dos SEPs.

Os sistemas de proteção, em caso de ocorrência de faltas ocasionadas por falhas em equipamentos ou curtos-circuitos causados por intempéries ambientais, por exemplo, tomam medidas corretivas e protetivas, retirando o alimentador ou parte dele de operação (MAMEDE FILHO; MAMEDE, 2011; SATO; FREITAS, 2014). Esses sistemas, fundamentais para a segurança e confiabilidade dos SEPs, passaram por transformações e avanços tecnológicos consistentes no que se refere aos setores de transmissão e distribuição de energia. Além disso, em detrimento do advento das redes inteligentes nos últimos anos a área de distribuição tem recebido investimentos no tocante a estudos em sistemas de proteção. Desse modo, novas técnicas e equipamentos têm sido explorados para implementação nesta área, tornando-os mais robustos e eficientes frente aos obstáculos correntes (KINDERMANN, 2010; MAMEDE FILHO; MAMEDE, 2011; SATO; FREITAS, 2014).

Dentre estes obstáculos, as interrupções de energia elétrica causadas por faltas se destacam em virtude do potencial dano que podem causar ao SEP e seus elementos constituintes, às concessionárias de distribuição e aos consumidores, comprometendo inclusive, a qualidade da energia disponibilizada (KAGAN; OLIVEIRA; ROBBA, 2010). No Brasil, segundo as normas da Agência Nacional de Energia Elétrica (ANEEL), órgão regulador do seguimento de energia, as interrupções se enquadram no item Qualidade do Serviço referente à área de Qualidade da Energia Elétrica (QEE) do Módulo 8 do documento normativo Procedimentos de Distribuição de Energia Elétrica no Sistema Elétrico Nacional (PRODIST) (ANEEL, 2017). A alínea Qualidade do Serviço refere-se aos indicadores para contabilização 
da duração e frequência de interrupções no fornecimento de energia a que os consumidores ficam expostos, seja em virtude de interrupções por faltas no sistema ou atividades de manutenção programada (ANEEL, 2017).

A detecção, classificação e localização de faltas de forma rápida e precisa em sistemas de distribuição tem se mostrado um dos grandes desafios atuais, vislumbrando a operação segura e econômica do SEP (SAHA; IZYKOWSKI; ROSOLOWSKI, 2010). Observa-se na literatura correlata um grande número de pesquisas dedicado à elaboração de procedimentos e metodologias para este fim, baseadas principalmente em estudos das formas de onda fundamentais da tensão e corrente, análises de ondas viajantes, e na aplicação de sistemas inteligentes (LEE et al., 2004; HAN et al., 2007; POURAHMADI-NAKHLI; SAFAVI, 2011; JIANG et al. 2011; LIN et al., 2012; WONG et al., 2012; KRISHNATHEVAR; NGU, 2012; LOPES et al., 2015; BAHMANYAR et al., 2017).

Nesta conjuntura, frente às novas perspectivas dos SEPs insere-se a presente pesquisa, visando atender as necessidades crescentes das empresas do setor na busca por novas ferramentas e métodos que corroborem com a operação, controle e manutenção dos sistemas elétricos. Em vista aos anseios das concessionárias na busca por melhor atendimento às normas reguladoras, e sobretudo às exigências crescentes dos consumidores, ressalta-se cada vez mais a necessidade de redução da exposição às interrupções inesperadas e sustentada no fornecimento de energia. Assim, nesta tese propõem-se o desenvolvimento de uma metodologia para localização de faltas em sistemas de distribuição que contemplem as inovações tecnologias agregadas as redes inteligentes, bem como as possibilidades por elas oferecidas.

Após essa introdução, este primeiro capítulo trará na Seção 1.2 as principais motivações e justificativas referentes à pesquisa desenvolvida; na Seção 1.3 seus objetivos; na Seção 1.4 as contribuições originais desta tese; na Seção 1.5 as publicações científicas obtidas ao longo do período de doutorado; e na Seção 1.6 a forma como a presente tese fora organizada.

\section{2 - Justificativa e Motivação da Tese}

Um dos grandes problemas do setor elétrico deve-se a interrupções não programadas no fornecimento de energia por desligamentos de partes ou de todo o alimentador de distribuição, causadas por faltas temporárias ou permanentes. A ocorrência de faltas nos 
sistemas de distribuição deve-se a diferentes fatores, tais como problemas elétricos, mecânicos, de isolação, de manutenção e de natureza térmica, entre outros (KINDERMANN, 2010). Devido aos danos físicos para a rede elétrica e seus equipamentos sua correção deve ser realizada por equipes de manutenção, que em muitas situações fazem uso da inspeção visual para localização dos pontos de defeito (CAMINHA, 2004; MAMEDE FILHO; MAMEDE, 2011).

Nestas situações, o restabelecimento da energia pode ser extremamente oneroso e demorado, sobretudo em linhas de distribuição localizadas em regiões de difícil acesso ou em áreas rurais com linhas compostas por longos trechos. Além disso, as interrupções causadas por faltas no sistema elétrico podem ocasionar condições de operação indesejáveis, riscos aos usuários, transtornos a consumidores residenciais, e interrupção ou falha de processos industriais. Este conjunto de aspectos afeta diretamente os indicadores de qualidade e continuidade da energia, implicando em elevados custos operacionais às concessionárias devido às compensações aos consumidores afetados (DUGAN, 2003; KAGAN; ROBBA; SCHMIDT, 2009). Ademais, as concessionárias também têm custos financeiros devido a perdas de faturamento por energia não vendida, e custos sociais em decorrência de investimentos em marketing associados à manutenção da sua imagem junto aos clientes. Por outro lado, os clientes se veem atingidos por perdas de faturamento de suas unidades de negócio, tanto em atividades comerciais quanto industriais, implicando também em custos financeiros, por exemplo, pela perda de vendas ou elevação dos custos de produção (MAMEDE FILHO; MAMEDE, 2011).

Neste contexto, empregam-se os métodos de localização de faltas para que se possa chegar ao local do defeito, ou o mais próximo dele, o mais rápido possível, diminuindo assim o tempo de busca e deslocamento da equipe de manutenção, e consequentemente o tempo total de interrupção no fornecimento de energia. Para tanto, faz-se necessário o emprego de ferramentas que permitam a redução do tempo de restabelecimento de energia e o atendimento das metas instituídas pela ANEEL, a fim de prover maior confiabilidade aos sistemas elétricos e a minimização dos prejuízos financeiros ocasionados por seus desligamentos.

Diferentes métodos já foram propostos para localização de faltas nos sistemas de distribuição, diferindo-se em relação à quantidade de informações disponíveis, técnicas matemáticas aplicadas, e à instrumentação computacional utilizada. Entretanto, a ampla variação das particularidades dos sistemas de distribuição traz grandes implicações no desenvolvimento de ferramentas para localização de faltas, tornando esta tarefa difícil e complexa. Entre estas particularidades destacam-se a variação de topologia da rede, a 
característica das cargas, as condições construtivas da rede, a inserção de geradores distribuídos, e a ausência ou precariedade de equipamentos de monitoramento, comunicação, controle e automação (OLIVEIRA et al., 2000; SAHA; IZYKOWSKI; ROSOLOWSKI, 2010; GLOVER; SARMA; OVERBYE, 2011; BAHMANYAR et al., 2017).

Em virtude destes aspectos, buscam-se métodos para localização de faltas aplicáveis aos sistemas de distribuição modernos capazes de se adequar a essa nova realidade, os quais apesar das técnicas contemporâneas que têm sido desenvolvidas ainda procuram alcançar um grau de abrangência e desenvolvimento satisfatórios. Assim sendo, ante essas proposições, os objetivos gerais e específicos desta pesquisa são expostos na seção subsequente.

\section{3 - Objetivos}

O objetivo geral da pesquisa conduzida nesta tese é elaborar uma metodologia para localização de faltas a partir da aquisição de dados por medidores inteligentes alocados no lado de média tensão dos transformadores de sistemas de distribuição. O método proposto busca indicar de forma rápida e eficiente o local ou região mais próxima a falta valendo-se da capacidade de monitoramento da rede e aquisição de sinais proporcionada pela infraestrutura de medição avançada das redes elétricas inteligentes.

Para tanto, objetiva-se o desenvolvimento de uma metodologia que a partir da aquisição de sinais de tensão seja capaz de estimar a distância entre os medidores inteligentes e o local de ocorrência da falta, cruzando as informações das estimações com a topologia da rede para apontar o local ou região sob falta. Metodologia esta que se pautará na manipulação das tensões aplicando-se técnicas de análise de sistemas elétricos, classificação e estimação de atributos por sistemas inteligentes; e capacidade destes sistemas em mapear sistemas não-lineares e tratar eventuais incertezas associadas ao processo de localização de faltas

Por conseguinte, os objetivos específicos da tese podem ser pontuados da seguinte forma:

- Desenvolvimento de uma estratégia que, dadas às especificidades da tensão em diferentes pontos do sistema pós falta e as indicações de sensibilização dos medidores inteligentes, seja capaz de estimar o local de ocorrência da falta; 
- Extração das características e informações dos sinais de tensão de cada um dos medidores inteligentes baseada na análise de sistemas elétricos e desvios de tensão, a fim de avaliar o comportamento faltoso do sistema elétrico;

- Proposição e implementação de um sistema especialista que, a partir dos dados extraídos dos sinais de tensão, esteja apto a estimar de forma rápida e precisa o provável ponto de falta no sistema de distribuição em relação aos medidores inteligentes.

- Averiguação dos erros no apontamento do local ou região da falta pelo sistema inteligente em relação às variáveis selecionadas para treinamento, teste, e estimação, bem como referente à correlação entre elas.

Visando atingir tais objetivos, pretende-se contribuir na linha de pesquisa sobre localização de faltas em sistemas de distribuição como apresentado na próxima seção.

\section{4 - Contribuições Originais da Tese}

A presente tese trabalha na elaboração de uma metodologia que auxilie eficientemente na localização de faltas em sistema de distribuição contextualizados pela aplicação dos conceitos das redes inteligentes e que permita agilizar o reestabelecimento do fornecimento de energia. Para tanto, as principais contribuições originais da tese podem ser pontuadas como se segue:

- Utilização otimizada da capacidade de monitoramento da rede e aquisição de sinais de tensão por múltiplos medidores inteligentes no lado de média tensão do sistema de distribuição;

- Extração das características e informações dos dados de tensão sem utilização de técnicas de análise de sinais tais como Transformada de Fourier e Wavelet, diferentemente dos métodos habituais presentes na literatura correlata, visando à simplificação do processo de localização de faltas.

- Desenvolvimento de um sistema especialista que seja capaz de estimar de forma robusta a sensibilização dos medidores inteligentes e a distâncias dos mesmos ao ponto de falta apenas pela análise de sinais de tensão, a fim de apontar o local ou a região da falta; 
- Localização das faltas em relação aos pontos de instalação dos medidores inteligentes mais próximos ao local de ocorrência da falta, e não apenas em relação a subestações e aos extremos da rede, como geralmente observado na literatura técnico-científica correlata.

Na próxima seção são apresentas as publicações obtidas a partir de estudos ligados direta e indiretamente às pesquisas desta tese e realizados ao longo do período de doutorado.

\section{5 - Atividades de Divulgação Científica}

A partir de estudos realizados para o desenvolvimento das pesquisas da presente tese e de outros projetos correlatos do grupo de pesquisa do Laboratório de Automação Inteligente de Processos e Sistemas (LAIPS), foram realizadas atividades de divulgação científica que possibilitaram as seguintes publicações:

\section{- Artigos completos publicados em periódicos}

1. BATISTA, O. E.; FLAUZINO, R. A.; ARAUJO, M. A; MORAES, L. A.; SILVA, I. N. Methodology for information extraction from oscillograms and its application for high-impedance faults analysis. International Journal of Electrical Power \& Energy Systems. v.76, p.23 - 34, 2016.

2. ARAÚJO, MARCEL A.; FlaUZINO, ROGÉRIO A.; ALTAFIM, RUY A.C.; BATISTA, OURESTE E.; MORAES, LUCAS A. Practical methodology for modeling and simulation of a lightning protection system using metal-oxide surge arresters for distribution lines. Electric Power Systems Research (Print). v.118, p.47 - 54, 2015.

3. ARAUJO, M. A.; FlAuZINO, R. A.; Moro. V. C.; VIEIRA JUNIOR, J. C. M. Modeling and simulation of surge arresters for lightning protection of distribution systems. Revista IEEE América Latina, v.13, p.2225 - 2231, 2015. 


\section{- Artigos completos publicados em anais de congressos}

1. ARAUJO, M. A.; FLAUZINO, R. A.; MORAES, L. A.; BATISTA, O. E. Multilayer Fuzzy System Applied to Locate Faults in Distribution Systems Using Only Voltage Measurements. In: Seventh International Conference on Smart Grids, Green Communications and IT Energy-aware Technologies (ENERGY), 2017, Barcelona, Espanha.

2. ARAUJO, M. A.; FlauZinO, R. A.; BAtistA, O. E.; MORAES, L. A.; MARTINS, C. H. R. Proteção de Alimentadores de Distribuição contra Tensões Induzidas por Descargas Atmosféricas Indiretas In: VI Simpósio Brasileiro de Sistemas Elétricos (SBSE), 2016, Natal, Brasil.

3. ARAUJO, M. A.; FLAUZINO, R. A.; BATISTA, O. E.; MORAES, L. A. Processo Otimizado de Proteção de Linhas de Distribuição Contra Descargas Atmosféricas Indiretas pela Utilização de Sistemas Fuzzy In: Simpósio Brasileiro de Automação Inteligente (SBAI), 2015, Natal, Brasil.

4. MARTINS, C. H. R.; ARAUJO, M. A.; FLAUZINO, R. A. Power Transformer Fault Diagnosis using DGA and Group Decision Making with Intuitionistic Fuzzy Preference Relations. In: IEEE ISGT Latin America, 2015, Montevideo, Uruguay.

5. YONEDA, S. L.; FLAUZINO, R. A.; MORAES, L. A.; ARAUJO, M. A. Use of Artificial Neural Networks for Completing Data Series Streamflow Hydrologic In: World Congress in Computer Science, Computer Engineering, and Applied Computing (WORLDCOMP'14), 2014, Las Vegas, USA.

6. ARAUJO, M. A.; FlauZinO, R. A.; BAtista, O. E.; MORAES, L. A.; MARTINS, C. H. R. Protection of the Distribution Lines with Distributed Generation against Lightning Overvoltages by Surge Arrester in the Context of Smart Grids In: World Congress on Sustainable Technologies (WCST), 2013, London, UK. 
7. MORAES, L. A.; FlAUZINO, R. A.; ARAUJO, M. A.; BATISTA, O. E. A Fuzzy Methodology to Improve Time Series Forecast of Power Demand in Distribution Systems In: 2013 IEEE PES General Meeting, 2013, Vancouver, Canada.

8. ARAUJO, M. A.; FlauZino, R. A.; BAtista, O. E.; MORAES, L. A. Application of Surge Arrester for Overvoltage Protection Caused by Direct Lightning on Distribution Lines In: X Latin-American Congress on Electricity Power Generation, Transmission and Distribution (CLAGTEE), 2013, Vinã Del Mar, Chile.

9. ARAUJO, M. A.; FLAUZINO, R. A.; BATISTA, O. E.; MORAES, L. A. Protection of the Distribution Lines against Lightning Overvoltages by Surge Arrester in the Context of Distributed Generation and Smart Grids In: Innovative Smart Grid Technologies - IEEE ISGT Latin America, 2013, São Paulo, SP, Brasil.

10. Batista, O. E.; FlauzinO, R. A.; MORAeS, L. A.; ARAUJO, M. A. The Faults Variability In Distribution Systems with Distributed Generation and Robustness of Smart Grids In: Innovative Smart Grid Technologies - IEEE ISGT Latin America, 2013, São Paulo, SP, Brasil.

11. ARAUJO, M. A.; FlauZinO, R. A.; BAtista, O. E.; MORAES, L. A. Application of Fuzzy System for Analysis of Lightning Overvoltages and Protection of Distribution Systems by Surge Arresters In: World Congress in Computer Science, Computer Engineering, and Applied Computing (WORLDCOMP'13), 2013, Las Vegas, USA.

12. BATISTA, O. E.; FlAUZINO, R. A.; MORAES, L. A.; ARAUJO, M. A.; SILVA, I. N. Applying a Fuzzy System for Robust Fault Location in a Distribution System with Distributed Generation In: World Congress in Computer Science, Computer Engineering, and Applied Computing (WORLDCOMP'13), 2013, Las Vegas, USA.

Posto isto, a próxima seção aborda como os capítulos desta tese foram organizados. 


\section{6 - Organização da Tese}

A fim de alcançar os objetivos propostos a presente tese fora organizada em oito capítulos como descrito a seguir.

Neste primeiro capítulo desenvolve-se uma breve introdução ao tema estudado, apresentam-se as justificativas, motivações e objetivos da pesquisa, e as atividades de divulgação científica realizadas ao logo do período de doutorado do autor desta tese.

No segundo capítulo apresenta-se brevemente a constituição dos Sistemas Elétricos de Potência (SEPs) e a forma com que seus elementos se interconectam, além de aspectos referentes a conceituação, caracterização, desenvolvimento e implantação das Redes Elétricas Inteligentes (REIs). Expõem-se ainda atributos e funcionalidades da infraestrutura de medição inteligentes, focando-se nos medidores inteligentes, e o panorama de desenvolvimento e implantação de REIs em diferentes países.

No terceiro capítulo são expostos aspectos referentes às causas de faltas nos SEPs, à ocorrência específica das mesmas nos sistemas de distribuição e as particularidades e dificuldades evolvidas na sua localização nesta conjuntura. A seguir, efetua-se uma revisão bibliográfica e histórica sobre alguns dos principais métodos de localização de faltas, contextualizando o tema abordado e destacando os fundamentos e técnicas diretamente relacionados aos aplicados nesta pesquisa.

No quarto capítulo são apresentados os conceitos principais e mais atuais dos processes de extração de conhecimento de dados. A seguir, são destacadas as características dos sistemas de Aprendizado de Máquina (AM). Posteriormente, são expostos os principais conceitos e fundamentações das Árvores de Decisão (ADs), suas etapas e processos para construção, apresenta-se um exemplo de construção de uma $\mathrm{AD}$, e por fim são comentadas as métricas dos classificadores das mesmas.

No quinto capítulo são apresentados os conceitos básicos da metodologia proposta para localização de faltas, bem como a descrição das etapas envolvidas na mesma e o algoritmo para sua implementação. Além disso, é exposta neste capítulo a modelagem de um sistema elétrico real e os resultados de sua simulação para composição de um banco de dados que será utilizado para implementação e validação da presente metodologia ao longo desta tese.

No sexto capítulo são trabalhados os procedimentos para implementação e definição dos sistemas inteligentes baseados no uso das Árvores de Decisão por meio do software 
WEKA. São expostos os resultados da aplicação da metodologia proposta, assim como dois estudos de caso visando ilustrar o processo de análise das informações utilizadas pela mesma para localização de faltas. Por fim, são apresentados os erros de distância entre o local real e o definido pelo processo de localização para os testes de validação da metodologia.

No sétimo capítulo é realizado o levantamento das principais conclusões obtidas pela presente investigação cientifica com os estudos bibliográficos e históricos realizados, a utilização das árvores de decisão para implementação dos classificadores dos sistemas inteligentes, e os resultados alcançados para localização de faltas pela metodologia proposta. Também são expostas sugestões de trabalhos futuros para continuidade desta pesquisa.

Por fim, no oitavo capítulo é apresentada uma lista com as referências bibliográficas consultadas ao longo da pesquisa e utilizadas para confecção do texto desta tese. 



\section{CAPÍTULO 2}

\section{ASPECTOS RELACIONADOS AOS SISTEMAS DE DISTRIBUIÇÃO DE ENERGIA ELÉTRICA E ÀS REDES ELÉTRICAS INTELIGENTES}

No presente capítulo, inicialmente será apresentada de forma sucinta a composição básica dos sistemas elétricos de potência e descrita a forma com que seus elementos se interconectam desde a geração até a entrega de energia aos consumidores. A seguir, são delineados os embasamentos conceituais, características, funcionalidades, benefícios e desafios para o desenvolvimento e implantação das Redes Elétricas Inteligentes (REIs). Também se realiza um aprofundamento a respeito da infraestrutura de medição inteligente, pela exposição de atributos e funcionalidades de sua infraestrutura avançada de medição e de seus medidores inteligentes. Por fim, exibe-se o panorama de desenvolvimento e implantação de REIs em diferentes países, focando-se na parte final do capítulo nas iniciativas em andamento no Brasil por diferentes concessionárias de energia.

\section{1 - Composição Básica dos Sistemas Elétricos de Potência}

Os Sistemas Elétricos de Potência (SEPs) são definidos como o conjunto de todas as instalações e equipamentos destinados à geração, transmissão e distribuição de energia elétrica. Os três grandes blocos do SEP se interconectam conforme exposto no diagrama de blocos da Figura 2.1, e possuem as seguintes atribuições (KAGAN; OLIVEIRA; ROBBA, 2010):

- Geração: designado para o papel de conversão de alguma forma de energia (mecânica, térmica, entre outros) em energia elétrica.

- Transmissão: responsável pelo transporte da energia elétrica dos centros de produção aos centros consumidores. 
- Distribuição: encarregado de distribuir a energia elétrica recebida do sistema de transmissão aos grandes, médios e pequenos consumidores.

Seguindo o diagrama de blocos da Figura 2.1, observa-se que para a ligação entre o bloco de Geração e o de Transmissão inicialmente é realizada por uma Subestação Elevadora de Transmissão a elevação da tensão de geração para a tensão de transmissão em função da distância a ser percorrida e do montante de energia a ser transportado. A seguir, o Sistema de Transmissão se encarrega de transportar a energia dos centros de produção até os centros consumidores.

Caso existam consumidores que necessitem de energia nos níveis de tensão de transmissão, os mesmos são alimentados diretamente a partir destes ramais do sistema. Caso contrário, chegando aos centros de consumo, na Subestação Abaixadora de Subtransmissão, ocorre o primeiro abaixamento da tensão. Esta, então, é distribuída pelo Sistema de Subtransmissão para grandes consumidores atendidos por níveis de tensão de subtransmissão e a para as Subestações de Distribuição, nas quais se sucede a segunda diminuição dos níveis de tensão, reduzindo-se a tensão de subtransmissão para tensão de distribuição primária.

A seguir, o Sistema de Distribuição Primária atende diretamente os consumidores de médio porte em tensão de distribuição primária (média tensão), levando energia até os Transformadores de Distribuição, ponto este que é o foco dos estudos da presente pesquisa. Os Transformadores de Distribuição reduzem a tensão de distribuição primária e assim o Sistema de Distribuição Secundária distribui energia aos pequenos consumidores em tensão de distribuição secundária (baixa tensão).

$\mathrm{Na}$ Tabela 2.1 estas tensões de atendimento aos consumidores, anteriormente mencionadas, são apresentadas de acordo com o campo de aplicação e a área do sistema de potência a que se referem. Ressalta-se que o objetivo da pesquisa desenvolvida é a localização de faltas nas redes de distribuição, mais especificamente no campo de aplicação do SEP aqui nomeado como Distribuição Primária, o qual será trabalhado no desenvolvimento desta tese. 
Figura 2-1: Diagrama de blocos da constituição dos SEPs.

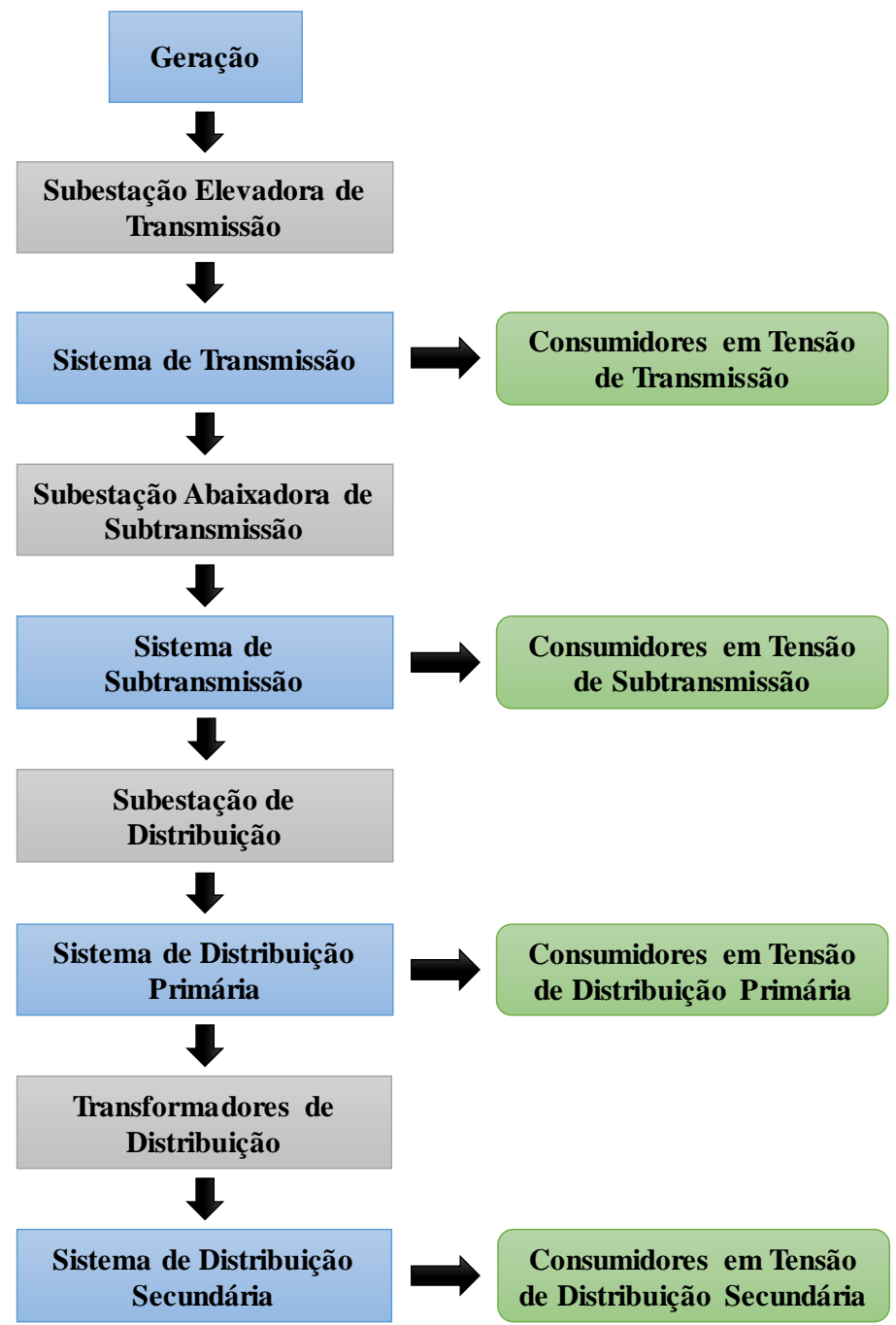

Fonte: adaptado de KAGAN, OLIVEIRA e ROBBA (2010).

Tabela 2-1: Tensões usuais em SEPs.

\begin{tabular}{|c|c|c|}
\hline Tensão Padronizada (kV) & Campo de Aplicação & Área do Sistema de Potência \\
\hline $0,220 / 0,127$ & \multirow{2}{*}{ Distribuição Secundária } & \multirow{7}{*}{ Distribuição } \\
\hline $0,380 / 0,220$ & & \\
\hline 13,8 & \multirow{2}{*}{$\begin{array}{c}\text { Distribuição } \\
\text { Primária }\end{array}$} & \\
\hline 34,5 & & \\
\hline 34,5 & \multirow{3}{*}{ Subtransmissão } & \\
\hline 69,0 & & \\
\hline 138,0 & & \\
\hline 138,0 & \multirow{4}{*}{ Transmissão } & \multirow{4}{*}{ Transmissão } \\
\hline 230,0 & & \\
\hline 345,0 & & \\
\hline 500,0 & & \\
\hline
\end{tabular}

Fonte: adaptado de KAGAN, OLIVEIRA e ROBBA (2010). 
Na Figura 2.2 tem-se um diagrama unifilar, uma maneira bastante usual de se representar um SEP, por meio da qual se observa de forma espacial como os blocos de um sistema elétrico típico se interconectam. Nesta figura, nota-se a presença de um bloco gerador formado por três usinas, um conjunto de linhas de transmissão, uma rede de subtransmissão, uma rede de distribuição primária (média tensão) e três redes de distribuição secundárias (baixa tensão) (KAGAN; OLIVEIRA; ROBBA, 2010).

Figura 2-2: Diagrama unifilar de um SEP típico.

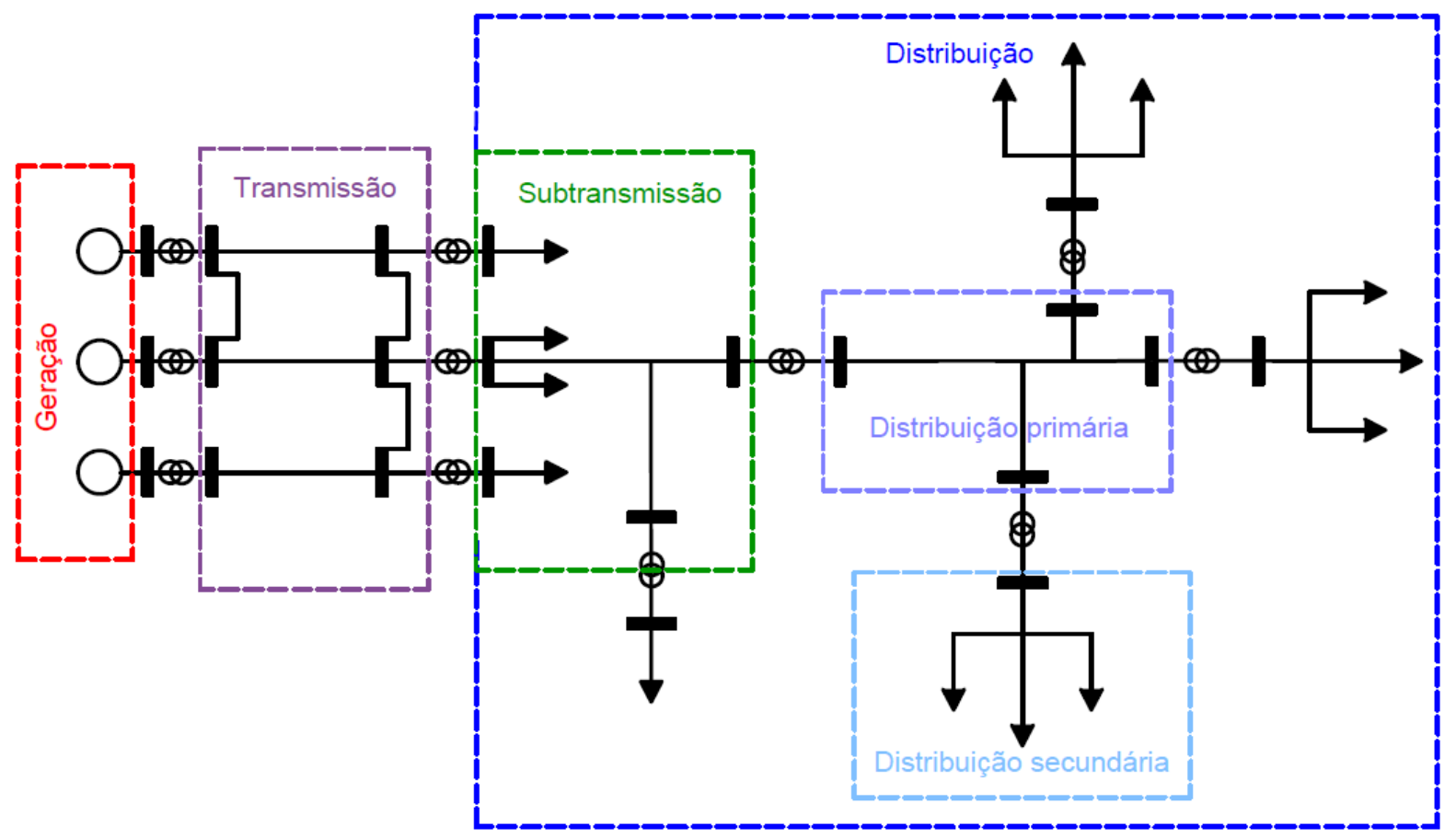

Fonte: adaptado de KAGAN, OLIVEIRA e ROBBA (2010).

Mesmo que os blocos de geração, transmissão e distribuição dos SEPs tenham passado por um processo crescente de investimentos e desenvolvimento no decorrer das últimas décadas, a maior parte dos mesmos ainda não possui grau avançado de monitoramento, automação e controle.

Além disso, a crescente escassez de recursos para produção de energia e necessidade do uso de fontes renováveis, o aumento da demanda, e a pressão por melhores indicadores de qualidade, continuidade e confiabilidade pelos agentes reguladores do setor de energia, vem exigindo a modernização do SEP como um todo, e principalmente dos sistemas de distribuição.

Nesta conjuntura, vislumbrando contornar estas adversidades tem ganho grande destaque a implementação dos conceitos e técnicas de Redes Elétricas Inteligentes (REIs), também conhecidas como Smart Grids, não só no Brasil como em países norte americanos, 
europeus e asiáticos. As REIs, de forma geral, buscam agregar as novas tecnologias de medição, informação, comunicação, automação, geração e infraestrutura às redes elétricas a fim de promover a aplicação e utilização de técnicas avançadas de monitoramento, controle, automação, operação, gerenciamento e manutenção.

Posto isto, dentro do escopo da proposta desenvolvida na presente tese, a seguir são expostos aspectos referentes às REIs mais direcionados aos sistemas de distribuição, bem como características e funcionalidades focadas no sistema e infraestrutura de medição inteligente. Também serão apresentados os projetos e inciativas de maior relevância atualmente em diferentes países, incluindo o Brasil, demonstrando suas principais áreas de desenvolvimento e implementação.

\section{2 - Redes Elétricas Inteligentes}

A definição de REIs apresenta-se aberta e tem diferentes conceituações, já em 2003 o DOE (United States Department of Energy) as previa como uma rede de distribuição de energia totalmente automatizada que monitora e controla cada cliente e nó, garantindo fluxo bidirecional de informações e de energia elétrica entre a usina e o aparelho, e todos os pontos entre eles (DOE, 2003).

Em 2006, a Comissão Europeia destinada ao estudo e avaliação das perspectivas tecnológicas das redes elétricas e de fontes de geração sustentáveis, conceituava REI como uma rede elétrica capaz de integrar de forma inteligente as ações de todos os usuários conectados a ela, sejam eles geradores, consumidores ou aqueles que assumem ambos os papéis, com a finalidade de prover energia elétrica de forma eficientemente, sustentável, econômica e segura (EUROPEAN COMMISSION, 2006).

Posteriormente, em (EPRI, 2008) apresenta-se uma definição segundo a qual REI pode ser entendida como a sobreposição dos sistemas unificados de comunicação e controle à infraestrutura de energia elétrica existente, para fornecer as informações certas para a entidade correta (por exemplo, equipamentos de uso final e consumidores) no instante adequado para se tomar a decisão correta. É um sistema que otimiza o suprimento e a entrega de energia, minimizando perdas, é auto recuperável, e permite a próxima geração eficiência energética e resposta à demanda de aplicação. 
Em (EPRI, 2009), a pedido do National Institute of Standards and Technology (NIST) dos Estados Unidos, é exposta uma das conceituações mais citadas na literatura, a qual aponta que REI refere-se a uma modernização do sistema de distribuição de eletricidade, para que o mesmo seja capaz de monitorar, proteger e otimizar automaticamente a operação dos seus próprios elementos interconectados, a partir da geração central e distribuída, passando pela rede de transmissão de alta tensão e do sistema de distribuição, até os usuários industriais e sistemas de automação predial, as instalações de armazenamento de energia e consumidores finais, e seus aquecedores, veículos elétricos, eletrodomésticos e outros aparelhos domésticos. Além disso, reporta-se que a REI será caracterizada por um fluxo bidirecional de eletricidade e informações para criar uma automatizada e amplamente distribuída rede de distribuição de energia, e que ela incorpora na rede os benefícios da computação e comunicações para fornecer informações em tempo real e permitir o equilíbrio quase instantâneo de oferta e demanda em nível de dispositivo.

Ainda em 2009, em (GELLINGS, 2009) REI é caracterizada pela utilização de sensores, comunicações, capacidade computacional e controle para melhorar a funcionalidade total do sistema de fornecimento de energia elétrica. Além disso, diz-se que um sistema convencional se torna inteligente a partir do sensoriamento, comunicação e inteligência aplicada, exercendo controle por meio de feedback ajustado continuamente. Para um sistema de potência, isto possibilita várias funções que permitem a otimização, em combinação, do uso de geração e armazenamento massivo, transmissão, distribuição, fontes distribuídas e uso final do consumidor com o objetivo de garantir confiabilidade, e otimizar ou minimizar o uso de energia, mitigar o impacto ambiental, gerenciar ativos e conter custos.

Já em (BORLASE, 2013) REI é definida como a integração de infraestruturas elétricas e de comunicações com avançados processos de automação e tecnologia da informação no âmbito da rede elétrica existente. REI representa uma mudança completa na forma como concessionárias, políticos, consumidores e outros participantes da indústria pensam a entrega de eletricidade e os serviços a ela relacionados. Este novo processo de pensamento provavelmente trará diferentes tecnologias e soluções de redes inteligentes, mas promoverá benefícios com maior integração da engenharia e operações das concessionárias e a partir de novos modelos de negócios.

Em (MCTI, 2014) apresenta-se umas das conceituações mais atuais estabelecidas por órgãos brasileiros dentro de um estudo aprofundado sobre o tema na conjuntura da cooperação Brasil-União Europeia segundo a qual entende-se REI por uma rede elétrica em que são utilizadas tecnologias digitais para monitorar e controlar o transporte de eletricidade em tempo 
real, havendo fluxo bidirecional de energia e de informações entre as concessionárias e o consumidor final. Essas tecnologias digitais são representadas por sistemas de medição, de automação e interação, com clientes, as quais por um lado apresentam funcionalidades que atendem os objetivos especificados e por outro necessitam de infraestrutura adequada de telecomunicação e de Tecnologia da Informação.

Atualmente, o DOE sinaliza que de forma resumida a tecnologia digital que permite a comunicação de duas vias entre a concessionária e os seus clientes, e o sensoriamento ao longo das linhas de transmissão é o que faz a rede inteligente. Como a Internet, a REI será composta de controles, computadores, automação e novas tecnologias e equipamentos que trabalhando em conjunto, mas, neste caso, estas tecnologias irão trabalhar com a rede elétrica para responder digitalmente as nossas rápidas mudanças de demanda de energia. Ressalta-se ainda que a REI representa uma oportunidade sem precedentes para mover a indústria de energia a uma nova era de confiabilidade, disponibilidade e eficiência que contribuirá para a nossa saúde econômica e ambiental. Durante o período de transição, será fundamental realizar testes, melhorias tecnológicas, educação do consumidor, desenvolvimento de normas e regulamentos, e compartilhamento de informações entre os projetos para garantir que os benefícios previstos a partir da REI se tornem uma realidade (DOE, 2017).

Neste contexto, observa-se que a definição de REIs se apresenta aberta e tem diferentes conceituações, as quais compartilham a opinião de que as mesmas trazem consigo ideias bastante abrangentes relativas a introdução de novas tecnologias nos SEP com perspectiva de mudanças regulatórias, estruturais, técnicas e comerciais. Ideias estas aplicáveis desde os sistemas de geração, transmissão e distribuição até os sistemas de geração distribuída e microgeração, indústrias, edifícios e casas inteligentes, veículos elétricos e armazenamento de energia, como ilustrado representativamente pela Figura 2.3. 
Figura 2-3: Representação de uma Rede Elétrica Inteligente.

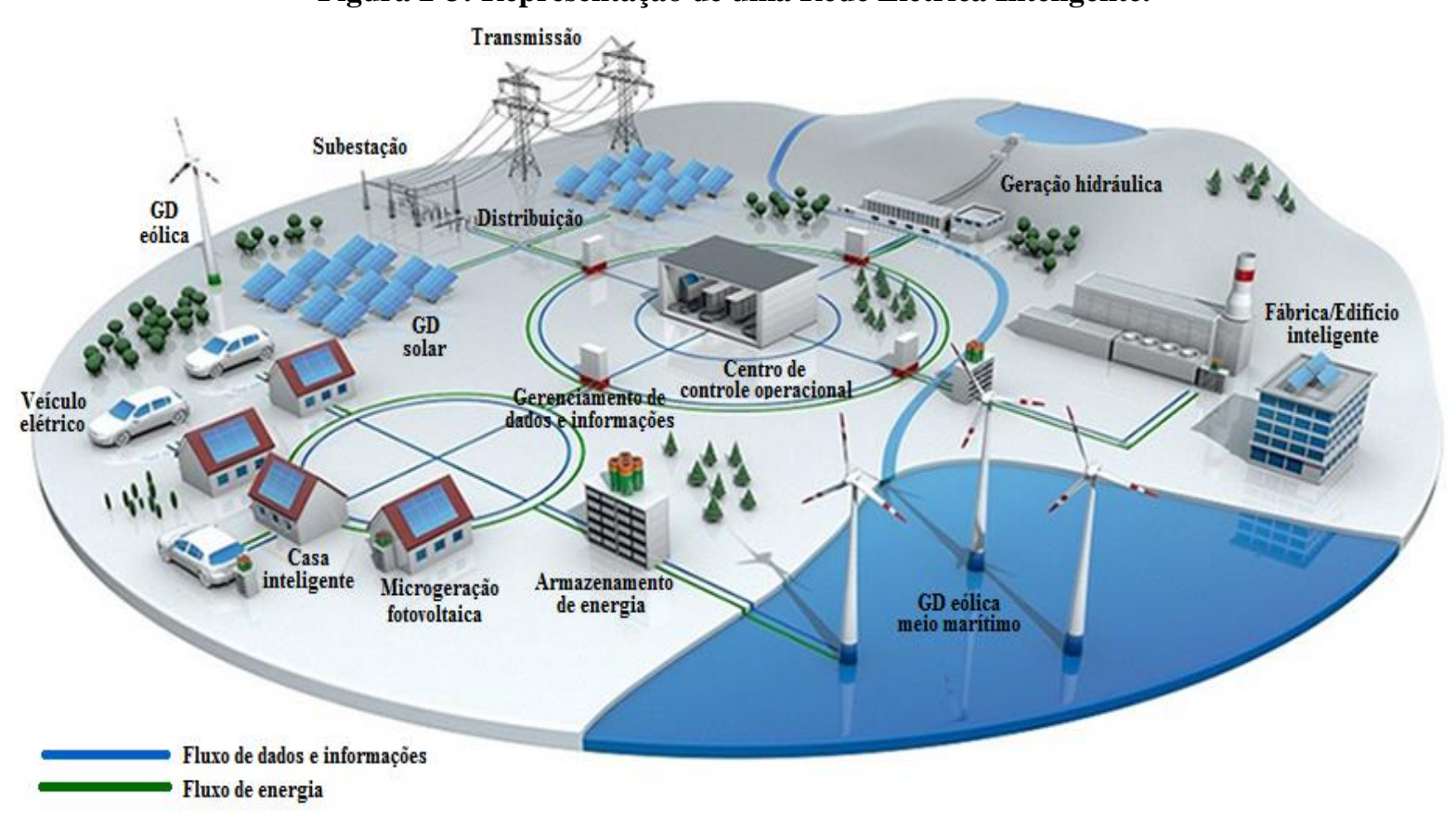

Fonte: adaptado de 3M (2017).

\section{3 - Características, Funcionalidades, Benefícios e Desafios das REIs}

A partir da aplicação dos conceitos de Redes Elétricas Inteligentes (REI) e do desenvolvimentos das mesmas espera-se prover modernização aos SEPs pela promoção de ações, tais como: gestão eficiente de ativos, gerenciamento do fluxo bidirecional de energia, fornecimento de informações em tempo real, inserção de fontes renováveis de geração, aumento do desempenho, eficiência, segurança e confiabilidade da operação, redução de perdas técnicas e comerciais, viabilidade da participação do usuário no controle de demanda/produção de energia, entre outros.

Para tanto, faz-se necessário às redes inteligentes possuir características e funcionalidades específicas, tais como (EPRI, 2009; GELLINGS, 2009; BORLASE, 2013; KAGAN et al., 2013, BAYINDIR et al., 2016):

- Infraestrutura de comunicação: dispositivos para envio e recebimento de dados e comandos operacionais entre a rede e o centro de operações; 
- Infraestrutura avançada de medição: disponibilidade de medidores com capacidade para medição multivariáveis em tempo real e comunicação bidirecional;

- Armazenamentos de dados: capacidade para armazenamento do grande fluxo de dados trocados entre os pontos da rede e centro de operações;

- Automação e controle: emprego de ferramentas ativas de apoio à operação na tomada de decisão;

- Monitoramento: disponibilidade de equipamentos para supervisão de demanda e fornecimento tanto por consumidores quanto pela concessionária;

- Auto recuperação: capacidade de automaticamente detectar, identificar, localizar, analisar e corrigir faltas na rede elétrica;

- Inclusão dos consumidores: fornecimento de meios para participação ativa dos consumidores no planejamento, gerenciamento e operação da própria demanda;

- Segurança: tolerância a ataques cibernéticos;

- Adaptabilidade: habilidade de gerir fluxo bidirecional de energia a partir da inserção e exclusão de fontes distribuídas de geração, saída de partes do sistema devido a faltas, aumento e diminuição da demanda, entre outros;

- Desempenho: respostas a comandos em tempo real e de forma adequada fornecendo energia de qualidade.

- Predição: capacidade de analisar dados operacionais a fim de prevenir potenciais falhas de equipamentos;

- Sustentabilidade: adoção e inclusão prioritária de fontes renováveis e de baixo impacto ambiental;

- Economia: operação capitalizada por regras de oferta e demanda definidas pelos órgãos reguladores tendo em vista geração, consumo e armazenamento de energia;

- Eficiência: redução das perdas técnicas e aumento no rendimento da geração.

O desenvolvimento de redes elétricas com tais características e funcionalidades poderá trazer inúmeros benefícios, dentre os quais destaca-se o fluxo bidirecional de energia e de informações possibilitando conhecimento em tempo real por parte dos consumidores da tarifa cobrada pela energia consumida. Assim, o consumidor, fazendo uso do seu direito de escolha, poderá decidir o melhor momento de consumo frente ao valor cobrado, e será capaz de atuar tanto como agente consumidor quanto como fornecedor de energia a partir da nova infraestrutura da rede (EPRI, 2009; BORLASE, 2013, COLAK et al., 2016). 
Além disso, frente a vasta e complexa rede de monitoramento, controle, automação e comunicação das REIs outra vantagem será a melhoria da qualidade, confiabilidade e continuidade da energia fornecida, uma vez que com o uso de tais tecnologias as mesmas tornar-se-ão capazes de identificar antecipadamente perturbações e prover a auto recuperação e reparação do sistema isolando circuitos e/ou redirecionando energia de fontes próximas ao local das faltas, minimizando distúrbios e reduzindo a ocorrência de interrupções (EPRI, 2009; BORLASE, 2013, COLAK et al., 2016).

Outro benefício com o qual espera-se contar é com alto grau de privacidade aos usuários e segurança da rede inteligente por meio do monitoramento constante e troca de informações em tempo real com o centro de operações, provendo segurança virtual frente a ataque aos sistemas de comunicação e informação, protegendo-se do roubo de dados do próprio sistema elétrico, pessoais e inclusive financeiros, referentes ao comércio de energia pelos usuários (EPRI, 2009; BORLASE, 2013, COLAK et al., 2016).

Também se objetiva maior sustentabilidade e eficiência energética pelo emprego distribuído de fontes renováveis de energia, otimização de recursos, aumento da produtividade da geração, armazenamento do excedente e energia e gerenciamento operacional, visando menos perdas nos processos de geração, transmissão e distribuição, bem como redução de picos de demanda e estímulo ao uso de equipamentos mais eficientes e ao consumo racional de energia (EPRI, 2009; BORLASE, 2013, COLAK et al., 2016).

Em contrapartida, para implementação das REIs surgirão desafios e obstáculos, os quais para serem superados necessitarão do desenvolvimento de novos softwares dedicados ao comportamento inteligente da rede, projeto de sistemas de medição, controle, automação e comunicação adaptáveis e robustos, concepção de estratégias para gerenciamento do grande volume de dados das redes inteligentes, atualização constante dos sistema de segurança virtuais frente as investidas de ataques cibernéticos cada vez mais evoluídos, entre outros (EPRI, 2009; BORLASE, 2013, COLAK et al., 2016).

Observa-se que as principais áreas envolvidas na aplicação dos conceitos de REI são medição, monitoramento, controle, automação, segurança, geração distribuída, comercialização de energia, e sustentabilidade, em meio as quais dentro do escopo das pesquisas da presente tese será destacada a seguir a infraestrutura de medição. 


\section{4 - Infraestrutura de Medição Inteligente}

A infraestrutura de medição inteligente, dentro do contexto das REIs, pauta-se na integração entre dispositivos eletrônicos inteligentes denominados IEDs (do inglês Intelligent Electronic Devices) e tecnologias de informação e comunicação, voltada para o processamento, armazenamento e comunicação de dados para consumidores e concessionárias a fim de monitorar e controlar as diferentes variáveis do SEP. A partir desta infraestrutura permitindo acesso em tempo real e de forma bidirecional, a tomada de decisão deixa de ser passiva por parte dos consumidores, perante suas necessidades de demanda, passando a ser ativa e incluindo a possibilidade de fornecimento de energia mediante a microgeração distribuída (EPRI, 2009; KAGAN et al., 2013, YOLDAS et al., 2017).

Baseando-se no exposto em (CGEE, 2012), (KAGAN et al., 2013), (SHARMA; SAINI, 2015) e (KABALCI, 2016), para contemplar o desenvolvimento e implementação desta infraestrutura destacam-se os seguintes aspectos:

- Smart Meter - Medidor Inteligente: medidor eletrônico ou digital com capacidade para aplicações que vão além da medição do consumo de energia, registrando dados de eventos e intervalos de tempo configuráveis, e com comunicação bidirecional com o Centro de Controle de Medição (CCM) para fins de monitoramento e faturamento. Para atender o usuário em ambiente residencial deve permitir integração com dispositivos domésticos inteligentes (Smart Appliances).

- Advanced Meter Management (AMM) - Gerenciamento do Medidor Avançado: plataforma técnica de gerenciamento de medidores inteligentes alocados em redes de comunicação, desempenhando leitura de perfis de carga em intervalos de tempo inferiores a uma hora. Apresenta como funções básicas: gerenciamento de dispositivo, permitindo a gestão de parâmetros dos medidores; gestão de grupo, possibilitando o controle de grupos de dispositivos, como configuração e upgrade de firmware; e gestão de plataforma de comunicação, assegurando comunicação confiável entre medidores e CCM. Ressalta-se que o AMM não realiza a função de armazenamento dos dados coletados pelos medidores (ou o faz apenas temporariamente), transmitindo-os ao gerenciador de dados do medidor, e de forma resumida pode ser entendido como toda ação de gerenciamento sobre o medidor como ativo da rede. 
- Meter Data Management (MDM) - Gerenciamento de Dados do Medidor: sistema de processamento e gerenciamento dos dados gerados pelos medidores e de informações adicionais além do consumo de energia, como fator de potência e indicadores de qualidade. Tem a finalidade de aperfeiçoar procedimentos como faturamento, eficiência operacional, serviços ao consumidor, previsão e gestão de demanda, gestão de fraudes, e gerenciamento do sistema de distribuição, entre outros, para assim gerir os dados e extrair mais informação deles. Tem como funções básicas: atuar como repositório de dados de registros, eventos e alarmes; e processar e analisar dados dos medidores, aplicando validação e retificação em dados inconsistentes e transformando perfis de carga elementares em informação útil à concessionária.

- Advanced Metering Infrastructure (AMI) - Infraestrutura de Medição Avançada: apontada como a parte fundamental da REIs, engloba desde os equipamentos de medição até as tecnologias de informação, comunicação e gerenciamento de dados que possibilita a bidirecionalidade de informações necessária para permitir as funcionalidades de medição inteligente conglomerando os conceitos de Smart Meter, AMM e MDM. É considerada a evolução das Automated Meter Reading (AMR) Leitura Automática do Medidor, conceito antigo de medição com comunicação unidirecional com um CCM para o processo de geração de fatura, visando maior exatidão nas medições e economia de custos com leituristas.

Dentre os aspectos levantados para desenvolvimento e implementação da infraestrutura de medição inteligente, os de maior relevância dentro do escopo da presente pesquisa que visa explorar a capacidade de aquisição de sinais de tensão pelos medidores inteligentes são Infraestrutura de Medição Avançada e o Medidor Inteligente, os quais são melhor descritos a seguir.

\subsection{1 - Infraestrutura de Medição Avançada}

A AMI configura-se como o elo de ligação principal entre a rede elétrica, as concessionárias, os consumidores com suas demandas e possíveis fontes de microgeração, os sistemas de armazenamento de energia, e as tecnologias de informação e comunicação. Atua na coleta, fornecimento, gerenciamento e análise de dados, proporcionando um panorama geral 
de operação do sistema de distribuição otimizando o monitoramento e controle da rede, a fim de garantir sua integridade e prover meios para gestão ativa de tarifas, quantidade e qualidade da energia consumida, usuários e recursos (EPRI, 2009; BORLASE, 2013; KAGAN et al., 2013).

A AMI agrega diversas funcionalidades às REI que dependem da aplicação específica a que se propõem e das tecnologias incorporadas a seus componentes. Neste contexto, a seguir são destacadas as principais funcionalidades comuns à sua infraestrutura (EPRI, 2009; GELLINGS, 2009; ACRA; THAKER, 2010; BORLASE, 2013; KAGAN et al., 2013, SHARMA; SAINI, 2015; KABALCI, 2016):

- Coleta de dados remota via rede de comunicação em intervalos definíveis pelo agente interessado (consumidor ou concessionária);

- Gravação e arquivamento de históricos de dados operativos da rede, bem como consumo, tarifas, e indicadores de qualidade de energia;

- Disponibilização em tempo real do consumo, faturamento, demanda, tarifação, e variação de preços de compra e venda de energia para os consumidores;

- Redução de custos operacionais nos processos de leitura, tarifação e cobrança frente a disponibilização de informações em tempo real aos consumidores e concessionárias;

- Diagnóstico e gerenciamento do sistema por parte da concessionária frente a análise em tempo real do balanço energético, controle de perdas, levantamento da curva de carga, registro de indicadores de qualidade e continuidade de energia, desequilíbrios de tensão e corrente, entre outros;

- Identificação, detecção e localização de furtos de energia por ligações ilícitas com possibilidade de desligamento remoto das unidades irregulares;

- Disponibilização de avisos de manutenção preventiva e corretiva na rede com seus respectivos tempos de restabelecimento de energia;

- Gestão de infraestrutura de telecomunicações e da infraestrutura física do sistema;

- Monitoramento das condições operativas dos equipamentos do sistema com possibilidade de comandos remotos de conexão e desconexão para manutenção do controle e automação da rede;

- Gerenciamento remoto da rede de regiões urbanas de difícil acesso e de áreas rurais;

- Disponibilização e acompanhamento de desempenho de protocolos de segurança para rede informatizada visando proteção contra possíveis ataques cibernéticos; 
- Concessão de novas tarifas a partir da análise do perfil dos consumidores pautada no tipo de geração, pico de demanda, e forma de pagamento;

- Oferta de novos serviços ligados a distribuição, microgeração, consumo e pagamento de energia.

A fim de prover estas funcionalidades a AMI geralmente constitui um sistema de gerenciamento de dados de medição composto por três redes conectadas a central de operações da concessionária de energia da seguinte forma: os mostradores visuais residenciais de diferentes consumidores compõem uma rede de área doméstica, a qual transmite bidirecionalmente seus dados aos medidores inteligentes, que por sua vez compõem uma nova rede com os medidores alocados em suas vizinhanças. Esta rede envia também bidirecionalmente dados para roteadores e coletores, os quais os transmitem a central da concessionária, responsável pelo armazenamento, configuração, gerenciamento e segurança destes dados, como ilustrado na Figura 2.4 (ACRA; THAKER, 2010; BORLASE, 2013).

Figura 2-4: Representação básica da Infraestrutura de Medição Avançada.

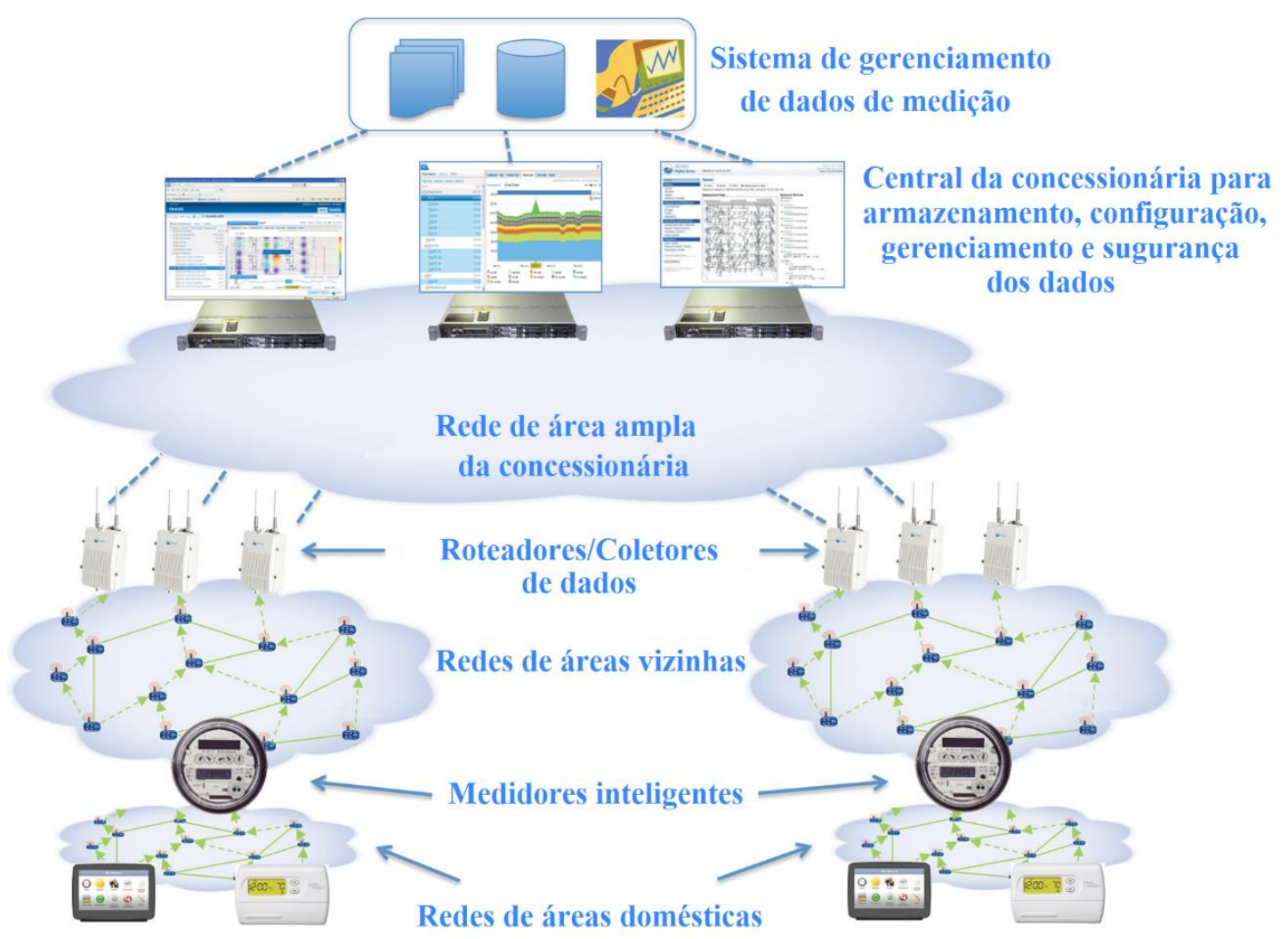

Fonte: adaptado de ACRA e THAKER (2010). 


\subsection{2 - Medidores Inteligentes}

Os medidores inteligentes constituem-se basicamente de um medidor eletrônico e um dispositivo de comunicação, a fim de medir, registrar, armazenar, disponibilizar, enviar e receber dados de maneira bidirecional e em tempo real. Disponibilizam dados e informações tanto para as concessionárias quanto para os consumidores permitindo aos mesmos alterar o gerenciamento e planejamento de suas atividades e operações por meio de ações de controle locais ou remotas (EPRI, 2009; BORLASE, 2013).

Ademais, existe uma vasta gama de medidores inteligentes destinados a aplicações variadas alocados nas instalações de consumidores residenciais, comerciais e industriais, e situados em postes junto aos transformadores de distribuição pelas concessionárias, situação na qual se enquadra a presente pesquisa. Suas características e funcionalidades variam segundo o fabricante, modelo, aplicação a que se destinam, e tecnologia incorporada, porém de forma geral pode-se destacar as seguintes (EPRI, 2009; GELLINGS, 2009; ACRA; THAKER, 2010; BORLASE, 2013; KAGAN et al., 2013, SHARMA; SAINI, 2015; KABALCI, 2016):

- Comunicação bidirecional;

- Medição do consumo de energia, tensão, corrente, fator de potência, ângulo de fase, e harmônicos, entre outros;

- Capacidade de indicação da interrupção no fornecimento de energia;

- Indicação e registro de indicadores de qualidade, continuidade e conformidade de energia;

- Armazenamento de dados;

- Capacidade de tarifação e emissão de fatura com possibilidade de pré ou pós pagamento;

- Registro de eventos de reconfiguração do sistema, falhas, alteração de tarifas, variação de carga, mudança de demanda, entre outros;

- Taxa de amostragem de dados programável;

- Demanda programável pelo próprio consumidor;

- Flexibilidade para mudança da comunicação (meio físico e protocolo);

- Adaptabilidade a inversão de fluxo frente a entrada e saída de geração distribuída;

- Apoio a tarifação e inserção na rede da energia proveniente de microgeração;

- Alarmes de notificação de violações físicas e defeito do próprio medidor; 
- Memória de massa integrada para registro de informações;

- Atualização local ou remota de software e firmware de metrologia e comunicação.

\section{5 - Panorama de Desenvolvimento e Implantação das REIs}

Nos últimos anos as Redes Elétricas Inteligentes (REIs) vêm se mostrando a principal alternativa para a modernização dos SEPs e têm recebido cada vez mais investimentos de órgãos governamentais e entidades privadas, alavancando seu processo de evolução em vários países, nos quais encontram-se diferentes projetos piloto de pesquisas em distintos estágios de desenvolvimento. Devido à variedade de testes, tecnologias, configurações e equipamentos necessários para a implantação das redes inteligentes, além da sua diversidade de conceitos de aplicação como verificado nas seções anteriores, torna-se difícil dimensionar comparativamente o grau de progresso de cada um destes estudos.

Por outro lado, depreende-se que esta variedade de situações e conformações provenientes do desenvolvimento e implantação das REIs trará consigo novas perspectivas e oportunidades relacionadas à inovação tecnológica e intelectual, e criação de novos produtos e serviços. As possíveis mudanças trazidas pelas redes inteligentes prenunciam ainda alterações em várias esferas ligadas ao setor elétrico, criando novas oportunidade e negócios que beneficiariam agentes produtores de energia, concessionárias, entidades de pesquisa, fabricantes de equipamentos, e principalmente consumidores.

Além disso, há diversos fatores motivadores para implantação das REIs de ordem econômica, política, tecnológica e ambiental, de acordo com as necessidades dos países que as desenvolvem. Nesta conjuntura, baseando-se em (CGEE, 2012), (ABDI, 2014), (MCTI, 2014) (KOLAK et al., 2016), (TUBALLA; ABUNDO, 2016) e (IQTIYANILLHAM; HASANUZZAMAN; HOSENUZZAMAN, 2017), a seguir são apresentadas por continente e/ou país as principais pesquisas e projetos de desenvolvimento e implantação de redes inteligentes em diferentes países. 


\subsection{1 - Ásia e Oceania}

\section{A - Japão}

No Japão, há uma diversidade de pesquisas e projetos de REI, sobretudo relacionadas a eficiência energética e geração de energia a partir de fontes renováveis em virtude dos problemas recentes que ocorreram em suas usinas nucleares. Ressalta-se o projeto Yokohama Smart City Project, focado em geração de energia limpa e sustentável por fontes renováveis, disponibilidade de serviços aos usuários, carregamento de veículos elétricos, medição inteligente e eficiência energética. Na mesma linha de pesquisas destacam-se os projetos Smart Melit, City of Kitakyushu e Keihanna que visam também metas de redução de emissões carbono, além dos aspectos apostados no projeto anterior.

\section{B - China}

$\mathrm{Na}$ China, o governo possui projetos ambiciosos de desenvolvimento e implantação de REIs em virtude de acordos internacionais firmados para adoção de políticas ambientais mais eficazes, já que a China é um dos maiores países com emissão de gases poluentes no mundo. Além disso, tem investido bastante na busca pela integração de fontes renováveis e em políticas de eficiência energética, sem se esquecer da competividade econômica do seu setor industrial. O foco principal tem sido o projeto Strong and Smart Grid, voltado para a transmissão de energia em ultra alta tensão com elevado grau de integração com as redes inteligentes, emprego de fontes renováveis como solar e eólica, proposição de soluções para armazenamento de energia. Há também um grande número de estudos vinculados a projetos de desenvolvimento de tecnologias nacionais para REIs coordenados pela China Southern Power Grid, os quais priorizam a área de distribuição de energia e a inovação de dispositivos para utilização pelos usuários finais das redes inteligentes.

\section{C - Austrália}

$\mathrm{Na}$ Austrália, tem se investido em redes inteligentes sobretudo em detrimento de questões ambientais e econômicas, em busca da inclusão de novas fontes de geração de energia, 
diminuição de custos do setor elétrico, estímulo a redução e ao consumo consciente e a uma política de eficiência energética. O principal projeto australiano denominado Smart Grid, Smart City, tem focado seus esforços no setor de distribuição, em tecnologias inteligentes aplicadas na área residencial, e conta com apoio governamental e de instituições privadas. Há também o projeto Smart City Trial coordenado pela Ausgrid e implementado majoritariamente pela EnergyAustralia, o qual baseia-se no emprego de comunicações com WiMAX oferecendo apoio a aplicações de automação de subestações e veículos elétricos híbridos plug-in, além de dar suporte a 50 mil medidores inteligentes e 15 mil dispositivos residenciais.

\subsection{2 - Estados Unidos}

Nos Estados Unidos, as redes inteligentes são impulsionadas por políticas governamentais, integração de fontes renováveis, redução de perdas comerciais, desenvolvimento industrial, integração de veículos elétricos, e políticas ambientais inclusas na implantação das REIs. O montante de investimentos pelo governo americano é um dos maiores, senão o maior, abarcando todas as áreas do setor elétrico, buscando desenvolver tecnologias, equipamentos, negócios, e soluções inovadores, além de criar um vasto conhecimento técnico e prático de pesquisadores e profissionais da área.

O principal órgão responsável pelas ações e investimentos na área é o DOE e as principais instituições de pesquisa são o NIST e o EPRI, mas empresas privadas também possuem grande atuação, especialmente em parcerias para desenvolvimento de equipamentos. Devido a legislação e regulação do setor elétrico americano ser de competência estadual, há uma diversificação de regras e modelos de negócios em curso nos seus diferentes estados do país, entre os quais destacam a comercialização livre praticada no Texas e as estratégias tarifarias diferenciadas implantadas na Califórnia.

Entre os principais americanos destaca-se o Smart Grid Investment Grant, responsável pela aceleração da modernização do sistema de transmissão e distribuição e busca por ações de invocação e melhoria na flexibilidade, funcionalidade, interoperabilidade, segurança digital e eficiência do setor elétrico. Também se sobressai o projeto Smart Grid Demonstration Program, cujo foco maior é a evolução dos sistemas de sensoriamento, comunicação, análise e fluxo de potência, integração a rede de fontes distribuídas renováveis e veículos elétricos plug-in, além do armazenamento de energia. 
Ainda se ressalta o programa Smart Grid Workforce Training and Development, que possui o objetivo de treinar cerca de 30.000 trabalhadores norte-americanos em tecnologias de redes inteligentes. Os projetos no âmbito deste programa visam facilitar o desenvolvimento de mão de obra treinada e qualificada composta por técnicos, engenheiros e gestores, capaz de implementar uma rede nacional inteligente de energia limpa. O programa também promove a sensibilização e interesse em carreiras na indústria de energia elétrica, e aborda três áreas temáticas: desenvolvimento e aprimoramento de programas de treinamento de mão de obra para o setor elétrico; treinamento estratégico e educação em sistemas de potência; e treinamento de mão de obra para REI.

\subsection{3 - Europa}

Nos países Europeus os agentes motivadores da REIs são bastante diversos em virtude da quantidade de países que a compõem, mas de forma geral destacam-se o desenvolvimento dos SEP europeus, as políticas governamentais, integração de fontes renováveis e de veículos elétricos, as políticas ambientais compreendidas pela implantação das redes inteligentes, e os elevados custos em países dependentes de fontes não renováveis e nucleares para produção de energia elétrica.

$\mathrm{Na}$ Europa, os investimentos e legislações para REI iniciaram-se em 2005 e fomentaram inúmeros projetos focados principalmente na área de geração distribuída e fontes renováveis, além de infraestrutura de medição, fazendo com que a implantação das redes inteligentes se encontre bastante avançada em vários de seus países membros. Entre estes países sobressamse a Alemanha, Espanha, França, Itália, Portugal, e o Reino Unido, com consideráveis investimentos em projetos e testes, e cujos resultados vem se mostrando bastante consistes e proeminentes.

\section{A - Alemanha}

$\mathrm{Na}$ Alemanha, um importante projeto é o eTelligence, com foco na implantação de tecnologias de comunicação e microgeração para formação de um mercado de energia na região de sua inserção, visando eficiência energética, segurança de alimentação, expansão das fontes renováveis e transparência no comércio de energia. As propostas apresentadas em E- 
Dema e MeRegio pautam-se no desenvolvimento de tecnologias para medição inteligente, redes de distribuição descentralizadas, eficiência energética e implantação de veículos elétricos. Os projetos MoMa e RegModHarz trabalham em soluções voltadas a inclusão da geração distribuída, microgeração e microrredes, além das também mencionadas nas duas propostas anteriores. Já o projeto Smart Watts visa prover conexão entre produtores de energias de fontes renováveis com distribuidores e consumidores finais, fornecendo ainda outros serviços aos consumidores como informações sobre onde foi produzida a energia, como foi transportada e seu custo atual.

\section{B - Espanha}

Na Espanha, também existem vários projetos relativos as REIs, entre os quais destacase o Twenties Project, cujo objetivo principal é desenvolver e implantar novas tecnologias para integração e regulação de fontes eólicas de geração, além de também buscar novas soluções para redes de alta tensão e medição, monitoramento e controle inteligente. As propostas apresentadas nos projetos STAR, BIDELEK e PRICE focam-se nas inovações em automação da rede, medição inteligente, disponibilização de novos serviços aos clientes, e eficiência energética. O projeto ENERGOS trata sobretudo do desenvolvimento de conhecimentos e tecnologias voltados para área de comunicação, processamento de informações, modelagens, transmissão de dados e geoposicionamento. Por fim, também se desenvolve o projeto Smart City na Espanha, assim como ocorre no Brasil e no Chile, focado em novas soluções para armazenamento de energia, fontes alternativas de geração, medição inteligente, serviços aos usuários, distribuição inteligente e integração de veículos elétricos.

\section{C - França}

$\mathrm{Na}$ França, um dos países com maior montante de investimentos da comunidade europeia, um importante projeto é o Greenlys, o qual trabalha o conceito de REI voltando-se bastante para o lado ambiental pelo desenvolvimento de casas ecológicas, redução da emissão de carbono, economia de energia e inserção de fontes de geração fotovoltaicas e de cogeração. Foca-se ainda em automação e controle da rede, serviços ao consumidor, monitoramento da carga, self-healing e medição inteligente. Os projetos GRIDTEAMS, MYRTE e REFLEXE também atuam mais na linha de sustentabilidade agregada as redes inteligentes pela agregação 
de geração distribuída e empego de fontes alternativas de energia. Já as propostas em PREMIO e Venteea buscam além de maior sustentabilidade novas soluções em monitoramento e controle, otimização dos custos de ligação, armazenamento de energia, automação da rede, e controle de demanda, entre outras.

\section{D - Itália}

Na Itália, o projeto recente mais relevante denomina-se Smart MV Networks cujos objetivos preponderantes são trabalhar na integração e gerenciamento de fontes renováveis de energia, principalmente plantas fotovoltaicas, produção distribuída de energia, medição inteligente, automação da rede elétrica, concepção de tecnologias para formatação de edifícios e iluminação pública inteligente, possibilitar a inserção de veículos elétricos e fomentar a configuração de rede em malha para aumentar o nível de curto-circuito.

\section{E - Portugal}

Em Portugal, o principal projeto até o momento é o InovGRID, caracterizado pela busca de inovações em medição inteligente, serviços aos consumidores, inclusão de veículos elétricos, detecção e solução de faltas na rede de distribuição, e eficiência energética, a fim de melhorar a qualidade de serviço, diminuir os custos de operação, promover a eficiência energética e sustentabilidade ambiental, potencializar a penetração das energias renováveis e do veículo elétrico.

\section{F - Reino Unido}

No Reino Unido, pode-se destacar dois importantes projetos de pesquisa, o primeiro deles intitulado Smart Grid Demonstration System visa a implementação de sistemas de comunicações para medições inteligentes, foco na redução de custos e do consumo de energia elétrica, automação da rede e oferta de serviços ao consumidor. O projeto Cryogenic Storage está mais voltado os conceitos ambientais e sustentáveis relacionadas as redes inteligentes, trabalha principalmente no desenvolvimento e implantação de fontes renováveis e no armazenamento de energia. 


\subsection{4 - Brasil}

No Brasil, diferentemente do que foi exposto para os países anteriormente apresentados, os motivadores principais para implantação das REIs são distintos, dado que a matriz energética nacional é majoritariamente hidroelétrica, e, portanto, composta por fonte renovável; o consumo de energia é menor que em países de temperaturas mais extremas ao longo do ano; e o potencial de recursos renováveis ainda pode ser bastante explorado.

Por outro lado, impulsionam as pesquisas em REI a busca por maior confiabilidade e segurança no fornecimento de energia, dada a má gestão da geração frente a variações climáticas como a seca recente (2014-2017); políticas de eficiência energética, já que muitas fontes geradoras são subaproveitadas; redução de perdas técnicas, problema recorrente na transmissão de energia devido as dimensões continentais do país; e perdas comerciais; fruto de roubos de energia por instalações irregulares; entre outros.

Neste contexto, mais de 200 projetos vêm sendo desenvolvidos no Brasil para propor soluções às dificuldades levantadas, integrando esforços de instituições governamentais, órgão reguladores do setor elétrico, concessionárias de energia, universidades, entidades privadas de pesquisa, e fabricantes de equipamentos. Posto isto, pautando-se em (MCTI, 2014) serão apresentados a seguir os onze principais projetos brasileiros na área de REI de acordo com a distribuidora ou concessionária responsável.

\section{A - Companhia Energética de Minas Gerais - CEMIG Distribuidora}

O projeto de REI Cidades do Futuro da CEMIG Distribuidora desenvolve-se na cidade de Sete Lagoas/MG e é um dos mais abrangentes no Brasil pela diversidade da área geográfica e categorias de consumidores que o compõem, assim como pela infraestrutura implantada e suas integrações sistêmicas. Os objetivos desta iniciativa são estabelecer um modelo de referência para subsidiar futuras implantações; analisar os impactos nos processos de negócio da CEMIG, na cadeia de valores de redes inteligentes e de necessidade de capacitação de profissionais para atuar na área; e avaliar aspectos técnicos, socioeconômico, financeiros, regulatórios e de percepção dos clientes. Esta proposta foca-se na automação de subestações e redes de distribuição com função de localização de faltas, isolamento e restabelecimento de serviço; medição inteligente com funções de qualidade da energia, notificação de falhas e 
instabilidades, violações no medidor, corte e religamento remotos, balanceamento energético e aplicação de tarifas diferenciadas; redes de comunicação operacionais; sistemas computacionais para operação do SEP; gerenciamento e integração de microgeração distribuída solar; aplicação de planta solar fotovoltaica com solução de armazenagem de energia; impacto da integração de veículos elétricos; rede de comunicações multisserviços para suporte às aplicações de automação e medição inteligente; ferramentas de relacionamento com o consumidor; e iluminação de LED.

\section{B - Light Serviços de Eletricidade}

O projeto de REI Smart Grid Light da Light Serviços de Eletricidade já teve seu programa demonstrativo encerrado abarcando a região metropolitana do Rio de Janeiro/RJ, obtendo como resultado novos produtos e serviços em tecnologias de automação e medição aplicadas desde as redes de distribuição até a residência dos consumidores. Foram trabalhados a introdução de medidores inteligentes com função de corte e religação, a automatização de câmaras subterrâneas e chaves religadoras, e a implantação de uma rede de comunicação e sistemas computacionais de suporte às aplicações. Além disso, esta iniciativa focou-se na medição inteligente de energia, com desenvolvimento de medidores com leitor embutido para instalação residencial e medidores com leitor remoto para instalação em postes de distribuição; certificação digital; criação de novas tarifas, produtos e serviços, inclusive com possibilidade de pré-pagamento; automação da rede e residencial (tomadas inteligentes telecomandadas); inserção de geração distribuída pela instalação de painéis fotovoltaicos e integração de sistemas de armazenamento de energia; operação em modo ilhado; terminais de recarga inteligentes para veículos elétricos e híbridos recarregáveis; e sistemas de telecomunicações e computacionais para interação eficiente e de custo reduzido entre os produtos supracitados.

\section{C - Amazonas Distribuidora de Energia - Eletrobrás}

O projeto de REI denominado Projeto Parintins é desenvolvido pela Amazonas Distribuidora de Energia, a qual é controlada pela Eletrobrás, na cidade de Parintins no interior do estado do Amazonas e próximo à divisa com o estado do Pará, destacando-se como a única iniciativa da área na região Norte do país. O objetivo do projeto é o desenvolvimento de um modelo de referência para redes inteligentes a partir da avaliação de procedimentos de 
automação da distribuição, medição e monitoramento de transformadores, e da análise da substituição de medidores dos consumidores do grupo B na região de sua implantação, oferecendo tarifas diferenciadas ao longo do dia e estimulando o consumo fora dos horários de pico de demanda. Não obstante, esta iniciativa foca-se na medição inteligente de energia, avaliando 4 medidores com diferentes tecnologias; inserção de geração distribuída pela instalação de painéis fotovoltaicos; instalação de uma rede Backhaul de radiocomunicação para transmissão de dados; utilização de tecnologia LED para avaliação de sua aplicabilidade na iluminação pública; e desenvolvimento de um Portal e aplicativo móvel para o monitoramento da conta de energia pelo cliente. Ressalta-se que a instalação de sistema de gestão de consumo prevista inicialmente no projeto foi abandonada em virtude da incompatibilidade dos equipamentos nos clientes com as novas tecnologias inteligentes.

\section{D - Ampla Energia e Serviços}

O projeto de REI Cidade Inteligente Búzios da Ampla Energia e Serviços desenvolvese na cidade de Búzios com objetivo de ser um estudo de caso em iniciativas de implantação de redes inteligentes sobre aspectos como operação, infraestrutura, custos, avaliação de impactos econômicos, socioambientais e de qualidade do serviço. Esta proposta foca-se na medição inteligente, pela análise de alternativas tecnológicas para a comunicação de dados de última milha; automação de distribuição por meio de chaves motorizadas; inserção de geração distribuída por painéis solares e aerogeradores; armazenamento de energia; veículos elétricos; iluminação pública com luminárias LED; sistema de automação e telecontrole da rede de média tensão; e piloto de prédio inteligente com a disponibilização de plataforma de controle de potência e energia.

\section{E - Companhia Energética de Pernambuco - Celpe}

O projeto de REI Arquipélago Fernando de Noronha da Celpe desenvolve-se na Ilha de Fernando de Noronha/PE com objetivo de aplicar os conceitos de redes inteligentes a um local com severas restrições ambientais por se tratar de uma reserva ecológica, promovendo a inserção de tecnologias de automação, telecomunicação, medição e microgeração distribuída. A proposta também busca avaliar a viabilidade de sua aplicação sob os aspectos sustentabilidade, qualidade da energia elétrica, suprimento a veículos elétricos, estudo de 
aplicação de tarifas diferenciadas e segurança do trabalho. Esta iniciativa pauta-se na medição inteligente de unidades consumidoras do grupo B; automação descentralizada de três alimentadores por meio de religadores e sinalizadores de falta; microgeração solar e eólica e com armazenamento; potencial de uso de veículos elétricos e modelo de serviço de abastecimento com eletroposto desconectado da rede abastecido com energia renovável; rede híbrida com fibra óptica e rádiocomunicação; iluminação pública de LED; e tecnologia de submedição e análise da resposta de demanda dos consumidores.

\section{F - EDP Bandeirante}

O projeto de REI InovCity da EDP Bandeirante desenvolve-se na cidade de Aparecida do Norte/SP e baseia-se na experiência adquirida pela EDP em uma iniciativa de mesmo nome voltada para redes inteligentes desenvolvida na cidade de Évora em Portugal e citada anteriormente na seção 2.4.3 do presente capítulo. O objetivo desta proposta é transformar a cidade de Aparecida do Norte em um laboratório em escala real para testar várias das funcionalidades das REIs e assim analisar a viabilidade de suas tecnologias em relação a eficiência e qualidade na prestação de serviços ao cliente. Este projeto foca-se na medição inteligente, pela instalação de medidores de fronteira, de unidades consumidoras, de transformadores e concentradores de medição; automação da rede com religadores telecomandados; estudos de análise da inserção de geração distribuída; previsão de promoção e incentivo ao uso de veículos elétricos; sistema de gestão InovCity; iluminação pública de LED; e testes e pesquisas de opinião com consumidores a respeito de temas como prépagamento, tarifa branca e bandeiras tarifárias.

\section{G - Companhia Paulista de Força e Luz - CPFL}

A CPFL ainda não possui projeto em local específico para implantação de REI, porém já vem trabalhando no desenvolvimento de tecnologias aplicáveis às redes inteligentes e instalando algumas delas em redes de distribuição de cidades do interior do estado de São Paulo. Entre os equipamentos já instalados destacam-se medidores inteligentes para clientes do Grupo A e rede de telecomunicações por radiofrequência RF Mesh, formada por concentradores de dados, repetidores de radiofrequência e cartões de interface de rede, compondo um sistema de medição inteligente. Na mesma área está prevista também a 
instalação de medidores em instalações de consumidores do grupo B com início no fim de 2015, e para automação da distribuição estão sendo desenvolvidos projetos visando a automação de serviços como o desligamento e religamento automático de energia. Pretende-se ainda integrar usinas solares a rede de distribuição no tocante a geração distribuída, e em relação a inclusão de veículos elétricos tem sido realizado testes com os automóveis que compõem sua própria frota empresarial.

\section{H - Companhia Energética do Ceará - Coelce}

O projeto de REI Cidade Inteligente Aquiraz da Coelce desenvolve-se na cidade de Aquiraz/CE e caracteriza-se sobretudo por medidas de automação da rede pela instalação de religadores automáticos, e também pelo desenvolvimento de um sistema de recomposição automática e de ajustes automático da proteção, além da implantação de sistema de supervisão e controle atualmente em andamento. Em relação a medição está sendo desenvolvido um projeto em Fortaleza, que conta com instalação de medidores inteligentes e de concentradores de dados nos postos de transformadores que trocam informações com esses medidores.

\section{I - Companhia Paranaense de Energia - Copel}

A Copel em parceria com o governo estadual do Paraná desenvolve projetos piloto de REI vinculados ao programa Smart Energy Paraná nas cidades de Curitiba/PR e Fazenda Rio Grande/PR, os quais contam com sistemas de medição compartilhados com Compagas (Companhia Paranaense de Gás) e Sanepar (Companhia de Saneamento do Paraná). O programa proposto visa implantação e teste de tecnologias de redes inteligentes no setor de distribuição de energia, em área de alta densidade de carga e visibilidade visando a antecipação de aplicações futuras. As iniciativas deste projeto focam-se na medição inteligente pela instalação de medidores de energia, água e gás; automação da distribuição pela implantação de técnicas de reconfiguração automática, sensoriamento de faltas, controle Volt-VAr, e self healing; instalação de microgeração distribuída solar conjunta com sistema de armazenamento de energia; integração de veículos elétricos em estudo a partir da análise de desempenho de um taxi elétrico e da instalação de um eletroposto para recarga já concluído; rede de comunicações em fibra óptica e com tecnologia GPRS (General Packet Radio Services); e a nível residencial 
avaliação da proposta Casa do Futuro, que inclui sistemas de microgeração, armazenamento de energia, mobilidade elétrica e automação residencial.

\section{J - ELEKTRO}

A ELEKTRO desenvolve um projeto de REI na cidade de São Luiz do Paraitinga/SP com o objetivo de implantar e testar tecnologias de redes inteligentes para avaliar os principais impactos nos processos técnico-operacionais e nas mudanças de hábito do consumo dos consumidores. Ademais, com a participação e conscientização da população de São Luiz do Paraitinga vislumbra-se aumento do uso racional de energia e eficiência energética. A Elektro também participa de outras iniciativas na área em projetos de Pesquisa e Desenvolvimento junto a automação de distribuição, geração distribuída, veículos elétricos e interação com clientes.

\section{K - AES Eletropaulo}

A AES Eletropaulo possui vários projetos de REI em desenvolvimento, entre os quais destaca-se o Eletropaulo Digital, as ações em curso nas cidades de Barueri/SP e Vagem Grande Paulista e no Bairro do Ipiranga na capital paulista, perfazendo os maiores investimentos e amplos projetos do país. No Bairro do Ipiranga foram instalados medidores inteligentes com o objetivo de implementar soluções de medição remota com função de corte e religamento integradas a outras soluções de automação. A AES pretende instalar soluções de configuração automática da rede em Vargem Grande Paulista, visa tonar Barueri o primeiro município em região metropolitana do Brasil com rede inteligente de distribuição de energia.

Já sua principal iniciativa, o projeto Eletropaulo Digital, caracteriza-se pela utilização do conceito living lab, que remete a criação de um ambiente de inovação contínua, em um ambiente com alta densidade de carga e complexidade urbana, característica das grandes metrópoles. O objetivo desta proposta é implementar tecnologias e funcionalidades de REI adequadas à rede elétrica, ao mercado e aos desafios estratégicos e operacionais do sistema elétrico sob análise. Para tanto, busca desenvolver equipamentos de medição e balanço energético, além de integrar soluções inovadoras nas áreas de medição, automação e telecomunicação, aplicáveis em toda a área de concessão da AES Eletropaulo. 
Além disso, o projeto Eletropaulo Digital foca-se na medição pelo desenvolvimento de um módulo de comunicação para última milha, medidores inteligentes e roteadores; e automação da distribuição pela instalação de dispositivos de detecção de falta em redes aéreas, self healing, controle Volt-VAr em subestações e alimentadores, e desenvolvimento de um portal e aplicativos móveis ligados ao sistema SCADA (Supervisory Control and Data Acquisition) para visualização de informações operativas em tempo real. Também se volta para área de geração distribuída por meio de um estudo teórico sobre o impacto global da mesma em sua rede de distribuição; integração de veículos elétricos por meio da preparação de rede e iniciativa de teste com taxis elétricos; e a criação de uma Smart Home pautada no conceito de Gestão Energética integrado a automação residencial e AMI. Em relação a novos produtos e serviços visa a interação do cliente por meio de um portal e de aplicativos; estudo de integração de redes inteligentes com outros serviços públicos pela iniciativa denominada Multi-utility; e investimento em capacitação de técnicos sobre as tecnologias e os conceitos de REIs.

\section{6 - Considerações Parciais sobre Sistemas de Distribuição de Energia Elétrica e as Redes Elétricas Inteligentes}

Ao longo deste capítulo observou-se que os sistemas elétricos como um todo estão passando por transformações e atualizações pautadas nos conceitos de Redes Elétricas Inteligentes (REI) visando sua modernização, entre as quais são foco maior desta pesquisa principalmente as relacionadas a área de distribuição de energia elétrica.

As redes inteligentes têm sido vistas como a principal solução para a modernização da infraestrutura do setor elétrico pela possibilidade de prover medição avançada, automação de sistemas e processos, trocas de informações bidirecionalmente em tempo real, aumento da eficiência e segurança energética, redução de perdas e custos, participação ativa dos consumidores, e maior viabilização da inclusão de fontes alternativas a matriz energética por meio da geração e microgeração distribuída, entre outros aspectos.

No contexto da proposta da presente pesquisa ressalta-se entre as funcionalidades de REI as voltadas para medição inteligente, devido a sua capacidade de monitoramento, processamento, armazenamento e comunicação de dados em tempo real e de forma bidirecional. As mesmas poderão contribuir nos processos de localização de faltas pelo 
fornecimento de históricos de dados e disponibilização avançada de parâmetros operacionais, informações e diagnóstico do sistema, facilitando a identificação de distúrbios, localização e gerenciamento remoto dos pontos sob falta.

Outrossim, consta-se que são diversos os motivadores para investimentos e pesquisas em REIs, além dos estágios de desenvolvimento e implantação também bastante diversificado entre iniciativas em um mesmo país. Os países europeus têm despendido muitos esforços na busca por alternativas de geração por fontes renováveis e inserção junto aos seus sistemas elétricos pela integração dos conceitos de REI. Já nos Estado Unidos a preocupação maior está na modernização do setor elétrico, na comercialização de energia e na importância da mesma para o desenvolvimento industrial do pais. Os países asiáticos, como Japão e China, têm maior foco na redução da emissão de poluentes pelo emprego de fontes renováveis e na melhoria da eficiência energética em virtude da escassez de fontes de geração.

Por fim, no Brasil observa-se que os maiores motivadores são a busca por melhorias na confiabilidade e segurança no fornecimento de energia, redução de perdas técnicas e perdas comerciais, além da modernização dos sistemas de distribuição. Os projetos levantados focamse, sobretudo no desenvolvimento da infraestrutura de medição inteligente, automação da distribuição, tecnologias de informação e comunicação e incentivo e inserção da geração distribuída. No entanto, nota-se que há menos pesquisas em tecnologias para armazenamento de energia, integração de veículos elétricos, disponibilização de novos serviços aos consumidores, e construção de edifícios inteligentes. 



\section{CAPÍTULO 3}

\section{ASPECTOS RELACIONADOS À LOCALIZAÇÃO DE FALTAS EM SISTEMA DE DISTRIBUIÇÃO DE ENERGIA ELÉTRICA}

Primeiramente, são expostas neste capítulo as principais situações causadoras de faltas nos SEPs, bem como a classificação das mesmas de acordo com a natureza do agente causador e seu respectivo percentual de ocorrência. Posteriormente, são apresentados diferentes aspectos referentes ao acontecimento de faltas especificamente nos sistemas de distribuição de energia elétrica, e elencam-se percentualmente os principais agentes causadores e tipos de faltas nestes sistemas. Em seguida, são delineadas as particularidades pertinentes a localização de faltas nos sistemas de distribuição, assim como as dificuldades encontradas nesta atividade frente à variação das características das redes de distribuição. Por fim, realiza-se uma revisão bibliográfica e histórica sobre alguns dos principais métodos de localização de faltas que empregam análise de circuitos e sistemas elétricos, medição e diagnósticos de apenas sinais de tensão, e utilização de sistemas inteligentes, destacando suas particularidades, melhorias e deficiências caso existam.

\section{1 - Principais Conceitos Relativos às Faltas nos Sistemas Elétricos de Potência}

Os SEPs são projetados e constituídos visando sua operação em regime permanente e de forma constante, porém estão frequentemente expostos às condições mais diversas e imprevisíveis, sujeitando-se a perturbações. Estas perturbações fazem com que o sistema elétrico atue fora de seu regime de operação normal alterando grandezas elétricas como tensão, 
corrente e frequência, caracterizando assim a ocorrência de uma falta (KINDERMANN, 2010; MAMEDE FILHO; MAMEDE, 2011).

Dentre as inúmeras situações causadoras de faltas podem-se destacar as seguintes (KINDERMANN, 2010):

- Problemas de Isolação - as tensões nos condutores do sistema podem se elevar e consequentemente, rupturas para a terra ou entre cabos podem ocorrer por motivos como desenho inadequado da isolação dos equipamentos, estruturas ou isoladores; material empregado na fabricação de má qualidade ou impróprio; envelhecimento do próprio material.

- Problemas Mecânicos - são oriundos da natureza e que provocam ação mecânica no sistema elétrico, como, por exemplo, ação do vento; neve; contaminação; árvores.

- Problemas Elétricos - problemas elétricos intrínsecos da natureza ou os devido a operação do sistema, entre eles descargas atmosféricas diretas ou indiretas; surtos de chaveamento (manobra); sobretensão no sistema.

- Problemas de Natureza Térmica - o aquecimento nos cabos e equipamentos do sistema, além de diminuir a vida útil, prejudica a isolação, e pode ocorrer em virtude de sobrecorrentes em consequência da sobrecarga do sistema; sobretensão no sistema; desbalanceamento na rede.

- Problemas de manutenção - substituição inadequada de peças e equipamentos; pessoal não treinado e qualificado; peças de reposição não adequadas; falta de controle de qualidade na compra do material; inspeção na rede não adequada; poda de árvores.

- Problemas de outra Natureza - atos de vandalismo, terrorismo e sabotagem; queimadas, inundações; desmoronamentos; acidentes de qualquer natureza.

As faltas podem ser classificadas como temporárias ou permanentes, de acordo com a natureza do agente causador. As faltas temporárias são geralmente causadas por toques momentâneos entre cabos, contato entre galhos de árvores e animais com cabos, ou perdas de isolação com consequente formação de arco elétrico, e podem ser corrigidas pelo religamento automático do sistema elétrico (CAMINHA, 2004; KINDERMANN, 2010; SAHA; IZYKOWSKI; ROSOLOWSKI, 2010). Contudo, com a localização das mesmas é possível definir locais mais adequados para instalação de equipamentos de proteção, como por exemplo, para-raios, além de possibilitar análises do sistema sob estas condições para se tomar medidas preventivas contra este tipo de ocorrência. 
Já as faltas permanentes habitualmente são causadas por rompimento de cabos condutores, quedas de árvores sobre a rede elétrica, queda de postes, descargas atmosféricas diretas, vandalismo ou queimadas, entre outros (CAMINHA, 2004; KINDERMANN, 2010; SAHA; IZYKOWSKI; ROSOLOWSKI, 2010). Devido aos danos físicos para a rede elétrica e seus equipamentos sua correção deve ser realizada por equipes de manutenção, que em muitas situações ainda fazem uso da inspeção visual para localização dos pontos de defeito.

A falta mais comum nos sistemas de potência é o curto-circuito, o qual geralmente ocasiona a circulação de elevadas correntes pelos elementos energizados que compõem o SEP, acarretando distúrbios de tensão ao longo de todo sistema, e consequentemente danos físicos irreparáveis ao sistema elétrico e as instalações das unidades consumidoras. Além disso, as sobrecargas também podem causar anomalias nos SEPs e, por conseguinte, danos significativos, assim como as sub e sobretensões (KINDERMANN, 2010; MAMEDE FILHO; MAMEDE, 2011).

Nos SEPS, em meio aos tipos de curtos-circuitos existentes, o mais frequente é o faseterra, motivado, por exemplo, por contatos entre cabos ou entre cabos e galhos, e o menos habitual o trifásico em decorrência da própria natureza física dos mesmos, e dentre os monofásicos os mais recorrentes são os temporários, como observa-se nas Tabela 3.1 e 3.2.

Tabela 3-1: Ocorrência de curtos-circuitos nos SEPs.

\begin{tabular}{c|c}
\hline Tipos de curto-circuito & Ocorrência (\%) \\
\hline Trifásico & 6 \\
\hline Fase-fase & 15 \\
\hline Fase-fase à terra & 16 \\
\hline Fase-terra & 63 \\
\hline
\end{tabular}

Fonte: adaptado de KINDERMANN (2010).

Tabela 3-2: Ocorrência de curtos-circuitos permanentes e temporários nos SEPs.

\begin{tabular}{c|c}
\hline Curto-circuito monofásico à terra & Ocorrência $(\boldsymbol{\%})$ \\
\hline Permanentes & 4 \\
\hline Temporários & 96
\end{tabular}

Fonte: adaptado de KINDERMANN (2010). 


\section{2 - Particularidades das Faltas nos Sistemas de Distribuição}

Os sistemas de distribuição são os responsáveis diretos por entregar energia aos consumidores, sejam eles urbanos ou rurais, de grande, médio ou pequeno porte. As linhas rurais geralmente são aéreas e localizam-se em meio a pastagens a campo aberto, estando expostas a faltas causadas principalmente por descargas atmosféricas diretas, queimadas, rajadas fortes de vento, entre outros. Já nas áreas urbanas a grande maioria das redes de distribuição é do tipo aéreo e localiza-se em regiões com elevado adensamento populacional, cercada por grandes edifícios, galpões industriais, casas, antenas de telecomunicações, e árvores, entre outros, aumentando sua exposição a acidentes diversos entre seus componentes e elementos externos ao sistema elétrico.

Além disso, por possuírem trechos com muitas ramificações e consumidores requerem um número maior de diferentes dispositivos e equipamentos para transformação, manobra, compensação reativa, regulação de tensão, e proteção. Dessa forma, por estarem mais expostas e conterem mais equipamentos as redes aéreas urbanas de distribuição estão mais sujeitas a faltas devido, por exemplo, a descargas atmosféricas indiretas, toque de cabos com árvores, e falhas em equipamentos (SHORT, 2004; SAHA; IZYKOWSKI; ROSOLOWSKI, 2010).

Na Tabela 3.3 observa-se que mais de $50 \%$ das faltas em sistemas de distribuição aéreos são causadas por condições climáticas adversas ou problemas acarretados por agentes relacionados ao meio ambiente (fauna e flora). A partir da Tabela 3.4 nota-se que quase $80 \%$ das faltas em sistemas de distribuição são fase-terra. Isto decorre do fato de a maior parte da rede de distribuição ser constituída por ramais monofásicos e devido à probabilidade de faltas fase-terra ser maior dada à ocorrência de falhas em equipamentos e contato de animais com a rede elétrica, que possuem aproximadamente $21 \%$ de chance de acontecer segundo os dados da Tabela 3.3. Árvores também podem causar faltas fase-terra sobre estruturas trifásicas, mas neste caso as faltas fase-fase são mais comuns, e as descargas atmosféricas tendem a causar faltas entre duas ou três fases e a terra em estruturas trifásicas (SHORT, 2004).

Ressalta-se que os dados apresentados em (SHORT, 2004) se referem a ocorrências de faltas em sistemas de distribuição dos Estados Unidos e Canada, que apesar de apresentarem características distintas das redes de distribuição brasileiras contribuem com informações importantes para composição de conhecimento a respeito da ocorrência de faltas. 
Tabela 3-3: Principais agentes causadores de faltas em sistemas de distribuição.

\begin{tabular}{c|c}
\hline Agente causador da falta & Ocorrência (\%) \\
\hline Descarga atmosférica & 19 \\
\hline Contato com árvore & 19 \\
\hline Falha de equipamento & 13 \\
\hline Animal & 8,5 \\
\hline Vento & 7 \\
\hline Escavação & 4 \\
\hline Acidente veicular & 3 \\
\hline Gelo/neve & 1 \\
\hline Vandalismo & 1 \\
\hline Atividade construtiva & 1 \\
\hline Outros & 27 \\
\hline
\end{tabular}

Fonte: adaptado de SHORT (2004).

Tabela 3-4: Probabilidade de ocorrência para cada tipo de falta em sistemas de distribuição.

\begin{tabular}{c|c}
\hline Tipo de falta & Ocorrência $(\boldsymbol{\%})$ \\
\hline Fase-terra & 78 \\
\hline Fase-fase & 11 \\
\hline Fase-fase neutro & 2 \\
\hline Fase-fase à terra & 2 \\
\hline Trifásica & 2 \\
\hline Trifásica à terra & 1 \\
\hline Outros & 4 \\
\hline
\end{tabular}

Fonte: adaptado de SHORT (2004).

Entre 50 e $90 \%$ das faltas nos sistemas de distribuição são temporárias, causando queda de tensão no ramal sob falta e nos seus ramos adjacentes, e interrupções momentâneas em todo alimentador caso estas faltas ocorram no seu tronco principal. Além disso, geralmente este tipo de falta não danifica permanentemente qualquer equipamento do sistema elétrico, o qual volta a operar normalmente após um pequeno intervalo de tempo entre a abertura e fechamento dos religadores do circuito afetado restabelecendo o fornecimento de energia aos consumidores, a não ser que a falta evolua para uma falta permanente. As principais causas de faltas temporárias 
incluem descargas atmosféricas, condutores entrando em contato entre si devido ao vento, galhos de árvores ou animais tocando os condutores da rede, e flashover em isoladores causado pela poluição (SHORT, 2004).

Ressalta-se que apesar das precauções e cuidados adotados no decorrer da fase de projeto e de execução das instalações, seguindo as normas e recomendações existentes, as faltas são inerentes ao funcionamento dos SEPs, podendo acarretar consequências pouco relevantes ou danosas aos mesmos, dependendo da sua detecção, identificação, localização e reparação.

Nesta conjuntura, busca-se além de procedimentos para detecção e identificação, principalmente métodos para localização de faltas, os quais baseiam em diferentes conceitos, técnicas e ferramentas numéricas e computacionais, cuja revisão bibliográfica e histórica a seguir procura evidenciar.

\section{3 - Tópicos Fundamentais sobre a Localização de Faltas nos Sistemas de Distribuição}

O processo de localização de faltas nos sistemas de distribuição consiste em determinar o local exato, ou mais próximo possível, da ocorrência de uma falta, a partir do processamento das informações extraídas das formas de onda de tensão e corrente, geralmente em relação à origem do sistema, que neste caso é a subestação de distribuição. O conhecimento preciso da localização da falta no menor tempo possível potencializa a atuação da equipe do centro de operação da concessionária agilizando a restauração ou reconfiguração da rede e o deslocamento das equipes de manutenção.

As metodologias desenvolvidas para esta finalidade devem prezar pela rapidez da indicação do ponto sob falta de forma eficiente e robusta minimizando os inconvenientes causados aos consumidores pelas interrupções de energia e as concessionárias frente às penalizações dos órgãos reguladores, haja vista fatores tais como: atendimento as características e aos requisitos operacionais, disponibilidade de equipamentos e informações ofertada pelo sistema elétrico, possibilidades operacionais da concessionária de distribuição de energia elétrica, relação complexidade/precisão/velocidade/custo do processo de localização, entre outros. 
Neste contexto, a localização de faltas torna-se complexa e onerosa, sobretudo em virtude da variação das características das redes de distribuição, tais como (OLIVEIRA et al., 2000; SAHA; IZYKOWSKI; ROSOLOWSKI, 2010; GLOVER; SARMA; OVERBYE, 2011):

- Topologia variável da rede com possibilidade de presença de ramos laterais de diferentes extensões ao longo do alimentador principal;

- Desbalanço do sistema em virtude de cargas distribuídas e desbalanceadas (cargas monofásicas, bifásicas e trifásicas);

- Operação radial da rede com fluxo de potência unidirecional em oposição aos sistemas de transmissão interligados em rede malhada;

- Possibilidade da presença de linhas aéreas e subterrâneas nos trechos urbanos;

- Heterogeneidade do alimentador devido a sua construção com condutores de bitolas distintas, variedade de tipos de equipamentos, e disparidade na configuração do posicionamento dos condutores nos postes de sustentação;

- Desconhecimento dos níveis de carregamento da rede em virtude das suas reconfigurações causadas pelo comportamento dinâmico das cargas;

- Conexão e desconexão de geradores distribuídos ao longo de diferentes pontos do sistema;

- Ausência ou precariedade de equipamentos de monitoramento, comunicação, controle e automação.

Visando contornar as restrições decorrentes de tais particularidades, no decorrer das últimas décadas vários métodos para localização de faltas foram propostos, diferindo-se em relação à quantidade de informações disponíveis, tipos de dados e técnicas de análise circuitos e de sistemas elétricos utilizados, ferramentas matemáticas aplicadas, e instrumentação computacional empregada. A seguir, doravante o progresso e abrangência destes métodos ao longo do tempo em virtude da evolução de novas técnicas e inclusão de inovações tecnológicas, apresentam-se as principais pesquisas estudadas durante o desenvolvimento da proposta desta tese. 


\section{4 - Revisão Bibliográfica e Histórica dos Métodos de Localização de Faltas}

As metodologias propostas para localização de faltas podem ser agrupadas de diferentes formas de acordo com a base conceitual em que se fundamentam, tais como: convencionais; baseadas em análise de circuitos e de sistemas elétricos, sinais, ondas viajantes, impedância e sistemas inteligentes, entre outros. A revisão apresentada nesta tese traz vários métodos sem agrupá-los por verossimilhança, destacando as particularidades e avanços de cada um deles. Contudo, confere-se maior destaque aos métodos que empregam análise de sistemas elétricos, medição e diagnósticos de apenas sinais de tensão e utilização de sistemas inteligentes, em virtude de a metodologia proposta nesta pesquisa trabalhar com estas ferramentas no decorrer do seu desenvolvimento.

Os primeiros e mais elementares métodos de localização de faltas baseavam-se apenas no despacho de equipes de manutenção para inspeção visual do sistema elétrico. A equipe devia buscar identificar de forma visual, a priori, ou por meio de manobras em ramais do sistema, qual o ponto sob defeito da rede e tomar as devidas providencias a fim de repará-lo. Entretanto, este processo poderia levar muito tempo, dependendo do número de ligações de consumidores, tipo e quantidade de ocorrências de faltas, horário do evento, e das condições geográficas e climáticas da área.

Entre 1950 e 1980, com o desenvolvimento de equipamentos de medição e oscilografia de sinais de tensão e corrente surgiram métodos ainda simples para localização de faltas, porém importantes para a evolução das pesquisas da época, dirigidos tanto a linhas de transmissão quanto distribuição, porém com maior enfoque nas primeiras.

Dentro do escopo da presente tese a primeira metodologia a se destacar foi proposta por Takagi et al. (1982b) para linhas curtas de transmissão de energia, pautada nas pesquisas publicadas em (TAKAGI et al., 1981) e (TAKAGI et al., 1982a) e na análise de circuitos e sistemas elétricos.

O método exposto em (TAKAGI et al., 1982b) foi desenvolvido utilizando-se o teorema da superposição, descompondo o sistema faltoso em um sistema pré-falta e um puramente faltoso, admitindo que a linha era suficientemente curta e com geometria assimétrica, e utilizando dados de apenas um terminal. Seu equacionamento foi elaborado para faltas fase- 
terra considerando um circuito monofásico e a reatância medida a partir dos fasores fundamentais de tensão e corrente no terminal local da linha.

Este método apresenta boa precisão para faltas cuja resistência seja zero, porém a estimação errônea da corrente de falta vista do terminal local causada pela utilização do teorema da superposição para faltas de resistência superior a zero reduz sua precisão. A estimação fornecida por esta técnica ainda é influenciada pela impedância equivalente dos terminais da linha e pela localização do ponto de ocorrência da falta.

Pouco tempo depois, em (SRINIVASAN; ST.-JACQUES, 1989) apresenta-se uma das primeiras metodologias dedicadas a sistemas de distribuição. A mesma destina-se a localização de faltas em linhas longas e curtas de sistemas de subtransmissão e distribuição transpostas aplicando a análise de componentes simétricas. Além disso, destaca-se por considerar passivo o sistema equivalente no terminal remoto da linha, não tomar a corrente de falta em fase com a corrente medida nos terminais da subestação, e incluir o efeito da alocação de cargas intermediárias ao longo da rede.

A consideração da existência das cargas trouxe maior realidade a proposta e também novos desafios para obtenção do ponto sob falta frente às diversas estimativas encontradas pela influência das ramificações da rede. Estes obstáculos foram contornados por uma seleção lógica entre as múltiplas possibilidades obtidas a partir da análise da conexão das cargas em diferentes pontos da linha em estudo, e pela adoção de um equivalente para as cargas alocadas a jusante do ponto de falta, obtendo-se bons resultados. Ademais, para cargas que se comportam como impedância constante, os valores pré-falta das variáveis do sistema são suficientes para o esquema de localização de falta, caso contrário é necessário o conhecimento prévio do modelo da carga na outra extremidade da linha.

Alguns anos depois, em (GIRGIS; FALLON; LUBKEMAN, 1993) exibe-se uma técnica para localização de faltas em alimentadores de distribuição rurais que faz uso de valores de tensão e corrente medidos em um único local do sistema. O método apresentado procura considerar os múltiplos ramais laterais, as condições de desequilíbrio e a natureza assimétrica dos alimentadores de distribuição atualizando continuamente os vetores de tensão e corrente em locais definidos dentro do sistema pelo emprego de um algoritmo recursivo de estimação ótima.

Admite-se o efeito das correntes de carga e o desbalanço do sistema por meio do uso de um modelo de impedância constante para as cargas e do cálculo do fluxo de potência trifásico para determinar o estado operativo do sistema. A distância do ponto de falta à subestação, inclusive com capacidade de determinação de faltas em ramos laterais, é calculada 
utilizando-se um método abalizado no conceito da impedância aparente e nos vetores de tensão e corrente estimados. Por fim, os autores apontam como fontes de imprecisão ao processo de localização de faltas o desequilíbrio da rede, a resistência de falta, e as correntes de carga.

No ano seguinte, em (JARVENTAUSTA; VERHO; PARTANEN, 1994) propõe-se um dos primeiros métodos a empregar os conceitos de sistemas inteligentes baseado na teoria dos conjuntos fuzzy para lidar com as incertezas envolvidas no processo de localização de faltas em redes de distribuição. Este episódio advém do fato de que no diagnóstico de faltas computadorizado das redes de distribuição o conhecimento heurístico dos operadores dos centros de controle pode ser combinado com informações obtidas a partir do banco de dados da rede e do sistema SCADA. No entanto, a natureza do conhecimento heurístico é inexata e incerta e as informações obtidas a partir do sistema de controle podem conter incertezas, estar incorretas, conflitantes ou inadequadas.

A metodologia proposta inicia-se pela composição de uma terminologia de inferência fuzzy para o modelo da rede sob defeito de acordo com a base de dados do sistema, ao mesmo tempo em que as entradas para o módulo de inferência são obtidas a partir dos dados do sistema SCADA (por exemplo, corrente de curto-circuito, operação de detectores de falta, e condições climáticas) e da base de dados de rede (por exemplo, propriedades e condições do terreno e dos componentes de rede). São atribuídos diferentes graus de pertinência as situações de defeito e ao aplicar as regras fuzzy definidas de acordo com a proposição do método elaborado, as zonas candidatas para falta podem ser obtidas e organizadas de acordo com sua possibilidade de ocorrência. Os resultados demonstram a boa atuação do método, porém deixam abertura para a necessidade de desenvolvimento de algoritmos de ajuste do sistema de inferência fuzzy.

Logo em seguida, em (MOHAMED; RAO, 1995) apresenta-se um dos primeiros sistemas de diagnóstico de faltas para alimentadores de distribuição baseado no emprego de Redes Neurais Artificiais (RNAs). Estrutura-se uma RNA multicamadas usando o algoritmo de aprendizagem back-propagation e apenas tensões e correntes medidas na subestação, sem necessidade de dados adicionais, com alta eficiência computacional resultando em uma resposta rápida pelo sistema. O primeiro bloco da RNA detecta a falta incipiente no alimentador de distribuição, enquanto o segundo localiza a seção sob falta utilizando medições locais e o terceiro e quarto classificam as faltas detectadas em duas categorias, alta e baixa impedância.

O sistema de diagnóstico de faltas proposto é caracterizado por sua estrutura simples e de fácil aplicação, desempenho global eficiente, e adaptabilidade para uso frente uma ampla variedade de topologias de rede. Os resultados dos testes realizados em um alimentador de 
pequeno porte composto por três seções ligando uma subestação a uma carga apresentam elevado grau de acerto, acima de 96\%, na validação do método. Entretanto, necessita-se de mais testes em sistema mais complexos, com variações de carga e presença de ramificações, para uma análise mais consistente desta metodologia.

Posteriormente, em (ZHU; LUBKEMAN; GIRGIS, 1997) é descrita uma das primeiras técnicas para localização de faltas em sistemas de distribuição pautada na aplicação dos conceitos de componentes de fase, e não de componentes simétricas, como usualmente ocorrerá. O equacionamento para determinação do local da falta se baseia na aplicação de um algoritmo iterativo para o cálculo da corrente de falta, e na comparação entre a impedância estimada no ponto da falta e a impedância equivalente da carga. $\mathrm{O}$ efeito capacitivo não é considerado por este método, porém as ramificações da rede o são, as cargas a jusante da falta são tomadas por seu equivalente, as tensões e correntes são estimadas a cada iteração.

O algoritmo iterativo realiza a busca pelo nó sob falta inicialmente pelo ramo principal conectado diretamente a subestação, a seguir, são atualizadas as tensões e correntes em todos os nós à jusante do primeiro, e havendo ramificações laterais obtêm-se múltiplas estimativas para o local da falta. Esta múltipla estimação é contornada pela averiguação da atuação dos equipamentos de proteção e pela avaliação das características da rede, por meio da análise das medidas de tensão e corrente e da variação de carga do sistema. Ademais, esta metodologia ainda conta com uma extensão probabilística do algoritmo para determinação da região de provável ocorrência das faltas, e faz uso da comparação entre as tensões e correntes medidas e simuladas em busca do melhor acerto possível para o local sob falta, mas sua aplicação foi analisada somente para faltas fase-terra.

Em (DAS; SACHDEV; SIDHU, 2000) apresenta-se uma evolução da metodologia exposta em (NOVOSEL et al., 1998) para localização de faltas em linhas curtas com características semelhantes as redes de distribuição. Nesta técnica consideram-se tanto cargas intermediárias como as derivações laterais da linha, mas não se analisa a contribuição do seu efeito capacitivo. Por meio de um processo iterativo compara-se a impedância aparente durante a falta com a impedância entre a subestação e cada um dos ramais da rede indicando um possível ponto para a falta, e convertem-se os ramos laterais a montante e jusante do mesmo em seus equivalentes.

A seguir, a partir da atualização das tensões e correntes novas estimações são realizadas dependendo da configuração do sistema e das condições da falta até que se encontre a seção faltosa devido à obtenção de uma impedância puramente resistiva. Ainda são obtidas duas outras estimativas, uma para uma seção à jusante da primeira seção estimada e outra à montante 
da mesma acarretando um problema de múltipla estimação. Este obstáculo não é contornado pelo método proposto, porém os autores sugerem a utilização de indicadores de falta instalados no início de cada um dos ramais laterais da linha para contorna-lo e assim apontar um único local para a falta.

Já em (GALIJASEVIC; ABUR, 2002) é exposta uma técnica para localização de faltas em sistemas de distribuição cuja origem está no conceito de contorno de vulnerabilidade, o qual é usado para delimitação de uma determinada área da rede a partir de afundamentos de tensão. Além disso, a metodologia baseia-se na suposição de que há um número limitado de barras onde as tensões são registadas, e assume-se a incidência direita de faltas nos barramentos do sistema.

O método é composto por uma etapa on-line, em que são medidas as quedas de tensão nas barras selecionadas do sistema, e em uma fase off-line na qual se busca estimar a resistência de falta e sua localização provável a partir da análise de correspondência dos afundamentos de tensão medidos e calculados. Para lidar com as incertezas inerentes ao problema, aplicam-se os conceitos de lógica fuzzy para melhorar o procedimento de estimativa desenvolvido, e os resultados mostram que esta ação traz uma melhoria significativa no desempenho do método proposto, mas não se consideram ramificações do alimentador e o carregamento da rede inerente aos sistemas de distribuição.

Em sequência, em (LEE et al., 2004) desenvolve-se um algoritmo para localização de faltas baseado em (ZHU; LUBKEMAN; GIRGIS, 1997), o qual fundamenta-se na estimação iterativa das correntes para cada seção da linha. As cargas à jusante do possível ponto de falta são representadas pelo seu equivalente, considerando a dependência com a tensão aplicada em seus terminais e admitindo-se a associação entre a impedância da linha e a das cargas, desde que se tenha conhecimento da impedância das cargas, pois, caso contrário, desconsidera-se o acoplamento mútuo entre ambas.

Incialmente, o algoritmo proposto identifica os locais de falta candidatos usando uma estimativa iterativa das correntes de cargas e da corrente de falta em cada seção de linha. A seguir, a fase de diagnóstico determina a localização da falta comparando os padrões esperados da forma de onda de corrente com os padrões obtidos frente à atuação dos equipamentos de proteção. Se necessário, ainda se realiza a comparação da carga interrompida com a carga alimentada e gera-se a decisão final sobre o local da falta. Os testes realizados em relação ao efeito da incerteza de carga e resistência de falta demonstram resultados satisfatórios, porém ressalta-se que o método desenvolvido não realiza a atualização das correntes de falta durante o processo iterativo de estimação. 
No ano subsequente, em (SENGER et al., 2005) uma metodologia baseada no uso de IEDs é desenvolvida com foco na localização de faltas em redes de distribuição primárias. Por meio da mesma propõem-se o diagnostico automático das faltas pautado nas medições e oscilografias dos sinais da rede disponibilizadas pelos IEDs alocados nos nós iniciais do alimentador, e apoiado na coleta e análise de informações sobre a topologia e parâmetros do sistema.

Emprega-se um módulo DSP (Digital Signal Processing) para determinar o instante da falta, o tipo e a fase envolvida, e estimar os fasores pré e em falta, e a rejeição de carga. A modelagem das cargas, o processo iterativo para atualização das tensões e correntes, bem como a determinação do ponto sob falta se assemelham ao apresentado em (LEE et al., 2004). A fim de testar o método proposto, um sistema em hardware foi instalado em uma subestação real e seu desempenho aferido, demonstrando a capacidade do localizar de faltas na redução tempo de inatividade do sistema, diminuição de custos operacionais, e otimização de manutenção corretiva.

Ao mesmo tempo, em (PENKOV et al., 2005) é exposta uma das primeiras técnicas a considerar o impacto da inserção de Geração Distribuída (GD) no sistema elétrico no processo de localização de faltas em alimentadores de distribuição. Este método visa localizar faltas trifásicas, fundamenta-se na determinação da impedância aparente de sequência positiva e avalia a entrada em operação de GD mediante a atuação de geradores síncronos modelados de forma real e de maneira ideal.

A formulação foi desenvolvida em componentes simétricas, sem considerar o desequilíbrio de linhas e cargas, tendo em vista a possibilidade de inserção de múltiplas unidades geradoras no sistema, e admitiu-se a tensão nos pontos em que estão conectados os geradores distribuídos igual a tensão da subestação. A adoção deste último pressuposto foi realizada para tornar possível a determinação da contribuição da corrente proveniente de cada uma das unidades geradoras para a falta, mas ressalta-se que sua adoção é válida apenas para o sistema operando com baixo nível de carregamento.

Os testes realizados com o método proposto demonstram que a GD influencia seu desempenho proporcionalmente a quantidade de unidades geradoras inseridas no sistema e ao nível de potência de cada uma delas. Também se observa que cargas intermediárias alocadas entre a subestação e o ponto de falta podem afetar a distância aferida dependendo do seu dimensionamento, e que os erros máximos causados quando se utilizam os geradores modelados de forma ideal são de aproximadamente $0,6 \%$ e de maneira real cerca de 7,5\%. Destaca-se a representatividade da performance deste método, porém deve-se tomar atenção 
as simplificações adotadas e proposições admitidas, as quais podem não ser aplicáveis a sistema elétricos com diferentes características.

Em seguida, em (BRETAS; SALIM, 2006) outra metodologia averiguando o comportamento do processo de localização de faltas na presença de GD é apresentada baseando-se no método iterativo para estimação das correntes de cargas e da corrente de falta para cada seção do alimentador exposto em (LEE et al., 2004). Assim como em (PENKOV et al., 2005) a presente técnica trabalha com componentes simétricas e baseia-se na análise da impedância aparente de sequência positiva.

No entanto, em contrapartida ao método anteriormente citado o atual desenvolve-se para avaliação da inserção de apenas uma unidade de GD, realiza uma análise pré-falta do sistema a fim de determinar as tensões e correntes em todas as barras, e estima a corrente do gerador sob condição de falta a partir dos dados do sistema e do próprio gerador. A unidade de GD é implementada segundo o modelo do gerador síncrono apresentado em (KUNDUR, 1994) em condição subtransitória.

Além disso, para faltas a jusante da GD utiliza-se a representação de uma carga equivalente na extremidade remota do sistema para a condição faltosa, caso a falta ocorra a montante aplica-se a representação composta por uma carga equivalente em série com uma fonte de tensão. Os testes com esta metodologia mostraram a elevada eficiência da mesma com erro máximo de apenas $0,2 \%$ do comprimento total da linha, inclusive para faltas entre o ponto de alocação da GD e a extremidade remota do alimentador, mas a proposição da existência de apenas uma unidade geradora apresenta-se como um fator limitante à sua ampla aplicação.

Posteriormente, em (SALIM et al., 2009) expõem-se uma nova técnica inspirada no método proposto em (LEE et al., 2004), com a inclusão do efeito capacitivo da linha na sua formulação e a modelagem de linha utilizando circuito $\pi$ com parâmetros calculados na frequência fundamental do sistema em componentes de fase. Além disso, o equacionamento do algoritmo de localização desenvolvido passa a possibilitar a análise de todos os tipos de faltas, o cálculo de fluxo de potência pré-falta para atualização da corrente de falta, e o cálculo da variação das cargas tornando possível a avaliação do seu desequilíbrio sobre o sistema.

A fim de compreender a resposta das equações polinomiais de segunda ordem obtidas pela nova proposta em relação ao local da falta frente a diferentes casos de faltas, avalia-se do ponto de vista matemático, físico, e numérico as soluções das mesmas. Por fim, os resultados apresentados para análise da influência da resistência, distância, e tipo de falta, do desequilíbrio de carga e da estimativa inicial da corrente de falta, mostraram boa melhoria em relação à proposta inicial de Lee et al. (2004). 
Em (PEREIRA et al., 2009) exibe-se um método baseado em medições esparsas de tensão de baixo esforço computacional aplicada a sistemas aéreos de distribuição radiais e trifásicos com cargas desequilibradas e ramais polifásicos. O princípio básico do algoritmo baseia-se no fato de que quando ocorre uma falta no alimentador as quedas de tensão propagam-se apresentando características diferentes para cada nó do sistema. Assim com o conhecimento da magnitude dos afundamentos de tensão, é possível localizar o nó sob defeito ou a área defeituosa do alimentador.

O método emprega os fasores de frequência fundamental de tensão e corrente medidos na subestação antes e durante a falta, e a magnitude dos afundamentos de tensão medidos durante a falta em alguns nós remotos ao longo do alimentador. Ainda faz uso de parâmetros do sistema contidos em seu banco de dados, tais como informações sobre a topologia do alimentador, impedância das seções de linha e potência nominal de transformadores.

A fim de avaliar a eficiência e a robustez da técnica desenvolvida, analisa-se seu desempenho frente à variação do modelo de cargas adotado, carregamentos dos transformadores, e quantidade de medidores utilizados. Os resultados dos testes mostram que o algoritmo é bastante adequado devido não só a localização do ponto de falta, mas também a área em falta, e que quanto maior o número de nós de medição melhor a precisão do algoritmo. Entretanto, a precisão aumenta até certo número de nós de medição ser atingido, o qual é definido pelas características básicas do alimentador, como topologia, nível de carregamento, e quantidade de ramificações laterais.

Ressalta-se a simplicidade da aplicabilidade do método para localização de quaisquer tipos de faltas, uma vez que não é necessário conhecimento a respeito da impedância de falta na modelagem usada no algoritmo. Também se destaca que poderia ser utilizada uma técnica de otimização para definição da quantidade e alocação dos dispositivos de medição a fim de aumentar a precisão e velocidade de estimação do algoritmo.

Já em (ZAYANDEHROODI et al., 2010) desenvolve-se um método para localização de faltas automatizado utilizando RNA do tipo Função de Base Radial (RBF) para uma rede de distribuição com GD através da identificação da linha defeituosa. A técnica proposta determina o tipo de falta através da normalização da corrente de falta da fonte principal de energia do sistema (subestação), enquanto a localização das faltas é determinada pela utilização de duas redes RBF. A primeira RBF é empregada para determinação da distância da falta à subestação e aos pontos de GD, e a segunda para indicação da linha sob falta, tendo em vista o tipo da mesma falta. 
Para cada tipo de falta identificado, as três correntes de fase da subestação e de todas as GDs são usadas como entradas da primeira rede RBF, e as saídas desta, que são as distâncias a falta, são utilizadas como entradas da segunda rede RBF. Em seguida, realizando o cruzamento das saídas das duas redes RBFs defini-se de forma precisa e automatizada o ponto de ocorrência da falta. Os testes realizados mostram o excelente desempenho do método desenvolvido e a comparação com resultados de teste utilizando RNA do tipo Perceptron Multicamadas (PMC) demonstram o melhor desempenho em termos de precisão e tempo de treinamento da RNA do tipo RBF.

No ano seguinte, em (LOPES et al., 2011) é descrita uma metodologia de localização de faltas para redes inteligentes de transmissão e distribuição com base na teoria de ondas viajantes pela utilização de um algoritmo auto adaptativo capaz de calcular automaticamente o ponto de falta. Diferentemente de alguns métodos convencionais, o algoritmo proposto utiliza apenas amostras atuais de tensão, e é capaz de monitorar todas as três fases através da análise de apenas um sinal de tensão.

Os sinais de tensão são coletados por meio de gravadores digitais de faltas (Digital Fault Recorders - DFRs), aplica-se a técnica de Ciclo Completo de Fourier aos mesmos para calibração do localizador de faltas, e executa-se a detecção de transitórios através da aplicação da transformação de Park. A seguir, por meio da utilização do Sistema de Posicionamento Global (GPS) sincronizam-se os dados provenientes dos dispositivos da rede inteligente, e torna-se possível utilizar a detecção dos instantes iniciais dos transitórios para determinar a estimativa do ponto de falta.

Os testes realizados apontam o bom desempenho do método e rapidez na indicação do ponto sob falta, e os autores destacam que esta técnica se mostra adequada para aplicações em redes inteligentes, porque é auto-adaptativa frente os níveis de desequilíbrio dos sistemas de energia e estima automaticamente o ponto de falta de forma muito rápida imediatamente após a ocorrência da mesma sem necessidade de uma análise off-line dos registros oscilográficos dos sinais.

Ao mesmo tempo, em (POURAHMADI-NAKHLI; SAFAVI, 2011) é apresentado um método desenvolvido a partir do exposto em (BORGHETTI et al., 2006) e (BORGHETTI et al., 2008) para a localização de faltas em sistemas de distribuição radiais. Esta metodologia trabalha na localização de falta fase-terra pela extração de informações de tensões transitórias e emprega os conceitos de ondas viajantes, transformada wavelet, análise multiresolução, energia do sinal e redes neurais artificiais. 
Analisa-se a propagação de ondas viajantes ao longo do alimentador de distribuição e a reflexão das mesmas nas terminações de linha, junções entre trechos, ramos laterais, e no ponto sob falta, uma vez que em cada nó o espectro de energia do sinal transitório tem diferentes características. A tensão transitória é decomposta por um filtro wavelet, e dependendo da largura de banda do filtro e de suas frequências características o sinal decomposto contém uma determinada percentagem de energia que é utilizada como entrada da RNA do tipo PMC.

Os testes realizados mostram que a energia da tensão transitória está associada às características do espectro de frequência do sinal, o qual depende não apenas do ponto de localização de faltas, mas também da topologia do sistema. Os resultados também revelam a robustez do método frente à variação dinâmica da carga, ângulo e impedância de falta, e a eficácia e precisão do algoritmo de localização. Observa-se que o mesmo apresenta baixa sensibilidade a variação de carga e tem sua robustez aumentada com a introdução de diferentes cenários para o treinamento da RNA pela variação do ângulo e impedância de falta, porém necessita-se da extensão da análise de sua aplicação a faltas bifásicas e trifásicas.

Ainda em 2011, em (KEZUNOVIC, 2011) é exposta uma explanação a respeito das implicações e possibilidades trazidas pelas redes inteligentes para o sistema elétrico como um todo, e mais especificamente para a melhoria dos processos de localização de faltas. Discutese a utilização dos IEDs para aquisição de dados em maior quantidade e qualidade, bem como o tratamento e seleção do seu grande volume de informações para aprimoramento dos métodos de localização de faltas em redes inteligentes.

Além disso, apresenta-se um exemplo para localização de faltas em linhas de transmissão e o outro para redes de distribuição baseados na aplicação e emprego das ferramentas disponíveis nas redes inteligentes. A metodologia proposta para sistemas de distribuição pauta-se no exposto em (PEREIRA et al., 2009) e baliza-se na análise da forma de onda de afundamentos de tensão para indicação dos possíveis locais ou regiões de ocorrência de falta tendo em vista a relação entre amplitude do afundamento e distância do medidor até o ponto sob falta.

Faz-se uso de dados de tensão e de corrente medidos na subestação pré-falta e durante a falta, bem como informações sobre o conhecimento das fases em falta e o tipo de falta ocorrida. As medições pré-falta são usadas para estimar variações de carga e atualizar os modelos de carga, e os dados obtidos durante a falta são utilizados no processo de localização. A partir da simulação de faltas em cada nó do alimentador modelado comparam-se as tensões 
dos afundamentos simulados com as medidas e a que apresenta maior semelhança é considerada para indicação do nó sob falta.

Adverte-se que as propostas apresentadas demonstram o desenvolvimento conceitual dos métodos para localização de faltas, porém os autores não realizam testes com os mesmos, tornando impossível conhecer o nível de precisão e suas limitações frente a aplicações práticas.

Posteriormente, a pesquisa desenvolvida em (GONG, Y.; GUZMÁN, 2013) exibe uma solução para localização de faltas em sistema de distribuição não homogêneos pela utilização de informações de IEDs e medições de corrente e tensão gravadas por relés digitais durante condições de falta. A metodologia desenvolvida emprega impedâncias e informações de comprimento de cada secção do alimentador para acomodar a não homogeneidade da rede. Além disso, faz uso de um método baseado na reatância para minimizar o impacto das cargas e da resistência de falta na precisão da estimativa da localização das mesmas. Ainda utiliza um algoritmo de processamento de topologia e pesquisa avançada para identificar as possíveis localizações da falta com base nas informações da topologia detalhada do alimentador.

Sequencialmente, primeiro o método proposto emprega as medições de corrente e tensão de fase de sequência negativa durante uma falta para determinar o tipo da mesma e calcular a reatância entre o ponto de defeito e o IED mais próximo a falta. Em seguida, estimam-se os possíveis locais de falta com base na reatância e no relatório de eventos capturados pelo modelo detalhado do alimentador, e por fim reduz o número de pontos candidatos pela avaliação das indicações fornecidas pelos IEDs apontando o local da falta.

Os resultados dos testes realizados para localização de faltas bifásicas e fase-terra demonstram a exatidão do método e indicam que a precisão dos modelos dos alimentadores fornecidos por uma concessionária de energia contribuiu para sua eficiência. Também se observa que o uso de correntes de sequência negativa minimiza erros devido ao acoplamento mútuo e cargas, e que o cálculo da reatância em relação aos IEDs mais próximos ao ponto de defeito reduz os erros causados por parâmetros de linha imprecisos.

Já em (TRINDADE; FREITAS; VIEIRA, 2014) é proposto um método para localização de faltas em alimentadores de distribuição pautado na capacidade de monitoramento de afundamentos de tensão por medidores inteligentes alocados em diferentes barras do sistema, sem a necessidade prévia do conhecimento da resistência e corrente de falta. A queda de tensão é estimada pela diferença entre a tensão medida antes e durante a falta em cada um dos nós em que houver medidor.

Busca-se obter o local da falta relacionando, pela aplicação da teoria de cálculo de curto-circuito, as quedas de tensão aferidas por cada um dos medidores com os elementos da 
matriz de impedância para o cálculo da corrente de falta nos diferentes nós do sistema. Assim, o ponto sob falta é indicado como sendo o nó em que os valores de corrente de curto-circuito calculados forem próximos o suficientemente entre si.

Esta metodologia ainda faz uso do mapeamento automático das interrupções para diminuir o espaço de busca no processo de localização da falta e minimizar a ocorrência de múltiplas estimações, porém isto requer a instalação e coleta de dados de um número maior de medidores. A fim de melhorar a precisão do método as cargas são representadas por modelos de impedância constante e incluídas na matriz impedância de barra.

Os resultados de estudos de sensibilidade mostram que o método é robusto, pois tem bom desempenho para diferentes valores de resistência de falta, quantidade e localização dos medidores inteligentes, bem como erros de estimativa de medição e carga. Além disso, os autores apontam que alguns temas relacionados com o método proposto exigem uma investigação mais aprofundada, tal como a viabilidade de alocação ótima dos medidores dedicados ao processo de localização de faltas, e a possibilidade de consideração de GD e sua representação na matriz impedância de barra.

\section{Em (MORA-FLÓREZ; HERRERA-OROZCO; BEDOYA-CADENA， 2015)} apresenta-se uma técnica para localização de faltas em sistemas de distribuição considerando a presença de GD e as incertezas associadas à resistência de falta, magnitude e modelo de carga, tipo de falta e nó faltoso. A abordagem exposta utiliza apenas correntes e tensões medidas na subestação do alimentador e na fonte de GD, evitando o uso dos parâmetros da GD que são usualmente desconhecidos, e assim permitindo que a técnica proposta possa ser implementada em sistemas de distribuição reais.

No equacionamento para localização de falta a GD é considerada tendo em vista sua corrente em estágio pré-falta e em falta, coletada por medidores alocados junto a fonte de GD, tornando desnecessário uso do modelo do gerador. Realizam-se diversos testes em um alimentador com ramificações laterais monofásicas e trifásicas, com diferentes tipos de faltas a distintas distâncias da subestação, admitindo vários valores para resistências de falta e variações na magnitude e modelo das cargas.

Os resultados demonstram a robustez da técnica proposta frente aos erros de estimação obtidos, os quais são menores que 9\%, mesmo em situações de carregamento excessivo do sistema. Ainda pode ser visto que os erros de estimação para determinação do local da falta são diretamente proporcionais ao carregamento do sistema. Isto ocorre porque as incertezas da variação aleatória da carga introduzem erros nas estimativas das tensões e correntes ao longo do alimentador, as quais são utilizadas no algoritmo para determinação do local sob defeito 
como exposto anteriormente. O melhor desempenho é geralmente obtido no caso de se utilizar o modelo de carga com impedância constante, porém na presente metodologia faz-se uso da compensação da corrente a fim de reduzir o efeito dos diferentes modelos de carga.

No ano seguinte em (NTALAMPIRAS, 2016) é proposta uma estrutura cognitiva de diagnóstico de faltas para redes inteligentes que explora as relações temporais e funcionais existentes nos fluxos de dados provenientes dos nós da rede. Esta estrutura é capaz de aprender de forma autônoma o modelo do estado nominal da rede utilizando os respectivos dados por meio de modelos de Markov escondidos que operam no espaço de parâmetros de modelos lineares invariantes no tempo.

Posteriormente, a estrutura é capaz de detectar dados que não pertençam ao estado nominal e localizar a falta potencial no nível cognitivo, sendo o isolamento da falta pautado em uma representação gráfica da rede inteligente revelando as correlações entre os nós com base na causalidade de Granger. Fazendo uso do sistema IEEE de 9 barras testa-se o modelo da estrutura desenvolvido, personalizado para o cenário de uma rede inteligente com os seguintes recursos: a) capacidade de lidar com mudanças na carga representadas por funções de rampa aleatória, b) habilidade de lidar com ruído normalmente distribuído e c) não requer disponibilidade do modelo para geração de dados. Segundo o autor da pesquisa os resultados alcançados se mostram encorajadores em termos de taxa falso positiva/negativa e atraso de detecção/isolamento pelo sistema de diagnóstico de faltas.

Ainda em 2016, em (BATISTA et al., 2016) são apresentados os resultados de uma nova metodologia para localização de faltas monofásicas de alta impedância em sistemas de distribuição empregando uma técnica denominada decomposição por componentes ortogonais. Esta técnica se baseia em um novo método matemático para análise de eventos transitórios em sistemas de energia, e fora utilizada nas pesquisas deste artigo para o pré-processamento de sinais com a finalidade de localizar e identificar faltas.

A técnica de decomposição por componentes ortogonais foi testada qualitativamente com o auxílio do registro de um oscilograma de falta real em uma subestação de distribuição de energia. Além disso, por meio da análise de correlação buscou-se estabelecer uma relação entre as componentes ortogonais e as seguintes características das faltas monofásicas: momento de ocorrência, fase envolvida na falta, distância da falta até o detector de sinal e resistência da falta.

Com esta análise nota-se que os conjuntos de componentes correlacionados com distância e com a resistência da falta são independentes, o que confere à técnica de decomposição por componentes ortogonais uma característica distinta que não fora encontrada 
nas técnicas utilizadas para estimar a distância ao local de uma falta com base na análise de circuitos elétricos. Somado a este fato, observa-se ainda que a decomposição por componentes ortogonais foi capaz de extrair informações com mais de $80 \%$ de correlação com a ocorrência de falta e quase $70 \%$ para a localização, e mostrou grande imunidade ao efeito da variação da resistência a falta.

Por fim, em (JAMALI; BAHMANYAR; BOMPARD, 2017) é exposto um método baseado em estimação de estado para localização de faltas em redes de distribuição usando as medidas fornecidas pelos medidores inteligentes. Durante o funcionamento normal do sistema, os métodos de estimação de estado tratam os erros de medições reais ou pseudomedições para fornecer a melhor estimação de estado do sistema e para identificar grandes erros de medição, chamados de dados ruins. Este conceito é estendido neste artigo em condições de falta em que a mesma é considerada como uma carga desconhecida e temporariamente conectada que pode ser tratada como os chamados dados ruins.

Desse modo, o método proposto usa a técnica de identificação de dados incorretos da matriz de ponderação variável para encontrar a localização da falta. O método é algoritmicamente simples e não requer o tipo de falta. A precisão da localização de faltas por este método é verificada por testes de simulação em uma rede de distribuição real de 13,8 kV e 134 nós para diferentes cenários de faltas. Os resultados indicam que o método tem um bom desempenho sob condições em que há erros em dados de medição e carga, e também para a rede elétrica com variações nos locais de colocação e quantidade de medidores inteligentes.

\section{5 - Considerações Parciais sobre Localização de Faltas nos Sistemas de Distribuição}

No decorrer do presente capítulo observou-se que os agentes causadores de faltas nos SEPs são bastante diversos, podendo estar atrelados a problemas com equipamentos ou distúrbios de propriedades do próprio sistema, e muitas vezes imprevisíveis, relacionando-se a intempéries naturais e ações humanas inesperadas. Ademais, expôs-se que nos sistemas de distribuição, dada a sua própria constituição, maior probabilidade de ocorrência de falta em equipamentos e contato de animais com a rede elétrica, $80 \%$ das faltas são monofásicas 
envolvendo fase-terra ou fase-neutro, sendo que entre 50 e $90 \%$ das faltas nos alimentadores de distribuição são temporárias.

Frente à inerência das faltas na operação dos sistemas de distribuição e visando a qualidade, continuidade e confiabilidade do fornecimento de energia elétrica, procedimentos e métodos para localização de faltas são de suma importância. No entanto, como apresentado anteriormente pelas principais metodologias analisadas esta tarefa esbarra em diversas limitações, as quais ainda não foram inteiramente contornadas por nenhuma técnica até então desenvolvida.

A evolução dos métodos para localização de faltas mostrada neste capítulo, desde os primeiros até os mais atuais, aponta para a possibilidade do desenvolvimento de novas técnicas que agreguem os pontos benéficos das já existentes com as recentes tecnologias que vem sendo aplicadas aos sistemas elétricos, sobretudo as contidas nas redes inteligentes. Buscam-se métodos que façam uso de técnicas consistentes e de simples aplicação em análise de circuitos e sistema elétricos, porém altamente eficientes, aplicando os conceitos de sistemas inteligentes para tratamento das possíveis incertezas e imprecisões de dados e informações, a fim de prover maior robustez e agilidade ao processo de localização.

Além disso, nota-se que a tendência em maior evidência é a exploração da multimedição dos sinais de tensão e corrente além da subestação e o uso de informações adicionais referentes às particularidades dos sistemas e respectivas reconfigurações frente à inserção de pontos de geração distribuída. Dentre as tecnologias em eminência na conjuntura das redes inteligentes de distribuição, destaca-se o emprego dos IEDs, fornecendo dados e informações em maior quantidade e qualidade aos agentes operadores do sistema elétrico corroborando com as atividades de monitoramento, comunicação e controle.

Tendo em mente os aspectos pontuados, no próximo capítulo apresenta-se a metodologia proposta na presente tese para localização de faltas pautada na aplicação dos conceitos de análise de sistemas elétricos, sistemas inteligentes e multimedição de tensão por IEDs. 


\section{CAPÍTULO 4}

\section{ASPECTOS RELACIONADOS AO APRENDIZADO DE MÁQUINA E ÀS ÁRVORES DE DECISÃO}

A princípio, no presente capítulo serão apresentados os conceitos principais e mais atuais dos processes de extração de conhecimento de dados. A seguir, são destacadas as características dos sistemas de Aprendizado de Máquina (AM), área da inteligência artificial que busca desenvolver algoritmos e técnicas computacionais para aprendizado e aquisição de conhecimento a partir de grandes conjuntos de dados. A posteriori, foca-se na apresentação das Árvores de Decisão (AD), técnica de AM aplicada à classificação de padrões. São expostos os principais conceitos e fundamentações das Árvores de Decisão, suas etapas e processos para construção, apresenta-se um exemplo de construção de uma $\mathrm{AD}$, e por fim são comentadas as métricas dos classificadores das mesmas.

\section{1 - Conceitos Básicos sobre Extração de Conhecimento de Dados}

Na última década, com os avanços tecnológicos e a implantação crescente de sistemas de medição, controle e monitoramento nos mais diversos processos e seguimentos, a geração e o armazenamento de dados aumentou consideravelmente. Esse crescimento da massa de dados armazenada está trazendo consigo a necessidade de aprimoramento e desenvolvimento de novas técnicas e ferramentas automatizadas que possam auxiliar na transformação desses dados em informações e conhecimentos uteis.

Nesse contexto, tem-se desenvolvido o processo de Descoberta de Conhecimento em Bancos de Dados (Knowledge Discovery in Databases - KDD), definido inicialmente como a 
extração de informação implícita, previamente desconhecida e potencialmente útil a partir de dados (FRAWLEY; PIATETSKY-SHAPIRO; MATHEUS, 1992).

Uma das principais definições de KDD aponta que "Descoberta de conhecimento em bases de dados é o processo de identificação de padrões válidos, novos, potencialmente úteis e compreensíveis em repositórios de dados" (FAYYAD; PIATESKY-SHAPIRO; SMYTH, 1996). Segundo essa definição o termo "dados" se refere a um conjunto de fatos ou instâncias de um montante de dados; "processo" é um conjunto de vários passos a serem realizados no decorrer do KDD; "padrão" é uma expressão em determinada linguagem descrevendo fatos em um subconjunto dos dados; "válidos" remete à padrões descobertos que devem ser verdadeiros em "novos" dados (grau de novidade ou surpresa) com algum nível de certeza; "potencialmente útil" remete à padrões que devem levar a alguma atitude prática; e "compreensível” é tornar padrões compreensíveis para seres humanos, a fim de gerar melhor compreensão dos próprios dados (FAYYAD; PIATESKY-SHAPIRO; SMYTH, 1996).

De acordo com o exposto em (SILVA, 2004), de forma simplificada o processo de KDD pode ser descrito pelas 7 etapas abaixo, cujo inter-relacionamento está ilustrado na Figura 4.1.

1. Dados: conjunto de fatos, como instâncias de um banco de dados, a partir dos quais ocorre a definição do tipo de conhecimento a descobrir. Pressupõe uma compreensão do domínio da aplicação e do tipo de decisão que este conhecimento pode contribuir para melhorar.

2. Seleção: selecionar um conjunto ou subconjunto de dados no qual a descoberta deve ser realizada.

3. Pré-Processamento: limpeza de dados por meio de operações de tratamento dos dados tais como: remoção de ruídos; coleta da informação necessária para modelar ou estimar ruído; escolha de estratégias para manipular campos de dados ausentes; formatação de dados de forma a adequá-los à ferramenta de mineração.

4. Formatação: localização de características úteis para representar os dados dependendo do objetivo da tarefa, visando a redução do número de variáveis e/ou instâncias a serem consideradas para o conjunto de dados, bem como o enriquecimento semântico das informações.

5. Mineração de dados: seleção dos métodos a serem utilizados para localizar padrões nos dados, seguida da efetiva busca por padrões de interesse em uma forma particular de representação ou conjunto de representações. Busca pelo melhor ajuste dos parâmetros do algoritmo para a tarefa em questão. 
6. Interpretação/Avaliação: interpretação dos padrões minerados com um possível retorno aos passos 1-6 para posterior iteração.

7. Conhecimento: implantação do conhecimento descoberto ao incorporar este conhecimento à performance do sistema, ou documentá-lo e reportá-lo às partes interessadas.

Figura 4-1: Representação do processo de KDD.

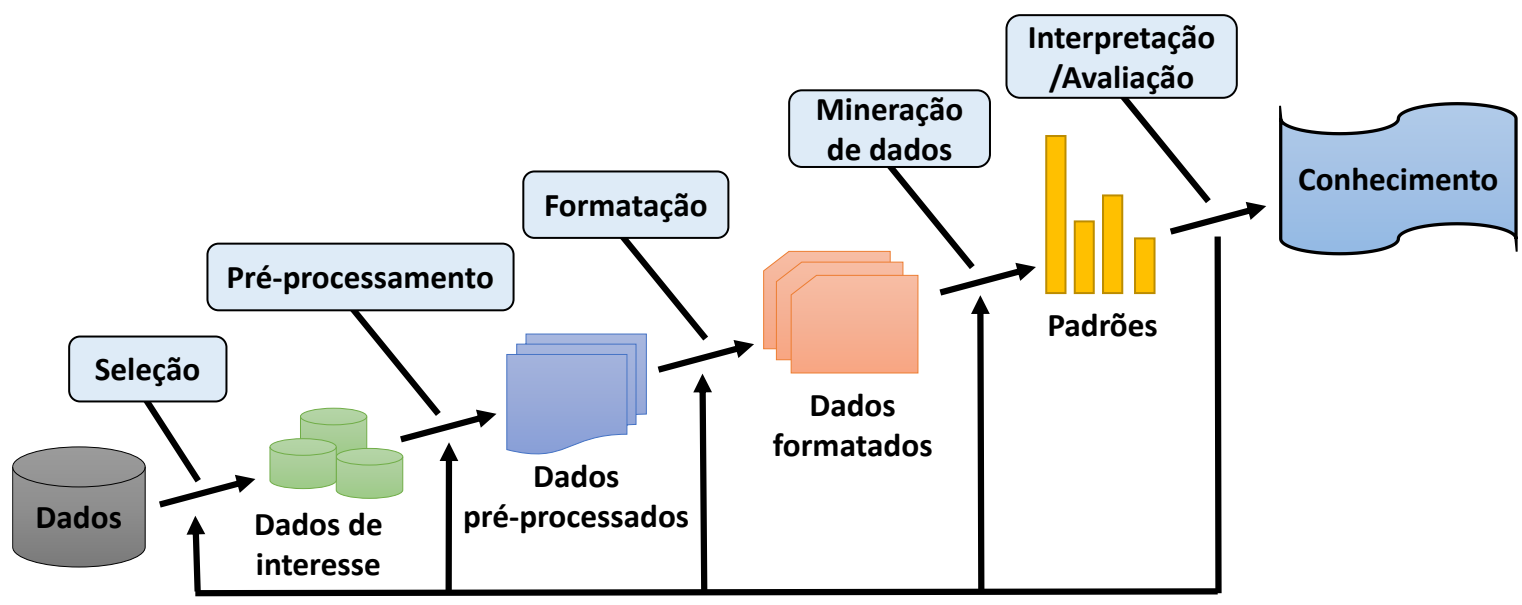

Fonte: adaptado de SILVA (2004).

Não obstante, destaca-se que no processo de KDD a Mineração de Dados tem grande destaque, pois objetiva a extração de padrões e características dos dados cuja interpretação possibilitará o uso do conhecimento descoberto para a solução de problemas. Esta etapa se baseia na aplicação de técnicas e ferramentas para predição e descrição, dentre as quais destacam-se o aprendizado de máquina, o reconhecimento de padrões e as análises estatísticas. A utilização de Aprendizado de Máquina (AM) para a descoberta de conhecimento compõe o núcleo da Mineração de Dados e de vários Sistemas Especialistas voltados para o apoio à decisão. Estes sistemas reúnem conhecimentos acerca de áreas específicas e são capazes de simular o comportamento humano diante de situações a eles apresentadas.

Para PRATI (2006), o Aprendizado de Máquina pode ser caracterizado por uma série de práticas destinadas à solução de problemas para os quais na maioria das vezes não se conhece a priori uma solução ou modelagem capaz de resolvê-los. O que se conhece é um conjunto finito de fatos que descrevem objetos, processos, situações, ou ambientes, e o objetivo é encontrar alguma solução a partir desses fatos. AM tem uma grande sobreposição com estatística, uma vez que ambas as áreas estudam a análise de dados. Entretanto, diferentemente da estatística, que se foca principalmente em modelos teóricos bem definidos e ajuste de 
parâmetros a esses modelos, Aprendizado de Máquina tem um foco mais algorítmico, utilizando representações de modelos mais flexíveis e heurísticas para a realização de busca.

Tendo em vista a utilização de ferramentas e técnicas de AM no desenvolvimento da presente pesquisa, a seguir serão apresentados os pontos e características principais do mesmo.

\section{2 - Principais Aspectos Relativos ao Aprendizado de Máquina}

Aprendizado de Máquina é uma área da inteligência artificial que busca desenvolver algoritmos e técnicas computacionais de aprendizado e aquisição de conhecimento que permitam que o computador seja capaz de aprender a partir de exemplos históricos. O que torna esse aprendizado possível são os sistemas de aprendizado, os quais são programas de computador capazes de tomar decisões baseados em resoluções bem-sucedidas de problemas exemplo já vistos por eles em experiências anteriores (GOLDSCHIMIDT, 2010).

Em virtude do aumento do volume e variedade de dados, ampliação da potencialidade de processamento computacional com menores custos, e necessidade de armazenamento de grande massa de dados de forma mais acessível, o desenvolvimento e aplicação das técnicas de AM tem ganho destaque. Isto decorre da sua capacidade de inferir modelos automatizados com baixo esforço computacional para análise de grandes e complexos bancos de dados, fornecendo resultados mais rápidos e mais precisos, mesmo que em larga escala (BELL, 2014; GOLLAPUDI, 2016; HAYKIN, 2008).

Os exemplos históricos empregados para aquisição de conhecimento pelos algoritmos de Aprendizado de Máquina são representados por meio de um conjunto de características, também denominadas de atributos. Os atributos procuram descrever o problema a ser tratado e suas particularidades variam de acordo com o contexto em que são empregados. A seleção dos atributos para descrição dos exemplos de uma aplicação influencia na qualidade do conhecimento adquirido pelos algoritmos de aprendizado, e para cada situação os atributos possuem valores específicos que descrevem determinado estado ou condição. A representatividade dos exemplos fornecidos durante o processo de aprendizado também interfere no desempenho dos seus algoritmos implementados, haja vista que a qualidade do 
conhecimento por eles abstraído está intimamente ligada aos exemplos fornecidos (GOLDSCHIMIDT, 2010).

Além disso, no processo de aprendizagem os algoritmos partem de exemplos específicos para construção de seus modelos de conhecimento que sejam compatíveis, não apenas com os exemplos utilizados durante o aprendizado, mas também com novos exemplos que possam surgir. A capacidade de um modelo de conhecimento gerado por um algoritmo de aprendizado ser compatível com novos exemplos é denominada generalização, e quanto maior esta capacidade mais útil e desejável tal modelo se torna para aplicações práticas reais (GOLDSCHIMIDT, 2010).

Este processo de aprendizagem está relacionado com a correta manipulação de conhecimento prévio e de novas observações que possam levar a novos conhecimentos, sendo esta manipulação relacionada aos métodos de inferência lógica. De forma geral, os métodos de inferência lógica podem ser agrupados em três grandes classes, descritas a seguir (PRATI, 2006).

- Dedução: poder ser definida como uma forma de inferência logicamente correta, isto é, a conclusão obtida a partir de um conjunto de premissas iniciais verdadeiras sempre preserva a verdade. Por esta abordagem o conhecimento aprendido é resultado de transformações sobre o conhecimento existente, preservando a veracidade, porém a inferência dedutiva só pode ser aplicada para obter informações que já estão contidas, de forma implícita, nas premissas. Em geral, na aprendizagem por dedução, realiza-se uma sequência de deduções e cálculos a respeito das informações presentes, visando a elucidação do conhecimento oculto, mas já existente nessas premissas.

- Abdução: na inferência por abdução busca-se inferir um conhecimento particular a partir de observações e outras informações conhecidas, uma vez que possíveis hipóteses abdutivas são construídas a partir de um conjunto de predicados específicos não observados. As hipóteses abdutivas são aquelas que trabalham com conhecimento incompleto, completando o conhecimento a respeito de um caso particular sobre um determinado indivíduo. Em uma inferência abdutiva, assume-se que a descrição do domínio de um problema é suficiente, no sentido de que com a quantidade de informação disponível é possível aplicar inferências sobre ela. Na prática, isso significa que a parte incompleta da teoria pode ser isolada em alguns predicados não observados, que são chamados de predicados abdutíveis (ou abertos). 
- Indução: é uma forma de inferência lógica que permite extrapolar as premissas, obtendo conclusões genéricas a partir de exemplos particulares, pois a indução caracteriza-se como uma forma de raciocínio que parte de um conceito específico e o generaliza, sem necessariamente preservar a verdade, mesmo que o conjunto de premissas utilizado na inferência seja verdadeiro. Por esse motivo, o resultado da inferência indutiva é geralmente chamado de hipótese, o qual mesmo que não possa ter sua validade garantida pode ter atribuído a si um certo grau de confiança, baseado na quantidade e qualidade das premissas. Quando as premissas utilizadas em uma inferência indutiva são verdadeiras, e existe uma quantidade suficiente de premissas, é possível dizer que uma hipótese provavelmente é verdadeira.

Não obstante, de acordo com a necessidade de predição os sistemas de aprendizagem podem ser classificados a partir dos seguintes modos de aprendizado (PRATI, 2006):

- Aprendizagem não-supervisionada: dado um conjunto de observações ou exemplos não rotulados, o objetivo é tentar estabelecer a existência de grupos ou similaridades nesses exemplos.

- Aprendizagem semi-supervisionada: dado um pequeno conjunto de observações ou exemplos rotulados e um conjunto de observações ou exemplos não rotulados, o objetivo é utilizar ambos os conjuntos para encontrar uma hipótese capaz de classificar novas observações entre as classes já existentes.

- Aprendizagem supervisionada: dado um conjunto de observações ou exemplos rotulados, isto é, conjunto de observações em que a classe, denominada também atributo meta, de cada exemplo é conhecida, o objetivo é encontrar uma hipótese capaz de classificar novas observações entre as classes já existentes.

- Aprendizagem por reforço: o agente aprendiz interage com o meio ambiente que o cerca e aprende uma política ótima de ação por experimentação direta com o meio. Dependendo de suas ações, o aprendiz é recompensado ou penalizado. O objetivo do aprendiz é desenvolver uma política ótima que maximize a quantidade de recompensa recebida ao longo da sua execução.

Já os paradigmas de aprendizado dizem respeito à forma com que o espaço de busca por um modelo de conhecimento (que represente os dados históricos disponíveis) deve ser 
percorrido. Estes paradigmas podem ser utilizados tanto para predição quanto para descrição do conjunto de dados existente, e seus tipos principais são (GOLDSCHIMIDT, 2010):

- Simbólico: compreende a construção da representação de conceitos a partir da análise de exemplos. Neste paradigma o modelo de conhecimento construído pode ser representado por meio de expressões lógicas, árvores, regras, redes semânticas, entre outros.

- Estatístico: neste tipo de paradigma, métodos estatísticos, geralmente paramétricos, são utilizados para encontrar boas aproximações do modelo de conhecimento que esteja sendo induzido.

- Baseado em Exemplos: envolve a busca de casos existentes similares ao novo exemplo a ser analisado para deduzir a saída do sistema. Neste paradigma, é ideal a utilização de casos anteriores representativos.

- Conexionista: utiliza modelos matemáticos simplificados inspirados no modelo biológico do sistema nervoso para tentar abstrair mapeamentos de novos exemplos nas saídas desejadas ou agrupamentos de exemplos similares.

- Evolucionário: baseia-se nos modelos biológicos da evolução natural e da reprodução genética para evoluir soluções que competem entre si a fim de abstrair um modelo que solucione o problema em questão.

Para que o processo de Aprendizado de Máquina ocorra representando ocorrências reais por métricas computacionais é necessário definir sua forma de aprendizado. Os algoritmos de aprendizagem podem ser classificados de duas maneiras segundo o modo em que os exemplos são apresentados, as quais são (PRATI, 2006):

- Não incremental: necessita que todos os exemplos estejam disponíveis simultaneamente para que seja induzido um conceito. É vantajoso usar esses algoritmos para problemas de aprendizagem nos quais todos os exemplos estão disponíveis e, provavelmente, não irão ocorrer mudanças.

- Incremental: revê a definição do conceito corrente, se necessário, em resposta a cada novo exemplo observado considerando-os um a um pelo sistema, isto é, o sistema avalia o primeiro exemplo e, de acordo com ele constrói uma determinada hipótese; a seguir considera um segundo exemplo, que pode ou não modificar a primeira hipótese, baseando-se em como ela classifica o segundo exemplo. Dessa forma, o sistema continua modificando o conceito à medida que mais exemplos são a ele apresentados. 
Já as tarefas de aprendizado empregadas para aquisição e extração de conhecimento a partir de exemplos, são definidas a partir do tipo de atributo que é disponibilizado ao sistema de aprendizagem e de acordo com o modelo que se deseja criar a partir destes exemplos. Se o atributo é discreto, o problema é conhecido como problema de classificação, e o objetivo é classificar futuros casos em cada uma das classes pré-estabelecidas (PRATI, 2006).

Caso o atributo seja contínuo, o problema é geralmente conhecido como problema de regressão, e o objetivo é prever o valor desse atributo com base nas características dos exemplos. No caso do atributo meta ser ordinal, o problema é conhecido como ordenação ou regressão logística, e o objetivo é ordenar um conjunto de casos de acordo com uma característica de interesse (PRATI, 2006).

Cabe ressaltar que mesmo que os problemas sejam definidos de acordo com o tipo do atributo meta, é possível utilizar variáveis de outros tipos para cumprir a tarefa. Por exemplo, é possível discretizar um atributo meta contínuo e prever uma faixa de valores (atributo discretizado) ao invés de um valor contínuo. Também é possível prever um valor contínuo para um problema com atributo meta discreto, e cada classe pode ser associada a uma faixa de valores contínuos (PRATI, 2006).

Além disso, existem diferentes linguagens para descrever objetos e/ou eventos que se buscam representar, bem como o inter-relacionamento entre eles, com distintas complexidades. Ao solucionar problemas com o uso de computadores por meio do aprendizado de máquina necessita-se traduzi-los em termos computacionais, representando exemplos, hipóteses e conhecimento do domínio, o que é realizado pela combinação atributo-valor e/ou várias funções matemáticas pelas seguintes linguagens (REZENDE, 2003):

- Linguagem de Representação de Exemplos (LRE)

- Linguagem de Representação de Hipóteses (LRH)

- Linguagem de Representação de Conhecimento do Domínio (LRC)

Para fins de delimitação da presente pesquisa, a descoberta de conhecimento a partir dos dados de tensão e indicação de sensibilização dos medidores inteligentes será conduzida por um processo de classificação de padrões. Buscar-se-á a extração de conhecimento pela exploração do espaço de hipóteses baseada no uso da informação presente no conjunto de dados aquisitados empregando técnicas de aprendizado de máquina voltadas para classificação.

O reconhecimento de padrões pode ser definido como a descoberta de simetrias em dados por meio de algoritmos computacionais e uso dessas informações para classificar objetos 
em categorias ou classes diferentes. Assim sendo, o reconhecimento de padrões atua na classificação de um dado de entrada através da seleção de atributos importantes a partir de uma grande quantidade de exemplos de treinamento (THEODORIDIS; KOUTROUMBAS, 2008; GONZALEZ; THOMASON, 1978).

Dessa forma, de modo geral o problema de classificação de padrões pode ser dividido basicamente em duas etapas, aprendizagem e classificação. Com a aprendizagem a finalidade é obter, a partir de um conjunto de exemplos de treinamento "T", um conjunto de regras ou classificador " $\mathrm{R}$ " capaz de reconhecer padrões em um conjunto de atributos " $\mathrm{X}$ ". $\mathrm{Na}$ classificação o conjunto de regras "R" é utilizado para atribuir uma classe "Y" para novos indivíduos "X” (STANGE, 2011). A Figura 4.2, a seguir, ilustra este processo.

Figura 4-2: Etapas do processo de classificação de padrões.

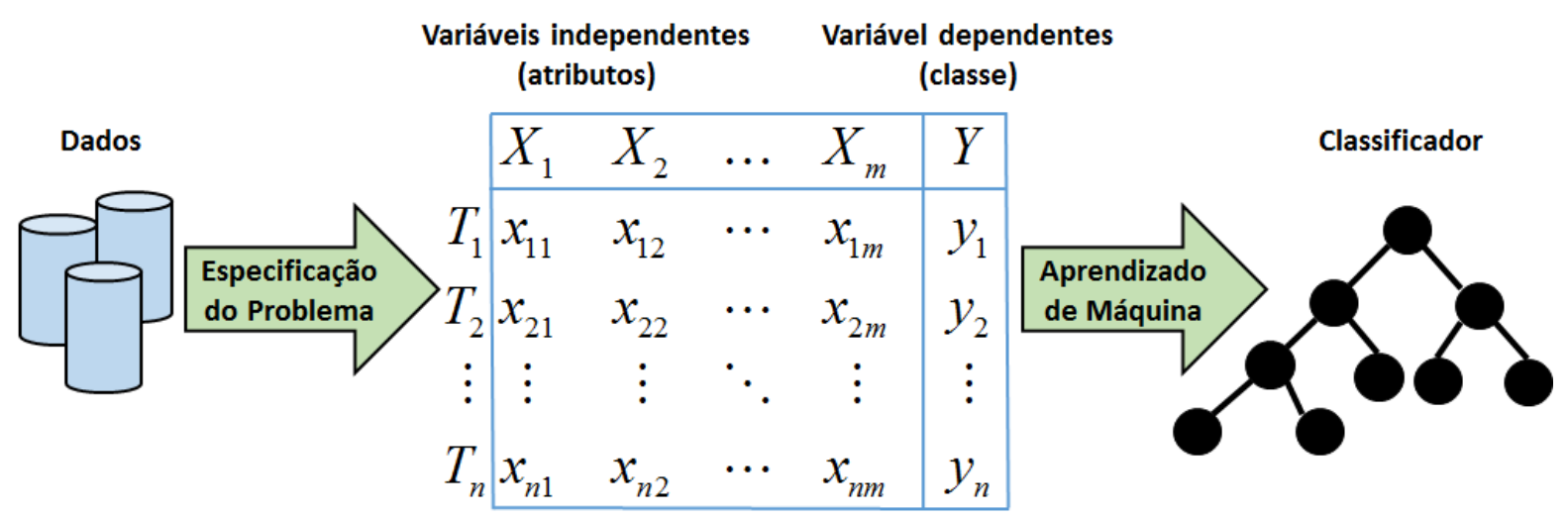

Fonte: adaptada de REZENDE (2003).

Os processos de aprendizagem de máquina podem incorporar a função de reconhecimento de padrões a partir da utilização de uma das suas técnicas de classificação, tais como: Redes Neurais Artificias, Máquinas de Vetores Suporte, Naive Bayes, e Árvores de Decisão. Dentre estas técnicas, as Árvores de Decisão (ADs), as quais compõe um fluxograma em forma de árvore com nós e folhas conectando valores a classes, serão empregadas nesta pesquisa e descritas em detalhes na próxima seção.

\section{3 - Fundamentos sobre Árvores de Decisão}

O conhecimento formalizado em bases de conhecimento pode ser representado por meio de regras, mapeadas em Árvores de Decisão cujo objetivo é criar um modelo viável que 
preveja o valor de uma variável desconhecida com base no conjunto de variáveis de entrada. Amplamente utilizadas em algoritmos de classificação, as Árvores de Decisão são representações simples do conhecimento e um meio eficiente de construir classificadores que predizem classes baseadas nos valores de atributos de um conjunto de dados (GOLDSCHIMIDT, 2010).

Esta técnica de Aprendizado de Máquina utiliza uma representação em árvore para classificação e predição das amostras desconhecidas, sendo estruturada hierarquicamente em um conjunto de nós interconectados. Os nós internos testam um atributo de entrada com uma constante de decisão e determinam qual será o próximo nó descendente, enquanto os nós folhas classificam as instâncias que os atingem de acordo com o rótulo associado a ele. Dessa maneira, o conhecimento em uma árvore de decisão é representado por cada nó, que ao ser testado conduz a busca para um nó filho, até chegar em um nó folha (BORGES, 2013).

As Árvores de Decisão (ADs) se destacam pela facilidade de interpretação e análise do seu modelo, possibilidade de verificação dos passos que estão sendo realizados quando a árvore está sendo modelada, operação com atributos de tipos numéricos e nominais, facilidade de apresentação e entendimento do seu modelo por terceiros, disponibilidade de algoritmos que permitem resolver problemas binomiais e multinomiais, e desempenho comprovado por distintas pesquisas (BELL, 2014).

Entre as características relevantes que viabilizam a técnica e implementação das AD, tem-se (BORGES, 2013):

- Precisão: habilidade do modelo para avaliar ou prever corretamente classes, agrupamentos, regras;

- Velocidade: uma vez construída uma árvore de decisão, seu uso é imediato e sua execução é computacionalmente muito rápida;

- Robustez: habilidade do modelo para avaliar ou prever corretamente, utilizando dados ruidosos ou com valores ausentes;

- Escalabilidade: capacidade de construir modelos eficientes a partir de grandes volumes de dados;

- Interpretabilidade: alto nível de compreensão fornecido pelo modelo;

- Flexibilidade: o espaço das instâncias é particionado em subespaços e cada subespaço é adaptado a diferentes modelos. 
Por outro lado, as AD podem criar modelos demasiadamente complexos dependendo das regras definidas e do conjunto de dados de treinamento, acarretando overfitting do algoritmo de aprendizado de máquina. Isto pode ser evitado pela revisão dos dados de treinamento e poda de determinados valores do conjunto de dados em um processo de refinamento e ajuste do modelo de árvore criado (BELL, 2014). Ademais, a análise detalhada dos dados no decorrer do processo de construção da $\mathrm{AD}$ pode requerer grande esforço computacional dependendo da dimensão e do tamanho da amostra de dados fornecida para seu processo de indução (BORGES, 2013).

Existem vários algoritmos que foram desenvolvidos especificamente para implementação das Árvores de Decisão e da tarefa de classificação, entre os quais os três principais são (VON ZUBEN; ATTUX, 2010): CART (BREIMAN et al., 1984), ID3 (QUINLAN, 1986) e C4.5 (QUINLAN, 1994).

- CART: se baseia em uma técnica não-paramétrica para árvores de classificação (atributo nominal) ou árvores de regressão (atributo contínuo). Dentre suas características as de maior destaque são: capacidade de pesquisa de relações entre os dados, mesmo que as mesmas não sejam evidentes; geração de árvores binárias simples e com grande legibilidade; tratamento diferenciado para atributos ordenados e possibilidade de realização de combinações lineares entre atributos (agrupamento de valores em vários conjuntos); expansão exaustiva da árvore gerada e pós-poda por meio da redução do fator custo-complexidade.

- ID3: é um algoritmo recursivo e baseado na busca dos atributos que melhor dividem os exemplos apresentados para indução da árvore, gerando sub-árvores a partir dos mesmos. Dentre suas características as de maior destaque são: trabalha com atributos categóricos não-ordinais (nominais), impossibilitando a análise atributos contínuos, a não ser que os mesmos sejam previamente discretizados; usa o ganho de informação para selecionar a melhor divisão dos exemplos sem considerar o número de arestas, o que pode acarretar árvores muito complexas; não apresenta nenhum método de póspoda para reduzir o problema da indução de árvores complexas; e não apresenta mecanismo para tratar valores desconhecidos.

- C4.5: é o algoritmo sucessor do ID3 e dentre suas características as de maior destaque são: trabalha com atributos categóricos (ordinais ou não-ordinais) e com atributos contínuos; trata valores desconhecidos de maneira diferenciada e não os utiliza nos cálculos de ganho de informação e entropia; emprega a medida de razão do ganho de 
informação para selecionar o atributo que melhor divide os exemplos gerando árvores mais precisas e menos complexas; e apresenta um método de pós-poda das árvores geradas por meio de uma busca de baixo para cima na árvore, transformando em nós folha aqueles ramos que não apresentam nenhum ganho de informação significativo.

Um modelo de pseudocódigo da função recursiva do algoritmo C4.5 é apresentado abaixo, no qual a função $\mathrm{C} 4.5$ recebe como entradas dois valores, o primeiro corresponde ao conjunto de atributos $\mathrm{R}$, e o segundo corresponde aos dados de treinamento $\mathrm{S}$.

\section{Função C4.5 (R: conjuntos de atributos, S: conjunto de treinamento) \\ se $\mathrm{S}$ está vazio \\ falha}

\section{fim se}

se $\mathrm{S}$ contém exemplos de mesma classe retorna um nó folha com valor da classe

\section{fim se}

se R está vazio

retorna uma folha com o valor da classe mais frequente

\section{senão}

calcula o atributo D com maior ganho de informação, entre os atributos restantes de $\mathrm{R}$

acrescenta um nó possuindo o atributo D

divide $\mathrm{S}$ em subconjuntos de acordo com os valores de $\mathrm{D}$

chama função $\mathrm{C} 4.5$ para cada um desses subconjuntos

\section{fim se}

\section{fim função}

Neste modelo, a função $\mathrm{C} 4.5$ escolhe um atributo $\mathrm{D}$, entre todos os atributos, que possui um maior ganho de informação e então divide o conjunto de treinamento $\mathrm{S}$ em vários subconjuntos, de acordo com os valores do atributo D. A função C4.5 é então chamada novamente, passando como parâmetro cada subconjunto (BORGES, 2013).

Destaca-se que no desenvolvimento das pesquisas desta tese fora empregado o algoritmo C4.5 em virtude de suas características acima apresentadas, o qual é implementado em linguagem Java pelo Software WEKA (WEKA, 2017) e nomeado como algoritmo J48. A seguir são apresentadas as etapas e procedimentos para construção de uma Árvore de Decisão. 


\subsection{1 - Etapas do Processo de Construção de Árvores de Decisão}

Em uma Árvore de Decisão cada atributo é representado por um nó de decisão, cuja função é testar o valor desse atributo. Uma classe é representada por um nó folha, que reúne todos os exemplos que chegarem a ele depois de satisfazerem os testes dos nós de decisão intermediários. Desse modo, em uma AD a classificação de um exemplo desconhecido implica percorrer toda a árvore a partir de um nó raiz, testando atributos em sucessivos nós internos até chegar a um nó folha, que lhe atribuirá uma classe (QUILICI-GONZALVEZ; ZAMPIROLLI, 2014).

Segundo MILARÉ (2003) uma AD, como a ilustrada na Figura 4.3 é uma estrutura que consiste em um conjunto de nós internos, representados nessa figura por elipses, e um conjunto de nós folhas, representados por retângulos. O nó inicial é denominado de nó raiz, cada nó interno representa um teste, e cada nó folha uma decisão. Em virtude do resultado obtido em um teste, deve-se descer por um dos ramos da árvore de decisão e ao ser atingido um nó folha é tomada uma decisão. A AD da Figura 4.3 mostra um exemplo de tomada de decisão sobre a saúde de um paciente, cujo objetivo é diagnosticar se um paciente está ou não doente.

Figura 4-3: Árvore de decisão para diagnostico da saúde de um paciente.

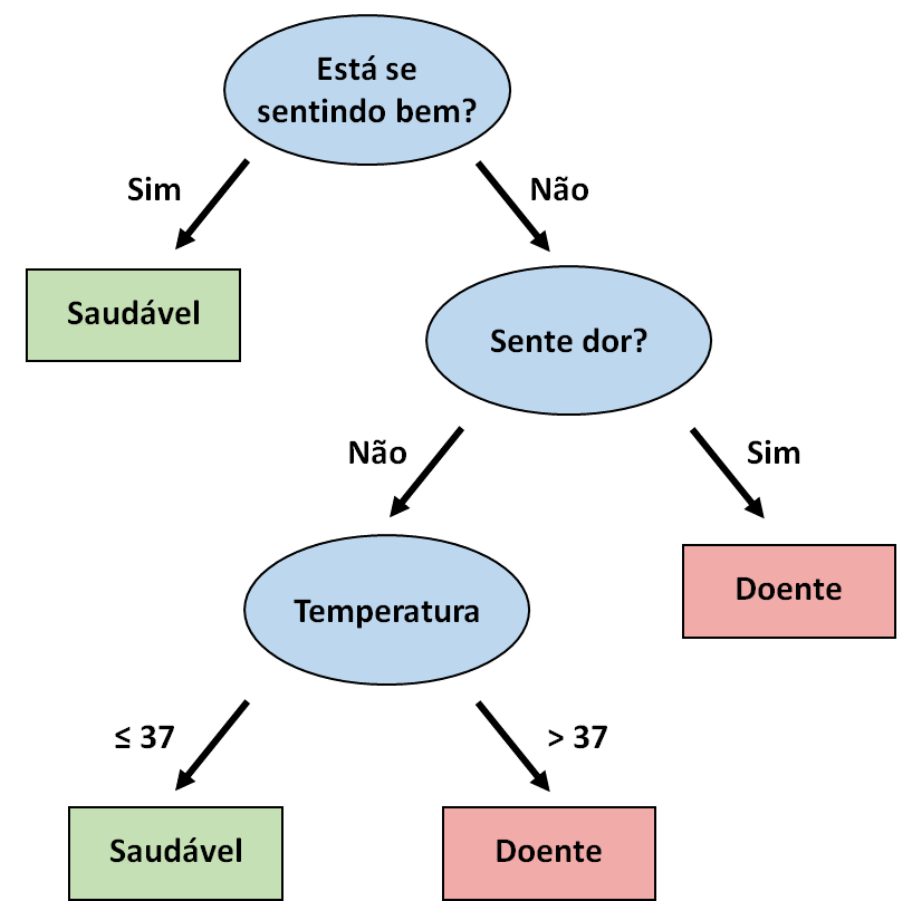

Fonte: autoria própria. 
Analisando a AD da Figura 4.3 pode-se notar que a mesma pode ser representada como um conjunto de regras, em que cada regra tem seu início na raiz da árvore e caminha até uma de suas folhas. Esta árvore pode ser lida, por exemplo, pelo seguinte conjunto de regras (REZENDE, 2003):

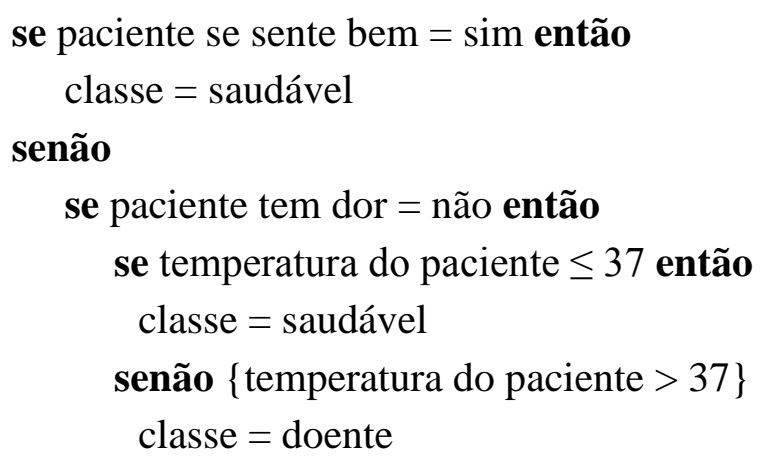

\section{fim se}

senão $\{$ paciente tem dor $=\operatorname{sim}\}$

classe $=$ doente

\section{fim se}

\section{fim se}

Entretanto, como as regras que representam uma AD são disjuntas, ou seja, apenas uma regra dispara quando um novo exemplo é classificado, uma forma alternativa de representar tais regras é escrever uma regra para cada nó folha, iniciando pela raiz. Assim, nenhum else é necessário e pode-se representar a árvore anterior pelas seguintes regras (REZENDE, 2003):

se paciente se sente bem $=$ sim então

classe $=$ saudável

\section{fim se}

se paciente se sente bem = não and paciente tem dor $=$ não and temperatura do paciente $\leq 37$ então

classe $=$ saudável

\section{fim se}

se paciente se sente bem = não and paciente tem dor $=$ não and temperatura do paciente $>37$ então

$$
\text { classe }=\text { doente }
$$

\section{fim se}

se paciente se sente bem $=$ não and paciente tem dor $=\operatorname{sim}$ então classe $=$ doente

\section{fim se}


O processo para construir a estrutura de uma árvore de decisão a partir de exemplos é conhecido como Indução de Árvores de Decisão, cujas regras são descritas resumidamente conforme exposto em (MILARÉ, 2003). Seja $E=\left\{E_{1}, E_{2}, \ldots E_{N}\right\}$ um conjunto de exemplos e $\mathrm{C}=\left\{\mathrm{C}_{1}, \mathrm{C}_{2}, \ldots \mathrm{C}_{\mathrm{Ncl}}\right\}$ o conjunto de valores que o atributo classe pode assumir, os passos a seguir descrevem o processo de construção de uma AD.

1. Se todos os exemplos de $\mathrm{E}$ pertencem à classe $\mathrm{Cj}$, então um nó folha é criado e associado à classe $\mathrm{Cj}$.

2. Se E não contém nenhum exemplo, então um nó folha é criado, entretanto, a classe associada a este nó deve ser determinada a partir de outra informação e não de E. A classe associada a este nó folha pode ser, por exemplo, a classe mais frequente de seu nó antecessor.

3. Se E contém exemplos pertencentes à várias classes, então um teste é escolhido baseado em um atributo que possui um conjunto de valores mutuamente exclusivos, denotado por $V=\left\{V_{1}, V_{2}, \ldots V_{r}\right\}$. Em seguida, E é particionado nos subconjuntos disjuntos $P_{1}$, $\mathrm{P}_{2}, \ldots \mathrm{P}_{\mathrm{r}}$, no qual $\mathrm{P}_{\mathrm{i}}$ contém todos os exemplos de $\mathrm{E}$ que possuem o valor $\mathrm{V}_{\mathrm{i}}$ para o teste escolhido. Nessa situação são criados um nó interno que é associado ao teste escolhido e um ramo para cada um dos possíveis valores do atributo relacionado ao teste escolhido.

4. Os passos 1, 2 e 3 são recursivamente aplicados em cada um dos subconjuntos de exemplos $\mathrm{P}_{1}, \mathrm{P}_{2}, \ldots \mathrm{P}_{\mathrm{r}}$.

5. Na maioria das vezes depois da construção da AD é realizado um processo denominado de poda, o qual depende das características da árvore criada e será comentado posteriormente.

De modo alternativo, o processo de indução de uma AD pode ser descrito por meio de uma estratégia de "dividir para conquistar", a qual consiste em dividir o espaço definido pelos atributos em subespaços menores, de maneira tal que cada subespaço possa ser subdividido em novos subespaços ou associados a uma classe. A Figura 4.4 representa os passos desta estratégia de "dividir para conquistar" para classificação de duas classes, em que inicialmente o valor de um atributo é comparado com uma constante $\mathrm{C} 1$, dividindo-se o espaço em duas partes que melhor represente as duas classes, conforme a Figura 4.4 (a). Contudo, como não se consegue dividir totalmente os dados em duas classes distintas, os valores dos atributos são comparados com uma constante $\mathrm{C} 2$ estabelecendo novas fronteiras que separam os atributos em classes diferentes, conforme Figura 4.4 (b) (BORGES, 2013). 
Figura 4-4: Processo de classificação de duas classes utilizando a estratégia de "dividir para conquistar" das AD: (a) obtenção da primeira fronteira de decisão; (b) segunda fronteira de decisão

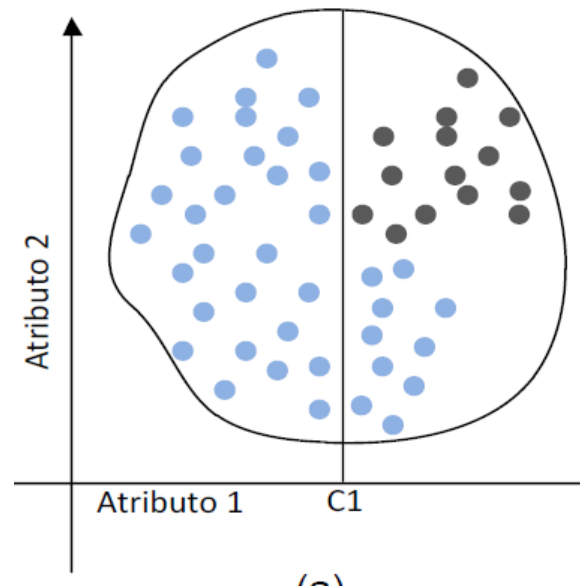

(a)

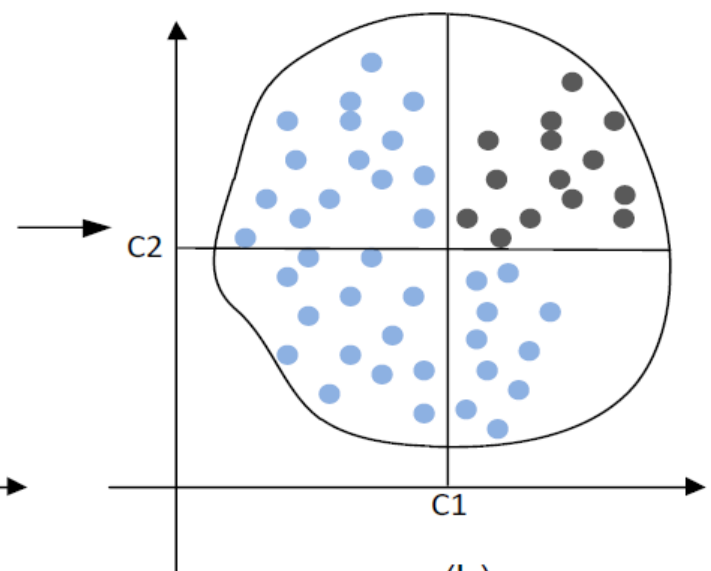

(b)

Fonte: BORGES (2013).

Uma das principais etapas da indução da árvore é a seleção adequada do atributo associado ao teste de divisão de um nó interno, que tem influência direta no tamanho final da AD. Há diferentes métodos para este procedimento, entre os quais o mais utilizado é a avaliação do ganho de informação baseado no cálculo da entropia do atributo, antes e depois da seleção do mesmo. Este é o método padrão utilizado nos algoritmos ID3 e C4.5 (QUINLAN, 1994).

O conceito físico de entropia remete tanto a um estado como a uma tendência, no primeiro caso ao grau de desorganização da matéria, já no segundo à tendência de desorganização de toda matéria. Em Termodinâmica afirma-se que a entropia nunca diminui em um sistema fechado, do que decorre que a entropia é um estado dinâmico que varia em função do estado inicial de organização da matéria e do tempo, caracterizando um processo irreversível (PINEDA, 2006).

Já no contexto do desenvolvimento da Teoria da Informação, Claude Shannon afirma que: 1) a entropia é relacionada com a frequência dos símbolos transmitidos (ou armazenados); 2) a entropia zero é obtida quando existe a certeza da transmissão de um único símbolo; 3) a entropia máxima é obtida quando a frequência dos símbolos é equiprovável; 4) a entropia não está relacionada ao significado ou a questões subjetivas (PINEDA, 2006). Em outras palavras, a entropia remete a desordem ou aleatoriedade e conforme a desordem aumenta perde-se informação sobre a amostra tornando-se mais difícil representa-la. Logo, quanto maior a entropia (desordem) menor a informação da amostra. 
Ainda segundo Shannon, o processo de geração de informação é um processo nãodeterminístico, uma vez que é geralmente impossível saber de antemão o que o canal vai transmitir, e deve ser analisado de maneira probabilística, ou seja, considerando em conjunto as probabilidades de ocorrência dos eventos possíveis. Dessa forma, a quantidade de informação gerada deve somar todas as probabilidades " $p$ " de ocorrência do evento, multiplicado pelo seu próprio logaritmo (PINEDA, 2006), conforme expresso na equação 4.1:

$$
H=-K \sum_{i=1}^{m} p_{i} \log _{2}(p i)
$$

Em que $K$ é uma constante arbitrária que expressa a unidade de medida. Esta medida calcula a quantidade média de informação por sinal de um sistema (repertório), o que pressupõe que a soma de todas as probabilidades $p_{i}$ é igual a 1 . O caso mais simples que se pode conceber é a ocorrência de um evento com duas possibilidades, cujas probabilidades são $p$ e $q=1-p$ (PINEDA, 2006). A entropia deste repertório é dada pela equação 4.2:

$$
H=-\left[p \log _{2}(p)+q \log _{2}(q)\right]
$$

Shannon relata que a entropia máxima ocorre quando as possibilidades são equiprováveis, ou seja, esta é a situação de maior incerteza, porém quanto maior for a diferença entre as probabilidades, menor será a entropia, e no caso particular de uma das probabilidades ser $100 \%$, a entropia será zero (PINEDA, 2006).

Na conjuntura de aplicação à seleção de atributos das Árvores de Decisão, conforme exposto em (GOLLAPUDI, 2016), na versão original do algoritmo C4.5 um nó raiz é escolhido baseando-se no quanto a entropia total é reduzida caso esse nó seja selecionado. Considera-se que há maior ganho de informação através do atributo que, ao se tornar um nó, produz subconjuntos com menor entropia. Neste caso, o ganho de entropia pode ser calculado de acordo com a equação 4.3:

$$
G=E_{\text {antes }}-E_{\text {depois }}
$$


Em que $G$ é o ganho de informação obtido, $E_{\text {antes }}$ é a entropia do sistema antes da divisão, e $E_{\text {depois }}$ é a entropia do sistema após a divisão. A entropia no sistema antes da divisão é obtida pela equação 4.4 , que é a mesma que a equação (4.1) para $\mathrm{K}=1$ :

$$
E=-\sum_{i=1}^{m} p_{i} \log _{2}(p i)
$$

Na qual $p_{i}$ é a probabilidade de ocorrências das saídas associadas a um atributo. Já para o cálculo da entropia depois da divisão, por exemplo, após usar $A$ para dividir e classificar $D$ em $n$ partições, emprega-se a equação 4.5 , em que $E\left(D_{i}\right)$ é a entropia da partição $i$ :

$$
E_{A}=-\sum_{i=1}^{n} \frac{D_{i}}{D} E\left(D_{i}\right)
$$

É possível induzir uma AD muito específica frente aos exemplos a partir da qual a mesma foi construída por meio da adição de ramos na árvore de decisão inicialmente criada para melhorar seu desempenho em relação aos exemplos usados na indução da árvore. Contudo, como o conjunto de exemplos de treinamento utilizado na indução da árvore é parte da amostra de todos os exemplos possíveis, seu desempenho se torna particularizado e a AD geralmente acaba respondendo com baixo nível de acerto para exemplos não utilizados na indução.

Ademais, no processo de indução das ADs suas arestas ou sub-árvores podem refletir ruídos ou erros da base de dados, o que também implica em problemas de sobreajuste da árvore a partir de um aprendizado muito específico e da geração de um modelo de baixa generalização. Esse problema é denominado overfitting e pode ser evitado nas ADs por meio da "Poda" (pruning) da árvore, a qual consiste em detectar e excluir as arestas e sub-árvores pela eliminação de ramos menos essenciais que podem ter sido criados em decorrência de exemplos particulares durante o processo de indução (MILARÉ, 2003; REZENDE, 2003).

A árvore podada se torna mais simples e possui maior capacidade de generalização, facilitando a sua interpretabilidade e melhorando seus índices de acerto nos processos de classificação. O método de poda varia de acordo com os diferentes algoritmos de indução de árvores de decisão, porém podem ser rotulados em pré-poda ou pós-poda. 
O método pré-poda é realizado durante o processo de construção da $\mathrm{AD}$, momento em que se pode parar de dividir o conjunto de elementos e transformar um nó corrente em um nó folha. Como critério de poda, geralmente utiliza-se o ganho de informação, por meio do qual caso todas as divisões possíveis utilizando um atributo gerem ganhos menores que um valor pré-estabelecido o nó se torna folha, representando a classe mais frequente no conjunto de exemplos.

Já o método pós-poda é realizado após a construção da AD por meio da remoção de ramos, em que tudo que está à frente de um determinado nó interno é excluído, tornado esse nó uma folha que representa a classe mais frequente no ramo. Ademais, para cada nó interno da árvore o algoritmo de poda calcula a taxa de erro caso a sub-árvore à frente desse nó seja podada, e em seguida é calculada a taxa de erro caso não ocorra poda. Caso a diferença entre essas taxas de erro configure um valor menor do que preestabelecido a árvore é podada, caso contrário não ocorre a poda.

Ambos os método são repetidos progressivamente, gerando um conjunto de árvores podadas, até se obter a árvore de melhor acurácia, porém deve-se tomar cuidado para não gerar uma árvore muito simplificada. Caso isso ocorra, pode acarretar um modelo de classificação cujo aprendizado sobre os dados de treinamento é insuficiente, sendo incapaz de classificar bem dados diferentes dos apresentados no processo de indução da AD.

Na próxima seção é apresentado um exemplo de construção de uma $\mathrm{AD}$, bem como as regras para sua criação e um possível cenário de poda.

\subsection{2 - Exemplo de Construção de uma Árvores de Decisão}

Conforme exposto em (QUILICI-GONZALVEZ; ZAMPIROLLI, 2014), a seguir é apresentado o processo de indução e criação de uma $\mathrm{AD}$ a partir dos dados do estudo de caso clássico da Tabela 4.1 apresentado por (QUINLAN, 1986). Os atributos de entrada são as condições do clima em determinado dia intitulados aqui por "Dia", "Temperatura", "Umidade" e "Vento", e como atributo de saída (ou classe) "Partida", que representa a ação de viajar ou não em decorrência do clima. Analisando os dados, observa-se que na verdade a saída é formada por duas classes, ou possibilidades, "Sim" e "Não", e deseja-se construir uma Árvore de Decisão que represente os exemplos contidos nessa tabela. Com a AD construída, dado um 
novo exemplo, será possível tentar predizer a solução para o problema se vai ou não haver "Partida" num determinado dia, sendo a resposta a combinação linear dos atributos de entrada.

Inicialmente, deve-se considerar individualmente para o nó raiz cada um dos quatro atributos de entrada possíveis e ver como o atributo de saída (Partida) se divide entre "Sim" e "Não". Na Tabela 4.2 é apresentado o atributo "Dia", na Tabela 4.3 o atributo "Temperatura", na Tabela 4.4 o atributo "Umidade", e na Tabela 4.5 o atributo "Vento".

Tabela 4-1: Conjunto de dados de exemplo.

\begin{tabular}{c|c|c|c|c|c}
\hline Dado & Dia & Temperatura & Umidade & Vento & Partida \\
\hline 1 & Ensolarado & Elevada & Alta & Falso & Não \\
\hline 2 & Ensolarado & Elevada & Alta & Verdadeiro & Não \\
\hline 3 & Nublado & Elevada & Alta & Falso & Sim \\
\hline 4 & Chuvoso & Amena & Alta & Falso & Sim \\
\hline 5 & Chuvoso & Baixa & Normal & Falso & Sim \\
\hline 6 & Chuvoso & Baixa & Normal & Verdadeiro & Não \\
\hline 7 & Nublado & Baixa & Normal & Verdadeiro & Sim \\
\hline 9 & Ensolarado & Amena & Alta & Falso & Não \\
\hline 10 & Ensolarado & Baixa & Normal & Falso & Sim \\
\hline 11 & Chuvoso & Amena & Normal & Falso & Sim \\
\hline 12 & Ensolarado & Amena & Normal & Verdadeiro & Sim \\
\hline 13 & Nublado & Amena & Alta & Verdadeiro & Sim \\
\hline 14 & Chublado & Elevada & Normal & Falso & Sim \\
\hline
\end{tabular}

Fonte: adaptado de QUILICI-GONZALVEZ e ZAMPIROLLI (2014). 
Tabela 4-2: Possíveis saídas para o atributo "Dia".

\begin{tabular}{c|c|c}
\hline Dado & Dia & Partida \\
\hline 1 & Ensolarado & Sim \\
\hline 2 & Ensolarado & Sim \\
\hline 3 & Ensolarado & Não \\
\hline 4 & Ensolarado & Não \\
\hline 5 & Ensolarado & Não \\
\hline 6 & Nublado & Sim \\
\hline 7 & Nublado & Sim \\
\hline 8 & Nublado & Sim \\
\hline 9 & Nublado & Sim \\
\hline 10 & Chuvoso & Sim \\
\hline 11 & Chuvoso & Sim \\
\hline 12 & Chuvoso & Sim \\
\hline 13 & Chuvoso & Não \\
\hline 14 & Chuvoso & Não \\
\hline
\end{tabular}

Fonte: adaptado de QUILICI-GONZALVEZ e ZAMPIROLLI (2014).

Tabela 4-3: Possíveis saídas para o atributo "Temperatura".

\begin{tabular}{c|c|c}
\hline Dado & Temperatura & Partida \\
\hline 1 & Elevada & Sim \\
\hline 2 & Elevada & Sim \\
\hline 3 & Elevada & Não \\
\hline 4 & Elevada & Não \\
\hline 5 & Amena & Sim \\
\hline 6 & Amena & Sim \\
\hline 7 & Amena & Sim \\
\hline 9 & Amena & Sim \\
\hline 10 & Amena & Não \\
\hline 11 & Amena & Não \\
\hline 12 & Baixa & Sim \\
\hline 13 & Baixa & Sim \\
\hline 14 & Baixa & Sim \\
\hline & Baixa & Não \\
\hline
\end{tabular}

Fonte: adaptado de QUILICI-GONZALVEZ e ZAMPIROLLI (2014).
Tabela 4-4: Possíveis saídas para o atributo "Umidade".

\begin{tabular}{c|c|c}
\hline Dado & Umidade & Partida \\
\hline 1 & Alta & Sim \\
\hline 2 & Alta & Sim \\
\hline 3 & Alta & Sim \\
\hline 4 & Alta & Não \\
\hline 5 & Alta & Não \\
\hline 6 & Alta & Não \\
\hline 7 & Alta & Não \\
\hline 9 & Normal & Sim \\
\hline 10 & Normal & Sim \\
\hline 11 & Normal & Sim \\
\hline 12 & Normal & Sim \\
\hline 13 & Normal & Sim \\
\hline 14 & Normal & Não \\
\hline
\end{tabular}

Fonte: adaptado de QUILICI-GONZALVEZ e ZAMPIROLLI (2014).

Tabela 4-5: Possíveis saídas para o atributo "Vento".

\begin{tabular}{c|c|c}
\hline Dado & Vento & Partida \\
\hline 1 & Verdadeiro & Sim \\
\hline 2 & Verdadeiro & Sim \\
\hline 3 & Verdadeiro & Sim \\
\hline 4 & Verdadeiro & Não \\
\hline 5 & Verdadeiro & Não \\
\hline 6 & Verdadeiro & Não \\
\hline 7 & Falso & Sim \\
\hline 8 & Falso & Sim \\
\hline 9 & Falso & Sim \\
\hline 10 & Falso & Sim \\
\hline 11 & Falso & Sim \\
\hline 12 & Falso & Sim \\
\hline 13 & Falso & Não \\
\hline 14 & Falso & Não \\
\hline
\end{tabular}

Fonte: adaptado de QUILICI-GONZALVEZ e ZAMPIROLLI (2014). 
Entre os quatro atributos candidatos para nó raiz, o atributo "Dia" se destaca porque dentre as três arestas restantes e que deverão ser ligadas a este nó ("Ensolarado", "Nublado" e "Chuvoso"), a aresta "Nublado" tem todos seus elementos pertencentes à uma única classe, "Sim". Portanto, esta aresta da Árvore de Decisão termina com um nó folha "Sim", conforme ilustrado na Figura 4.5 para esta primeira iteração na construção da AD.

Figura 4-5: Nó raiz para a Árvore de Decisão.

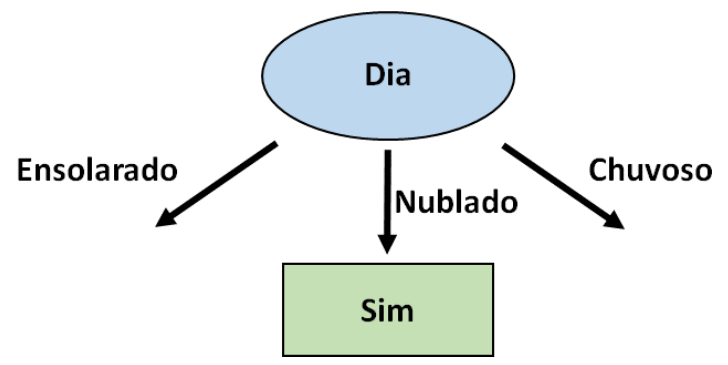

Fonte: adaptado de QUILICI-GONZALVEZ e ZAMPIROLLI (2014).

Tendo em vista que nas arestas "Ensolarado" e "Chuvoso" há elementos da classe "Sim" e da classe "Não", conforme Tabela 4.2, outro atributo deve ser escolhido para cada aresta, e assim sucessivamente até que todos os elementos de um ramo pertençam a uma mesma classe.

Como restam os atributos "Temperatura", "Umidade" e "Vento", retomando a Tabela 4.1, deve-se testar cada um deles em combinação com a aresta "Ensolarado". As Tabelas 4.6, 4.7 e 4.8, mostram as combinações possíveis de "Dia=Ensolarado" com "Temperatura", "Umidade" e "Vento".

Tabela 4-6: Relacionamento da aresta "Ensolarado" com o atributo "Temperatura".

\begin{tabular}{c|c|c|c}
\hline Dado & Dia & Temperatura & Partida \\
\hline 1 & Ensolarado & Elevada & Não \\
\hline 2 & Ensolarado & Elevada & Não \\
\hline 3 & Ensolarado & Amena & Sim \\
\hline 4 & Ensolarado & Amena & Não \\
\hline 5 & Ensolarado & Baixa & Sim \\
\hline
\end{tabular}

Fonte: adaptado de QUILICI-GONZALVEZ e ZAMPIROLLI (2014). 
Tabela 4-7: Relacionamento da aresta "Ensolarado" com o atributo "Umidade".

\begin{tabular}{c|c|c|c}
\hline Dado & Dia & Umidade & Partida \\
\hline 1 & Ensolarado & Alta & Não \\
\hline 2 & Ensolarado & Alta & Não \\
\hline 3 & Ensolarado & Alta & Não \\
\hline 4 & Ensolarado & Normal & Sim \\
\hline 5 & Ensolarado & Normal & Sim \\
\hline
\end{tabular}

Fonte: adaptado de QUILICI-GONZALVEZ e ZAMPIROLLI (2014).

Tabela 4-8: Relacionamento da aresta "Ensolarado" com o atributo "Vento".

\begin{tabular}{c|c|c|c}
\hline Dado & Dia & Vento & Partida \\
\hline 1 & Ensolarado & Falso & Sim \\
\hline 2 & Ensolarado & Falso & Não \\
\hline 3 & Ensolarado & Falso & Não \\
\hline 4 & Ensolarado & Verdadeiro & Sim \\
\hline 5 & Ensolarado & Verdadeiro & Não \\
\hline
\end{tabular}

Fonte: adaptado de QUILICI-GONZALVEZ e ZAMPIROLLI (2014).

Analisando as Tabelas 4.6, 4.7 e 4.8, nota-se que "Umidade" parece ser a escolha mais promissora porque todos os elementos de "Umidade=Alta" correspondem à classe "Não" e todos os elementos com "Umidade=Normal" pertencem à classe "Sim". Desse modo, tem-se mais dois nós folhas, favorecendo a construção de uma árvore mais compacta, conforme mostrado na Figura 4.6.

Figura 4-6: Combinação do atributo "Umidade" com atributo dia por meio da aresta "Ensolarado".

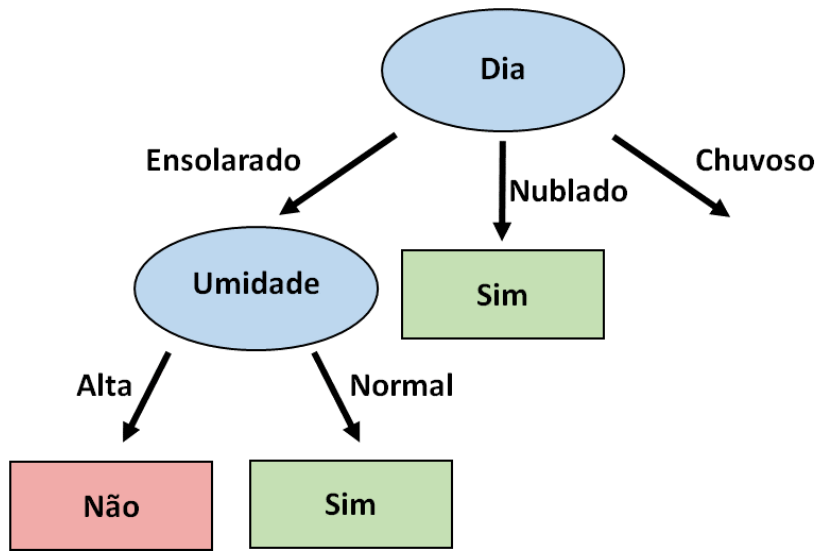

Fonte: adaptado de QUILICI-GONZALVEZ e ZAMPIROLLI (2014). 
Para a terceira aresta, "Chuvoso", restam duas alternativas, "Temperatura" e "Vento", cuja definição pode ser obtida a partir da construção das tabelas de combinação para descobrir a mais interessante. As Tabela 4.9 e Tabela 4.10 ilustram as possíveis combinações, por meio das quais nota-se que o atributo "Vento" é o mais indicado para esta iteração porque todos os elementos de "Vento=Falso" estão classificados como "Sim" e todos os elementos de "Vento=Verdadeiro" estão classificados como "Não". Portanto, estas duas arestas da Árvore de Decisão terminam com um nó folha cada, como apresentado na Figura 4.7.

Tabela 4-9: Relacionamento da aresta "Chuvoso" com o atributo "Temperatura".

\begin{tabular}{c|c|c|c}
\hline Dado & Dia & Temperatura & Partida \\
\hline 1 & Chuvoso & Baixa & Não \\
\hline 2 & Chuvoso & Baixa & Sim \\
\hline 3 & Chuvoso & Amena & Sim \\
\hline 4 & Chuvoso & Amena & Sim \\
\hline 5 & Chuvoso & Amena & Não \\
\hline
\end{tabular}

Fonte: adaptado de QUILICI-GONZALVEZ e ZAMPIROLLI (2014).

Tabela 4-10: Relacionamento da aresta "Chuvoso" com o atributo "Vento".

\begin{tabular}{c|c|c|c}
\hline Dado & Dia & Vento & Partida \\
\hline 1 & Chuvoso & Falso & Sim \\
\hline 2 & Chuvoso & Falso & Sim \\
\hline 3 & Chuvoso & Falso & Sim \\
\hline 4 & Chuvoso & Verdadeiro & Não \\
\hline 5 & Chuvoso & Verdadeiro & Não \\
\hline
\end{tabular}

Fonte: adaptado de QUILICI-GONZALVEZ e ZAMPIROLLI (2014).

Figura 4-7: Árvore de Decisão para o estudo de caso dos dados exemplo

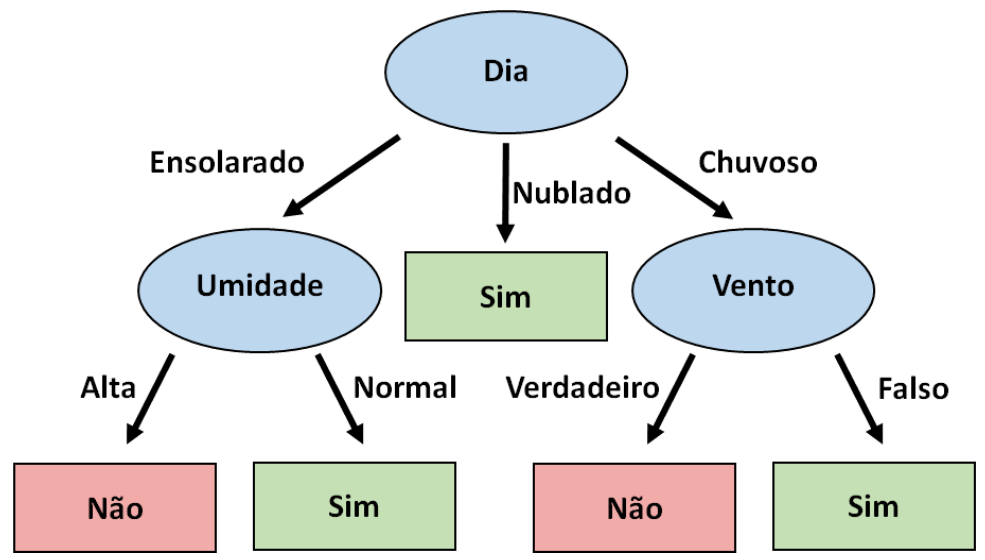

Fonte: adaptado de QUILICI-GONZALVEZ e ZAMPIROLLI (2014). 
Após esta iteração o algoritmo termina, pois todos os exemplos da Tabela 4.1 foram avaliados e classificados em suas respectivas classes, mas cabem algumas considerações. A seleção de atributos aqui realizada de forma intuitiva, pode ser feita empregando a avaliação do ganho de informação baseado no cálculo da entropia do atributo, conforme apresentado na seção anterior deste capítulo, capaz de avaliar a quantidade de informação do melhor atributo entre os candidatos para teste em um determinado nó.

Para o presente exemplo, o critério de escolha do melhor atributo para cada iteração é medido pela significância estatística expressa pela proporção de "Sim" e "Não" do atributo de saída "Partida". Conforme dito anteriormente, é mais adequado escolher um atributo que tenha associado a ele respostas compostas unicamente por "Sim" ou "Não" porque neste caso podese colocar um nó folha correspondente e terminar com as subdivisões reduzindo o número de testes a serem realizados. Todavia, se o conjunto de respostas é composto por uma mescla de "Sim" e "Não" faz-se necessário incluir mais um nó interno com um novo atributo sendo testado, implicando um crescimento da Árvore de Decisão.

De forma resumida e de acordo com a Equação (4.2) da seção anterior, a partir dos dados presentes na Tabela 4.2 pode-se calcular a quantidade de informação ou entropia para os atributos do estudo de caso apresentado, em que $p_{i}$ será proporção de "Sim" e "Não" associados aos atributos. Por exemplo, na Tabela 4.1 tem-se apenas duas classes ("Sim" e "Não"), sendo que dos 14 exemplos, 9 pertencem à classe "Sim" e 5 à classe "Não". Portanto, a entropia, ou quantidade de informação, associada ao conjunto total de dados pode ser calculada conforme equação (4.6):

$$
E_{\text {TOTAL }}=-\left\{\left[\frac{9}{14} \log _{2}\left(\frac{9}{14}\right)\right]+\left[\frac{5}{14} \log _{2}\left(\frac{5}{14}\right)\right]\right\}=0,94
$$

Uma forma alternativa de interpretar essa quantificação da entropia da informação, é pensar que se está interessado em medir o grau de "impureza" de um conjunto de respostas e que quanto menor a impureza melhor a resposta do conjunto. Se todas as respostas forem apenas "Sim" ou apenas "Não", então o grau de impureza do conjunto é 0. Por outro lado, se ocorre 64\% "Sim" e 36\% "Não", como no presente caso, o grau de impureza é 0,94.

Agora, aplicando este mesmo conceito para a escolha do atributo mais promissor em cada iteração para criação da $\mathrm{AD}$, calcula-se a entropia que se refere ao atributo "Dia", o qual se subdivide em três alternativas possíveis, com as seguintes proporções de "Sim" e "Não": “Ensolarado" (2“Sim"/3“Não"), "Nublado" (4“Sim"/0“Não") e "Chuvoso" (3"Sim”/2"Não"). 
Dessa forma, a entropia da informação para estas três alternativas é dada respectivamente pelas equações (4.7), (4.8) e (4.9):

$$
\begin{gathered}
E_{\text {Ensolarado }}=-\left\{\left[\frac{2}{5} \log _{2}\left(\frac{2}{5}\right)\right]+\left[\frac{3}{5} \log _{2}\left(\frac{3}{5}\right)\right]\right\}=0,97 \\
E_{\text {Nublado }}=-\left\{\left[\frac{4}{4} \log _{2}\left(\frac{4}{4}\right)\right]+\left[\frac{0}{4} \log _{2}\left(\frac{0}{4}\right)\right]\right\}=0,0 \\
E_{\text {Chuvoso }}=-\left\{\left[\frac{3}{5} \log _{2}\left(\frac{3}{5}\right)\right]+\left[\frac{2}{5} \log _{2}\left(\frac{2}{5}\right)\right]\right\}=0,97
\end{gathered}
$$

Fazendo a soma ponderada de cada uma dessas alternativas frente aos 14 exemplos apresentados, resulta a equação (4.10):

$$
E_{\text {Dia }}=0,97 * \frac{5}{14}+0,0 * \frac{4}{14}+0,97 * \frac{5}{14}=0,69
$$

Aplicando-se raciocínio semelhante para os atributos "Temperatura", "Umidade" e "Vento" obtêm-se os seguintes valores dados pelas equações (4.11), (4.12) e (4.13), respectivamente:

$$
\begin{gathered}
E_{\text {Temperatura }}=0,91 \\
E_{\text {Umidade }}=0,79 \\
E_{\text {Vento }}=0,89
\end{gathered}
$$

Portanto, dos quatro atributos possíveis na primeira iteração, o atributo "Dia" é o que tem menor entropia, ou grau mais baixo de impureza e, portanto, é o mais promissor para construir uma Árvore de Decisão. Continuando este procedimento de cálculo recursivamente para as demais etapas de indução da árvore, também se chega a Árvore de Decisão apresentada na Figura 4.7.

É possível que para alguns exemplos de teste os resultados produzidos por Árvores de Decisão compactas, como a da Figura 4.7, não sejam os mesmos de Árvores de Decisão ditas 
não-compactas, como a da Figura 4.8, mesmo que os resultados para todos os exemplos de treinamento tenham sido iguais. Isto pode decorrer da possibilidade de algumas arestas da AD refletirem a ocorrência de overfitting ou superajuste frente aos exemplos de treinamento. Tal situação geralmente acontece quando há ruído ou dados corrompidos no conjunto de treinamento fazendo com que a estrutura resultante da $\mathrm{AD}$ não reflita às relações essenciais entre os atributos da base de dados (QUILICI-GONZALVEZ; ZAMPIROLLI, 2014).

Para impedir o overfitting pode-se lançar mão da técnica conhecida como "Poda", que consiste em eliminar algumas arestas da Árvore de Decisão com base em medidas estatísticas dos exemplos. A Poda pode ocorrer sobre uma AD concluída por meio da eliminação de algumas arestas de que não representem perda de conhecimento, ou durante a construção com a introdução precoce de um nó folha em arestas com baixa importância estatística, por exemplo.

A fim de exemplificar este processo de Poda, na AD da Figura 4.8 pode-se remover algumas de suas arestas sem comprometer seriamente a taxa de acertos da classificação. Por exemplo, observando-se a Tabela 4.5 verifica-se que dos sete exemplos que apresentam "Umidade=Normal", seis têm rótulo de classe "Sim". Desse modo, o nó representando o atributo "Vento" à direita na Figura 4.8 poderia ser suprimido e substituído por um nó folha "Sim", uma vez que a maioria dos exemplos que chegam a este nó apresentam o rótulo de classe "Sim". Outrossim, o nó interno "Dia" também pode ser eliminado pois todos seus nós terminais passaram a ser do tipo "Sim". A Figura 4.9 mostra o resultado desse processo de Poda da AD da Figura 4.8 (QUILICI-GONZALVEZ; ZAMPIROLLI, 2014).

Figura 4-8: Árvore de Decisão não compacta antes da Poda.

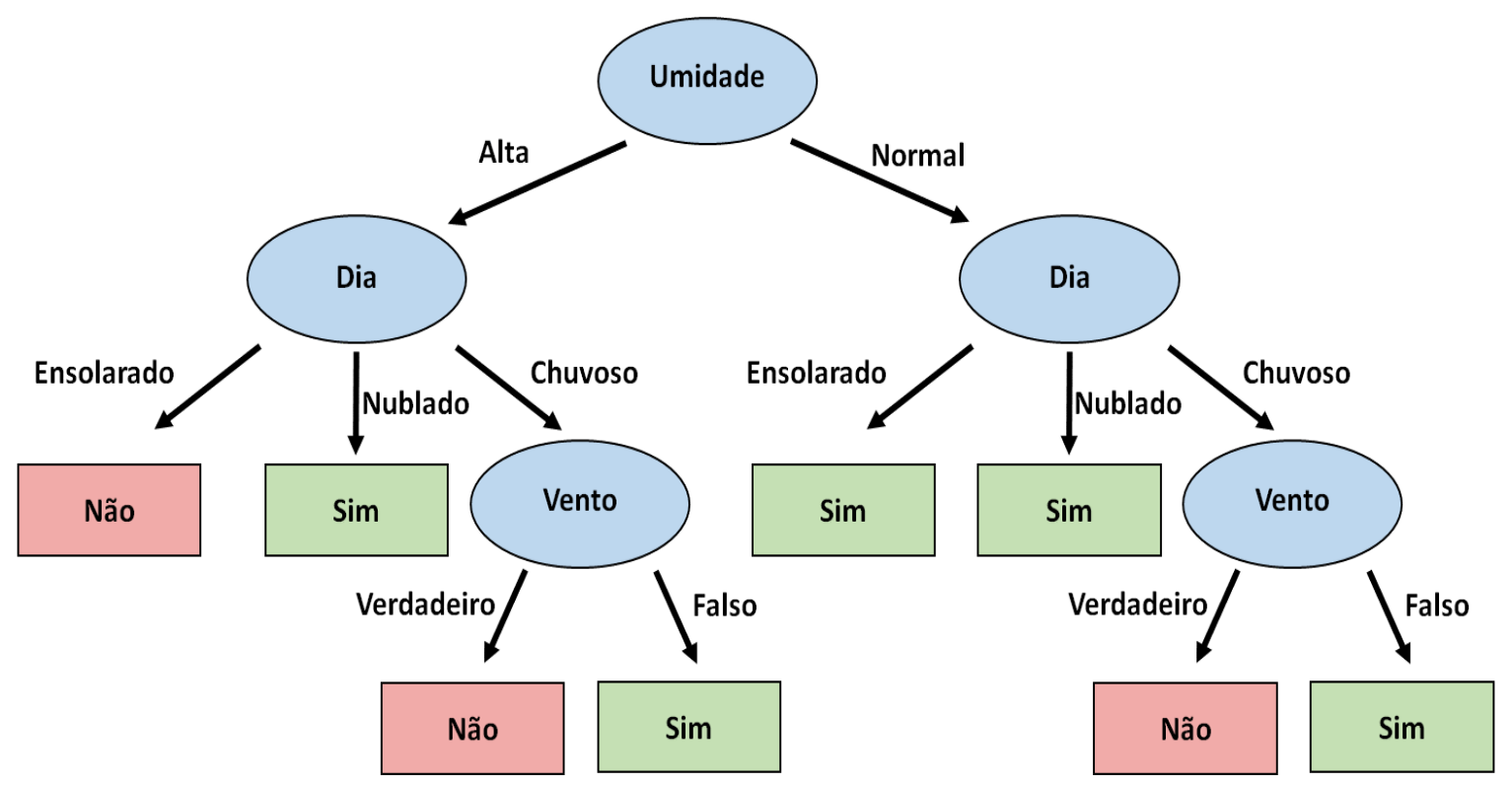

Fonte: adaptado de QUILICI-GONZALVEZ e ZAMPIROLLI (2014). 
Figura 4-9: Árvore de Decisão não compacta após a Poda.

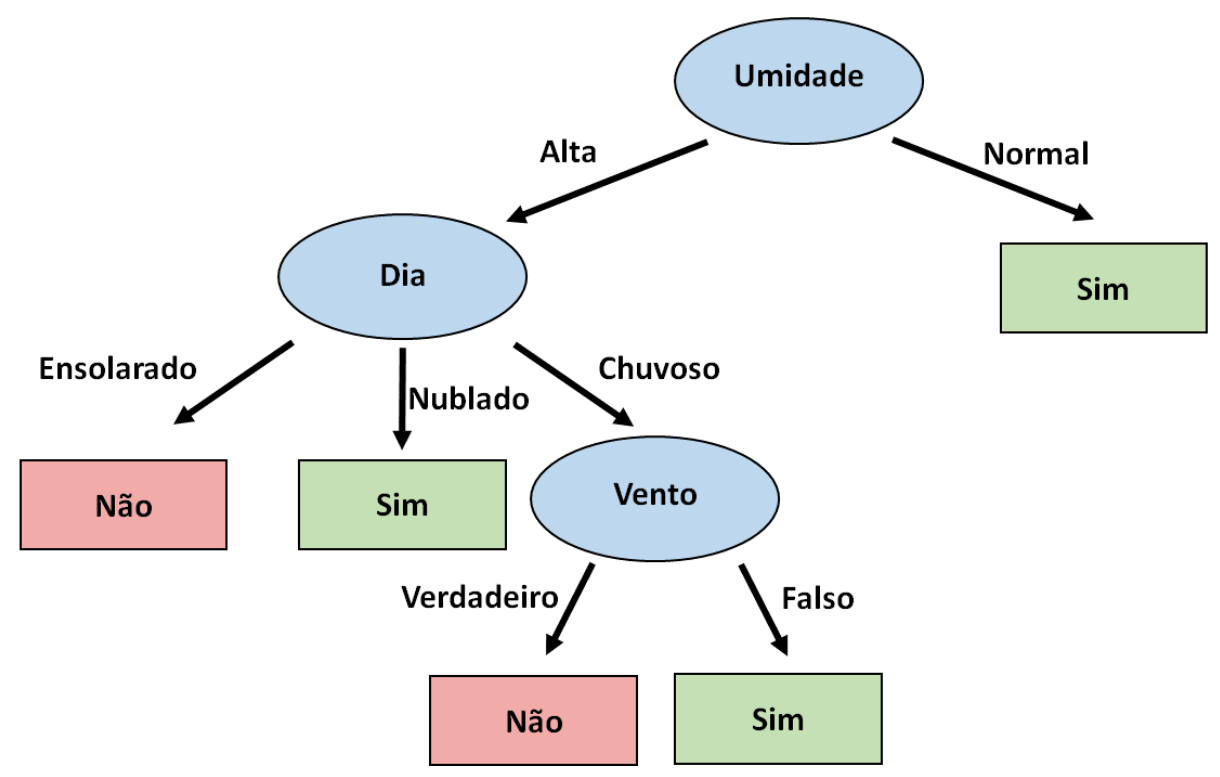

Fonte: adaptado de QUILICI-GONZALVEZ e ZAMPIROLLI (2014).

Para avaliar quantitativamente o desempenho de um modelo gerado, seja ele uma Árvore de Decisão ou um conjunto de Regras de Classificação, há técnicas e medidas de desempenho especialmente desenvolvidas para este fim, dentre as quais as mais relevantes são apresentadas a seguir.

\subsection{3 - Métricas do classificador da Árvores de Decisão}

Quando se trabalha com a aplicação dos conceitos de Árvore de Decisão sobre um conjunto de dados espera-se que ela classifique corretamente exemplos desconhecidos, porém verifica-se que na prática ocorrem classificações equivocadas. Usualmente, utilizam-se duas formas de se quantificar o nível de acerto e/ou erro de classificação: a primeira delas é a análise da matriz de contingência, voltada para avaliação de regras da AD criada; a segunda se refere a matriz de confusão, cuja finalidade é avaliar o classificador da AD como um todo. Como o objetivo desta tese é aplicar a AD como método de classificação, é de suma importância a atuação do classificador, logo a seguir são descritos os parâmetros de avaliação do classificador como um todo a partir da matriz de confusão (QUILICI-GONZALVEZ; ZAMPIROLLI, 2014; GOLLAPUDI, 2016).

$\mathrm{Na}$ matriz de confusão de um classificador os elementos das linhas (i) mostram o número de exemplos para os quais a classe é verdadeira e as classes preditas são apresentadas 
nas colunas $(\mathrm{j})$. A diagonal principal da matriz, elementos $(\mathrm{i}=\mathrm{j})$, representa os acertos do modelo, enquanto os demais elementos representam os erros, discriminados para cada uma das classes (QUILICI-GONZALVEZ; ZAMPIROLLI, 2014; GOLLAPUDI, 2016).

A Tabela 4.11 ilustra um exemplo de uma matriz de confusão para duas classes $\left(\mathrm{C}_{1} \mathrm{e}\right.$ $\mathrm{C}_{2}$ ), em que:

- Verdadeiros positivos (VP): ocorre quando os exemplos pertencem à classe $\mathrm{C}_{1}$ e são preditos como pertencentes a essa mesma classe.

- Falsos negativos (FN): ocorre quando os exemplos pertencem à classe $\mathrm{C}_{1} \mathrm{e}$ são preditos como pertencentes à classe $\mathrm{C}_{2}$.

- Falsos positivos (FP): ocorre quando os exemplos pertencem à classe $\mathrm{C}_{2}$ e são preditos como pertencentes à classe $\mathrm{C}_{1}$.

- Verdadeiros negativos (VN): ocorre quando os exemplos pertencem à classe $\mathrm{C}_{2}$ e são preditos como pertencentes a essa mesma classe.

Tabela 4-11: Matriz de confusão.

\begin{tabular}{c|c|c}
\cline { 2 - 3 } & \multicolumn{2}{c}{ Predita } \\
\hline \multirow{2}{*}{ Verdadeiro } & Verdadeiro Positivo (VP) & Falso Negativo (FN) \\
\cline { 2 - 3 } & Falso Positivo (FP) & Verdadeiro Negativo (VN) \\
\hline
\end{tabular}

Fonte: autoria própria.

Com os 4 valores fornecidos pela matriz de confusão é possível calcular 5 métricas do classificador da $\mathrm{AD}$ :

- Acurácia (ou taxa de acerto): representa a porcentagem de exemplos que foram classificados corretamente pelo classificador, dada pela equação (4.14).

- Sensitividade: representa a taxa de verdadeiros positivos, ou precisão da classe $\mathrm{C}_{1}$, dada pela equação (4.15).

- Especificidade: representa a taxa de verdadeiros negativos, ou precisão da classe $\mathrm{C}_{2}$, dada pela equação (4.16).

- Confiabilidade positiva: representa a confiabilidade de predição da classe $\mathrm{C}_{1}$, dada pela equação (4.17).

- Confiabilidade negativa: representa a confiabilidade de predição da classe $\mathrm{C}_{2}$, dada pela equação (4.18). 


$$
\begin{gathered}
a c c=\frac{V P+V N}{V P+F P+F N+V N} \\
\text { sens }=\frac{V P}{V P+F N} \\
\text { spec }=\frac{V N}{F P+V N} \\
\text { prel }=\frac{V P}{V P+F P} \\
\text { nrel }=\frac{V N}{F N+V N}
\end{gathered}
$$

Ressalta-se que é importante avaliar não só o acerto ou erro da classificação realizada por uma Árvore de Decisão, mas também a matriz de confusão, porque a mesma pode apresentar alto grau de acerto, mas nunca classificar os atributos dentro de determinada classe, o que é muito mais comprometedor ao modelo gerado do que alto grau de erro. Tal fato pode ocorrer devido a overfitting no processo de concepção da $\mathrm{AD}$ ou tipo de treinamento selecionado no processo de indução da árvore.

Além disso, o software WEKA, empregado na presente pesquisa, fornece métricas adicionais sobre os classificadores das ADs induzidas, os quais são: número de folhas, tamanho (número de nós) e tempo de construção da árvore; número total de instâncias testadas pelo classificador; Estatística Kappa; Erro Absoluto Médio; Raiz do Erro Médio Quadrático; Erro Relativo Absoluto; e Raiz do Erro Relativo Quadrático.

A quantificação do número de folhas se refere a contagem do número de nós folhas que classificam as instâncias que os atingem de acordo com o rótulo associado a eles. O tamanho da árvore faz a contagem de todos seus nós, somando a quantidade de nós folhas e nós internos, estes últimos responsáveis por testar os atributos de entrada com uma constante de decisão e determinar o próximo nó descendente da estrutura da árvore. Já o tempo de construção da árvore remete ao tempo que o algoritmo escolhido do WEKA leva para indução da mesma, e o número total de instâncias à quantidade de dados empregada no treinamento e/ou teste do classificador. 
A Estatística Kappa é uma medida que indica o grau de concordância entre dois classificadores mostrando quanto a concordância observada se aproxima da esperada, considerando para tanto as probabilidades de as concordâncias terem acontecido (LANDIS; $\mathrm{KOCH}, 1977)$. Uma das formas de calculá-la é por meio da equação (4.19), em que $P(a)$ é a probabilidade da concordância observada e $P(b)$ da concordância esperada.

$$
k=\frac{P(a)-P(b)}{1-P(b)}
$$

Para a avaliação de modelos induzidos, como os classificadores de Árvores de Decisão, a Estatística Kappa é calculada entre o classificador e o conjunto de treinamento, este último considerado como um classificador infalível. Segundo o apresentado por (LANDIS; KOCH, 1977) a Tabela 4.12 fornece uma interpretação para a Estatística Kappa, relacionando seu valor com o grau de concordância dos classificadores.

Tabela 4-12: Interpretação da Estatística Kappa.

\begin{tabular}{c|c}
\hline $\mathbf{k}$ & Interpretação \\
\hline$<0$ & nenhuma concordância \\
\hline $0-2$ & concordância baixa \\
\hline $0,21-0,4$ & concordância regular \\
\hline $0,41-0,6$ & concordância moderada \\
\hline $0,61-0,8$ & concordância substancial \\
\hline $0,81-1$ & concordância quase perfeita \\
\hline
\end{tabular}

Fonte: adaptado de LANDIS e KOCH (1977).

Para os cálculos dos outros parâmetros pelo WEKA deve-se tomar a seguinte notação: dada a i-ésima amostra na forma $\left(\mathrm{x}_{\mathrm{i}}, \mathrm{y}_{\mathrm{i}}\right), x_{i}$ é o atributo e $y_{i}=f\left(x_{i}\right)$ a classe rotulada pelo processo de classificação, em que $h(\cdot)$ é o classificador ou hipótese, e $n$ é o número de exemplos (REZENDE, 2003; WITTEN; FRANK, 2005). Tendo em vista esta notação a relação entre os valores exatos e aproximados para os classificadores pode ser estimada pelos seus erros, dentre os quais destaca-se o Erro Absoluto Médio (EAM) por meio da equação (4.20):

$$
E A M=\frac{1}{n} \sum_{i=1}^{n}\left|y_{i}-h\left(x_{i}\right)\right|
$$


A Raiz do Erro Médio Quadrático (REMQ) pela equação (4.21):

$$
R E M Q=\sqrt{\frac{1}{n} \sum_{i=1}^{n}\left(y_{i}-h\left(x_{i}\right)\right)^{2}}
$$

O Erro Relativo Absoluto (ERA) pela equação (4.22):

$$
E R A=\frac{\frac{1}{n} \sum_{i=1}^{n}\left|y_{i}-h\left(x_{i}\right)\right|}{\left.\frac{1}{n} \sum_{i=1}^{n} \mid y_{i}-\bar{y}\right) \mid}
$$

Em que $\bar{y}$ é a média dos valores para todas as classes, e a Raiz do Erro Relativo Quadrático (RERQ) é fornecida pela equação (4.23):

$$
R E R Q=\sqrt{\frac{\frac{1}{n} \sum_{i=1}^{n}\left|y_{i}-h\left(x_{i}\right)\right|}{\left.\frac{1}{n} \sum_{i=1}^{n} \mid y_{i}-\bar{y}\right) \mid}}
$$

\section{4 - Considerações Parciais sobre Aspectos Relacionados ao Aprendizado de Máquina e às Árvores de Decisão}

A fim de proporcionar um embasamento consistente para o desenvolvimento e a implementação dos sistemas inteligentes da metodologia proposta nesta tese para localização de falta, no presente capítulo foram apresentados os principais fundamentos e princípios sobre a extração de conhecimento de dados, o aprendizado de máquina e as árvores de decisão.

Fora apresentada uma breve contextualização sobre os processes de extração de conhecimento de dados, focando-se nas etapas do KDD (Knowledge Discovery in Databases). Entre estas etapas ressalta-se a Mineração de Dados, cujo objetivo é a extração de padrões e características dos dados, e que se baseia na aplicação de técnicas e ferramentas para predição e descrição, dentre as quais se destaca o Aprendizado de Máquina (AM). 
Em seguida foram expostos os conceitos relacionados a aquisição de conhecimento pelos algoritmos e técnicas computacionais do aprendizado de máquina, evidenciando sua capacidade de inferir modelos automatizados com baixo esforço computacional para análise de grandes e complexos bancos de dados, fornecendo resultados rápidos e precisos, o que lhe conferiu méritos para aplicação na presente pesquisa. Além disso, para acrescentar maior solidez ao embasamento teórico buscado foram apresentadas as principais características dos sistemas de AM, tais como os diferentes modos, paradigmas, formas e tarefas de aprendizado.

Ressaltou-se que na presente pesquisa, a descoberta de conhecimento a partir dos dados de tensão e indicação de sensibilização dos medidores inteligentes será conduzida por um processo de classificação de padrões empregando técnicas de aprendizado de máquina voltadas para classificação, mais especificamente as Árvores de Decisão (ADs). Então fora exposto os principais conceitos e fundamentações das $\mathrm{ADs}$, suas etapas e processos de indução e construção, as métricas de avaliação de seus classificadores, e um exemplo de como se dá a construção de uma árvore de decisão.

Cabe destacar que se decidiu pelo uso das ADs devido a seu desempenho com precisão, velocidade, escalabilidade, flexibilidade e robustez, e também em virtude da facilidade de interpretação e análise do seu modelo, assim como apresentação e entendimento deste modelo por terceiros. Como algoritmo de implementação evidenciou-se que o mais adequado a esta pesquisa é o algoritmo C4.5, que está presente no software WEKA nomeado como J48.

Dentre as características deste algoritmo que o demonstraram mais adequado se destacam: tratar valores desconhecidos de maneira diferenciada e não os utilizar nos cálculos do ganho de informação e entropia; empregar a medida de razão do ganho de informação para selecionar o atributo que melhor divide os exemplos, gerando árvores mais precisas e menos complexas; e apresentar um método de pós-poda das árvores geradas por meio de uma busca de baixo para cima na árvore, transformando em nós folha aqueles ramos que não apresentam nenhum ganho de informação significativo.

Posto isto, no próximo capítulo serão expostos os conceitos e etapas da metodologia proposta para localização de faltas e a modelagem de um sistema elétrico real com os resultados de sua simulação para composição de um banco de dados que será utilizado para aplicação desta metodologia. 



\section{CAPÍTULO 5}

\section{METODOLOGIA PROPOSTA PARA LOCALIZAÇÃO DE FALTAS}

No presente capítulo, inicialmente serão expostos os conceitos básicos da metodologia proposta para localização de faltas que se pretende desenvolver a partir das pesquisas desta tese. A seguir, são descritas as etapas da metodologia baseada na aquisição de sinais de tensão por medidores inteligentes e na estimação da distância elétrica em relação ao local da falta e do estado de sensibilização dos mesmos. Estas estimações serão realizadas por meio de sistemas inteligentes empregando a técnica de aprendizado de máquina denominada Árvore de Decisão. Por fim, ainda são apresentadas neste capítulo a modelagem de um sistema elétrico real e os resultados de sua simulação para composição de um banco de dados que será utilizado para implementação e validação da presente metodologia ao longo desta tese.

\section{1 - Metodologia proposta}

Métodos para localização de faltas em sistema de distribuição são importantes instrumentos na busca por melhor qualidade, confiabilidade e continuidade no fornecimento de energia elétrica, assim como para operação do sistema e redução de custos com manutenção e multas por descumprimento das normas regulatórias do setor.

Nesta conjuntura, algoritmos robustos, eficientes e rápidos para localização de faltas se fazem necessários, porém o desenvolvimento dos mesmos encontra dificuldades devido às características dos alimentadores de distribuição, as particularidades a serem atingidas em diferentes situações, a disponibilidade de dados para este procedimento e ao nível de tecnologia agregada a rede em que se pretende aplicá-los, como apontado nos capítulos anteriores.

Tendo em vista este cenário, a metodologia proposta para localização de faltas desta tese pauta-se na grande capacidade proporcionada pela infraestrutura de medição das Redes Elétricas Inteligentes (REIs) em monitorar, aquisitar e disponibilizar dados em tempo real com 
qualidade e em quantidade a partir de medidores inteligentes instalados nos postes de sistemas de distribuição junto ao lado de média tensão dos seus transformadores.

A ideia geral do método é compor um banco de dados a partir das informações fornecidas pelos medidores inteligentes em campo instalados em todos os transformadores de um determinado sistema de distribuição. Assim o banco de dados conformará uma representação tabulada das características do sistema elétrico real, possibilitando sua simulação computacional. Deste banco de dados serão extraídas informações do sistema elétrico tais como matrizes admitância e impedância, informações de curto-circuito, tensões em cada uma de suas barras, topologia de rede, entre outras. Sobre estas informações será realizada a aplicação de ferramentas de Aprendizado de Máquina para extração e processamento do conhecimento, o qual em conjunto com informações do sistema elétrico fornecerá o local ou região de possível ocorrência da falta.

O método desenvolvido baseia-se na análise da propagação de desequilíbrios de tensão pelo sistema elétrico em virtude da ocorrência de faltas, os quais apresentam diferentes variações nos distintos pontos da rede em função do local da falta e das características do sistema de distribuição.

A partir da aquisição e avaliação das tensões de fase e cálculo de tensões de linha e sequência, busca-se estimar por meio de dois sistemas inteligentes distintos (SI-1 e SI-2) as impedâncias de sequência zero $\left(Z_{0}\right)$ e positiva $\left(Z_{1}\right)$ entre os medidores e o local da falta, e posteriormente calcular as distâncias elétricas $\left(\mathrm{d}_{0}\right.$ e $\left.\mathrm{d}_{1}\right)$ dos medidores inteligentes em relação ao ponto sob falta.

Além disso, a metodologia proposta também faz uma avaliação da sensibilização dos medidores inteligentes pelas correntes de falta, estimando por meio de outro sistema inteligente independente (SI-3) a indicação da sensibilização (+1) ou não (-1) dos mesmos frente a ocorrência de faltas no sistema de distribuição, como ilustrado na Figura 5.1.

Os processos de estimação da distância elétrica e da sensibilização dos medidores inteligentes serão tratados como problema de classificação de padrões pelos sistemas inteligentes implementados, os quais serão pautados no emprego da técnica de aprendizagem de máquina denominada Árvore de Decisão (AD), apresentada no capítulo anterior.

Conforme ilustrado pela Figura 5.1, a partir do cruzamento das informações obtidas com as distâncias elétricas da falta em relação aos medidores e da sensibilização dos mesmos, será possível estimar o local ou região de ocorrência da falta no sistema de distribuição por meio de um algoritmo de baixo esforço computacional e resultados confiáveis empregando-se $\mathrm{AD}$. 
Figura 5-1: Ilustração representativa dos princípios básicos do método proposto.

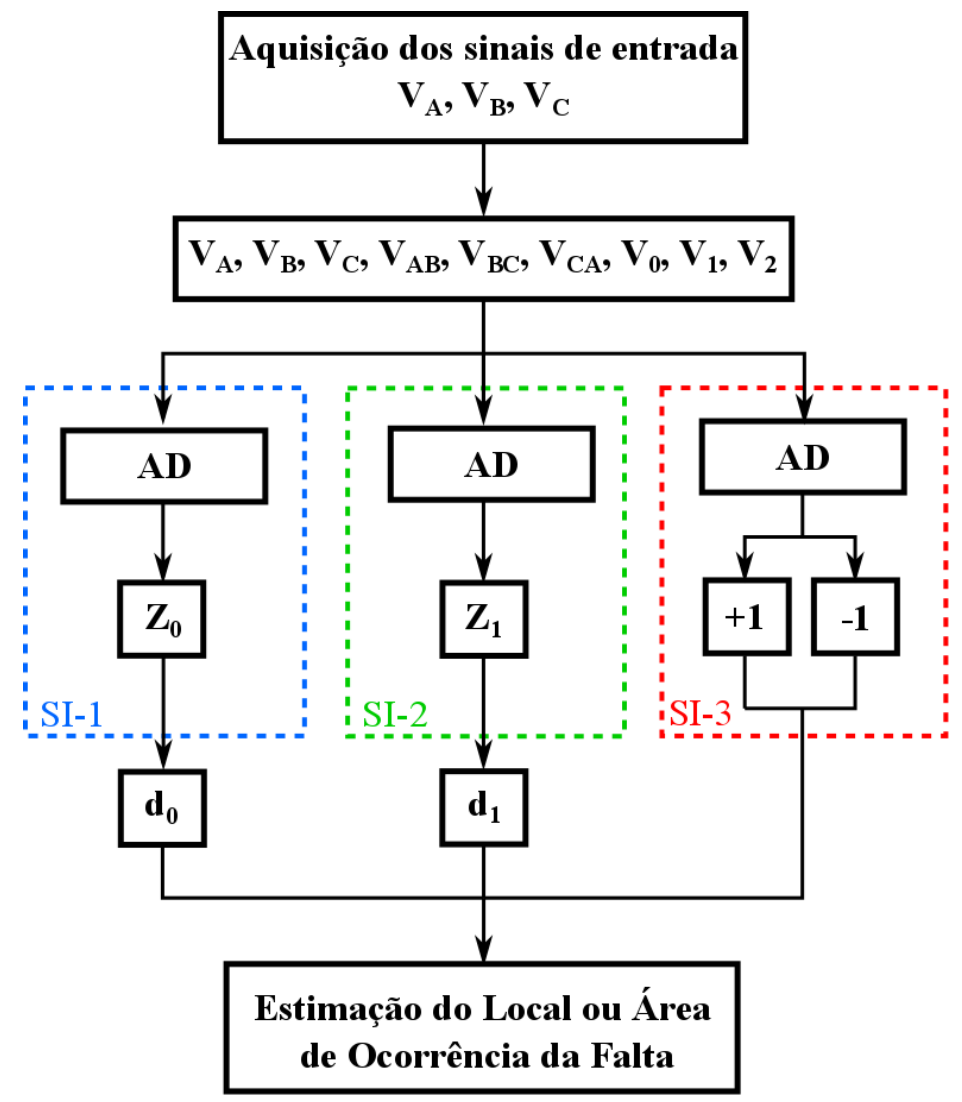

Fonte: autoria própria.

\subsection{1 - Descrição das etapas da metodologia proposta}

Inicialmente, para aplicação da metodologia proposta, deve ser realizada a aquisição do módulo das tensões de fase $\left(\mathrm{V}_{\mathrm{A}}, \mathrm{V}_{\mathrm{B}} \mathrm{e} \mathrm{V}_{\mathrm{C}}\right)$ pelos medidores inteligentes, e então calculados os módulos das tensões de linha e de sequência separando suas partes reais e imaginárias, pautando-se na teoria de circuitos exposta em (OLIVEIRA et al., 2000).

Tomando a tensão $\mathrm{V}_{\mathrm{A}}$ de um circuito trifásico, por exemplo, como tensão de referência para os cálculos, sua parte real será igual a seu próprio módulo e não se terá parte imaginária para a mesma, de forma a obter um total de 25 tensões, as quais seriam:

- $\mathrm{V}_{\mathrm{A}}, \mathrm{V}_{\mathrm{B}}, \mathrm{V}_{\mathrm{C}}$;

- $\mathrm{V}_{\mathrm{AB}}, \mathrm{V}_{\mathrm{BC}}, \mathrm{V}_{\mathrm{CA}}$;

- $\mathrm{V}_{0}, \mathrm{~V}_{1}, \mathrm{~V}_{2}$

- $\mathrm{V}_{\mathrm{BR}}, \mathrm{V}_{\mathrm{BIm}}, \mathrm{V}_{\mathrm{CR}}, \mathrm{V}_{\mathrm{CIm}}$;

- $\mathrm{V}_{\mathrm{ABR}}, \mathrm{V}_{\mathrm{ABIm}}, \mathrm{V}_{\mathrm{BCR}}, \mathrm{V}_{\mathrm{BCIm}}, \mathrm{V}_{\mathrm{CAR}}, \mathrm{V}_{\mathrm{CAIm}}$;

- $\mathrm{V}_{0 \mathrm{R}}, \mathrm{V}_{0 \mathrm{Im}}, \mathrm{V}_{1 \mathrm{R}}, \mathrm{V}_{1 \mathrm{Im}}, \mathrm{V}_{2 \mathrm{R}}, \mathrm{V}_{2 \mathrm{Im}}$. 
Ressalta-se que um procedimento análogo ocorreria para as tensões $V_{B}$ e $V_{C}$ caso fossem tomadas como referência nos cálculos realizados, obtendo-se igualmente 25 tensões como entradas dos sistemas inteligentes.

A seguir, para compor o conjunto de dados de saída para treinamento e teste dos sistemas inteligentes os medidores devem fornecer também o módulo das impedâncias $Z_{0}$ e $Z_{1}$ para os trechos entre seus respectivos pontos de alocação e pontos de falta, como mostrado na Figura 5.2, onde se tem $\left|Z_{0 \mathrm{M} 1}\right|$ e $\left|Z_{1 \mathrm{M} 1}\right|,\left|Z_{0 \mathrm{M} 2}\right|$ e $\left|Z_{1 \mathrm{M} 2}\right|$, e $\left|Z_{0 \mathrm{M} 3}\right|$ e $\left|Z_{1 \mathrm{M} 3}\right|$ como as impedâncias dos trechos entre os Medidores 1, 2 e 3 e o ponto de falta, respectivamente.

Caberá ainda aos medidores inteligente prover a indicação de sua sensibilização ou não, como também apresentado na Figura 5.2, por meio da qual nota-se a indicação “+1” para o Medidor 1, uma vez que a corrente de falta passa pelo mesmo em direção ao ponto sob falta. Na mesma figura observa-se a indicação “-1” para os Medidores 2 e 3 que se encontram fora do percurso da corrente de falta, e, portanto, não são sensibilizados pela mesma.

Figura 5-2: Representação da sensibilização e medição de impedâncias dos medidores em relação ao ponto de falta.

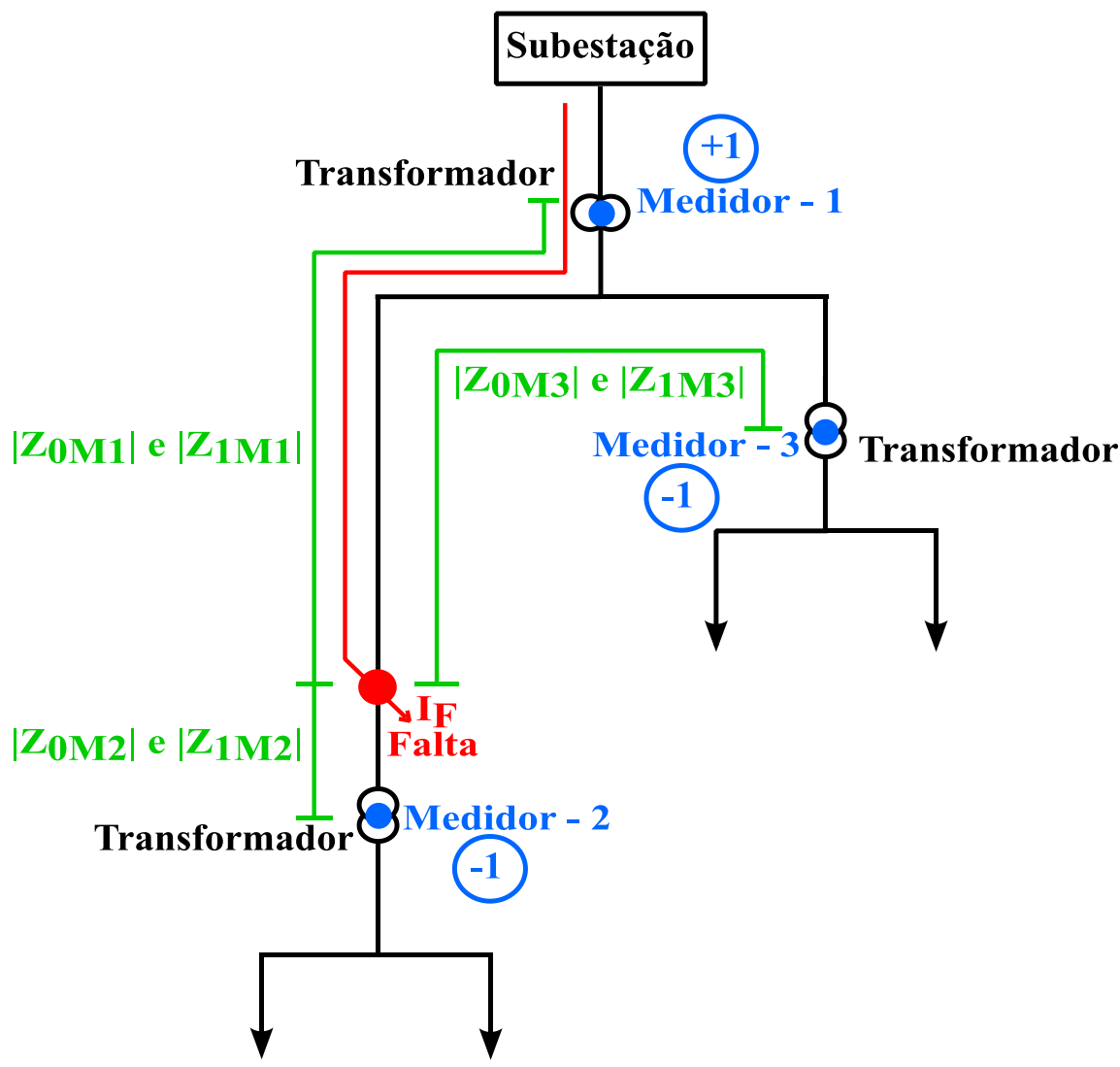

Fonte: autoria própria.

Posteriormente, com a obtenção dos dados necessários, os 3 sistemas inteligentes independentes serão treinados e testados empregando-se a técnica de classificação das Árvores 
de Decisão. Na presente metodologia esta técnica levará os sistemas inteligentes a avaliar dentre os 25 atributos de entrada (tensões) quais são os mais correlacionados com as saídas esperadas $\left(Z_{0}, Z_{1}\right.$, “1” e “-1") avaliando o ganho de informação e entropia para indução da AD, a fim de prover a melhor classificação de padrões e estimação possível, além do menor erro.

Tendo em vista a topologia diversificada dos sistemas de distribuição, o módulo das impedâncias $Z_{0}$ e $Z_{1}$ poderá apresentar valores bastante diferentes e em quantidades também distintas para pontos de maior concentração de ramais da rede elétrica em relação aos de menor concentração. Tal fato, poderá implicar em distorções na resposta do sistema de localização de faltas, porém a fim de contornar esta possível situação, será realizado e avaliado o agrupamento (clusterização) dos dados de impedância zero e positiva durante o processo de treinamento dos sistemas inteligentes SI-1 e SI-2.

A partir das impedâncias estimadas de sequência zero e positiva serão então calculadas as distâncias elétricas $\left(\mathrm{d}_{0 \mathrm{k}} \mathrm{e} \mathrm{d}_{1 \mathrm{k}}\right)$ equivalentes de todos os " $k$ " medidores em relação ao ponto sob falta. Para tanto, faz-se uso do cálculo da matriz impedância $\mathrm{Z}_{\mathrm{B} U \mathrm{~S}}$ do sistema elétrico com base na inversão da matriz admitância $\mathrm{Y}_{\mathrm{BUS}}$, aplicando o conceito de Matriz de Incidência Nodal, dado pela equação (5.1), em que H é a matriz de incidência e $\mathrm{H}^{\mathrm{T}}$ sua transposta.

$$
Y_{\text {bus }}=H^{T} Y_{0} H
$$

A Matriz de Incidência Nodal, como apresentado em (ANDERSON, 1995), corresponde a uma representação matricial do grafo topológico do circuito ou sistema elétrico orientado pelas correntes, na qual para um circuito com "m" nós e "b" ramos a matriz de incidência nodal é uma matriz com $b$ linhas e $m$ colunas, e o sentido de incidência dos ramos sobre os nós segue a seguinte regra para cada um de seus $a_{p, q}$ elementos:

$$
a_{p, q}=\left\{\begin{array}{c}
+1, \text { se a corrente no ramo } p \text { esta deixando o nó } q \\
-1, \text { se a corrente no ramo } p \text { esta entrando o nó } q \\
0, \text { se o ramo } p \text { não está conctado ao nó } p
\end{array}\right.
$$

A matriz admitância primitiva $\left(\mathrm{Y}_{0}\right)$ é esparsa e só tem elementos na sua diagonal principal, pois para fins de análise de curto-circuito pode-se desconsiderar o acoplamento mútuo da rede.

Após a determinação da matriz admitância YBus deve ser feita sua decomposição LU tanto para impedância de sequência zero quanto positiva, criando 2 matrizes L e duas U, a 
partir das quais é possível obter as impedâncias equivalentes de cada trecho do sistema, pois $\mathrm{Z}_{\mathrm{BUS}}=\mathrm{U}^{-1} \times \mathrm{L}^{-1}$ é uma matriz cheia, em que na sua diagonal principal tem-se as impedâncias equivalentes de cada barra.

Cabe ressaltar que para o cálculo das distâncias elétricas equivalentes em quilômetros optou-se pela estimação das impedâncias de sequência zero e positiva a fim de se obter mais informação do sistema elétrico. Assim cada ponto de medição passa a possuir um par de impedâncias, e, portanto, de distâncias elétricas, que dará uma localização melhor do que apenas uma individualmente, e que por meio da análise de correlação se mostraram bem relacionadas entre si.

Depois deste cálculo cada um dos medidores inteligentes passará a indicar um par de distâncias elétricas em relação a falta, uma proveniente da estimação de $Z_{0}$ e outra de $Z_{1}$. No entanto, como ainda não se sabe o local da falta pode-se assumir essas distâncias tanto em relação a pontos para trás do medidor como para frente, uma vez que se tem uma medida de distância, mas não se sabe em que direção.

Neste momento, far-se-á o cruzamento das informações obtidas pela análise destas distâncias com a indicação fornecida pelo sistema inteligente responsável pela estimação da sensibilização dos medidores, por meio do qual será possível saber se essas distâncias elétricas são em relação a um ponto para trás ou para frente do medidor.

Na Figura 5.3 é possível observar situações análogas as descritas, pois como o medidor M-1 tem indicação “+1" pode-se dizer que a falta ocorreu em um ponto à frente do mesmo, e, portanto, as distâncias elétricas estimadas referem-se ao trecho a sua frente. Já para os medidores M-2 e M-3 que possuem indicação “-1" uma vez que não são sensibilizados, o ponto de falta encontra-se atrás ou antes dos mesmos, e, por conseguinte, as possíveis distâncias elétricas estimadas referem-se a trechos anteriores ao ponto de alocação destes medidores. 
Figura 5-3: Representação da sensibilização e medição das distâncias elétricas dos medidores em relação ao ponto de falta.

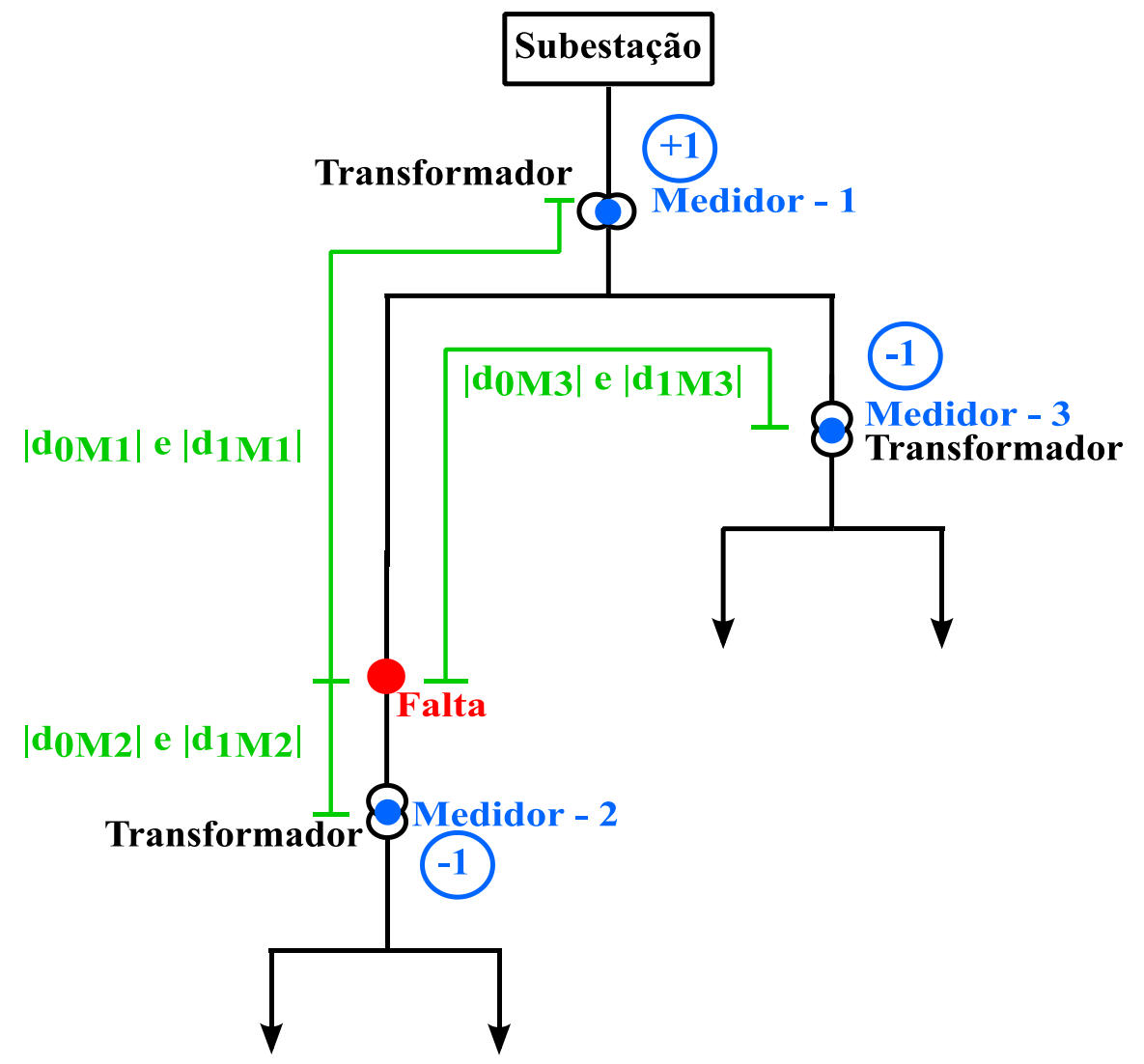

Fonte: autoria própria.

Definidas as direções das distâncias calculadas realiza-se a análise da indicação das mesmas em relação a topologia da rede de distribuição, de modo que o ponto ou a região com maior sobreposição de distâncias seja o local ou a área com maior probabilidade de falta. Contudo, devido à possibilidade de ocorrência de erros tanto na estimação das impedâncias, os quais se propagariam para as distâncias elétricas, quanto na sensibilização dos medidores, é necessária uma etapa para avaliação destes erros.

Isto se deve ao fato de que se os erros forem relativamente grandes quando comparados ao comprimento dos trechos do sistema de distribuição, por exemplo, o valor das distâncias elétricas será superestimado e assim pode-se obter um número grande de possíveis pontos de ocorrência da falta e/ou regiões muito amplas. Além disso, a estimação errônea da sensibilização dos medidores pode acarretar a indicação de diversos medidores em regiões bastante distintas do sistema elétrico sob condição de sensibilização, levando a indicação de múltiplos pontos ou soluções incompatíveis com a realidade da rede de distribuição em análise.

Neste contexto, será executada uma análise de erros na fase de teste dos sistemas inteligentes para que os mesmos sejam estimados, a fim de maximizar a capacidade de acerto 
do local de falta pelo método proposto. Assim, no momento de aplicação da metodologia desenvolvida será possível também analisar o ponto ou região estimados para falta tendo em vista o possível erro do método.

Para que as etapas anteriormente descritas sejam automatizadas por um sistema especialista formado pelos 3 sistemas inteligentes citados, a seguir são expostos os passos do algoritmo para localização de faltas.

I. Aquisitar os sinais de tensão de fase do sistema de distribuição por meio dos medidores inteligentes;

II. Calcular as tensões de linha e de sequências e suas respectivas partes reais e imaginárias, a partir dos dados aquisitados em I.

III. Estimar as impedâncias $\left|Z_{0 \mathrm{k}}\right|$ e $\left|Z_{1 \mathrm{k}}\right|$ para os k medidores inteligentes;

IV. Calcular as distâncias elétricas $\mathrm{d}_{0 \mathrm{k}}$ e $\mathrm{d}_{1 \mathrm{k}}$ para os $\mathrm{k}$ medidores inteligentes;

V. Estimar o estado de sensibilização dos k medidores inteligentes;

VI. Cruzar os dados dos Passos IV e V e definir a direção das distâncias elétricas $\mathrm{d}_{0 \mathrm{k}}$ e $\mathrm{d}_{1 \mathrm{k}}$ em relação a seus respectivos medidores;

VII. Analisar a indicação das distâncias elétricas $\mathrm{d}_{0 \mathrm{k}} \mathrm{e} \mathrm{d}_{1 \mathrm{k}}$ em relação a topologia da rede de distribuição;

VIII. Identificar o ponto ou área com maior sobreposição de distâncias elétricas como o local ou a região de maior probabilidade da falta em relação aos medidores inteligentes.

Após exposição da metodologia que se propõe aplicar para localização de faltas, na próxima seção apresenta-se o sistema elétrico e os resultados de sua modelagem para formação do banco de dados com as informações dos medidores inteligentes que será utilizado para aplicação e validação da metodologia.

\section{2 - Modelagem do Sistema Elétrico sob Estudo}

Para aplicação da metodologia proposta para localização de faltas apresentada na seção anterior, foi modelado um sistema elétrico real e realizadas simulações computacionais do seu comportamento frente a ocorrência de faltas. A partir destas simulações foi composto um banco de dados com a finalidade de entender o relacionamento existente entre as tensões, impedâncias, sensibilização dos medidores inteligentes, e comportamento da falta ao longo do 
sistema elétrico. Ademais, a formação deste banco de dados também tem a finalidade de fornecer dados para teste e validação dos classificadores dos sistemas inteligentes da metodologia proposta.

O alimentador piloto escolhido para avaliação nesta pesquisa faz parte do sistema de distribuição de uma concessionaria de energia elétrica do Estado de São Paulo, opera em 13,8 kV e a disposição geográfica da sua rede primária é apresentada na Figura 5.4. O presente alimentador de distribuição foi modelado com 1600 barras, a contar com a subestação, e 505 pontos de medição pela alocação de medidores inteligentes junto ao lado de média tensão de cada um dos transformadores do sistema. Na Figura 5.4 a subestação está representada por um círculo em alaranjado, as barras do sistema por anéis na cor ciano, e os medidores inteligentes alocados em cada um dos 505 transformadores por círculos em preto.

Além disso, para as simulações considerou-se que antes da ocorrência das faltas as tensões de fase do sistema têm mesmo módulo e estão defasadas de $120^{\circ}$, o sistema opera sem cargas e sem conexão de geradores distribuídos, e são simuladas faltas francas entre a Fase A e a terra em cada uma de suas 1599 barras (não foi simulada falta na barra da subestação).

A modelagem do alimentador foi realizada a partir das características elétricas dos seus parâmetros de rede, sendo que a subestação foi representada por seu circuito equivalente composto por uma fonte de tensão trifásica e uma impedância série a partir dos parâmetros fornecidos pela concessionária. Os transformadores foram modelados com seus dados nominais de placa, e os trechos aéreos do sistema de distribuição pelos respectivos modelos $\pi$.

Haja vista que o sistema elétrico sob análise é relativamente grande, apenas para ilustrar a modelagem realizada via MATLAB/Simulink, na Figura 5.5 apresenta-se a parte inicial do sistema partindo da subestação, na qual o bloco em alaranjado representa a subestação, os blocos em preto os transformadores, os verdes os trechos aéreos da rede elétrica, os azuis os medidores inteligentes, e o magenta o equivalente modelado para falta Fase A à terra. 


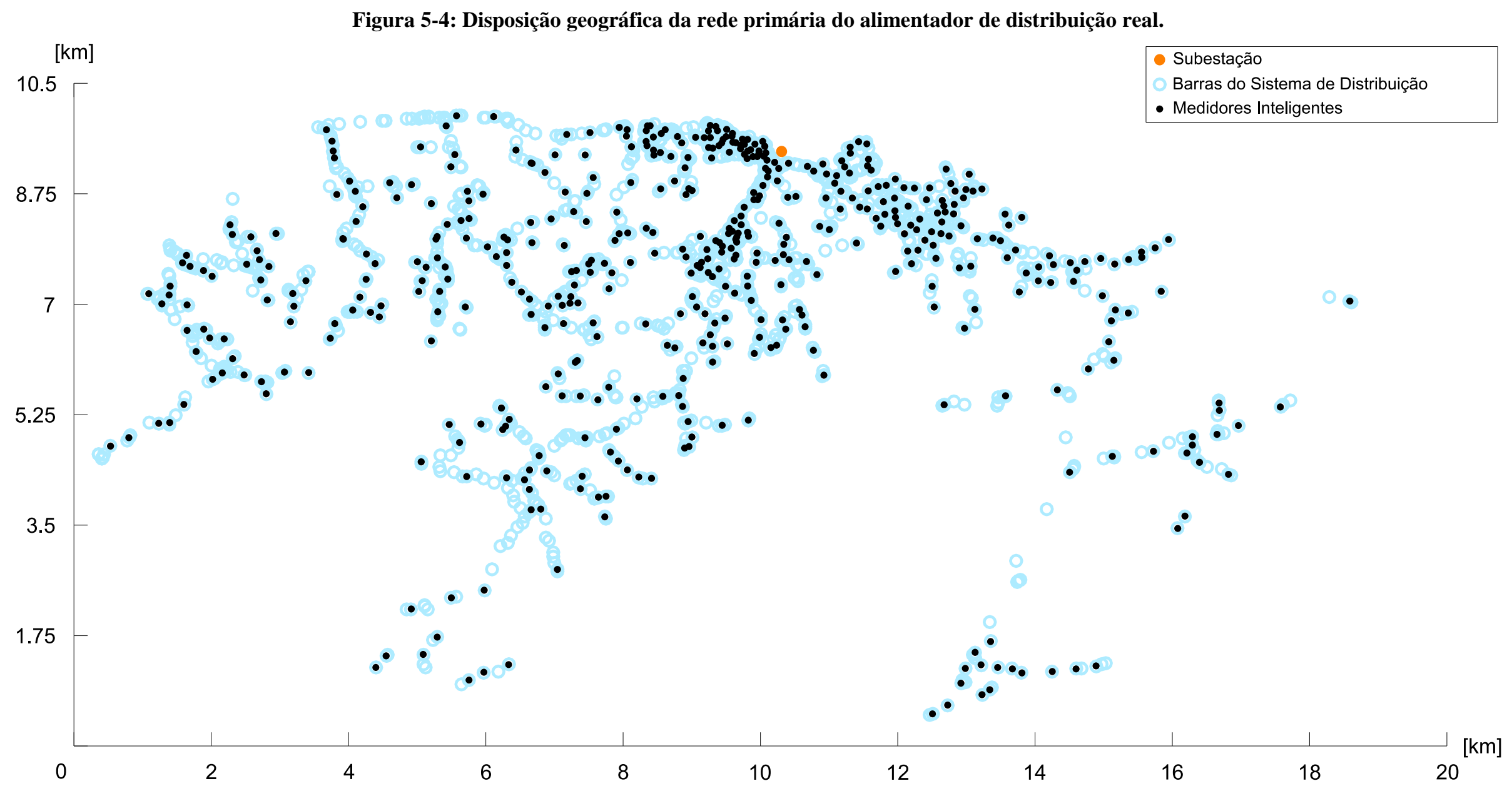

Fonte: autoria própria. 
Figura 5-5: Diagrama de blocos da modelagem no MATLAB/Simulink do alimentador piloto.

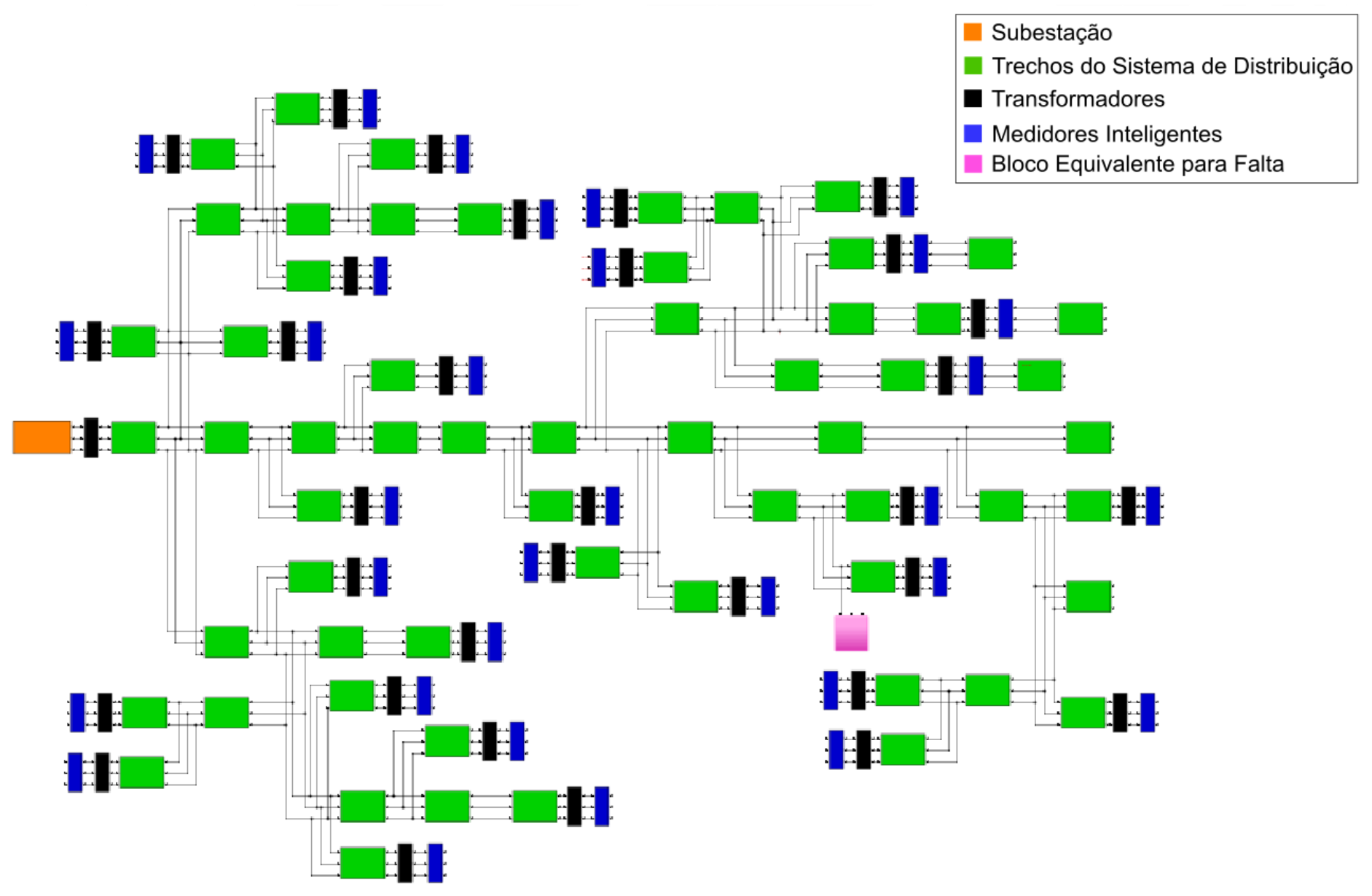

Fonte: autoria própria. 


\subsection{1 - Resultados das Simulações do Sistema Elétrico sob Estudo}

Tendo em vista que a propagação da falta ao longo de um sistema de distribuição depende de vários fatores particulares do sistema elétrico bem como das características e tipo da falta, foram simuladas ocorrências de faltas em cada uma das 1599 barras do sistema e aquisitadas as tensões pelos 505 medidores para cada uma dessas ocorrências. Os dados gerados nesta etapa são de suma importância, pois a análise dos mesmos visa descobrir as particularidades que influenciam o comportamento da rede elétrica frente as faltas, bem como serão utilizados para validar a metodologia proposta nesta tese.

A partir das simulações, o banco de dados foi formado pelas 25 tensões, 2 impedâncias e 1 indicação de sensibilização por corrente de falta para cada um dos 505 medidores para as 1599 faltas simuladas, totalizando um conjunto de dados com 22.609.860 parâmetros. Ressaltase que os medidores e barras do sistema foram numerados consecutivamente a partir da subestação, e ao longo da aplicação da metodologia proposta para localização de faltas será sempre assumida a mesma numeração inicialmente definida.

Em virtude do grande montante de dados, da Figura 5.6 à Figura 5.20 apresenta-se a distribuição dos mesmos por número de ocorrências após normalização em relação aos valores máximos e mínimos absolutos observados nas simulações, e com intervalos de amostragem discretizados em 10 partições.

Por meio das Figuras 5.6 e 5.7 nota-se que a tensão da Fase A tem maior concentração de ocorrências em valores menores do que as tensões da Fase B e C em virtude de estar sujeita aos afundamentos de tensão causados pelas faltas simuladas. Das Figuras 5.7 e 5.8 depreendese que as tensões de linha têm valores mais próximos da tensão nominal de operação do circuito, e a tensão $\mathrm{V}_{\mathrm{BC}}$ é a que possui menor correlação com o comportamento do sistema sob falta.

Já nas Figuras 5.9 e 5.10 as tensões de sequência apresentam valores condizentes com o teorema de Fortescue (STEVENSON, 1982), as tensões de sequência zero e negativa têm maior concentração em valores menores que a tensão de sequência positiva, e maior dispersão de valores uma vez que a tensão de sequência positiva se concentra bastante em torno de 0,7 pu. Por meio das Figuras 5.12 a 5.18 observa-se que na divisão entre parte real e imaginária das tensões há uma concentração de valores um pouco menor, com exceção das tensões $\mathrm{V}_{\mathrm{Br}}$, 
$\mathrm{V}_{0 \mathrm{r}}$ e $\mathrm{V}_{2 \mathrm{r}}$, o que poderá contribuir com informações mais variadas do sistema elétrico para o processo de treinamento das Árvores de Decisão.

Por outro lado, na Figura 5.19 nota-se uma divisão mais acentuada entre os estados de sensibilização dos medidores à passagem de corrente de falta, o que será benéfico para a localização das faltas ao restringir uma determinada área de localização destes medidores para definição da ocorrência da falta.

Finalmente, por meio da Figura 5.20 constata-se que os valores mais frequentes das impedâncias de sequência zero e positiva se concentram de forma acentuada até aproximadamente 0,2 pu e $0,3 \mathrm{pu}$, respectivamente. Isto se deve a topologia do sistema elétrico, o qual possui muitos medidores concentrados em ramos próximos a subestação e próximos entre si na maior parte da rede de distribuição. Este fato indica que para faltas ocorrendo em regiões onde as faixas de valores das impedâncias em relação aos medidores forem menores as ADs serão treinadas com grandes volumes de dados e terão maior chance de acerto na localização. Todavia, em contrapartida, para situações em que as impedâncias relativas entre os medidores e os pontos de falta forem elevadas, a tendência de acerto será menor.

Figura 5-6: Tensões normalizadas: (a) Fase A; (b) Fase B.
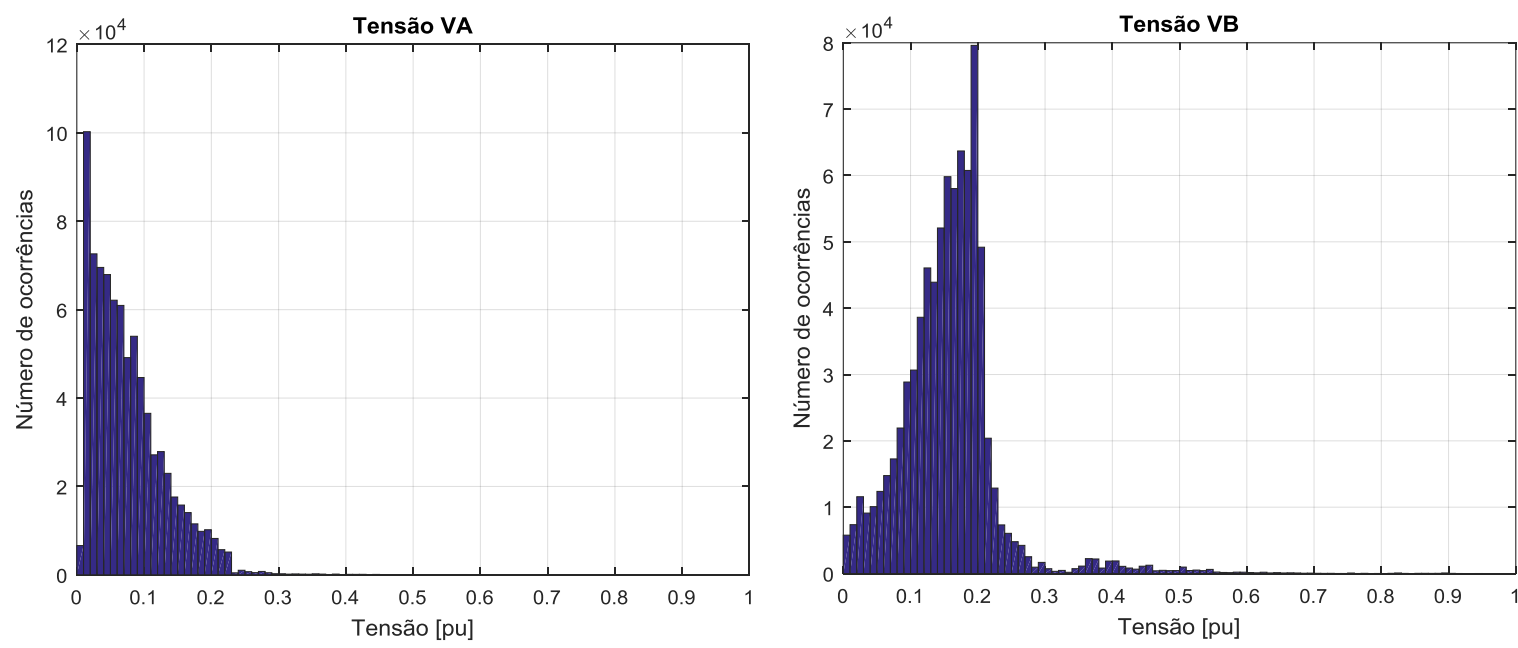

Fonte: autoria própria. 
Figura 5-7: Tensões normalizadas: (a) Fase C; (b) entre Fases A e B.
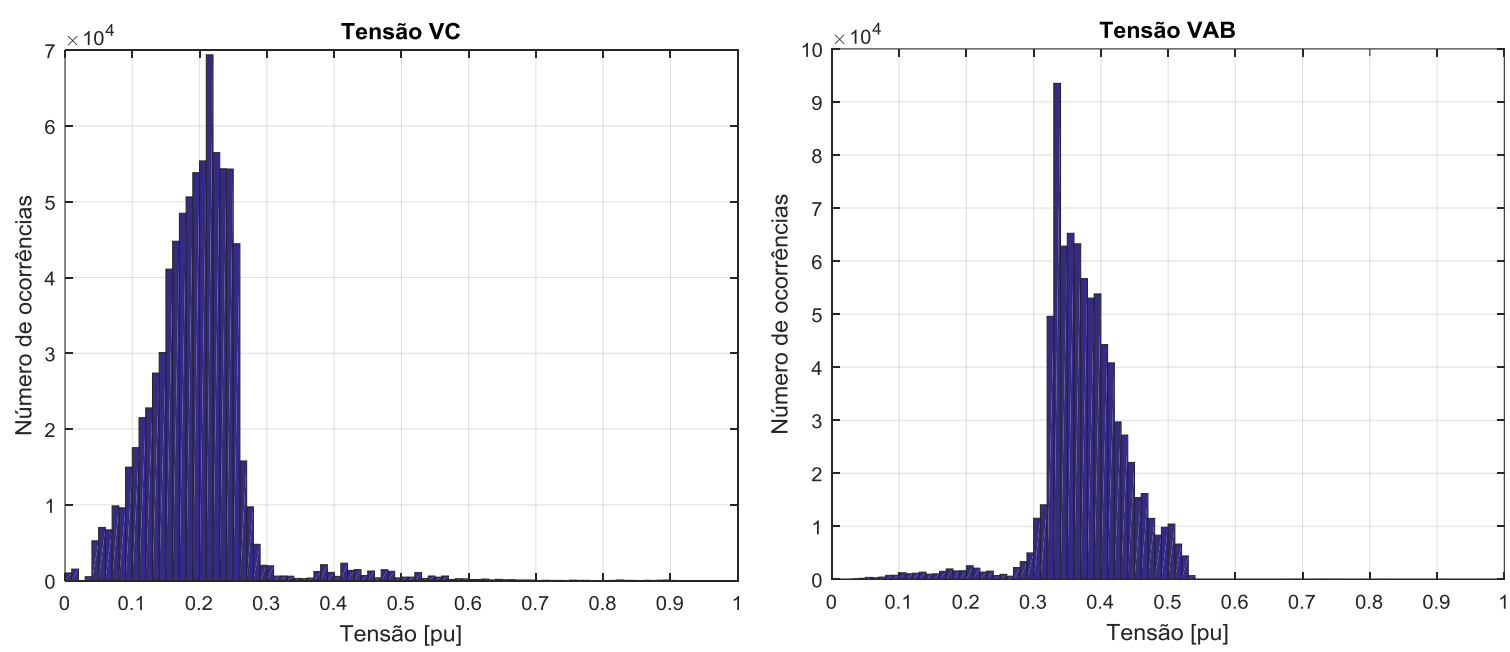

Fonte: autoria própria.

Figura 5-8: Tensões normalizadas: (a) entre Fases B e C; (b) entre Fases C e A.
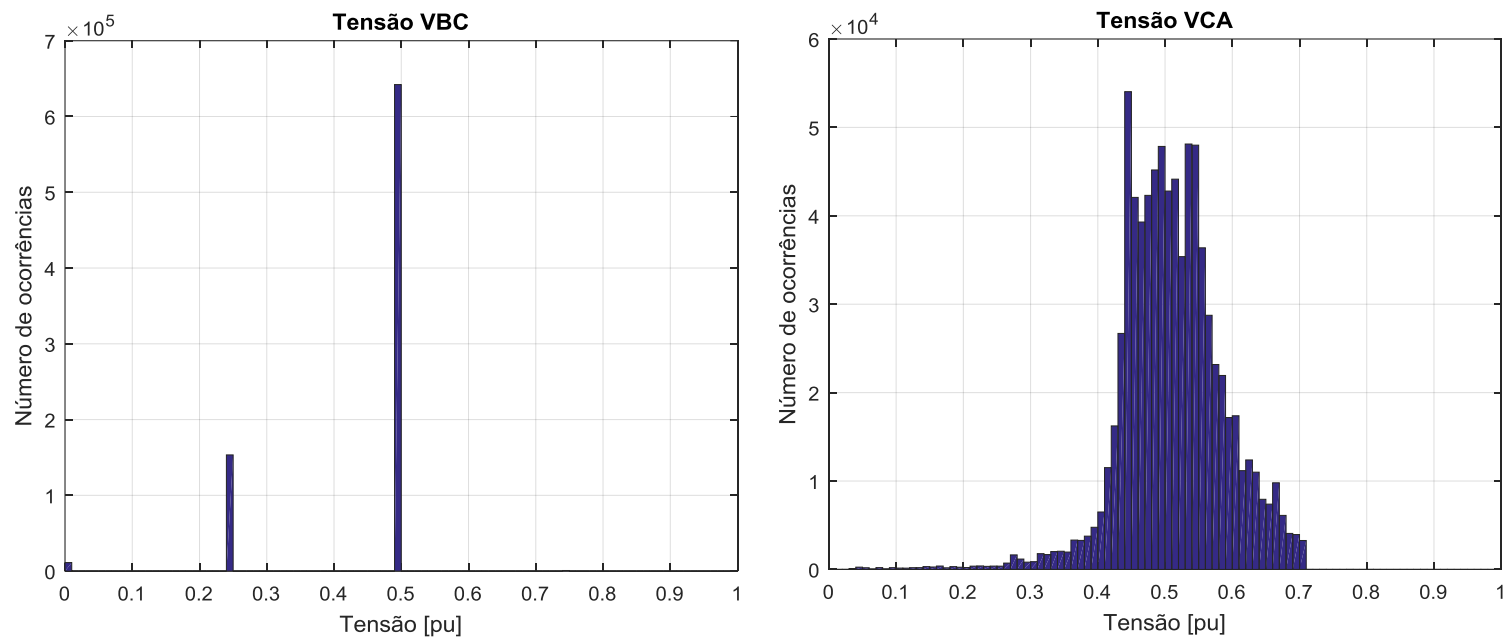

Fonte: autoria própria.

Figura 5-9: Tensões normalizadas: (a) componente de sequência zero; (b) componente de sequência positiva.
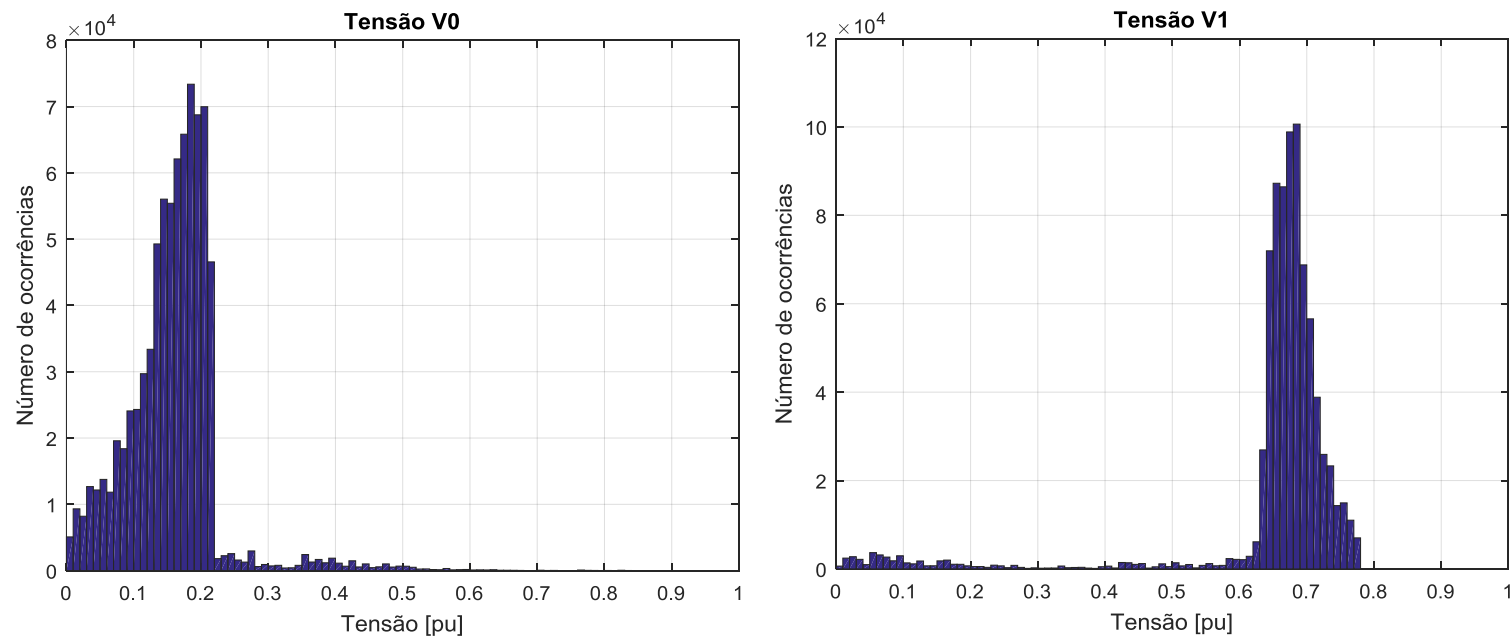

Fonte: autoria própria. 
Figura 5-10: Tensões normalizadas: componente de sequência negativa.

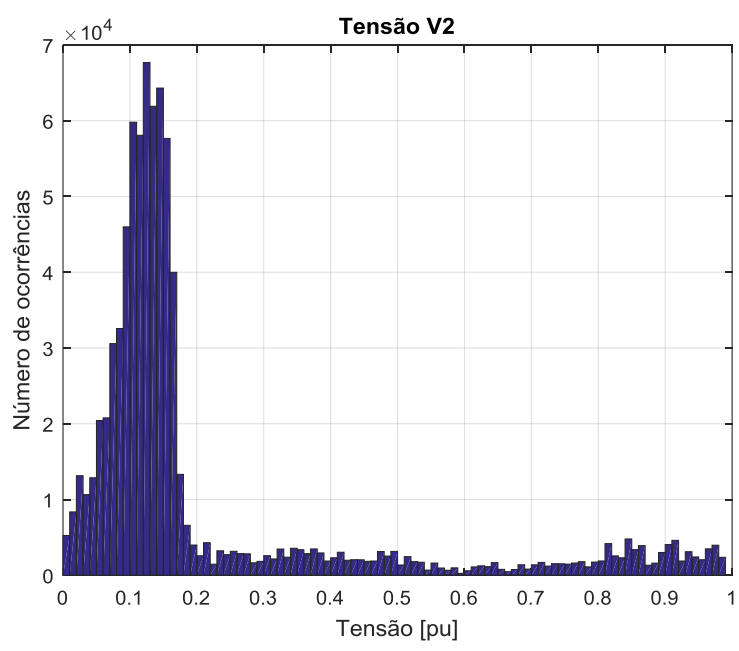

Fonte: autoria própria.

Figura 5-11: Tensões normalizadas: (a) componente real da Fase B; (b) componente imaginária da Fase B.
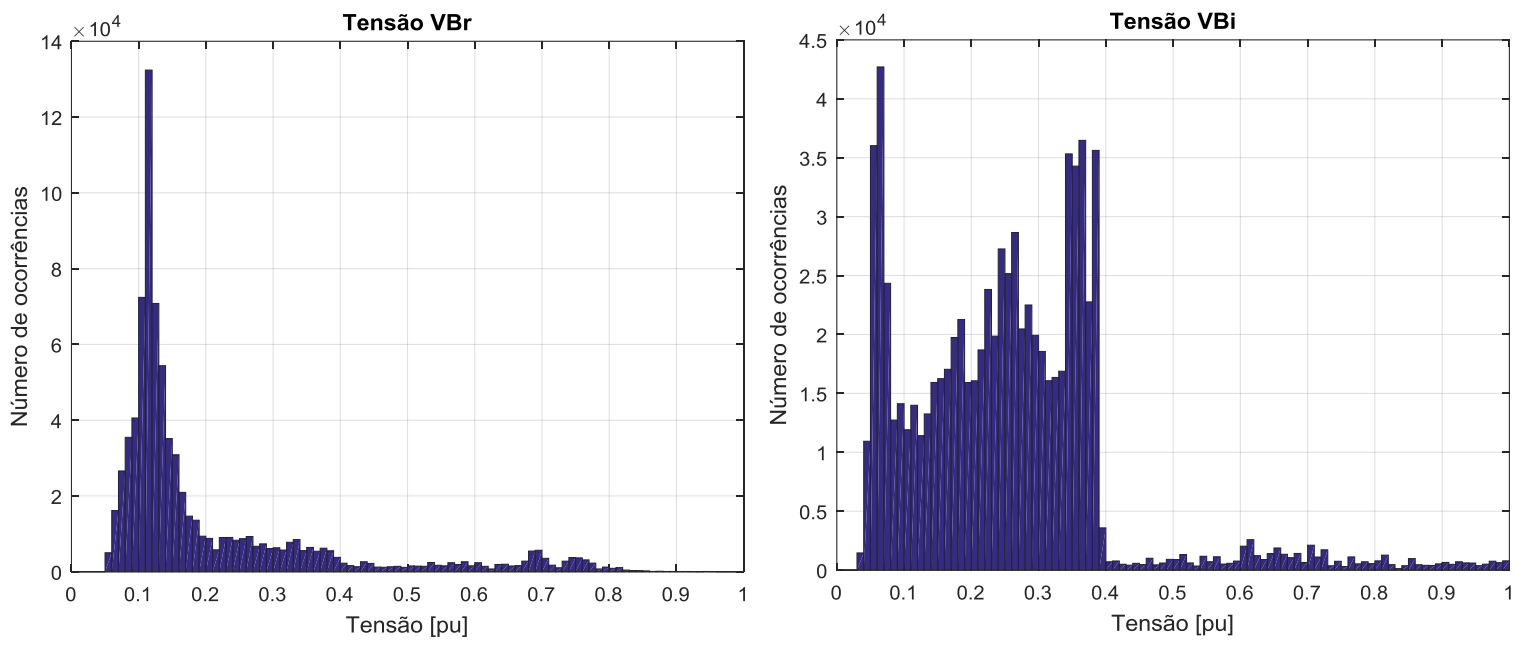

Fonte: autoria própria.

Figura 5-12: Tensões normalizadas: (a) componente real da Fase C; (b) componente imaginária da Fase C.
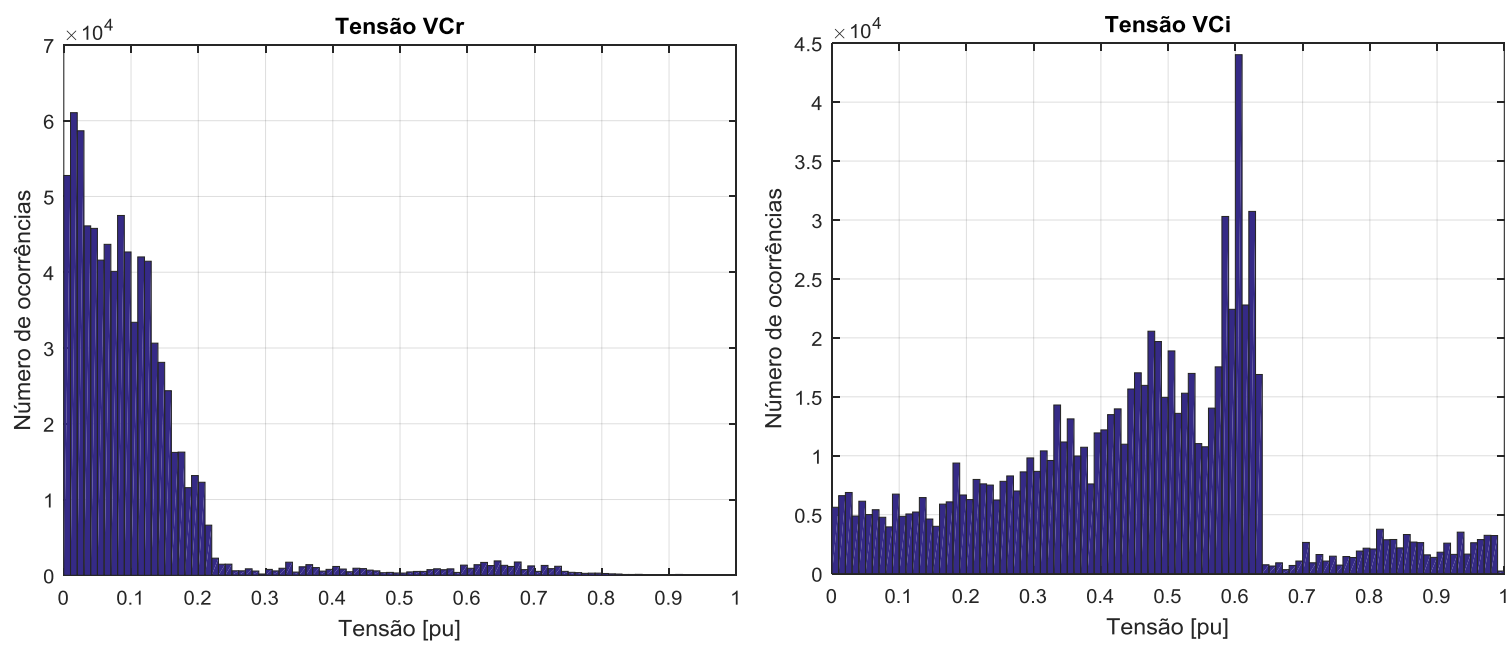

Fonte: autoria própria. 
Figura 5-13: Tensões normalizadas: (a) componente real da Fase AB; (b) componente imaginária da Fase AB.
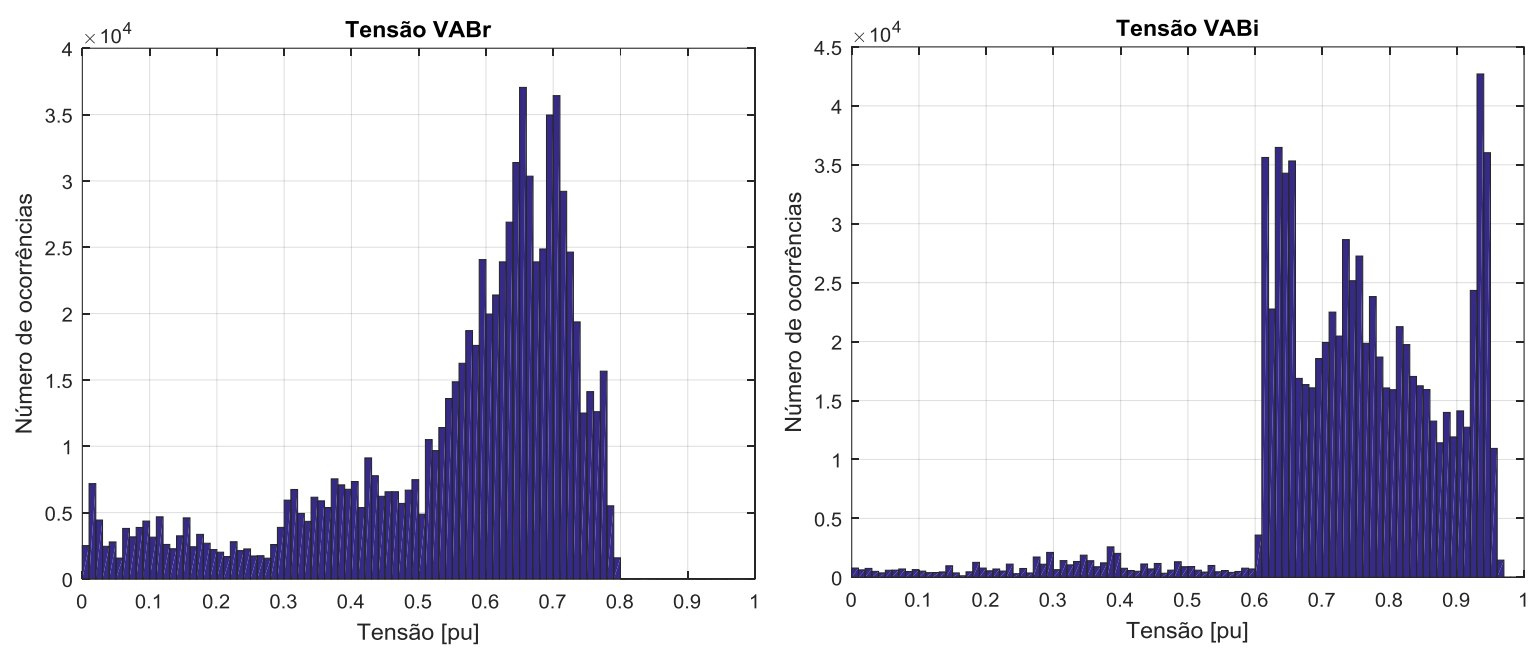

Fonte: autoria própria.

Figura 5-14: Tensões normalizadas: (a) componente real da Fase BC; (b) componente imaginária da Fase BC.
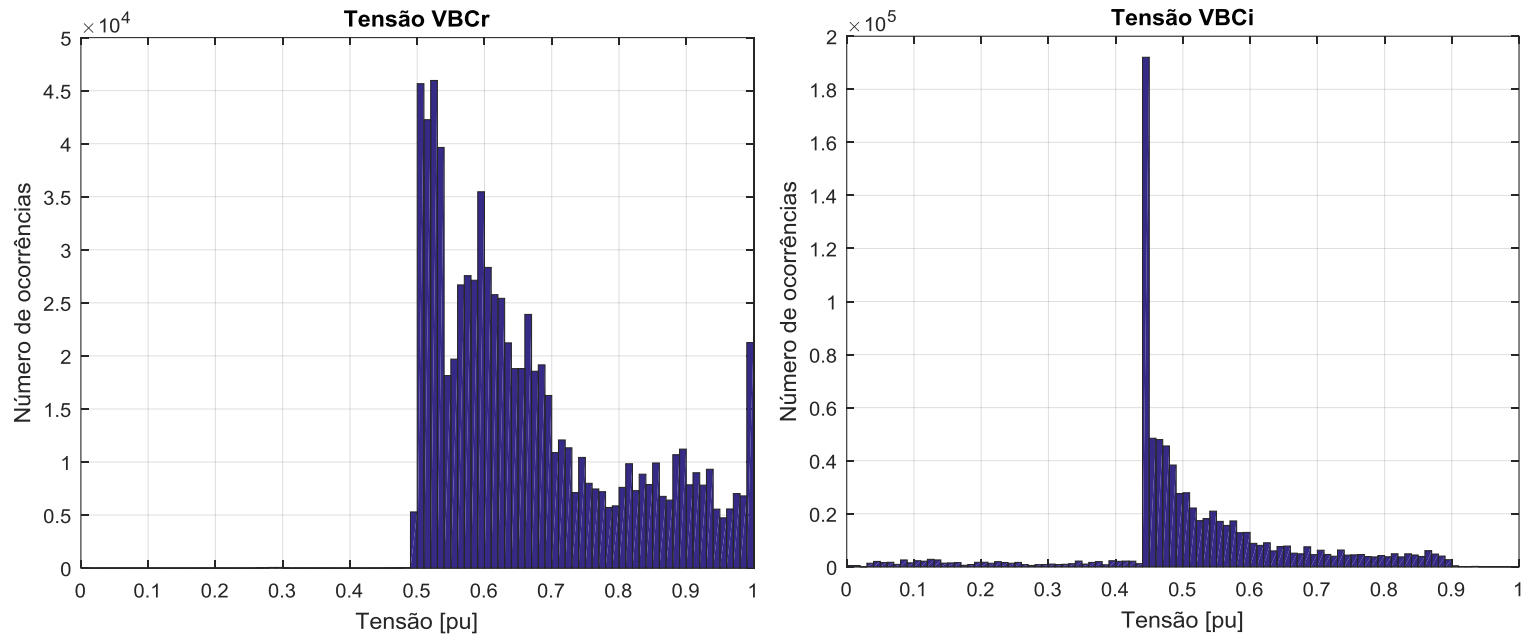

Fonte: autoria própria.

Figura 5-15: Tensões normalizadas: (a) componente real da Fase CA; (b) componente imaginária da Fase CA.
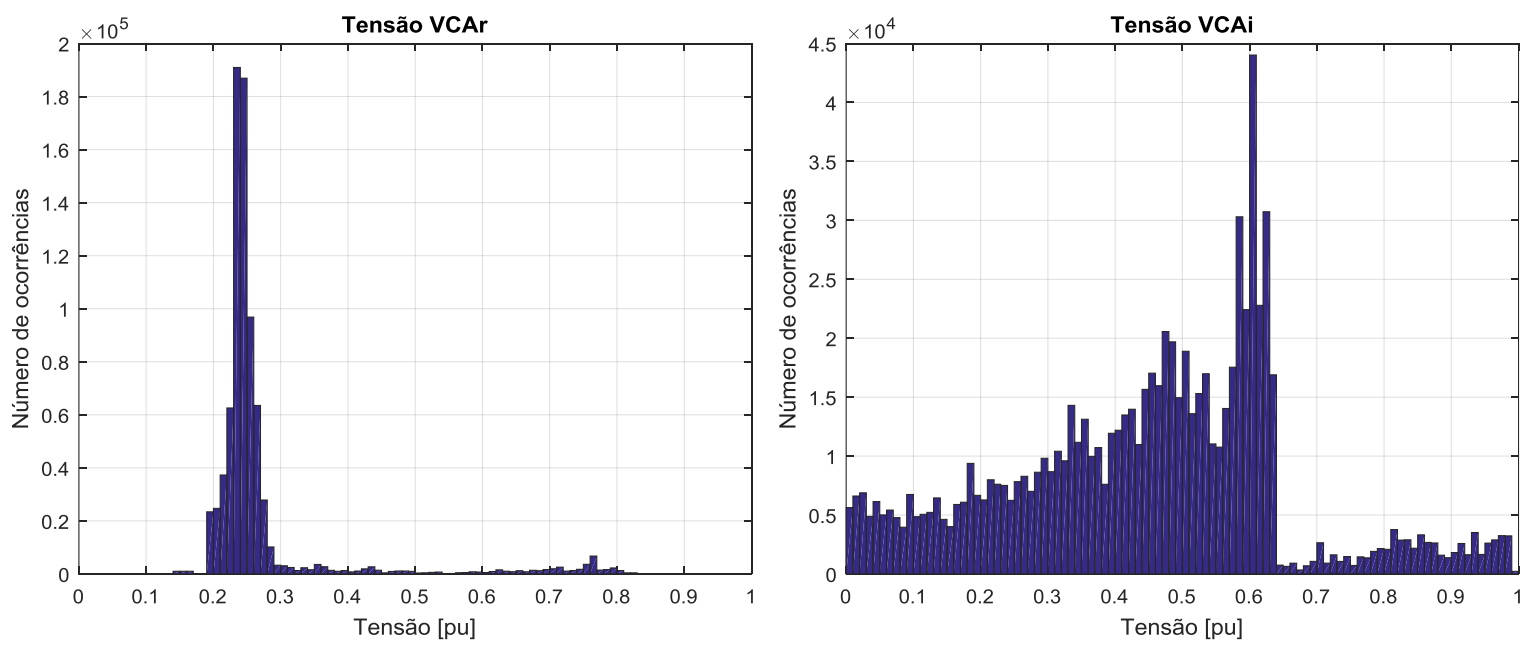

Fonte: autoria própria. 
Figura 5-16: Tensões normalizadas: (a) componente real de $\mathrm{V}_{\mathbf{0}}$; (b) componente imaginária de $\mathrm{V}_{0}$.
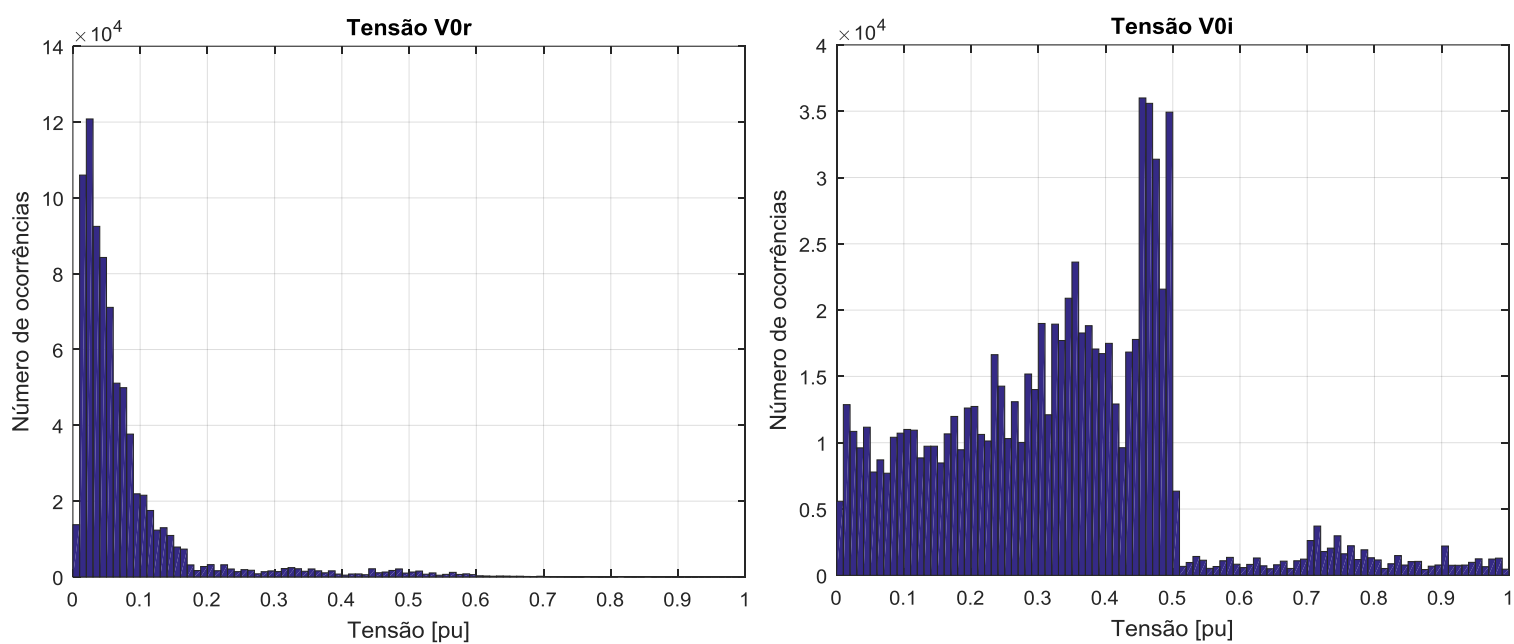

Fonte: autoria própria.

Figura 5-17: Tensões normalizadas: (a) componente real de $V_{1}$; (b) componente imaginária de $V_{1}$.
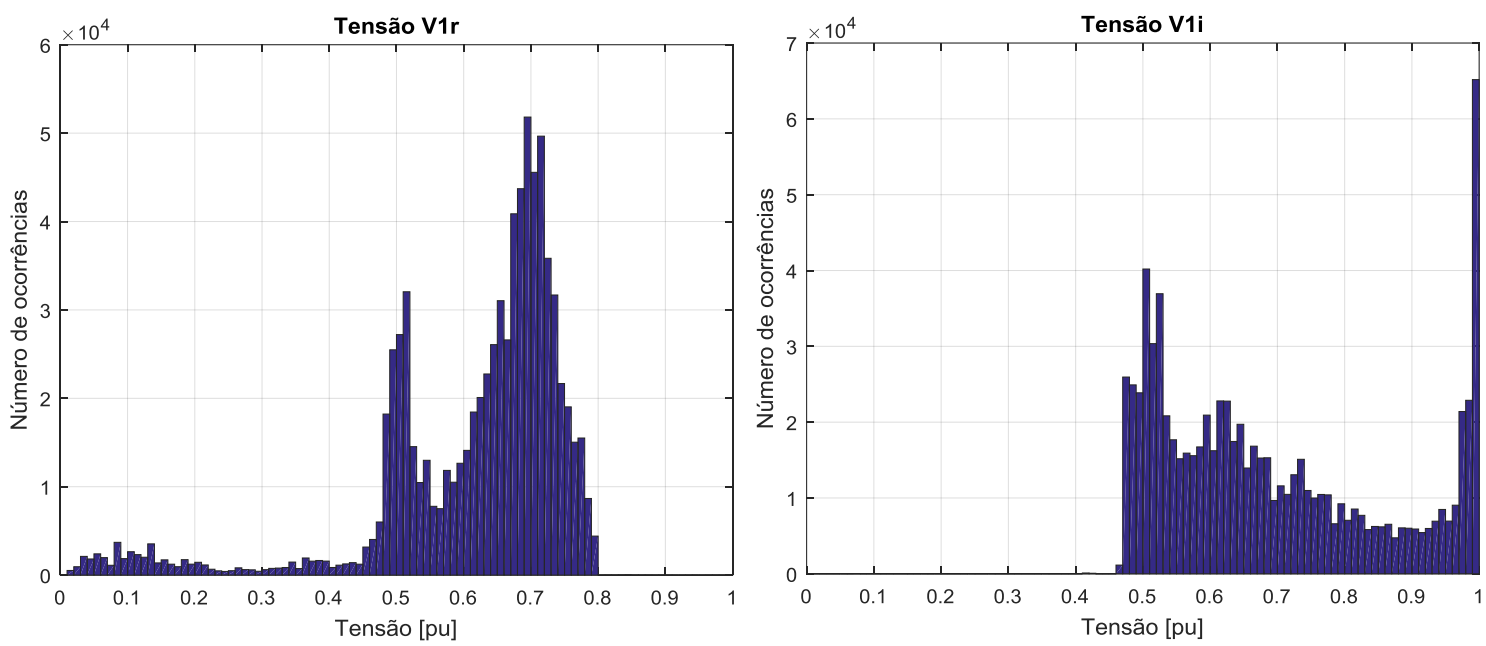

Fonte: autoria própria.

Figura 5-18: Tensões normalizadas: (a) componente real de $\mathrm{V}_{2}$; (b) componente imaginária de $\mathrm{V}_{2}$.
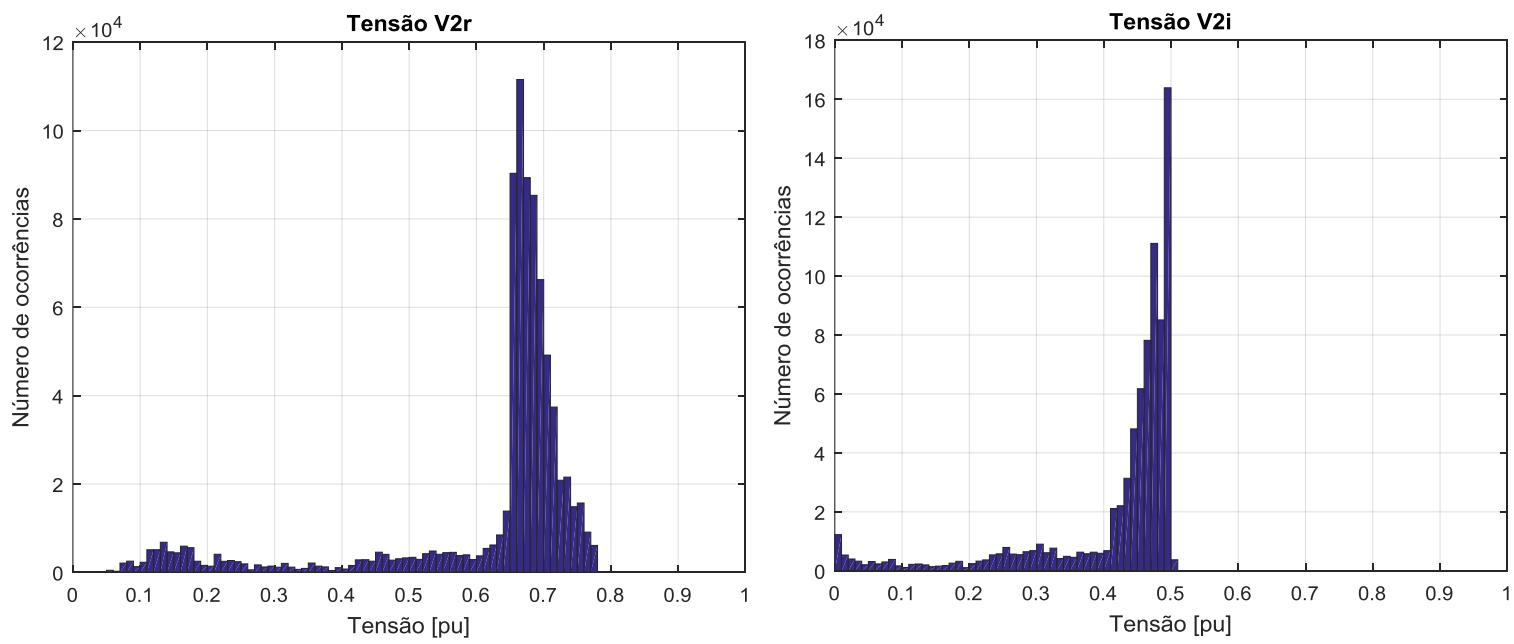

Fonte: autoria própria. 
Figura 5-19: Número de ocorrência de sensibilização ou não por correntes de falta dos medidores inteligentes.

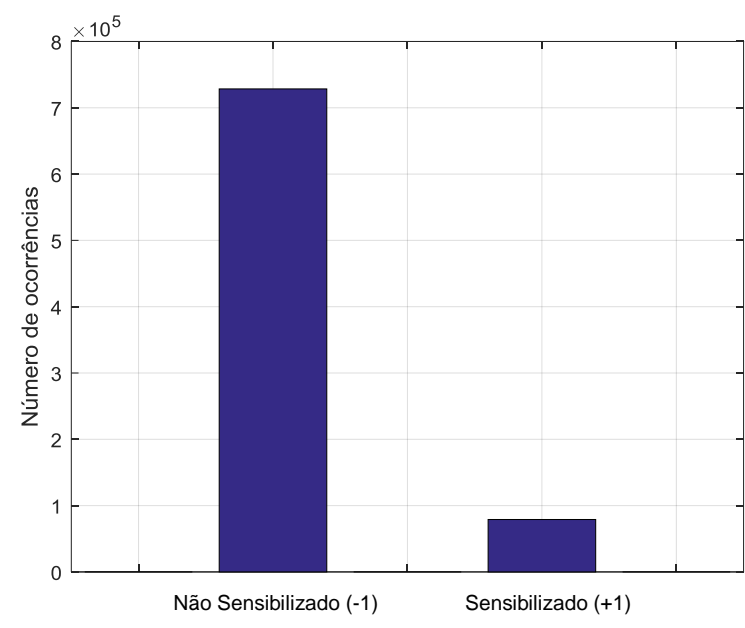

Fonte: autoria própria.

Figura 5-20: Impedâncias normalizadas: (a) sequência zero; (b) sequência positiva.
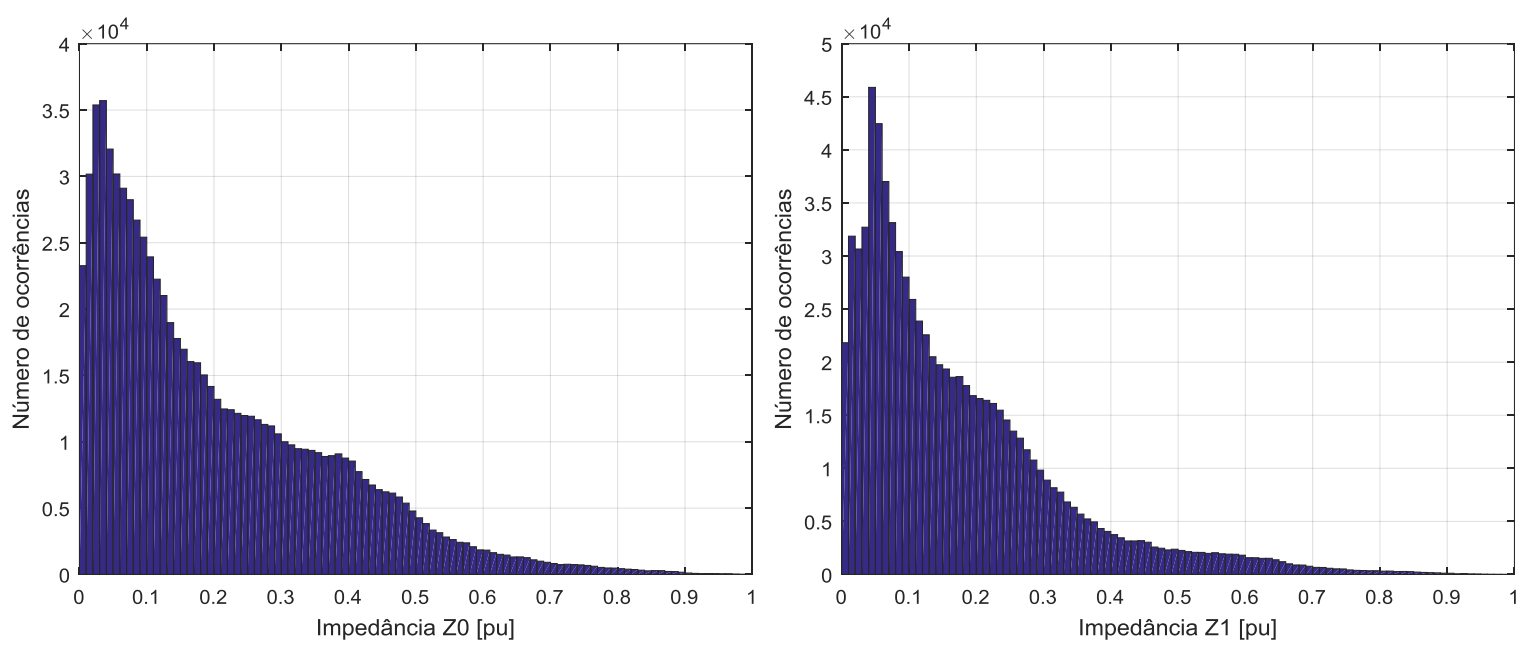

Fonte: autoria própria.

A partir do banco de dados formado conforme mencionado serão extraídas informações para treinamento e teste das Árvores de Decisão dos três sistemas inteligentes para localização de faltas segundo proposto pela metodologia desta tese. Para tanto, no próximo capítulo, serão apresentadas as etapas de desenvolvimento e definição dos sistemas inteligentes e os resultados da aplicação da presente metodologia para localização de faltas no sistema modelado computacionalmente. 


\section{3 - Considerações Parciais sobre a Metodologia Proposta para Localização de Faltas}

No decorrer do presente capítulo foi apresentada e descrita a metodologia em desenvolvimento a partir das pesquisas desta tese para localização de faltas em sistemas de distribuição que contemplem os conceitos e infraestruturas de Redes Elétricas Inteligentes (REIs). O presente método procura agregar ferramentas convencionais e inteligentes por meio da utilização de conceitos de análise de sistemas elétricos, diagnóstico dos sinais de tensão, e extração do conhecimento com aprendizado de máquina por meio da técnica de Árvores de Decisão (ADs).

A metodologia proposta baseia-se na capacidade de monitoramento, controle e operação da rede pela infraestrutura disponibilizada pelas REIs por meio dos medidores inteligentes, e na habilidade das mesmas em fornecer multimedições de tensão. Fazendo uso dos sinais de tensão aquisitados por medidores inteligentes busca-se estimar por meio de três sistemas inteligentes distintos as impedâncias de sequência zero e positiva entre os medidores e o local da falta e a indicação da sensibilização ou não destes medidores por correntes de falta. Em seguida, a partir destas estimações calculam-se as distâncias elétricas dos medidores inteligentes em relação ao ponto sob falta e define-se sua orientação em vista a sensibilização dos medidores, a fim de localizar o ponto ou região da falta.

Para tanto, os processos de estimação são tratados como problemas de classificação pelos sistemas inteligentes que fazem uso das Árvores de Decisão, uma vez que esta técnica de aprendizado de máquina possui capacidade de trabalhar com grandes quantidades de dados com baixo esforço computacional, e em virtude de a mesma prover maior agilidade e assertividade às estimações vislumbradas.

A seguir, foi apresentada a forma como fora modelado um sistema elétrico real e os resultados da aplicação de faltas Fase A à terra no mesmo para composição do banco de dados com as informações dos medidores inteligentes, o qual será utilizado para aplicação e validação da metodologia. Destaca-se que os dados gerados nesta etapa serão fundamentais para o processo de descoberta do conhecimento dos sistemas inteligentes, visando extrair as características e particularidades que influenciam o comportamento da rede elétrica frente as faltas. Por fim, com a apresentação da distribuição dos dados normalizados por número de ocorrências em relação a cada uma das 25 tensões, 2 impedâncias e a indicação de 
sensibilização dos medidores, foi possível observar a correlação entre as variáveis após ocorrência da falta, bem como a concentração do número de ocorrência dentro de determinadas faixas de valores, o que contribuirá com informações variadas para o processo de treinamento das ADs.

No próximo capítulo será trabalhada a implementação dos classificadores das Árvores de Decisão induzidas dos 3 sistemas inteligentes por meio do software WEKA, e a aplicação dos mesmos para validar a metodologia proposta, apresentando-se os resultados do processo de localização de falta para o conjunto de simulações de validação. 


\section{CAPÍTULO 6}

\section{APLICAÇÃO DA METODOLOGIA PARA LOCALIZAÇÃO DE FALTAS EM SISTEMAS DE DISTRIBUIÇÃO}

Primeiramente, serão expostos neste capítulo os procedimentos para implementação dos sistemas inteligentes da metodologia proposta para localização de falta por meio do software WEKA. São apresentadas as etapas de agrupamento e partição em classes dos dados para indução das Árvores de Decisão, e avaliadas as métricas e seleções dos parâmetros do algoritmo J48 para definição dos 3 classificadores dos sistemas inteligentes. A seguir, com a finalidade de validar a presente metodologia, são mostrados os resultados de sua aplicação para estimação das distâncias referentes as impedâncias de sequência zero e positiva, e para indicação de sensibilização dos medidores por correntes de falta. Na sequência, são expostos dois estudos de caso visando ilustrar o processo de análise das informações utilizadas pela metodologia proposta nesta tese para localização de faltas. Por fim, são apresentados os erros de distância entre o local real e o definido pelo processo de localização para os testes de validação.

\section{1 - Implementação dos Sistemas Inteligentes}

A partir do banco de dados formado com as informações obtidas pela modelagem e simulação computacional do sistema elétrico sob estudo, apresentadas na seção 5.2 do Capítulo 5, deu-se início a implementação dos três sistemas inteligentes distintos (SI-1, SI-2 e SI-3) para estimação das impedâncias de sequência zero $\left(Z_{0}\right)$, impedâncias de sequência positiva $\left(Z_{1}\right)$, e da sensibilização dos medidores inteligentes pelas correntes de falta, respectivamente. Para tanto, faz-se uso do algoritmo J48 da técnica de classificação Árvore de Decisão (AD) presente no software livre WEKA (WEKA, 2017). 
O algoritmo J48 é a implementação na linguagem Java do algoritmo C4.5 (comentado na seção 4.3 do Capítulo 4), o qual constrói um modelo de AD baseado em um conjunto de dados de treinamento para posterior classificação de outras instâncias de um conjunto de teste. Sua função de avaliação, utilizada para escolher qual atributo determinará a ramificação da árvore, baseia-se na análise da função do ganho de informação do atributo. $\mathrm{O}$ algoritmo J48 utiliza técnicas de poda para remover da AD os segmentos que possuem menor ganho de informação, inibindo a ocorrência de overfitting. Além disso, este algoritmo trabalha com atributos categóricos e contínuos, trata valores desconhecidos de maneira diferenciada e não os utiliza nos cálculos do ganho de informação e entropia, gerando árvores mais precisas e menos complexas.

A fim de evitar o overfitting do modelo de Árvore de Decisão a ser criado optouse pela validação cruzada (cross-validation) como método de treinamento e teste, pois por meio do mesmo cada um dos exemplos é utilizado tanto para treinamento quanto para teste. Por este método os exemplos são aleatoriamente divididos em $k$ partições mutuamente exclusivas de tamanho aproximadamente igual. Uma das partições é reservada para teste, enquanto as $k-1$ são empregadas no processo de treinamento. Este procedimento é executado $k$ vezes, em que em cada vez uma partição diferente é utilizada para teste. A taxa de erro após o termino deste processo é calculada como a média das taxas de erro obtidas para cada uma das k partições testadas.

$\mathrm{Na}$ literatura correlata, testes extensivos mostram que 10-fold cross-validation, ou seja, assumir $\mathrm{k}=10$, possibilita testes bastante eficientes para a validação cruzada, conforme exposto em (KOHAVI, 1995; DELEN; WALKER; KADAM, 2005; WITTEN; FRANK, 2005), e dessa forma este será o valor padrão adotado no desenvolvimento da $\mathrm{AD}$ desta pesquisa.

Para indução da AD no software WEKA pelo algoritmo J48 é necessário deixar o comando "unpruned" marcado como "False" para que seja realizada a poda da árvore pelo algoritmo, e o comando "subtreeRaising" deve ser "True" para que ocorra poda em cada sub-árvore criada. Deve-se tomar especial atenção com os parâmetros de entrada, "confidenceFactor" e "minNumObj”, os quais interferem diretamente nas regras criadas no processo de indução da $\mathrm{AD}$, e, por conseguinte, no tempo de criação das árvores e nos resultados de sua aplicação para classificação.

O parâmetro "confidenceFactor" representa o fator de confiança de uma regra na predição e define a precisão de cada regra gerada, já “minNumObj” se refere ao número mínimo de instância por classes que irá dividir o conjunto de entrada, ou seja, número 
mínimo de instâncias para uma regra da árvore existir. Tendo em vista a influência desses parâmetros no erro de classificação da $\mathrm{AD}$, os mesmos serão avaliados no processo de definição das árvores geradas.

Posto isto, os dados foram particionados em classes e agrupados para indução das Árvores de Decisão dos três sistemas inteligentes da metodologia proposta. Esta partição dos dados foi avaliada em relação à taxa de acerto da classificação das árvores criadas, quantidade de dados utilizada, e métricas dos classificadores, conforme apresentado a seguir.

\subsection{1 - Definição dos Parâmetros do Algoritmo J48 para implementação das Árvores de Decisão}

Trabalhando com todo o banco de dados, composto pelos 25 atributos de entrada (tensões) e as impedâncias de sequência zero e positiva como saídas, procurou-se definir a melhor relação entre o número de divisões de classes, o intervalo e particionamento das impedâncias, e a quantidade de dados utilizada para treinamento dos classificadores. Destaca-se que este procedimento busca descobrir os dados com maior conhecimento embutido, tem impacto positivo na redução do banco de dados exigindo menor capacidade de armazenamento de dados e esforços computacionais para desenvolvimento dos classificadores, e possibilita induzir árvores com menos dados e maior capacidade de generalização.

Para que isto fosse feito foi proposta a divisão das impedâncias de sequência zero e positiva em 4 conjuntos de classes, tomando-se o cuidado de compor cada classe sempre com mesmo número de dados para cada um dos 4 conjuntos, os quais foram definidos da seguinte forma:

- Conjunto 1 - 3 classes

- Conjunto 2 - 5 classes;

- Conjunto 3 - 7 classes;

- Conjunto 4 - 10 classes.

Ademais, as impedâncias foram tomadas por intervalos de valores em agrupamentos distintos a partir da sua faixa de variação. Analisando a impedância de 
sequência zero $\left(Z_{0}\right)$ observou-se que a mesma possuía valores entre $0 \quad \Omega$ e aproximadamente $60 \Omega$. Desse modo, dividiu-se a mesma em 7 agrupamentos como segue:

- Z-2: impedâncias entre $0 \Omega$ e $2 \Omega$;

- Z-5: impedâncias entre $0 \Omega$ e $5 \Omega$;

- Z-10: impedâncias entre $0 \Omega$ e $10 \Omega$;

- Z-20: impedâncias entre $0 \Omega$ e $20 \Omega$;

- Z-30: impedâncias entre $0 \Omega$ e $30 \Omega$;

- Z-45: impedâncias entre $0 \Omega$ e $45 \Omega$;

- Z-60: impedâncias entre $0 \Omega$ e $60 \Omega$.

Para a impedância de sequência positiva $\left(Z_{1}\right)$, como a mesma possuía valores entre $0 \Omega$ e aproximadamente $27 \Omega$, foi feita sua divisão em 7 agrupamentos da seguinte forma:

- Z-0,9: impedâncias entre $0 \Omega$ e $0,9 \Omega$;

- Z-2,25: impedâncias entre $0 \Omega$ e 2,25 $\Omega$;

- Z-4,5: impedâncias entre $0 \Omega$ e 4,5 $\Omega$;

- Z-9: impedâncias entre $0 \Omega$ e $9 \Omega$;

- Z-13,5: impedâncias entre $0 \Omega$ e 13,5 $\Omega$;

- Z-21: impedâncias entre $0 \Omega$ e $21 \Omega$;

- Z-27: impedâncias entre $0 \Omega$ e $27 \Omega$.

Desse modo, por meio da separação em classes e do agrupamento em intervalos de valores, os classificadores das impedâncias $Z_{0}$ e $Z_{1}$ foram avaliados em 28 situações diferentes, uma vez que para cada um dos 7 agrupamentos de impedâncias aplicam-se os 4 conjuntos de divisões em classes. Ressalta-se, que o conjunto de dados relativo a sensibilização dos medidores a passagem de corrente de falta não fora dividido desta forma, pois o mesmo já possuía suas duas classes de saída pré-definidas, uma referente a sua sensibilização e outra a não sensibilização.

Para a avaliação dos classificadores a partir destes procedimentos, a princípio, foram utilizados os valores padrão para os parâmetros "confidenceFactor" e "minNumObj" do algoritmo J48 do software WEKA, os quais são 0,25 e 0,2, respectivamente. 
Salienta-se que o processamento dos dados e as simulações desta pesquisa no software WEKA foram realizados em um desktop com processador Intel Core i5 3330 de 3 GHz, 8 GB de memória RAM e sistema operacional de 64 bits.

As Figuras 6.1 e 6.2 ilustram, por meio das taxas de acerto, o desempenho dos classificadores para as impedâncias $Z_{0}$ e $Z_{1}$ das Árvores de Decisão induzidas para as 28 situações avaliadas, e as Tabelas 6.1 e 6.2 mostram em detalhes estas taxas. Além disso, as Figuras 6.3 e 6.4 apresentam percentualmente a quantidade de dados utilizada para treinamento e teste em cada uma das 28 situações avaliadas em relação ao total de dados de impedância do banco de dados.

Por meio das Figuras 6.1 e 6.2 e das Tabelas 6.1 e 6.2 nota-se que os acertos dos classificadores para ambas as impedâncias crescem até uma certa faixa de valores de impedância, a partir do qual tendem a se estabilizar com pequenos decréscimos, sendo mais acentuado o decréscimo do acerto de classificação para a impedância $\mathrm{Z}_{1}$. Constatase ainda que a medida que se divide os dados em um número de classes maior, o acerto diminui para ambos os casos.

Situação semelhante é observada em relação à quantidade de dados utilizados, conforme Figuras 6.3 e 6.4, em que a medida que se utilizam dados em agrupamentos com faixas maiores de valores de impedância maior é a quantidade de dados utilizada, porém ao atingir certo ponto o aumento da faixa de valores promove uma queda brusca da quantidade de dados selecionados.

Figura 6-1: Taxa de acerto dos classificadores da impedância $Z_{0}$.

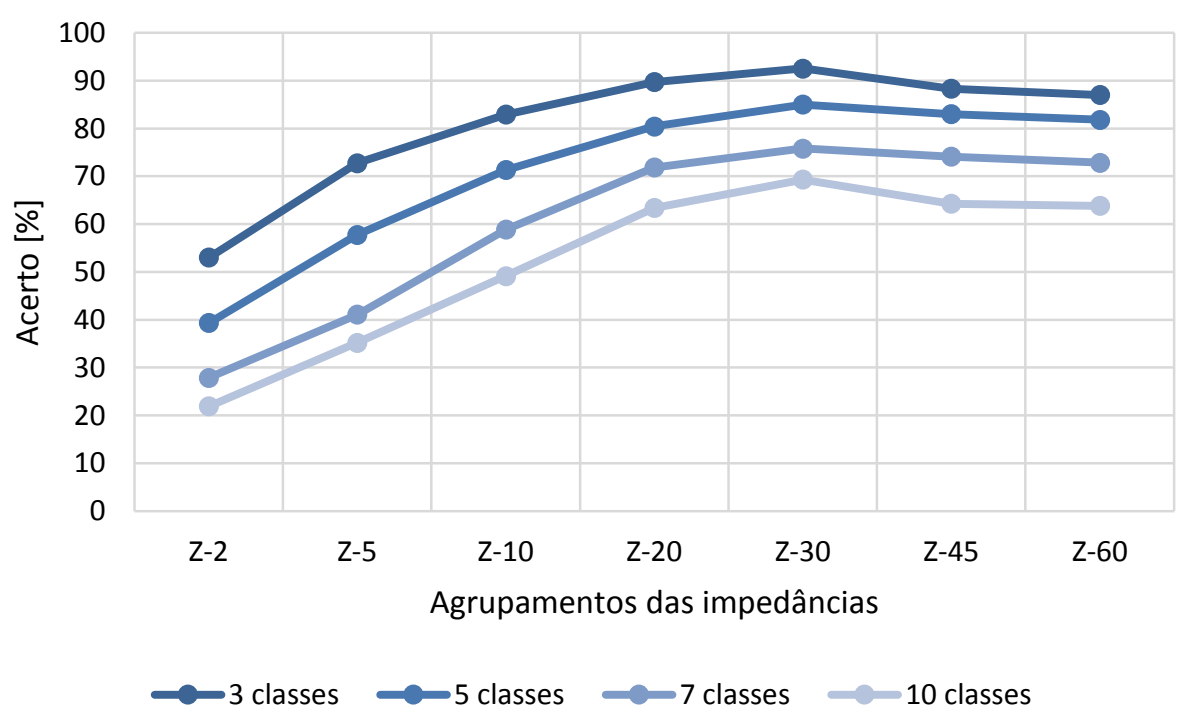

Fonte: autoria própria. 
Figura 6-2: Taxa de acerto dos classificadores da impedância $Z_{1}$.

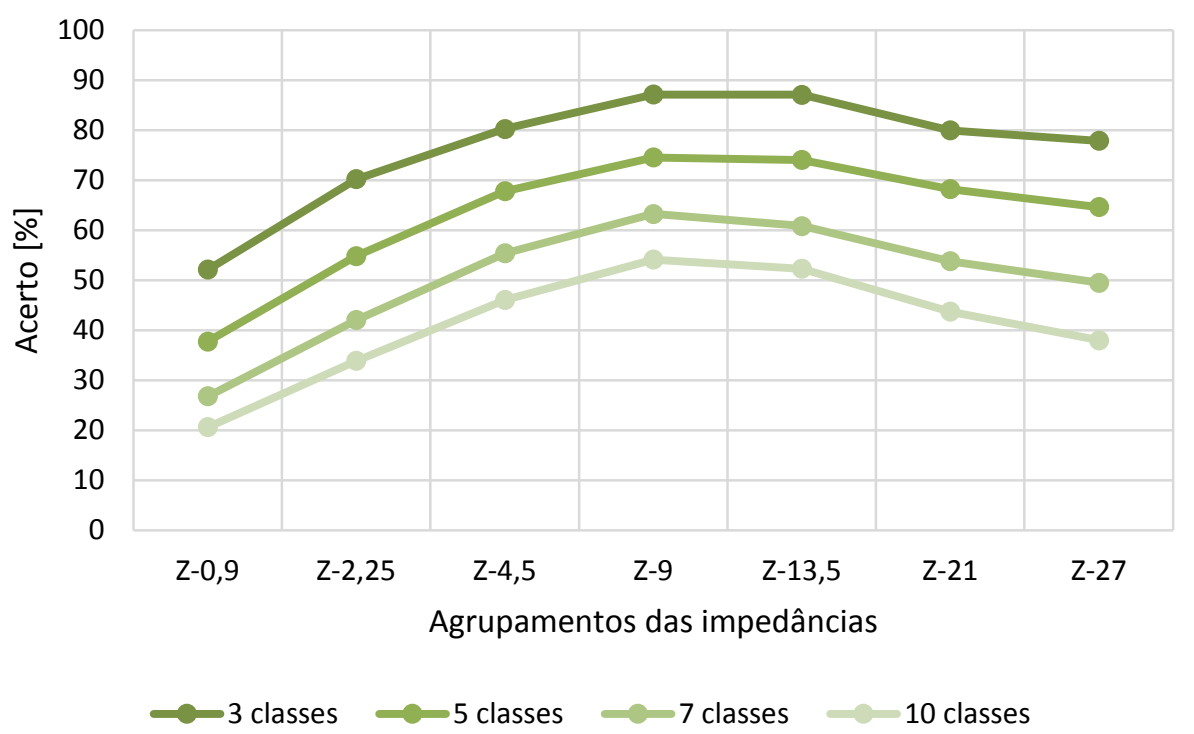

Fonte: autoria própria.

Tabela 6-1: Taxa de acerto dos classificadores para impedância $Z_{0}$.

\begin{tabular}{l|c|c|c|c|c|c|c}
\cline { 2 - 7 } & $\mathbf{Z - 2}$ & $\mathbf{Z - 5}$ & $\mathbf{Z - 1 0}$ & $\mathbf{Z - 2 0}$ & $\mathbf{Z - 3 0}$ & $\mathbf{Z - 4 5}$ & $\mathbf{Z - 6 0}$ \\
\hline $\mathbf{3}$ classes & $53,01 \%$ & $72,74 \%$ & $82,91 \%$ & $89,68 \%$ & $92,52 \%$ & $88,3 \% 1$ & $87,01 \%$ \\
\hline $\mathbf{5}$ classes & $39,32 \%$ & $57,76 \%$ & $71,31 \%$ & $80,41 \%$ & $84,98 \%$ & $82,97 \%$ & $81,82 \%$ \\
\hline $\mathbf{7}$ classes & $27,90 \%$ & $41,09 \%$ & $58,87 \%$ & $71,85 \%$ & $75,81 \%$ & $74,08 \%$ & $72,83 \%$ \\
\hline $\mathbf{1 0}$ classes & $21,93 \%$ & $35,19 \%$ & $49,13 \%$ & $63,37 \%$ & $69,30 \%$ & $64,26 \%$ & $63,84 \%$ \\
\hline
\end{tabular}

Fonte: autoria própria.

Tabela 6-2: Taxa de acerto dos classificadores para impedância $Z_{1}$.

\begin{tabular}{c|c|c|c|c|c|c|c}
\cline { 2 - 7 } & Z-0,9 & Z-2,25 & Z-4,5 & Z-9 & Z-13,5 & Z-21 & Z-27 \\
\hline 3 classes & $52,14 \%$ & $70,24 \%$ & $80,25 \%$ & $87,13 \%$ & $87,09 \%$ & $79,99 \%$ & $77,90 \%$ \\
\hline $\mathbf{5}$ classes & $37,77 \%$ & $54,86 \%$ & $67,80 \%$ & $74,57 \%$ & $74,05 \%$ & $68,22 \%$ & $64,65 \%$ \\
\hline $\mathbf{7}$ classes & $26,85 \%$ & $42,09 \%$ & $55,41 \%$ & $63,27 \%$ & $60,86 \%$ & $53,81 \%$ & $49,51 \%$ \\
\hline $\mathbf{1 0}$ classes & $20,67 \%$ & $33,91 \%$ & $46,06 \%$ & $54,13 \%$ & $52,32 \%$ & $43,75 \%$ & $38,04 \%$ \\
\hline
\end{tabular}

Fonte: autoria própria.

Relacionando as Figuras 6.1 e 6.2 com as Figuras 6.3 e 6.4, evidencia-se a relação entre quantidade de dados utilizados e acertos, em que a medida que se utilizam mais dados maior é a taxa de acerto. No entanto, novamente, os acertos crescem até certo ponto, a partir do qual a utilização de um conjunto de dados maior tende a reduzir a taxa de acerto dos classificadores para ambas as impedâncias. 
Figura 6-3: Quantidade de dados utilizada pelos classificadores da impedância $Z_{0}$.

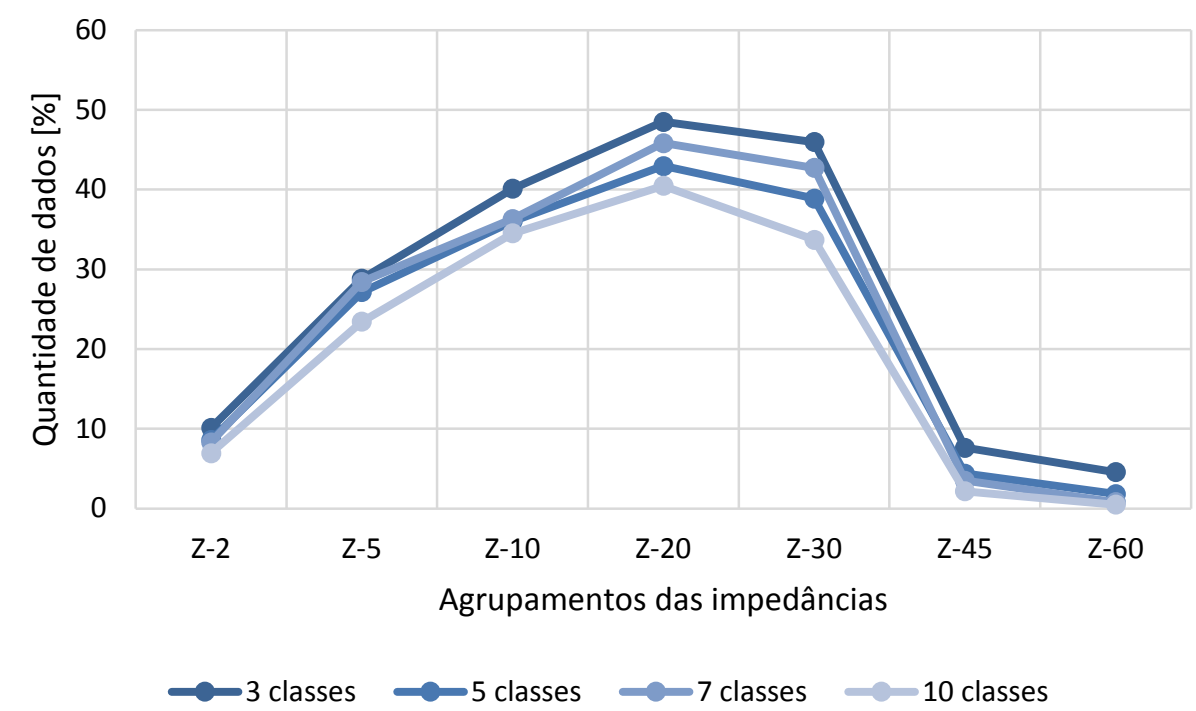

Fonte: autoria própria.

Figura 6-4: Quantidade de dados utilizada pelos classificadores da impedância $Z_{1}$.

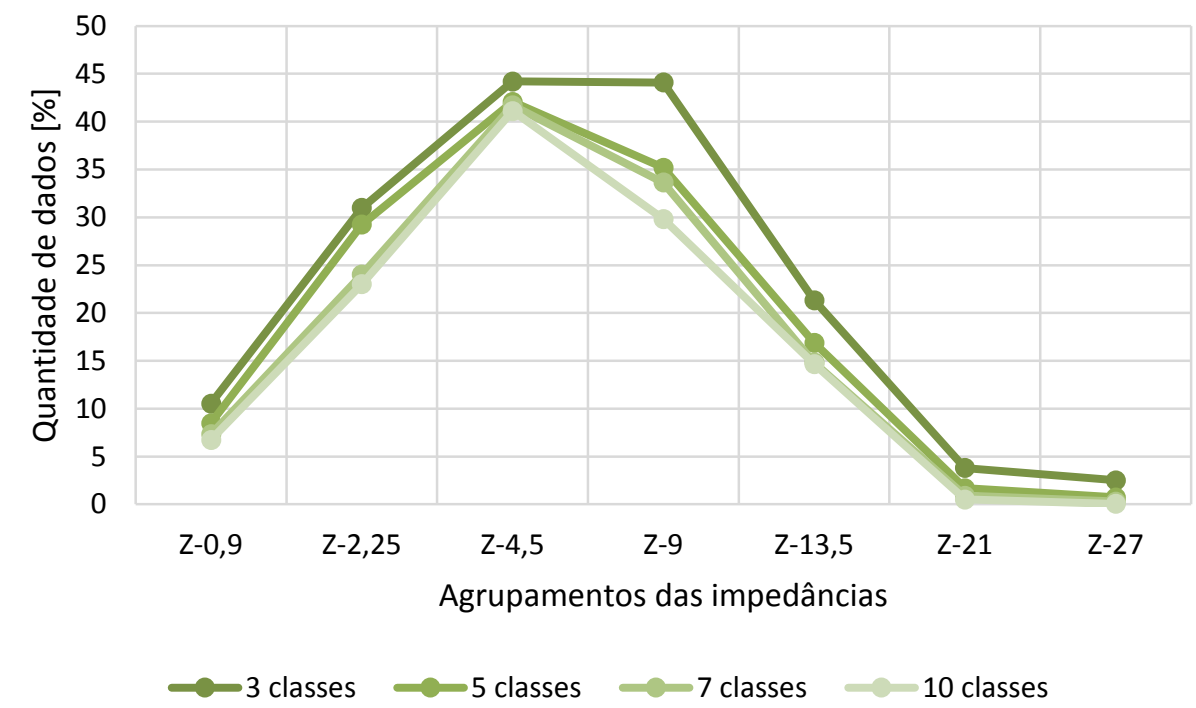

Fonte: autoria própria.

Neste contexto, ponderando os resultados apresentados nas Figuras 6.1 e 6.2 e nas Tabelas 6.1 e 6.2 o melhor classificador para impedância $Z_{0}$ é o que utiliza os dados referentes às impedâncias do intervalo entre $0 \Omega$ e $30 \Omega$ (Z-30) divididas em 3 classes, e para a impedância $Z_{1}$ é o que utiliza às impedâncias do intervalo entre $0 \Omega$ e $9 \Omega$ (Z-9) divididas também em 3 classes.

Ressalta-se que as baixas taxas de acerto observadas decorrem de duas situações principais, a dificuldade de generalização dos classificadores frente ao conjunto de dados 
apresentados para treinamento e teste e o baixo aprendizado no processo de indução das ADs.

Isto ocorre em virtude da dificuldade de generalização dos classificadores ao serem induzidos por intervalos de variação de valores de impedâncias extremos, um muito pequeno e outro muito amplo. Nestes casos, depara-se com condições em que há pouquíssimos medidores tanto muito próximos quanto muito longes em relação ao número total de possibilidades do local de falta. Além disso, quando se tem dados em uma faixa muito pequena de valores ou muito grande a complexidade de extração de conhecimento e reconhecimento de padrões pelos classificadores aumenta significativamente, implicando em sistemas menos assertivos.

Outrossim, o processo de divisão igualitária do número de dados por classe também influencia diretamente no acerto, pois a medida que se aumenta o número de classes necessita-se particionar mais os dados, e com o número maior de partições aumenta a probabilidade de haver menos valores inclusos dentro de um agrupamento menor. Desse modo, o processo de indução dos classificadores passa a utilizar menos dados para treinamento prejudicando o processo de aprendizado das ADs, e consequentemente cria árvores menos robustas e com menor capacidade de generalização dos resultados.

Além das taxas de acerto e quantidade de dados utilizada, conforme mencionado na seção 4.3.3 do Capítulo 4 o software WEKA fornece métricas importantes que contribuem para a análise do comportamento do processo de indução das ADs e dos resultados de seus classificadores, tais como: tamanho (número de nós) e tempo de construção da árvore; Estatística Kappa; Erro Absoluto Médio; Raiz do Erro Médio Quadrático; Erro Relativo Absoluto; e Raiz do Erro Relativo Quadrático.

Por meio das Figuras 6.5 e 6.6 e Figuras 6.7 e 6.8 observa-se a relação direta entre o tamanho das Árvores de Decisão induzidas e o tempo de construção das mesmas para as impedâncias $Z_{0}$ e $Z_{1}$, em que quanto maior a árvore, ou maior número de nós internos e nós folhas que a compõe, maior o tempo para constituição da mesma.

Traçando um paralelo entre a taxa de acertos e o tamanho das árvores, por meio das Figuras 6.1 e 6.2 e Figuras 6.5 e 6.7, nota-se a relação direta entre os mesmos, pois a variação dos acertos segue caminho semelhante a variação crescente e decrescente do tamanho das árvores para cada um dos conjuntos de classes e agrupamentos avaliados individualmente. 
Todavia, analisando esta relação entre os conjuntos de classes, observa-se uma variação inversa, pois as classes de maior acerto são as que possuem árvores menores, como ocorre com os classificadores de 3 classes com Z-30 e Z-9 para as impedâncias $Z_{0}$ e $Z_{1}$, respectivamente. Este fato se justifica, pois os classificadores com divisão em menor número de classes geram menos regras no processo de indução das árvores, logo seu tamanho e tempo de construção são menores.

Figura 6-5: Tamanho das ADs induzidas por classes e agrupamentos das impedâncias para $\mathrm{Z}_{0}$.

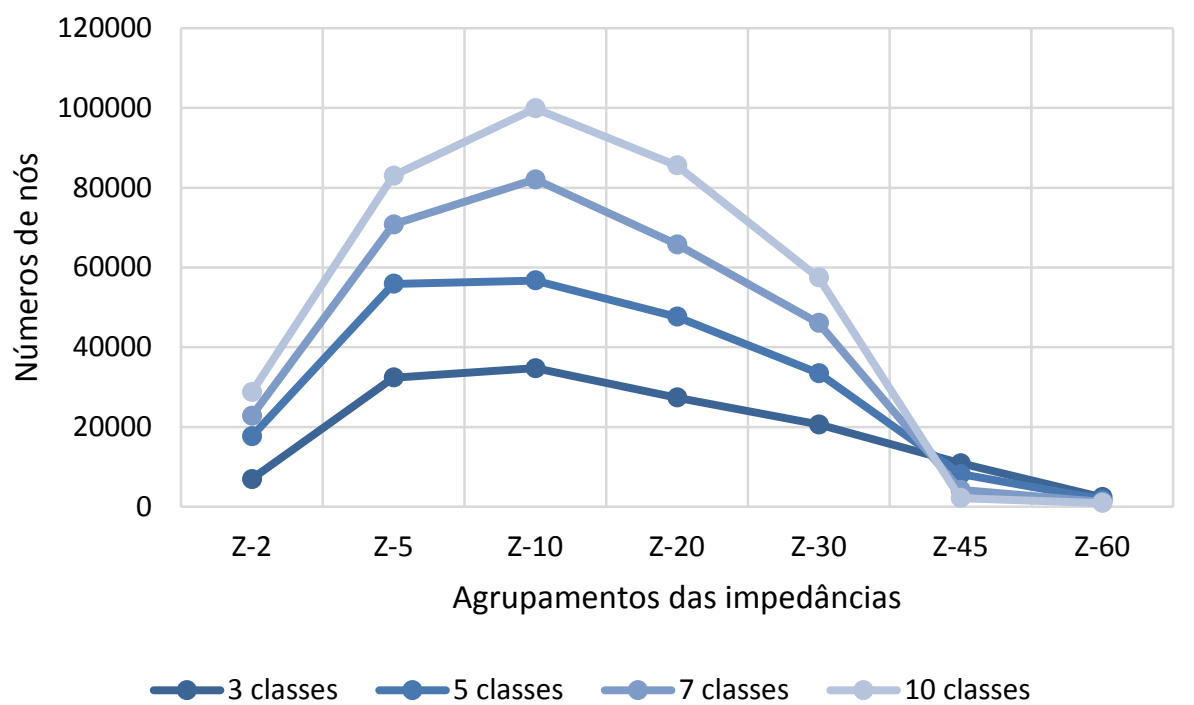

Fonte: autoria própria.

Figura 6-6: Tempo de construção das ADs induzidas por classes e agrupamentos das impedâncias para $Z_{0}$.

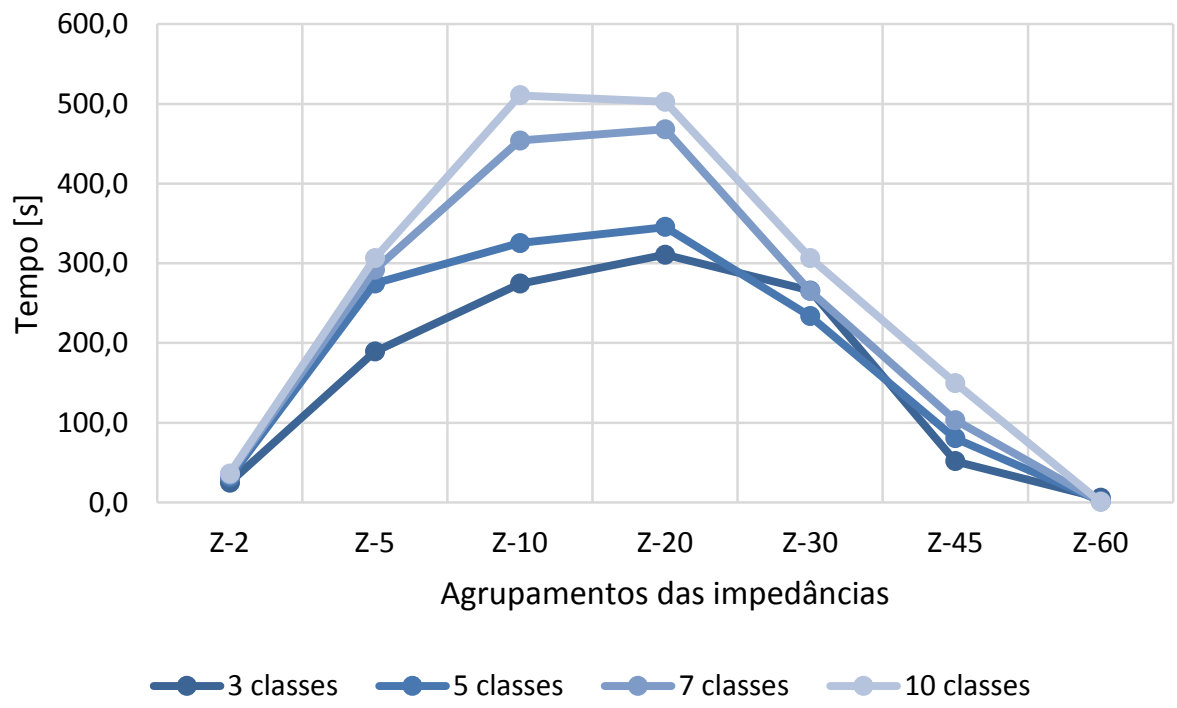

Fonte: autoria própria. 
Figura 6-7: Tamanho das ADs induzidas por classes e agrupamentos das impedâncias para $\mathrm{Z}_{1}$.

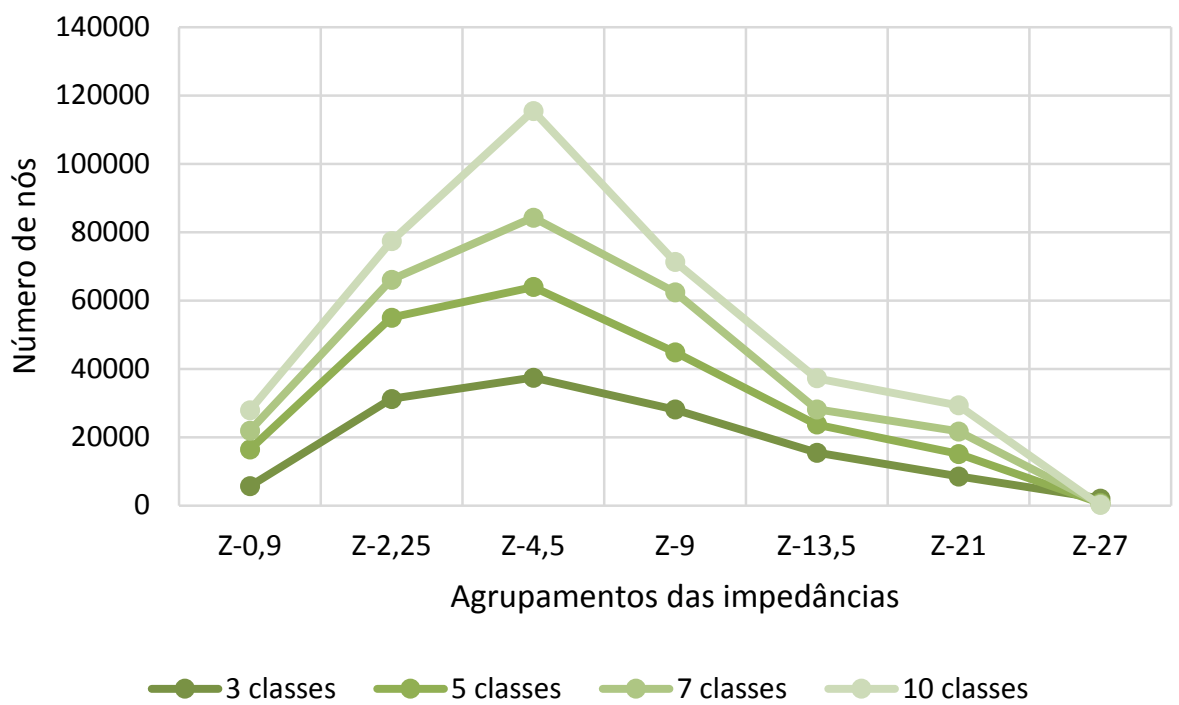

Fonte: autoria própria.

Figura 6-8: Tempo de construção das ADs induzidas por classes e agrupamentos das impedâncias para $Z_{1}$.

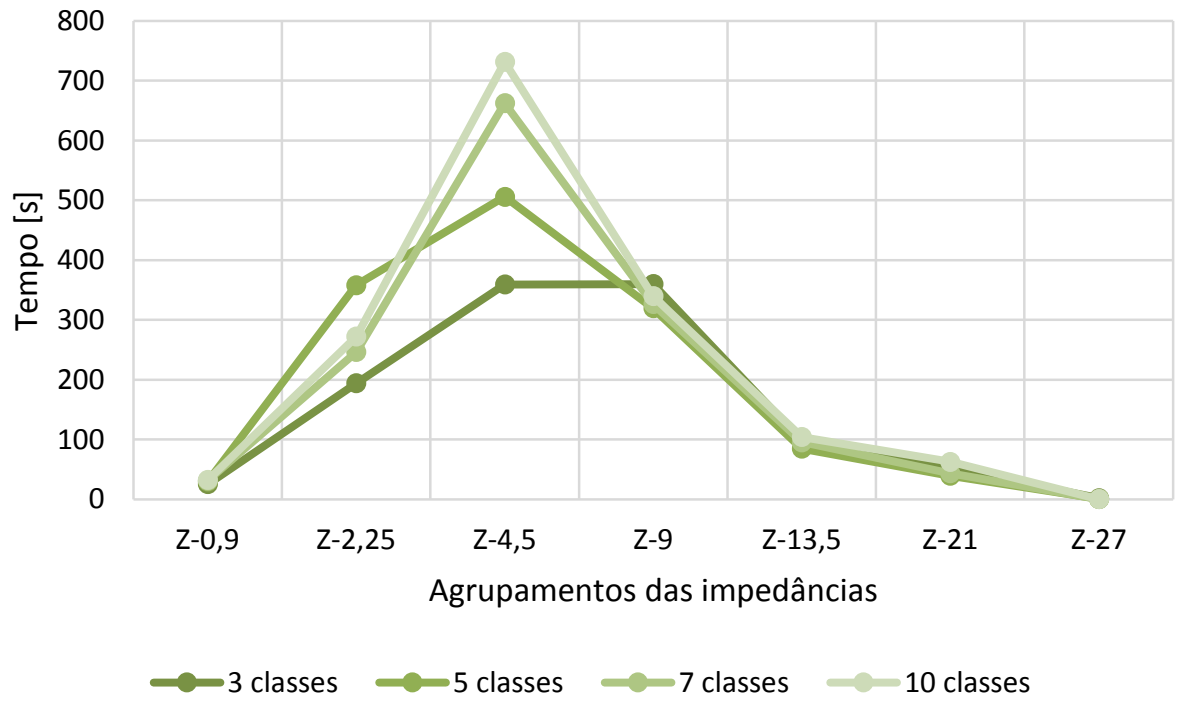

Fonte: autoria própria.

Nas Figuras 6.9 e 6.10 os índices da Estatística Kappa indicam aumento da concordância entre os classificadores dos modelos induzidos e os do conjunto de treinamento à medida que é aumentada a faixa de valores de impedâncias utilizada para indução das ADs. Destaca-se que para os classificadores de maior acerto (3 classes com Z-30 e Z-9), a Estatística Kappa indica concordância quase perfeita entre os 
classificadores dos modelos induzidos e os do conjunto de treinamento, corroborando com o maior acerto verificado para os mesmos.

Figura 6-9: Índices da Estatística Kappa para os classificadores da impedância Zo.

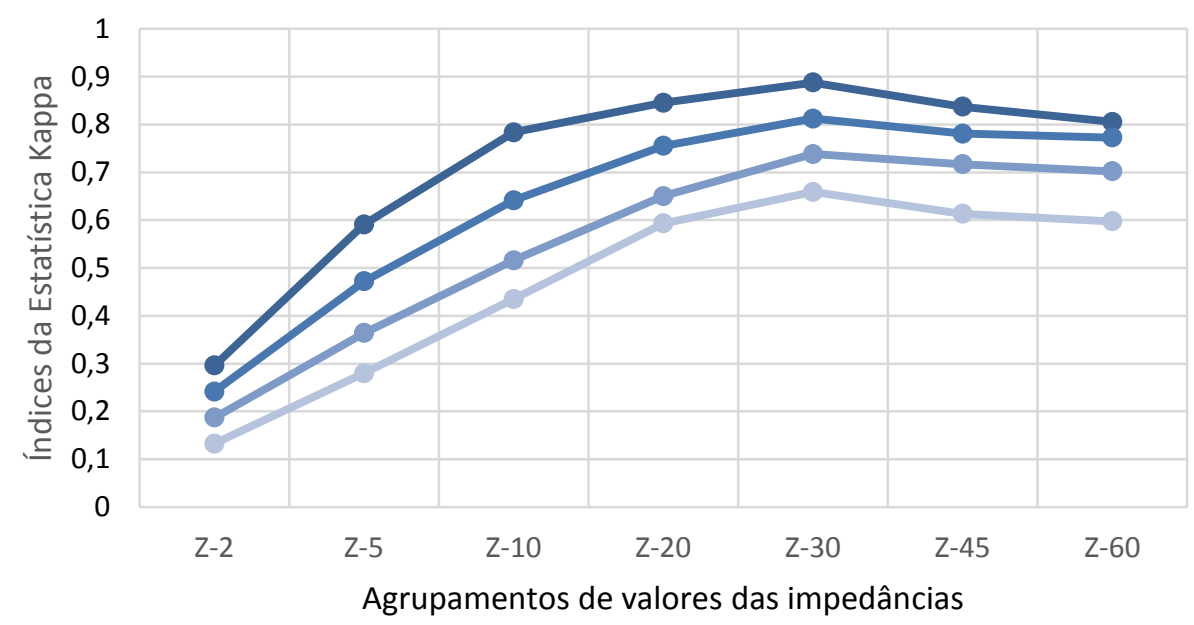

-3 classes $\quad-5$ classes $\quad-7$ classes $\quad-10$ classes

Fonte: autoria própria.

Figura 6-10: Índices da Estatística Kappa para os classificadores da impedância $Z_{1}$.

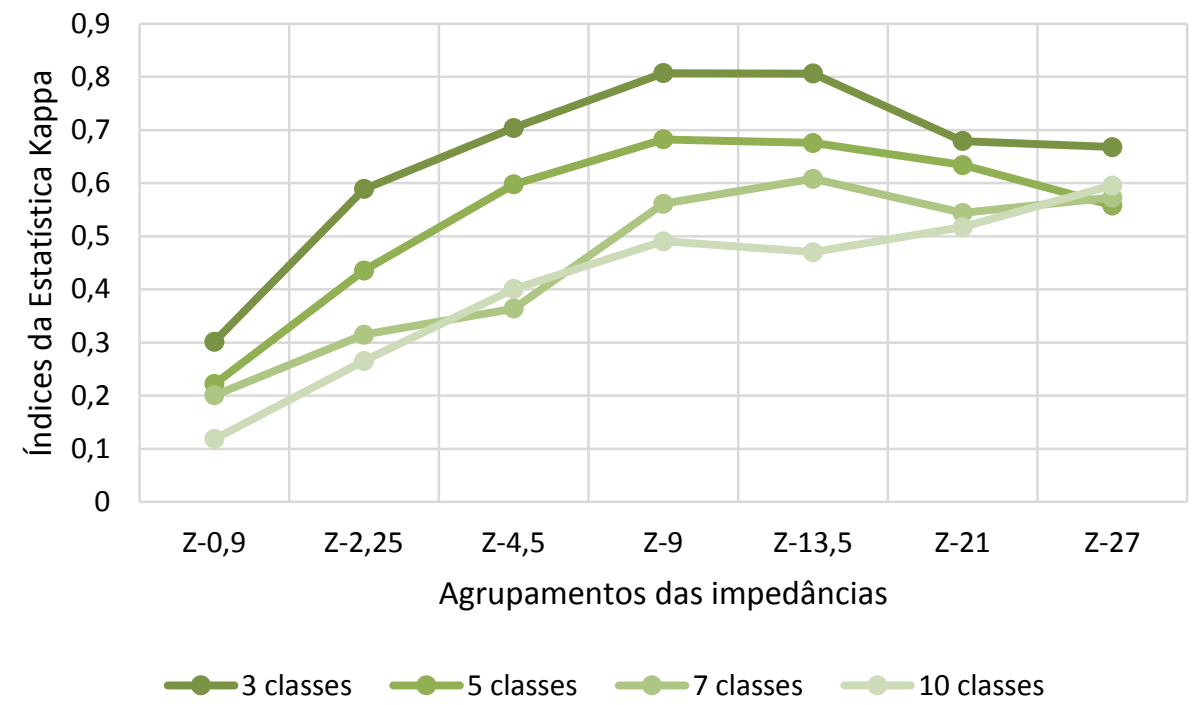

Fonte: autoria própria.

A fim de avaliar a capacidade de classificação das Árvores de Decisão induzidas e a acurácia das classificações por elas realizadas, o WEKA também disponibiliza as taxas de erro absoluto médio e absoluto relativo, para evidenciar a diferença entre a classificação obtida e a classificação correta esperada, e a relação entre o erro absoluto e 
a classificação fornecida pelo classificador. Neste contexto, por meio das Figuras 6.11 a 6.14 consta-se que os classificadores de 3 classes com Z-30 e Z-9 possuem baixos erros absoluto e relativo, mostrando a acurácia de suas classificações.

Figura 6-11: Taxa de erro absoluto médio para os classificadores da impedância $Z_{0}$.

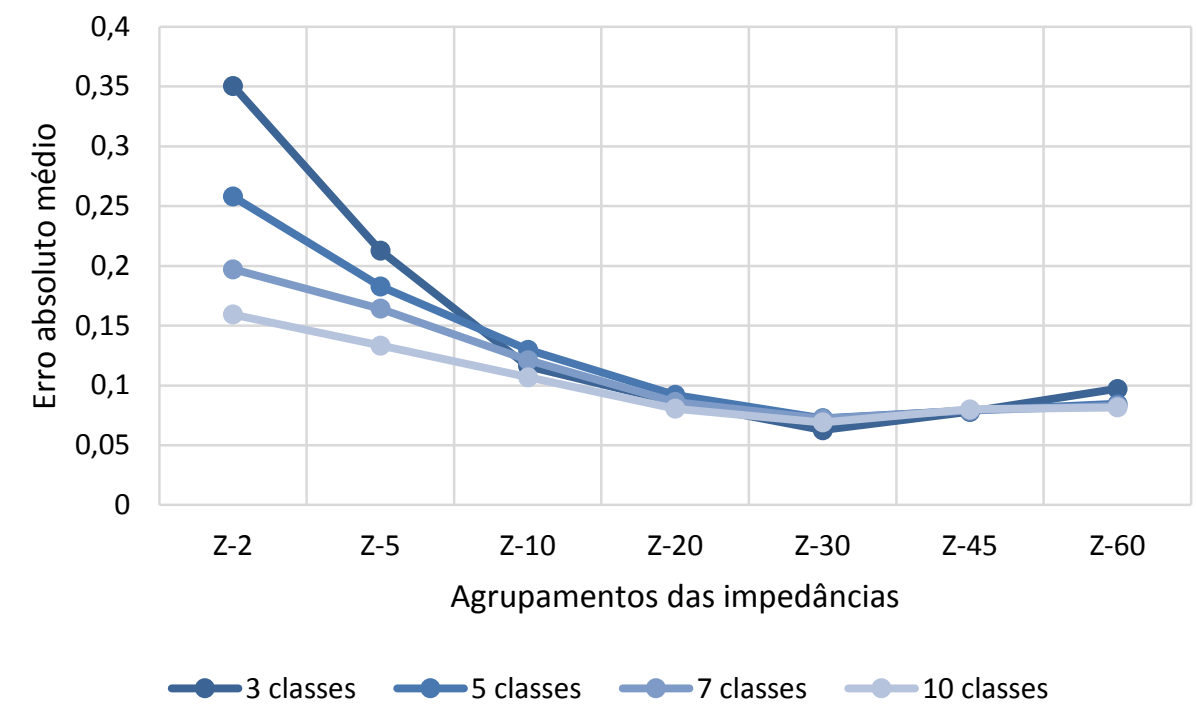

Fonte: autoria própria.

Figura 6-12: Taxa de erro absoluto médio para os classificadores da impedância $Z_{1}$.

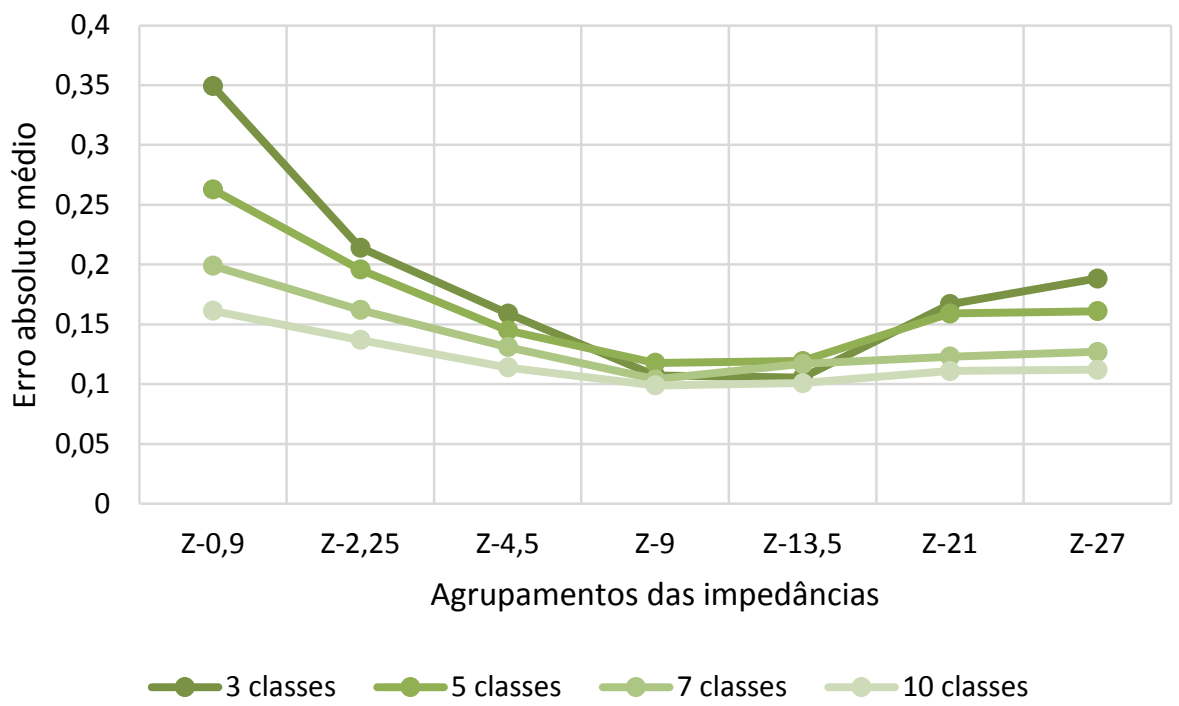

Fonte: autoria própria. 
Figura 6-13: Taxa de erro relativo absoluto para os classificadores da impedância $Z_{0}$.

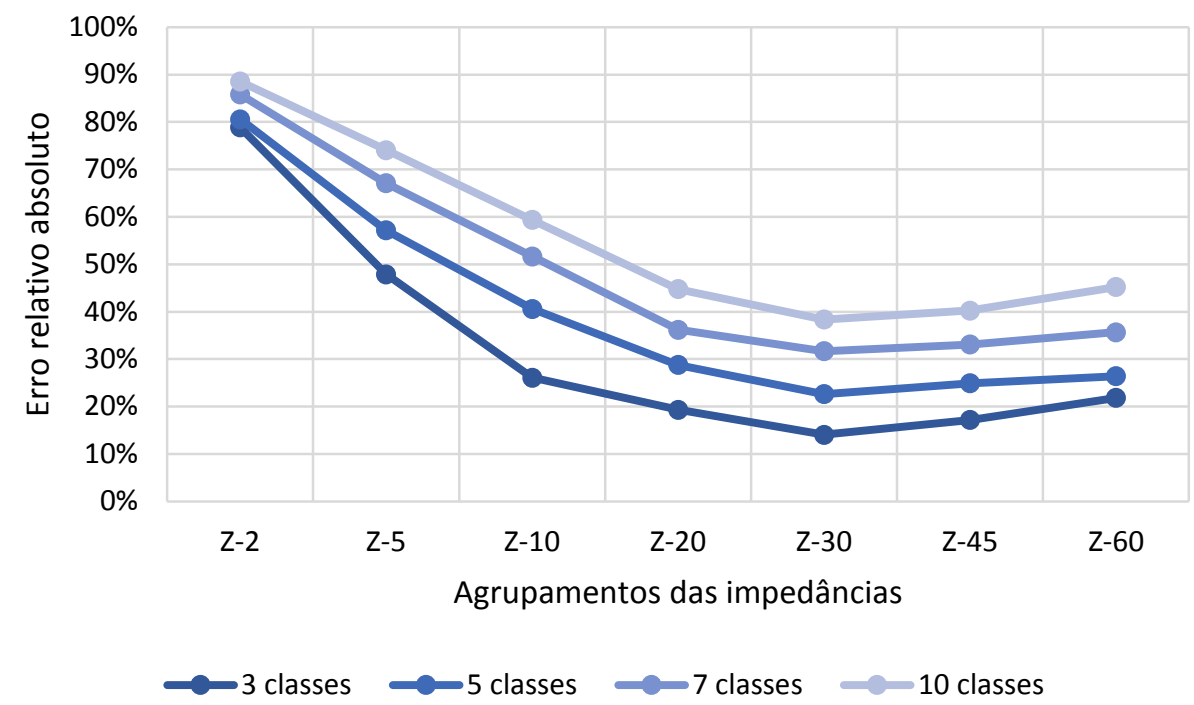

Fonte: autoria própria.

Figura 6-14: Taxa de erro relativo absoluto para os classificadores da impedância $Z_{1}$.

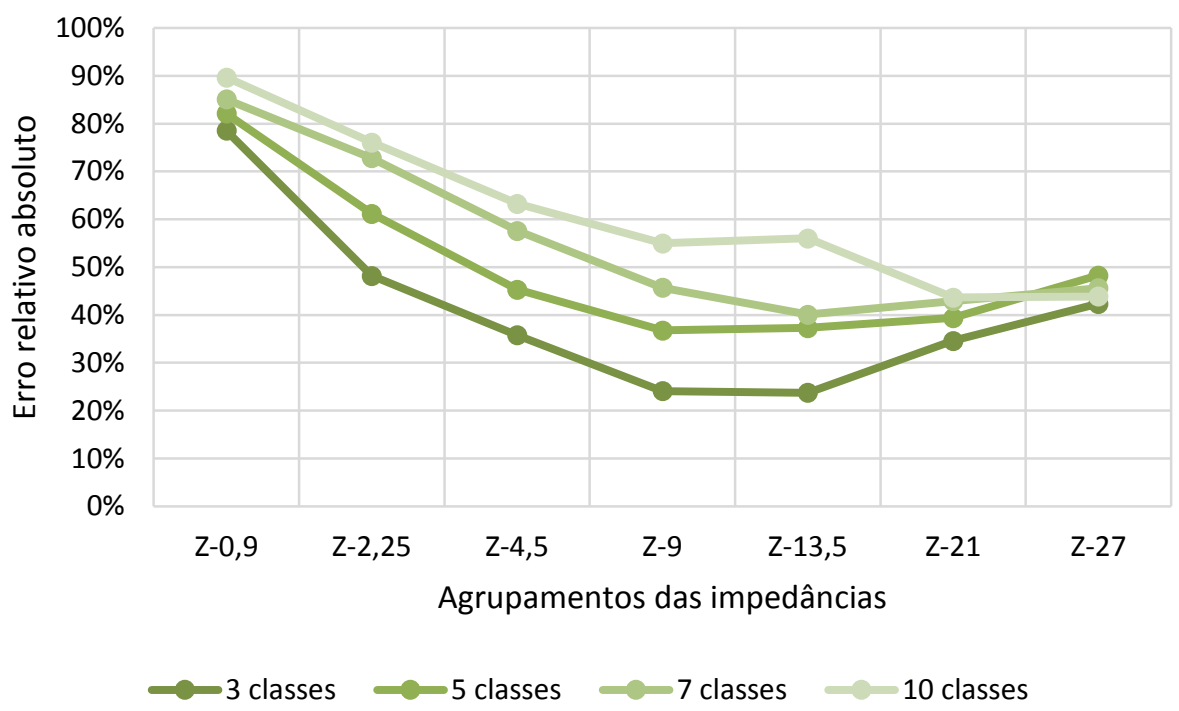

Fonte: autoria própria.

Já com a finalidade de aferir a qualidade do ajuste dos modelos dos classificadores treinados e testados, e de indicar quanto a classificação por eles realizada desvia da média esperada, o WEKA também disponibiliza a taxa da raiz do erro médio quadrático e da raiz do erro relativo quadrático. De acordo com as Figuras 6.15 a 6.18, mais uma vez os classificadores de 3 classes com Z-30 e Z-9 se destacam com os menores erros, corroborando os demais dados apresentados anteriormente. 
Figura 6-15: Taxa da raiz do erro médio quadrático para os classificadores da impedância $\mathrm{Z}_{0}$.

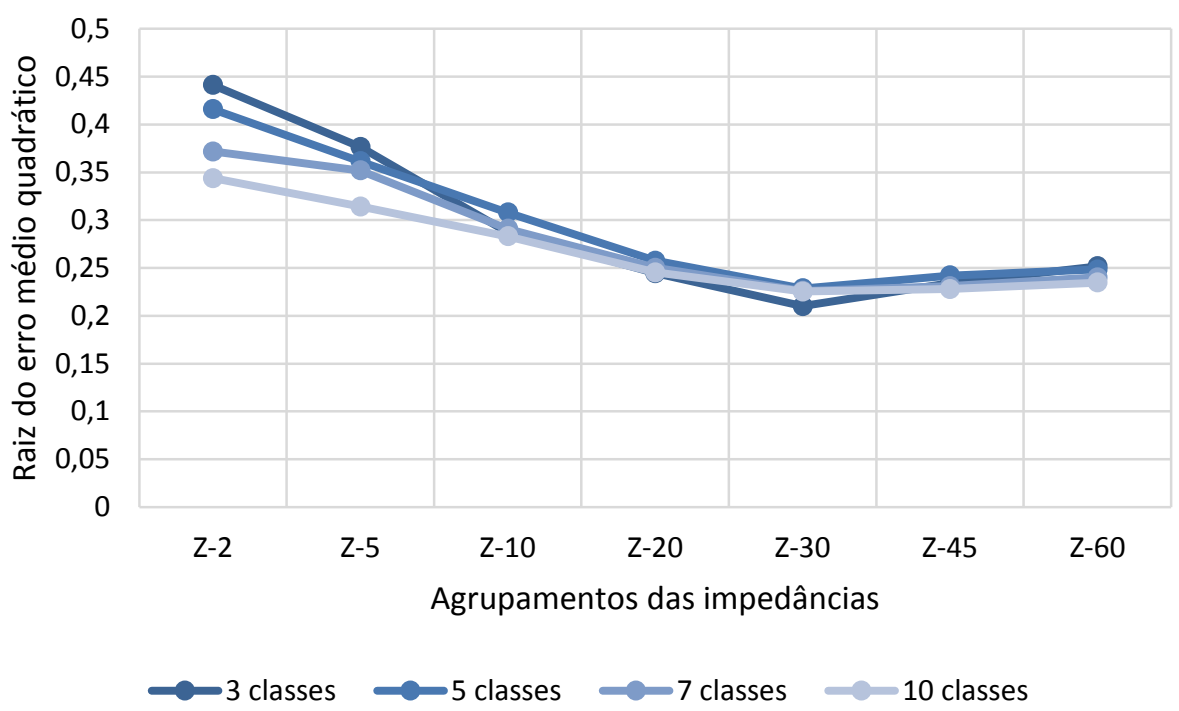

Fonte: autoria própria.

Figura 6-16: Taxa da raiz do erro médio quadrático para os classificadores da impedância $Z_{1}$.

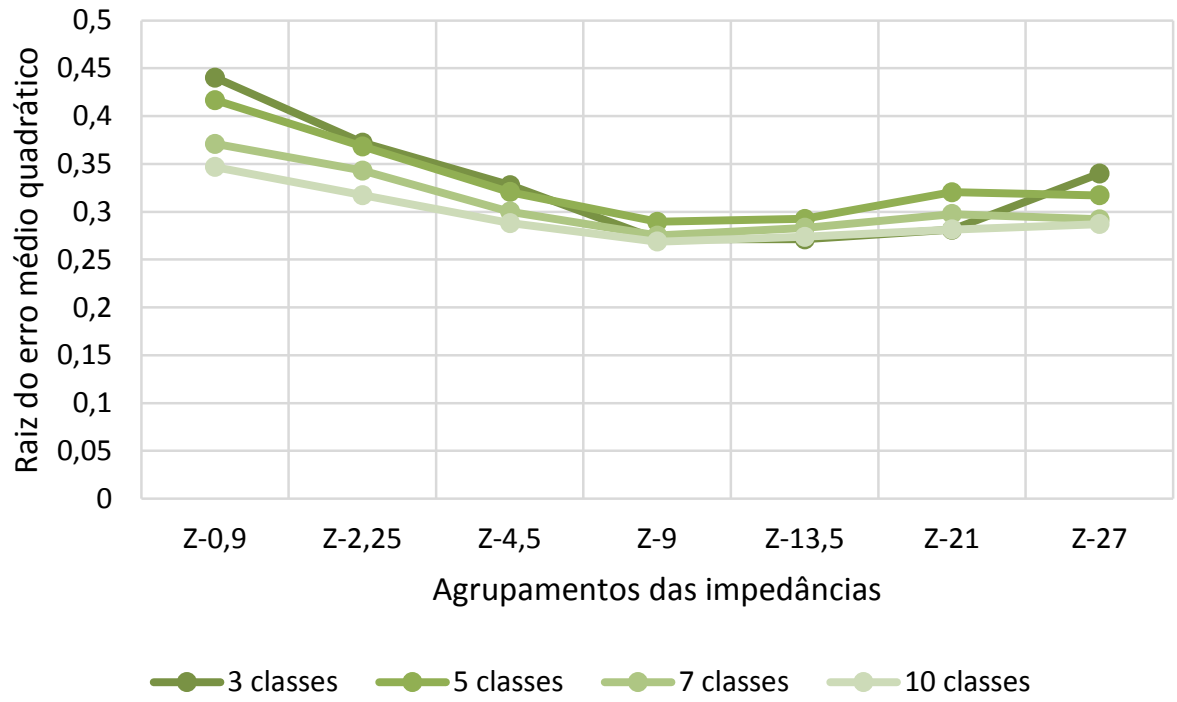

Fonte: autoria própria. 
Figura 6-17: Taxa da raiz do erro relativo quadrático para os classificadores da impedância $\mathrm{Z}_{0}$.

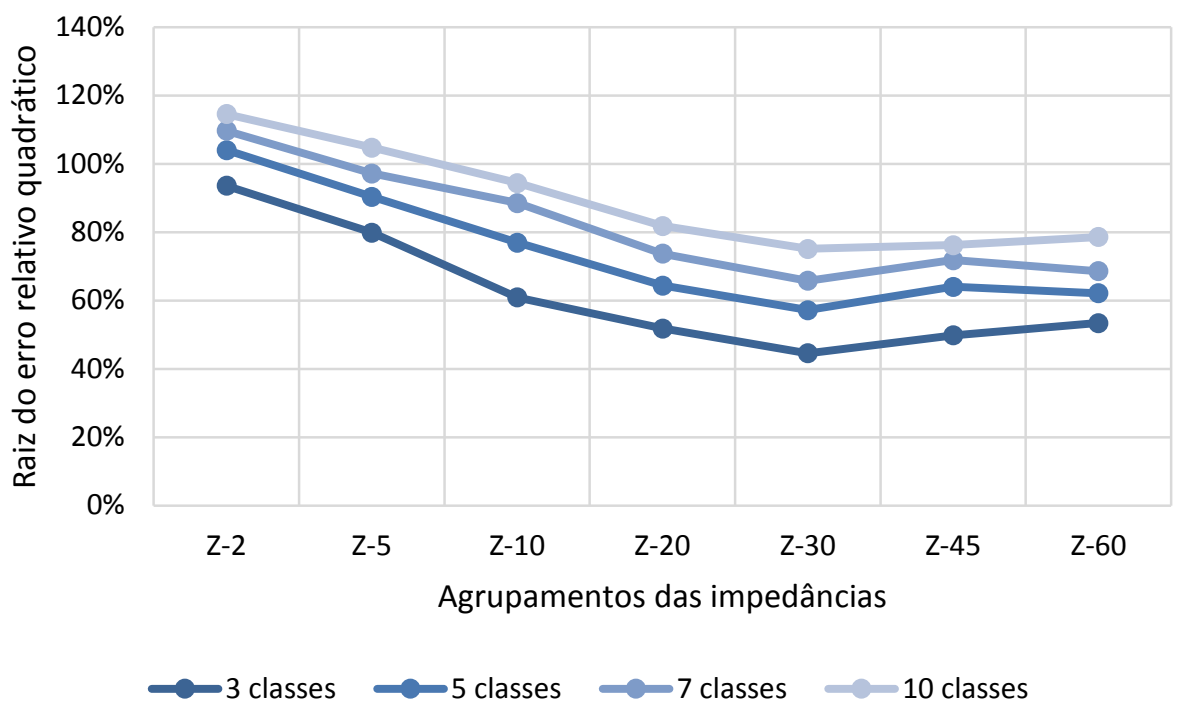

Fonte: autoria própria.

Figura 6-18: Taxa da raiz do erro relativo quadrático para os classificadores da impedância $Z_{1}$.

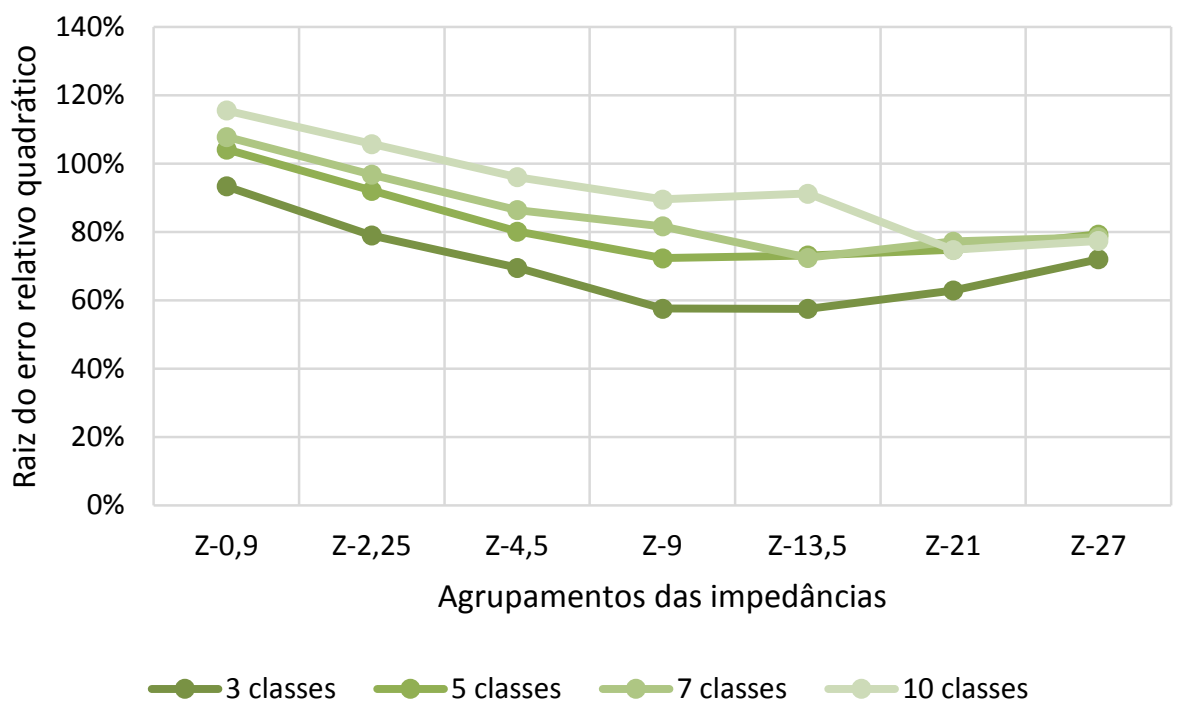

Fonte: autoria própria.

Posto isto, ponderando todos os resultados apresentados o melhor classificador para impedância $Z_{0}$ é o que utiliza os dados referentes às impedâncias do intervalo entre $0 \Omega$ e $30 \Omega$ divididas em 3 classes. Já o melhor classificador para impedância $Z_{1}$ é o que utiliza os dados referentes às impedâncias do intervalo entre $0 \Omega$ e $9 \Omega$ divididas também em 3 classes.

Agora, analisando a matrizes de confusão destes dois melhores classificadores, apresentadas nas Tabelas 6.3 e 6.4, e calculando duas de suas importantes métricas 
confirma-se o grau de acurácia total (ou taxa de acerto) e de precisão de cada uma de suas classes. A partir dos dados da matriz de confusão da Tabela 6.3 para o classificador da impedância $Z_{0}$ a acurácia do mesmo é 92,52\%, e a precisão das classes $\mathrm{A}, \mathrm{B}$ e C é 93,62\%, $88,85 \%$ e 95,08\%, respectivamente. Já a partir dos dados da matriz de confusão da Tabela 6.4 para o classificador da impedância $Z_{1}$ a acurácia do mesmo é 87,12\%, e a precisão das classes A, B e C é 90,02\%, 80,52\% e 90,88\%, respectivamente.

Destaca-se que em ambas as matrizes de confusão não há situação em que os classificadores não classificam os atributos nenhuma vez dentro de determinada classe, evidenciando que não houve overfitting no processo de concepção da $\mathrm{AD}$ ou que o tipo de treinamento selecionado no processo de indução fora incorreto.

Tabela 6-3: Matriz de confusão para o melhor classificador de $Z_{0}$.

\begin{tabular}{|c|c|c|c|}
\hline & A & B & $\mathrm{C}$ \\
\hline A & 34796 & 2140 & 231 \\
\hline B & 2154 & 32980 & 1981 \\
\hline $\mathrm{C}$ & 98 & 1726 & 35268 \\
\hline
\end{tabular}

Fonte: autoria própria.

Tabela 6-4: Matriz de confusão para o melhor classificador de $Z_{1}$.

\begin{tabular}{|c|c|c|c|}
\hline & A & B & $\mathrm{C}$ \\
\hline $\mathrm{A}$ & 32195 & 3198 & 368 \\
\hline $\mathrm{B}$ & 3511 & 28818 & 3458 \\
\hline $\mathrm{C}$ & 222 & 2995 & 32077 \\
\hline
\end{tabular}

Fonte: autoria própria.

Focando-se especificamente nas Árvores de Decisão com as configurações dos dois melhores classificadores, o próximo passo é analisar a influência dos parâmetros "confidenceFactor" e "minNumObj" do algoritmo J48 do software WEKA sobre os resultados dos classificadores.

Como os parâmetros "confidenceFactor" e "minNumObj" afetam a precisão de cada regra gerada e o número mínimo de instâncias para uma regra da árvore existir, o tamanho da árvore e a taxa de acerto dos classificadores de $\mathrm{Z}_{0}$ e $\mathrm{Z}_{1}$ são consequentemente influenciados, e, portanto, foram avaliados para 28 novas situações, conforme mostrado nas Tabelas 6.5 e 6.6 . 
Tabela 6-5: Desempenho do classificador de $Z_{0}$ em relação aos parâmetros "confidenceFactor" $e$ “minNumObj”, do algoritmo J48.

\begin{tabular}{|c|c|c|c|c|}
\hline Teste & confidenceFactor & $\operatorname{minNumObj}$ & $\begin{array}{c}\text { Tamanho da } \\
\text { árvore }\end{array}$ & $\begin{array}{c}\text { Taxa de } \\
\text { acerto }\end{array}$ \\
\hline 1 & 0,15 & 2 & 19193 & $92,41 \%$ \\
\hline 2 & 0,15 & 3 & 18002 & $92,07 \%$ \\
\hline 3 & 0,15 & 4 & 17542 & $91,81 \%$ \\
\hline 4 & 0,15 & 5 & 15839 & $91,73 \%$ \\
\hline 5 & 0,15 & 10 & 14336 & $89,07 \%$ \\
\hline 6 & 0,15 & 20 & 8751 & $87,29 \%$ \\
\hline 7 & 0,15 & 50 & 5273 & $82,38 \%$ \\
\hline 8 & 0,25 & 2 & 20607 & $92,52 \%$ \\
\hline 9 & 0,25 & 3 & 20181 & $92,24 \%$ \\
\hline 10 & 0,25 & 4 & 18677 & $91,89 \%$ \\
\hline 11 & 0,25 & 5 & 16219 & $91,78 \%$ \\
\hline 12 & 0,25 & 10 & 13183 & $89,18 \%$ \\
\hline 13 & 0,25 & 20 & 9217 & $87,75 \%$ \\
\hline 14 & 0,25 & 50 & 5329 & $82,41 \%$ \\
\hline 15 & 0,35 & 2 & 20815 & $92,77 \%$ \\
\hline 16 & 0,35 & 3 & 20253 & $92,37 \%$ \\
\hline 17 & 0,35 & 4 & 19807 & $92,04 \%$ \\
\hline 18 & 0,35 & 5 & 16545 & $91,83 \%$ \\
\hline 19 & 0,35 & 10 & 14385 & $89,43 \%$ \\
\hline 20 & 0,35 & 20 & 9862 & $87,91 \%$ \\
\hline 21 & 0,35 & 50 & 5399 & $84,17 \%$ \\
\hline 22 & 0,5 & 2 & 20939 & $92,51 \%$ \\
\hline 23 & 0,5 & 3 & 20308 & $92,21 \%$ \\
\hline 24 & 0,5 & 4 & 19870 & $91,88 \%$ \\
\hline 25 & 0,5 & 5 & 17908 & $91,62 \%$ \\
\hline 26 & 0,5 & 10 & 14571 & $88,94 \%$ \\
\hline 27 & 0,5 & 20 & 10017 & $87,62 \%$ \\
\hline 28 & 0,5 & 50 & 5479 & $82,35 \%$ \\
\hline
\end{tabular}

Fonte: autoria própria. 
Tabela 6-6: Desempenho do classificador de $Z_{1}$ em relação aos parâmetros "confidenceFactor" $e$ “minNumObj”, do algoritmo J48.

\begin{tabular}{|c|c|c|c|c|}
\hline Teste & confidenceFactor & $\operatorname{minNumObj}$ & $\begin{array}{c}\text { Tamanho da } \\
\text { árvore }\end{array}$ & $\begin{array}{c}\text { Taxa de } \\
\text { acerto }\end{array}$ \\
\hline 1 & 0,15 & 2 & 26043 & $87,05 \%$ \\
\hline 2 & 0,15 & 3 & 25681 & $86,82 \%$ \\
\hline 3 & 0,15 & 4 & 23466 & $86,31 \%$ \\
\hline 4 & 0,15 & 5 & 21125 & $86,13 \%$ \\
\hline 5 & 0,15 & 10 & 15781 & $83,57 \%$ \\
\hline 6 & 0,15 & 20 & 11873 & $80,41 \%$ \\
\hline 7 & 0,15 & 50 & 5969 & $75,87 \%$ \\
\hline 8 & 0,25 & 2 & 28101 & $87,13 \%$ \\
\hline 9 & 0,25 & 3 & 26114 & $87,01 \%$ \\
\hline 10 & 0,25 & 4 & 24647 & $86,62 \%$ \\
\hline 11 & 0,25 & 5 & 21905 & $86,17 \%$ \\
\hline 12 & 0,25 & 10 & 16482 & $83,61 \%$ \\
\hline 13 & 0,25 & 20 & 12530 & $80,84 \%$ \\
\hline 14 & 0,25 & 50 & 6093 & $75,91 \%$ \\
\hline 15 & 0,35 & 2 & 28761 & $87,15 \%$ \\
\hline 16 & 0,35 & 3 & 26648 & $87,02 \%$ \\
\hline 17 & 0,35 & 4 & 24792 & $86,67 \%$ \\
\hline 18 & 0,35 & 5 & 22513 & $86,19 \%$ \\
\hline 19 & 0,35 & 10 & 16537 & $83,61 \%$ \\
\hline 20 & 0,35 & 20 & 12673 & $80,85 \%$ \\
\hline 21 & 0,35 & 50 & 6167 & $75,90 \%$ \\
\hline 22 & 0,5 & 2 & 28875 & $87,15 \%$ \\
\hline 23 & 0,5 & 3 & 26761 & $87,01 \%$ \\
\hline 24 & 0,5 & 4 & 24872 & $86,64 \%$ \\
\hline 25 & 0,5 & 5 & 22603 & $86,18 \%$ \\
\hline 26 & 0,5 & 10 & 16673 & $83,58 \%$ \\
\hline 27 & 0,5 & 20 & 12802 & $80,85 \%$ \\
\hline 28 & 0,5 & 50 & 6263 & $75,88 \%$ \\
\hline
\end{tabular}

Fonte: autoria própria. 
Para ambos os classificadores se nota que o aumento do parâmetro "confidenceFactor" promove o aumento da taxa de acerto, porém este aumento é relativamente pequeno evidenciando que este parâmetro refina a precisão de cada regra gerada. Além disso, ocorre aumento da taxa de acerto até certo ponto, a partir do qual o crescimento do parâmetro "confidenceFactor" acarreta redução do acerto. Por outro lado, o refinamento das regras leva a um número maior de regras e por consequência a uma árvore também maior. Já o aumento do parâmetro "minNumObj" acarreta a necessidade de haver um número maior de instâncias por regra gerada e isso implica um classificador com menos regras, logo o tamanho da árvore é reduzido, porém com menos regras há menor acerto.

Avaliando individualmente a relação tamanho da árvore/taxa de acertos constatase que o melhor classificador para $\mathrm{Z}_{0}$ e $\mathrm{Z}_{1}$ é o do teste 15 , com confidenceFactor $=0,35$ e $\operatorname{minNumObj}=2$, o qual obteve taxa de acerto de $92,77 \%$ e $87,15 \%$, respectivamente. Ressalta-se que para o classificador de $Z_{1}$ a taxa de acerto dos testes 15 e 22 é a mesma, porém a árvore do teste 15 é $0,39 \%$ menor e por isto é considerada melhor.

Após ajustados os parâmetros dos classificadores para as impedâncias $\mathrm{Z}_{0}$ e $\mathrm{Z}_{1}$ trabalhou-se na indução e ajuste do classificador da indicação de sensibilização dos medidores inteligentes pela corrente de falta.

Conforme mencionado anteriormente, neste caso os dados já possuíam suas duas classes de saída pré-definidas, uma referente a sensibilização e outra a não sensibilização do medidor. Desse modo, não foram testadas partições dos dados em classes distintas e nem agrupamentos diferentes, mas também foi avaliada a influência dos parâmetros "confidenceFactor" e "minNumObj" sobre os resultados dos classificadores de acordo com o apresentado pela Tabela 6.7.

Ressalta-se que para o treinamento e teste deste classificador foram utilizados $50 \%$ dos dados referentes a esta variável e escolhidos de forma aleatória, seguindo a porcentagem de utilização dos dados semelhantes à dos classificadores das impedâncias $\mathrm{Z}_{0}$ e $\mathrm{Z}_{1}$.

Por meio da Tabela 6.7 é possível verificar respostas semelhantes às dos classificadores $Z_{0}$ e $Z_{1}$ para o classificador de sensibilização frente a variação dos parâmetros "confidenceFactor" e "minNumObj”. Para este caso, analisando a relação tamanho da árvore/taxa de acertos, averígua-se que o melhor classificador para sensibilização dos medidores é o do teste 8 , com confidenceFactor $=0,25$ e minNumObj 
$=2$, e que obteve taxa de acerto de 97,68\%. Destaca-se que a taxa de acerto dos testes 8 e 15 é a mesma, porém a árvore do teste 8 é 1,19\% menor e por isto é considerada melhor.

Tabela 6-7: Desempenho do classificador de sensibilização dos medidores inteligentes em relação aos parâmetros “confidenceFactor" e "minNumObj” do algoritmo J48.

\begin{tabular}{|c|c|c|c|c|}
\hline Teste & confidenceFactor & minNumObj & $\begin{array}{c}\text { Tamanho da } \\
\text { árvore }\end{array}$ & $\begin{array}{c}\text { Taxa de } \\
\text { acerto }\end{array}$ \\
\hline 1 & 0,15 & 2 & 15210 & $97,61 \%$ \\
\hline 2 & 0,15 & 3 & 13884 & $97,53 \%$ \\
\hline 3 & 0,15 & 4 & 12621 & $97,19 \%$ \\
\hline 4 & 0,15 & 5 & 10015 & $96,35 \%$ \\
\hline 5 & 0,15 & 10 & 8578 & $92,57 \%$ \\
\hline 6 & 0,15 & 20 & 6601 & $88,37 \%$ \\
\hline 7 & 0,15 & 50 & 3112 & $79,22 \%$ \\
\hline 8 & 0,25 & 2 & 15542 & $97,68 \%$ \\
\hline 9 & 0,25 & 3 & 14085 & $97,59 \%$ \\
\hline 10 & 0,25 & 4 & 12746 & $97,24 \%$ \\
\hline 11 & 0,25 & 5 & 10148 & $96,41 \%$ \\
\hline 12 & 0,25 & 10 & 8771 & $92,67 \%$ \\
\hline 13 & 0,25 & 20 & 6751 & $89,08 \%$ \\
\hline 14 & 0,25 & 50 & 3211 & $80,77 \%$ \\
\hline 15 & 0,35 & 2 & 15730 & $97,68 \%$ \\
\hline 16 & 0,35 & 3 & 14357 & $97,63 \%$ \\
\hline 17 & 0,35 & 4 & 12861 & $97,29 \%$ \\
\hline 18 & 0,35 & 5 & 10342 & $96,47 \%$ \\
\hline 19 & 0,35 & 10 & 8904 & $92,70 \%$ \\
\hline 20 & 0,35 & 20 & 6957 & $89,34 \%$ \\
\hline 21 & 0,35 & 50 & 3541 & $81,43 \%$ \\
\hline 22 & 0,5 & 2 & 15801 & $97,67 \%$ \\
\hline 23 & 0,5 & 3 & 14423 & $97,62 \%$ \\
\hline 24 & 0,5 & 4 & 12907 & $97,29 \%$ \\
\hline 25 & 0,5 & 5 & 10418 & $96,50 \%$ \\
\hline 26 & 0,5 & 10 & 8986 & $92,71 \%$ \\
\hline 27 & 0,5 & 20 & 7008 & $89,25 \%$ \\
\hline 28 & 0,5 & 50 & 3621 & $81,62 \%$ \\
\hline
\end{tabular}

Fonte: autoria própria. 
Definidos os classificadores para os três sistemas inteligentes, na próxima seção serão apresentados os resultados da aplicação da metodologia proposta empregando os mesmos.

\section{2 - Validação da Metodologia Proposta}

A fim de validar a metodologia proposta nesta tese, esta seção expõe os resultados de sua aplicação para estimação da distância de ocorrência de faltas fase-terra na Fase A em relação aos medidores inteligentes. Para tanto, são empregados os classificadores implementados e ajustados na seção anterior deste capítulo e 85 simulações escolhidas aleatoriamente, as quais representam aproximadamente $10 \%$ dos dados de simulação de faltas sobressalente do processo de treinamento e teste dos classificadores.

Conforme proposto na metodologia, para a localização da falta serão cruzadas as informações de estimação dos classificadores para as distâncias entre os medidores e os locais de falta decorrentes das impedâncias de sequência zero e positiva, e para indicação de sensibilização dos medidores por correntes de falta. Não obstante, este cruzamento visa trabalhar com a redundância de informações disponibilizadas pelos medidores inteligentes a fim de simplificar e agilizar o processo de localização da falta.

Nesta conjuntura, na Figura 6.19 são apresentados, para efeito de comparação, os resultados da estimação da impedância $Z_{0}$ e os valores reais esperados para o conjunto de dados de validação. De forma geral, observa-se que o classificador estima a impedância $Z_{0}$ para todo o espectro de valores prováveis com boa superposição entre os valores reais e estimados e segue seu perfil de distribuição. Contudo, nota-se um número de estimações menores do que o esperado para impedância nas faixas entre 0.5 e 1 pu e, sobretudo, 0 e $0.15 \mathrm{pu}$, intervalos nos quais há menos dados para treinamento e teste do classificador, se comparado com o total de dados, devido a topologia do sistema elétrico e naturalmente espera-se que haja menor acerto. Além disso, devido a manutenção do montante de dados, o número menor de estimações nestas faixas acarreta superestimação no intervalo entre 0.15 e 0.3 pu.

Na Figura 6.20 apresenta-se a distribuição do erro relativo da estimação da impedância $Z_{0}$, e verifica-se que a taxa de erro entre os valores esperados e os estimados concentra-se entre $\pm 0.2 \mathrm{pu}$, indicando que na faixa em que se tem maior número de 
ocorrências de erro, este é proporcionalmente baixo se comparado com o erro máximo, pois ocorre para impedâncias de menor valor.

Figura 6-19: Comparativo entre valores estimados e reais da impedância $Z_{0}$ para o conjunto de dados de validação.

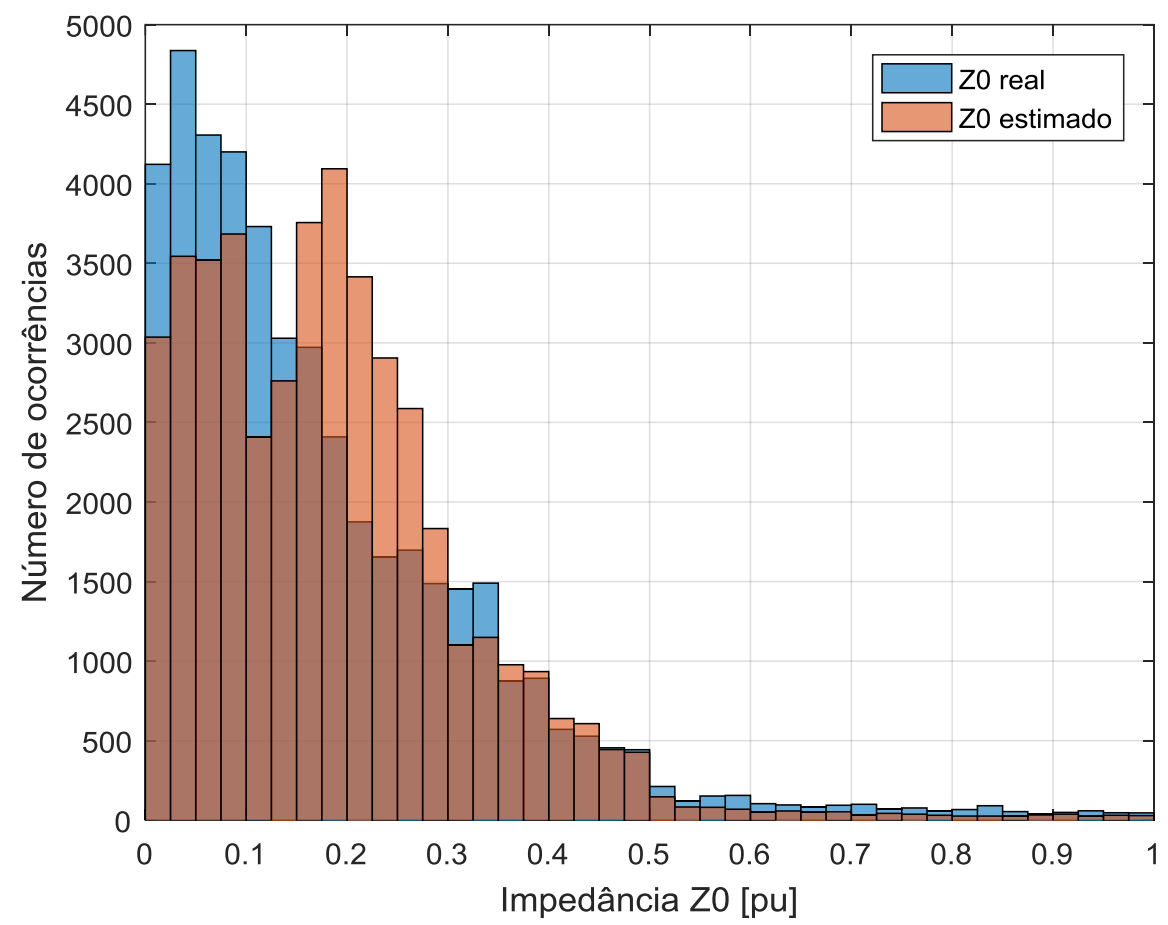

Fonte: autoria própria.

Figura 6-20: Erro de estimação da impedância $Z_{0}$ para o conjunto de dados de validação.

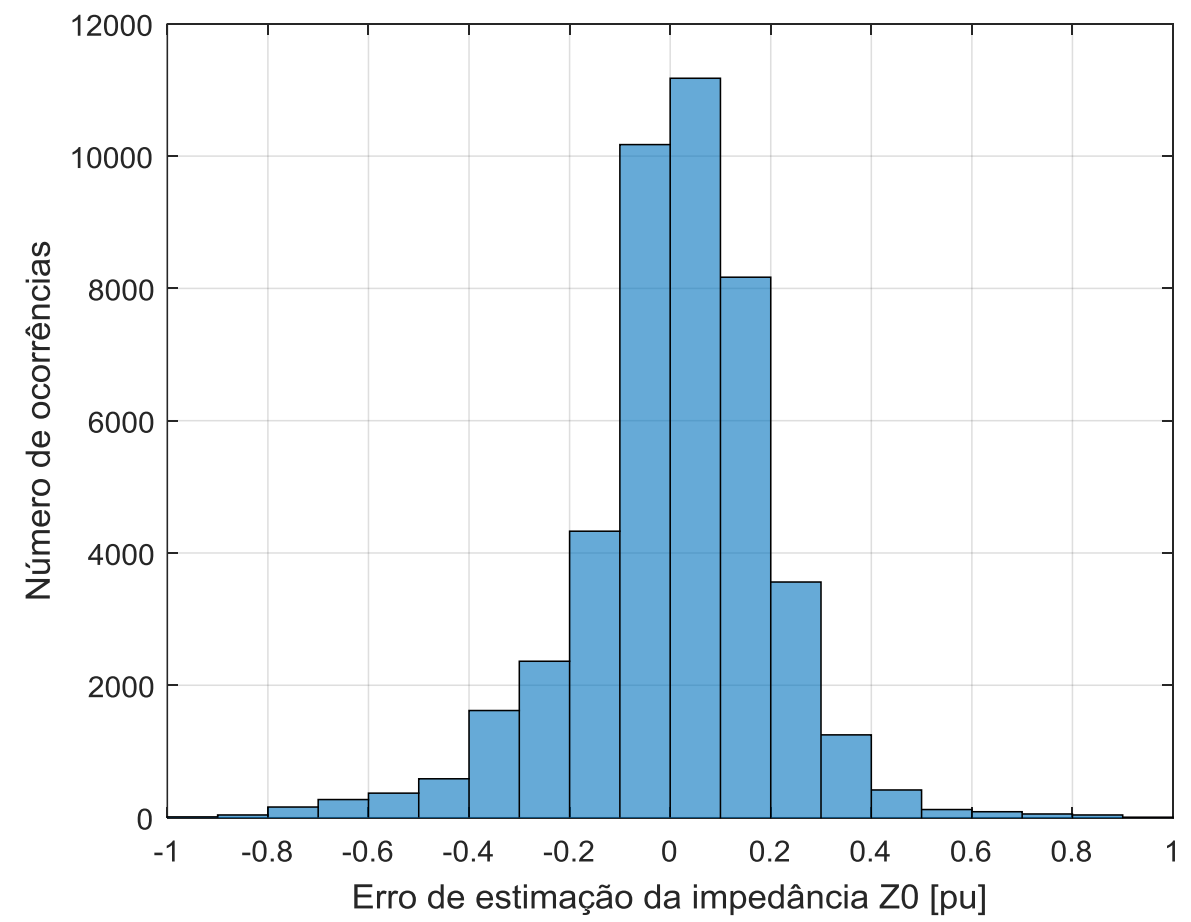

Fonte: autoria própria. 
Já na Figura 6.21 é mostrada a distância $\mathrm{d}_{0}$ entre o ponto de falta e os medidores inteligentes obtida a partir da impedância de sequência zero para as simulações do conjunto de dados de validação, e os resultados obtidos para a estimação da mesma. É notória a concentração de valores até próximo de $9 \mathrm{~km}$ devido a concentração dos medidores em barras próximas e as características de topologia do sistema elétrico sob análise. O classificador estima distâncias com perfil semelhante ao valor real, destoando do mesmo com menos estimações para valores até 4,5 $\mathrm{km}$ e com mais estimações que o esperado entre 4,5 e $9 \mathrm{~km}$.

Por meio da Figura 6.22, que expõe a distribuição do erro relativo entre os valores esperados e os estimados para a distância $\mathrm{d}_{0}$, observa-se a dilatação da faixa de concentração da taxa de erro em relação a estimação da impedância $\mathrm{Z}_{0}$. A maior parte dos erros se dá na faixa de $\pm 5 \mathrm{~km}$, o que pode dificultar a rápida localização da falta por se tratar de uma faixa com valores não muito baixos em relação ao comprimento total do alimentador, porém até $\pm 2.5 \mathrm{~km}$ o número de ocorrências do erro também possui valor elevado e o processo de cruzamento das informações contribuirá para restringir a área de possível local da falta.

Verifica-se pelas Figuras 6.21 e 6.22 a tendência de crescimento do erro com o aumento da distância de ocorrência da falta, o que já era esperado devido as observações realizadas no processo de definição, treinamento e teste do classificador, porém este fato não compromete a capacidade de generalização do estimador.

Ainda avaliando o erro de estimação da distância d calculou-se seu erro absoluto médio e erro relativo absoluto, os quais para os dados de validação são 1,78 km e 15,68\%, respectivamente. Dado o processo de estimação pelo classificador de $\mathrm{Z}_{0}$ com suas taxas de erros e a diferença de ordem de grandeza entre impedância em ohm e distância em quilômetros, pode-se dizer que ambos os erros calculados para $\mathrm{d}_{0}$ são condizentes, sobretudo o erro relativo absoluto, o qual para o classificador é de aproximadamente $14 \%$. 
Figura 6-21: Comparativo entre valores estimados e reais para a distância da falta em função da impedância $Z_{0}$ para o conjunto de dados de validação.

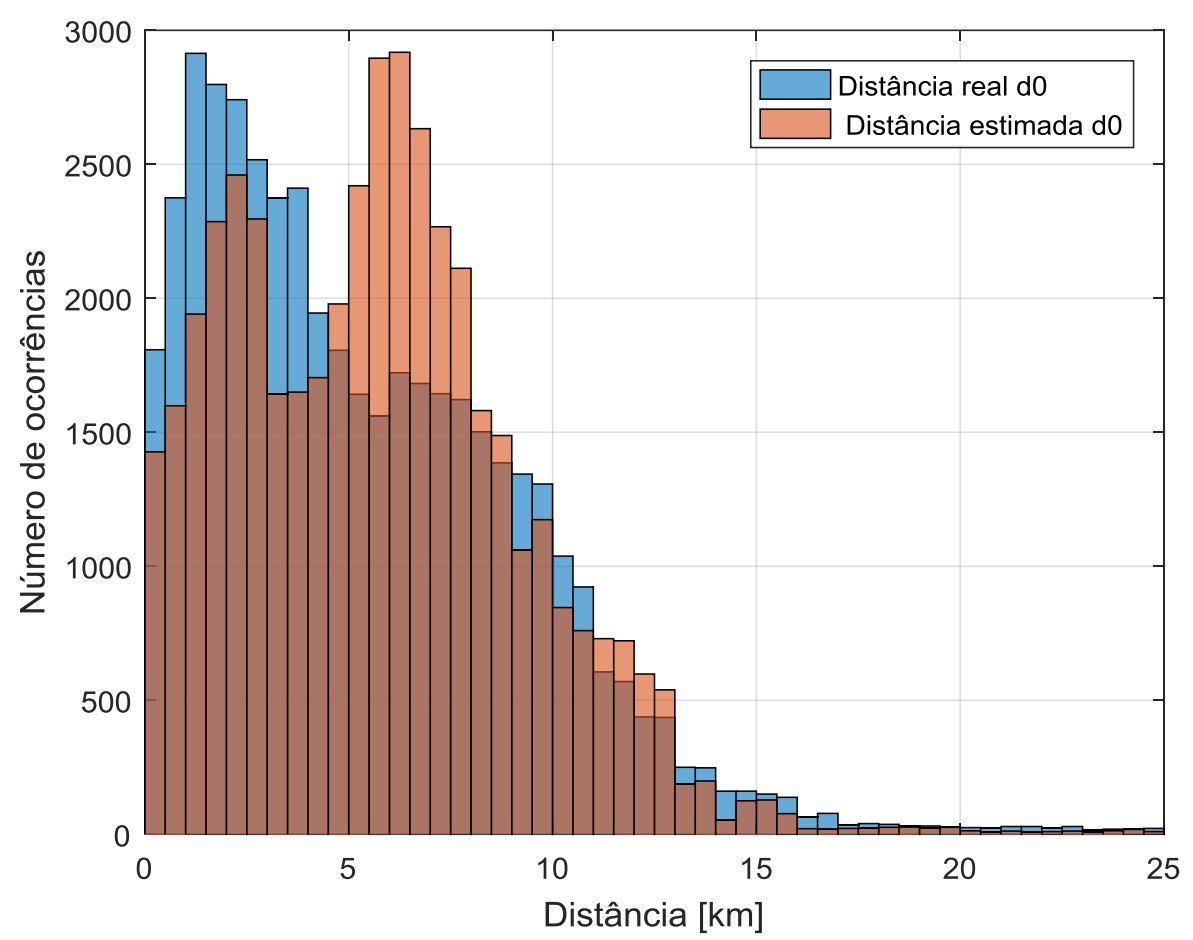

Fonte: autoria própria.

Figura 6-22: Erro de estimação da distância da falta em função da impedância $Z_{0}$ para o conjunto de dados de validação.

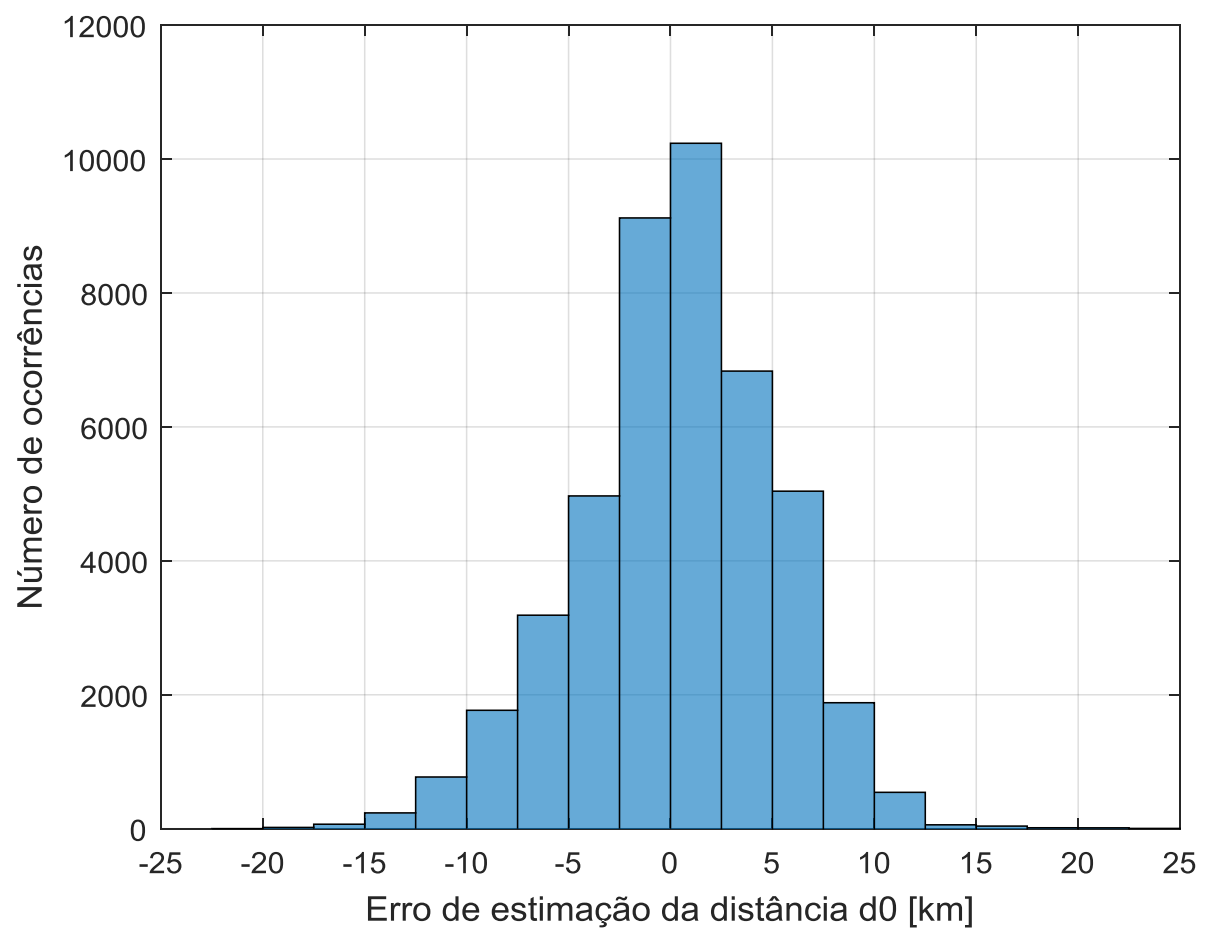

Fonte: autoria própria. 
Já na Figura 6.23 são expostos os resultados da estimação da impedância $\mathrm{Z}_{1}$ e seus valores reais esperados para o conjunto de dados de validação, por meio dos quais também se constata que de forma geral o classificador estima a impedância $Z_{1}$ para todo o espectro de valores prováveis com boa superposição entre os valores reais e estimados, e segue seu perfil de distribuição. Assim como ocorre para $\mathrm{Z}_{0}$ há uma quantidade de estimações menores do que o esperado para a impedância $Z_{1}$ na faixa entre 0 e 0.1 pu, porém há um número maior de estimações do que o esperado para uma faixa de valores maior do que para $\mathrm{Z}_{0}$, faixa esta que compreende valores entre 0.15 e 0.2 e entre 0.3 e $0.7 \mathrm{pu}$.

Na Figura 6.24 é mostrada a distribuição do erro relativo da estimação da impedância $Z_{1}$ na qual nota-se o reflexo das superestimações pela predominância maior de erros com sinal positivo, e que a taxa de erro entre os valores esperados e os estimados concentra-se entre -0.1 e $0.2 \mathrm{pu}$. Assim como para $\mathrm{Z}_{0}$, este fato indica que na faixa em que se tem maior número de ocorrências de erro, este é proporcionalmente baixo se comparado com o erro máximo, pois se dá para impedâncias de menor valor.

Figura 6-23: Comparativo entre valores estimados e reais da impedância $Z_{1}$ para o conjunto de dados de validação.

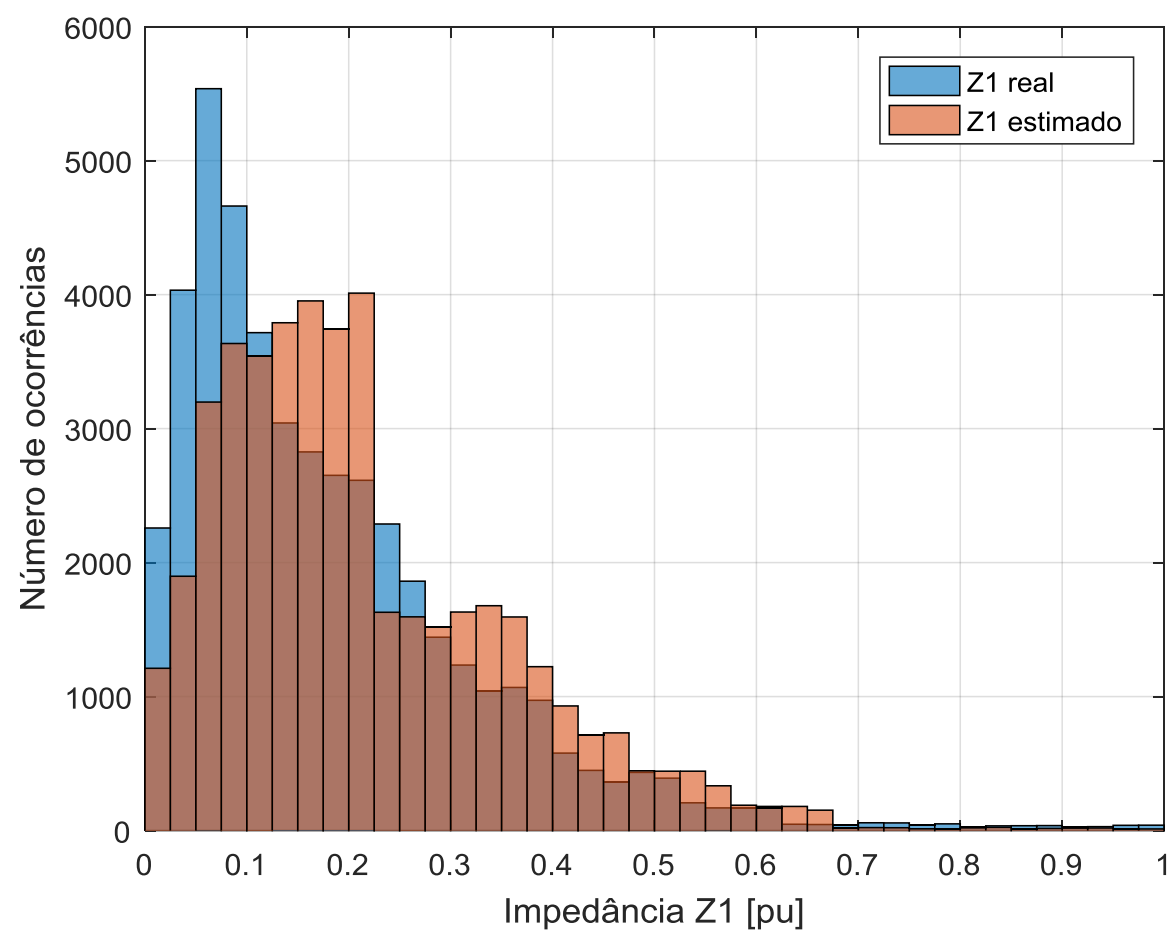

Fonte: autoria própria. 
Figura 6-24: Erro de estimação da impedância $Z_{1}$ para o conjunto de dados de validação.

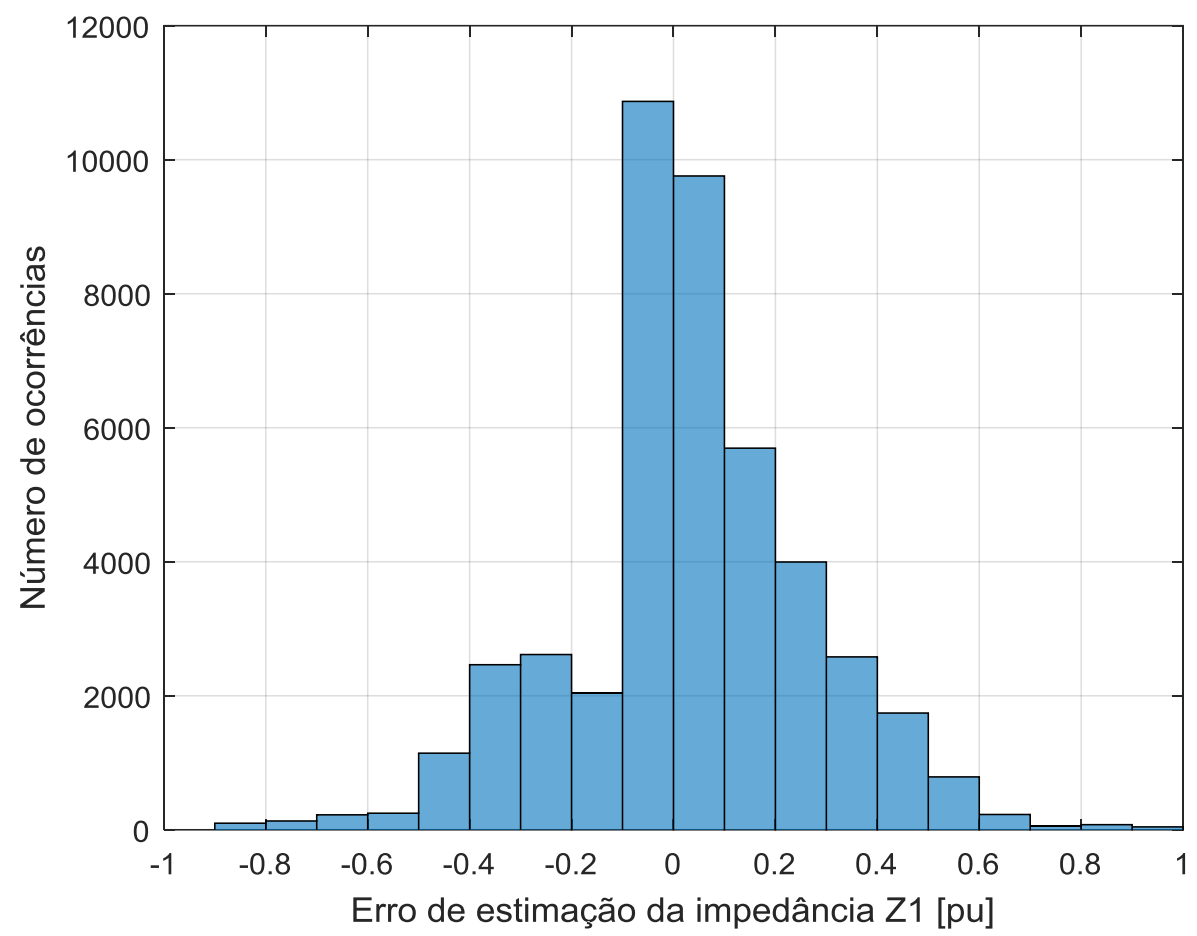

Fonte: autoria própria.

A Figura 6.25 apresenta a distância $\mathrm{d}_{1}$ entre o ponto de falta e os medidores inteligentes obtida a partir da impedância de sequência positiva para as simulações do conjunto de dados de validação, e os resultados obtidos para a estimação da mesma. Por meio desta figura observa-se uma concentração bastante acentuada de valores até $5 \mathrm{~km}$, reflexo também do agrupamento dos medidores e das características de topologia do sistema elétrico sob análise.

Nota-se ainda na Figura 6.25 uma subestimação do número de ocorrências para distância até $5 \mathrm{~km}$ e superestimações a partir deste ponto até a distância máxima de 25 $\mathrm{km}$, fato que não ocorre para a distância $\mathrm{d}_{0}$ e que agregará mais conhecimento no processo de localização de falta pela sobreposição das informações. Outrossim, esta diferença nas estimações se reflete na distribuição do erro relativo entre os valores esperados e os estimados para a distância $\mathrm{d}_{0}$, conforme ilustrado na Figura 6.26.

Por meio da Figura 6.26 observa-se um pico menor para o número de ocorrências de erros e a ampliação da faixa de concentração da taxa de erro, que agora ocorre entre -7.5 e $10 \mathrm{~km}$. Ressalta-se que mesmo com a dilatação desta faixa de concentração dos erros a redundância de informações disponibilizadas pelos medidores e pelos 3 parâmetros $\left(\mathrm{d}_{0}, \mathrm{~d}_{1}\right.$ e sensibilização dos medidores por correntes de falta) utilizados nesta metodologia busca contornar esta adversidade. 
Do mesmo modo como ocorreu para $\mathrm{d}_{0}$, verifica-se para $\mathrm{d}_{1}$ pelas Figuras $6.25 \mathrm{e}$ 6.26 a tendência de crescimento do erro com o aumento da distância de ocorrência da falta, o que já era esperado devido as observações realizadas no processo de definição, treinamento e teste do classificador, porém este fato não compromete a capacidade de generalização do estimador.

Por fim, calculando-se o erro absoluto médio e erro relativo absoluto da estimação da distância $\mathrm{d}_{1}$, cujos valores são 2,34 km e 21,05\%, averígua-se a coerência dos mesmos apesar da diferença de 2,95\% entre os erros absolutos relativos, uma vez que para o classificador este dado é de aproximadamente $24 \%$.

Figura 6-25: Comparativo entre valores estimados e reais para a distância da falta em função da impedância $Z_{1}$ para o conjunto de dados de validação.

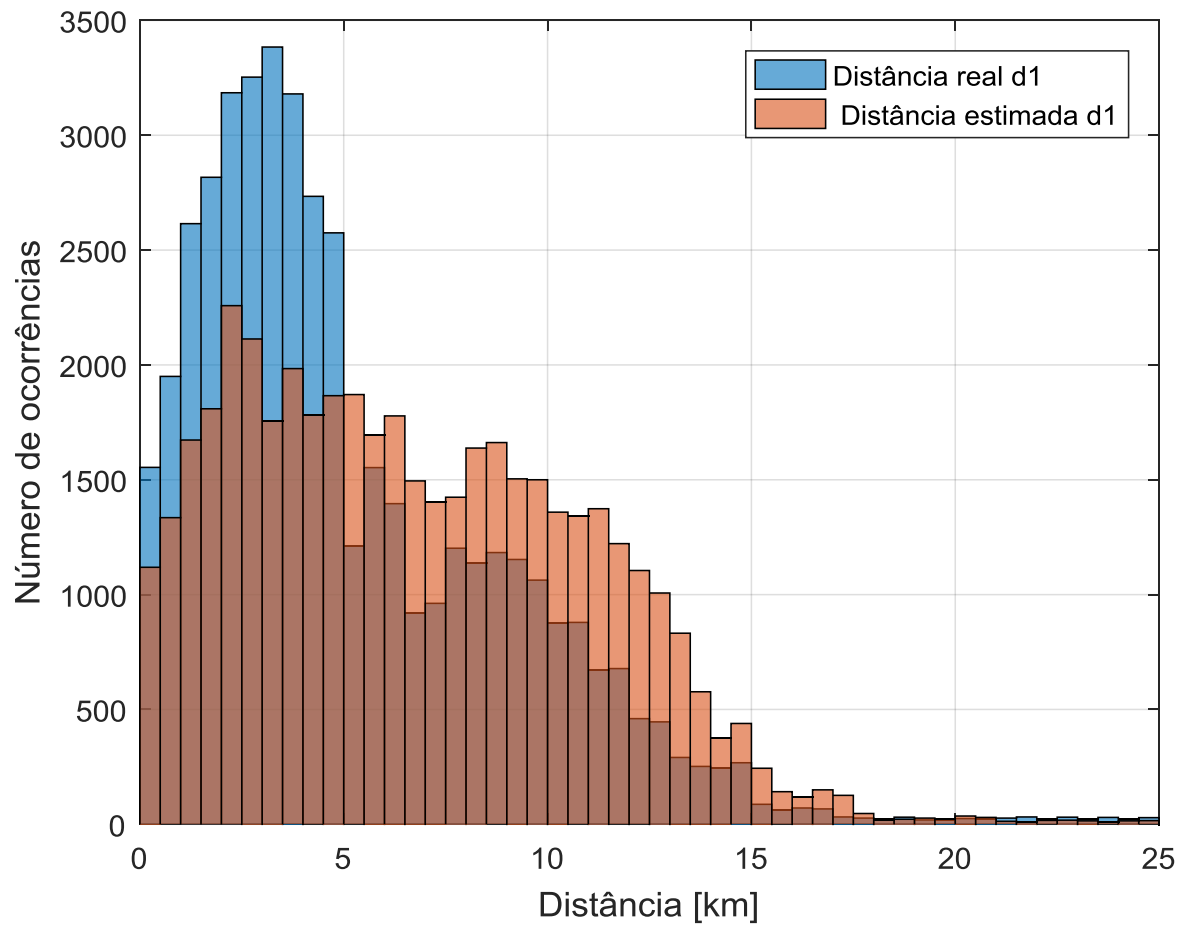

Fonte: autoria própria. 
Figura 6-26: Erro de estimação da distância da falta em função da impedância $Z_{1}$ para o conjunto de dados de validação.

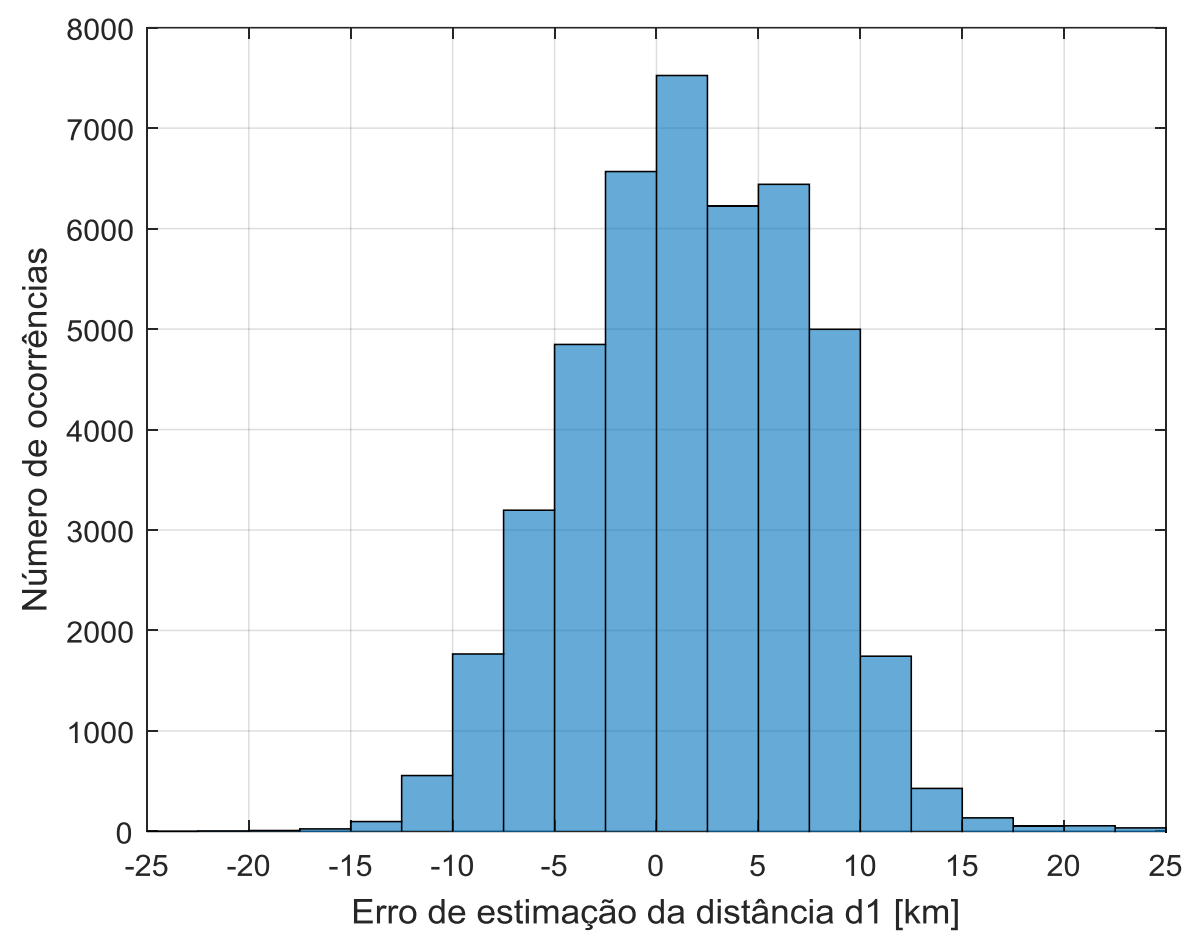

Fonte: autoria própria.

Posteriormente, para obter o terceiro parâmetro utilizado pela presente metodologia no processo de localização de faltas foi empregado o conjunto de dados de validação e o classificador para estimação da sensibilização dos medidores inteligentes a passagem da corrente de falta. Os resultados obtidos para estimação do estado de sensibilização dos medidores e apresentados na Figura 6.27 mostram o elevado grau de acerto entre o estado real e o estimado cuja taxa de erro relativo absoluto é de 6,73\%. 
Figura 6-27: Número de ocorrência de sensibilização ou não por correntes de falta dos medidores inteligentes para o conjunto de dados de validação.

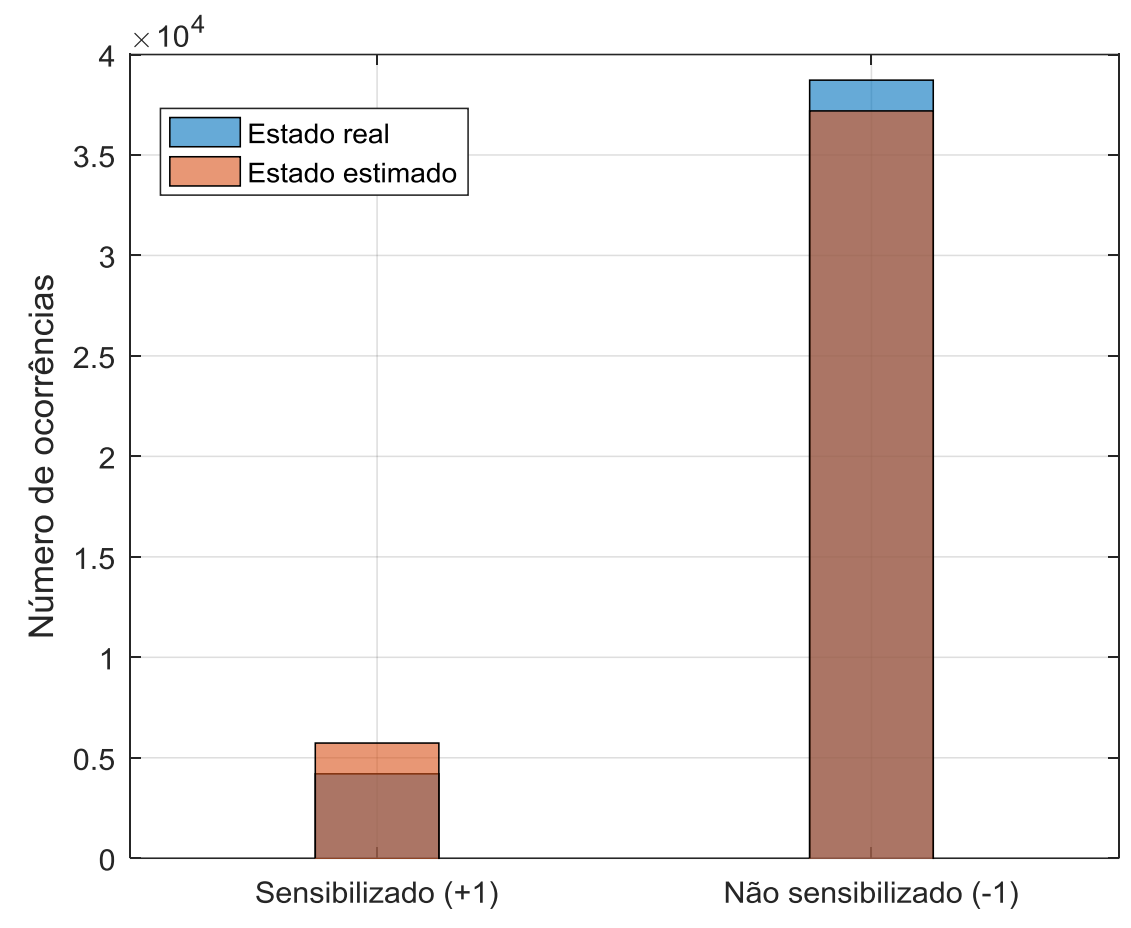

Fonte: autoria própria.

Fazendo uso das estimações dos 3 sistemas inteligentes e visando ilustrar o processo de análise das informações utilizadas pela metodologia proposta nesta tese, a seguir são apresentados dois estudos de caso específicos para faltas em pontos distintos do alimentador avaliado, selecionados entre as 85 simulações do conjunto de validação.

\subsection{1 - Estudo de caso 1 - falta na barra 462}

Neste estudo de caso averígua-se a ocorrência de uma falta na barra 462, conforme representado na Figura 6.28 pelo $\mathrm{X}$ na cor magenta, próxima a subestação e a uma região de concentração de medidores. Nesta figura observa-se que os medidores estimados como em estado de sensibilização pela passagem da corrente de falta (representados por círculos em vermelho) se dispersam por todo alimentador, porém há uma concentração dos mesmos seguindo o "caminho" entre a subestação e a barra sob falta, o que fornece uma ótima informação para o processo de localização. 
Destaca-se que o erro relativo absoluto de estimação de sensibilização dos medidores é de 5,35\% para este caso, e que os medidores erroneamente estimados como em estado de sensibilização e espalhados pela topologia do sistema elétrico não comprometem a indicação do local de falta. O mesmo ocorre com o medidor alocado entre subestação e próximo ao local de falta, cuja indicação de estado de não sensibilização também foi incorretamente estimada.

Em seguida, na Figura 6.29 são apresentados os resultados das estimações das distâncias $\mathrm{d}_{0}$ referentes a impedância $\mathrm{Z}_{0}$ para cada um dos medidores inteligentes em relação a barra sob falta, em que os triângulos em azul apontam para o local em que teria acontecido a falta. Constata-se uma grande quantidade de estimações com valores indicando o próprio local da falta e pontos próximos ao de sua ocorrência formando uma região com comprimento aproximado de 214 m, 107 m a montante e 107 a jusante do ponto sob falta. Novamente ocorrem estimações de pontos errôneos distribuídos ao longo do sistema elétrico, porém a redundância de informações disponibilizada pelos 505 medidores proporciona uma concentração dos pontos estimados próximos ao local da falta, contornado este obstáculo.

Salienta-se que em virtude da indicação de sensibilização dos medidores inteligentes se dar sempre até o ultimo medidor a montante do local da falta, na aplicação da presente metodologia será invariavelmente tomada a barra subsequente (a jusante) a indicação do último medidor sensibilizado para composição da região contendo o possível ponto de ocorrência da falta.

Na Figura 6.30 são apresentados os resultados das estimações das distâncias $d_{1}$ relativas a impedância $Z_{1}$, em que os quadrados na cor verde apontam para o local em que teria ocorrido a falta. Analisando as estimações para este tipo de distância observa-se que há uma região maior com concentração de pontos, incluindo pontos indicando o próprio local da falta, cujo comprimento aproximado varia entre $153 \mathrm{~m}$ a montante e 153 a jusante do ponto sob falta. Mais uma vez a redundância de informações minimiza a dispersão de estimações incorretas pela concentração dos pontos próximos ao local da falta. Ressaltase que devido as taxas de acerto dos classificadores da impedância $\mathrm{Z}_{0}$, e consequentemente das distâncias $\mathrm{d}_{0}$, serem maiores, a delimitação de uma área maior pela estimação das distâncias $d_{1}$ já era esperada e está condizente com as outras etapas da metodologia desenvolvida.

Cruzando as informações obtidas com os três parâmetros avaliados e fazendo a intersecção entre as regiões de concentração das estimações de distância é possível 
localizar a falta em um trecho do alimentador de no máximo $214 \mathrm{~m}$, ou seja, o erro absoluto máximo da metodologia de localização é de 214 m na presente situação. Esta estimativa fornece uma região que apesar de não ser estritamente reduzida tem comprimento representando $0,43 \%$ do comprimento total do alimentador sob estudo, o qual possui aproximadamente $50 \mathrm{~km}$ linhas de distribuição de energia. Deste modo, podese concluir que com a estimativa obtida a busca pelo local de ocorrência da falta pelas equipes de manutenção da rede seria consideravelmente reduzida. 
Figura 6-28: Indicação do ponto de falta na barra 462 e da estimação do estado de sensibilização dos medidores inteligentes a passagem de corrente de falta.

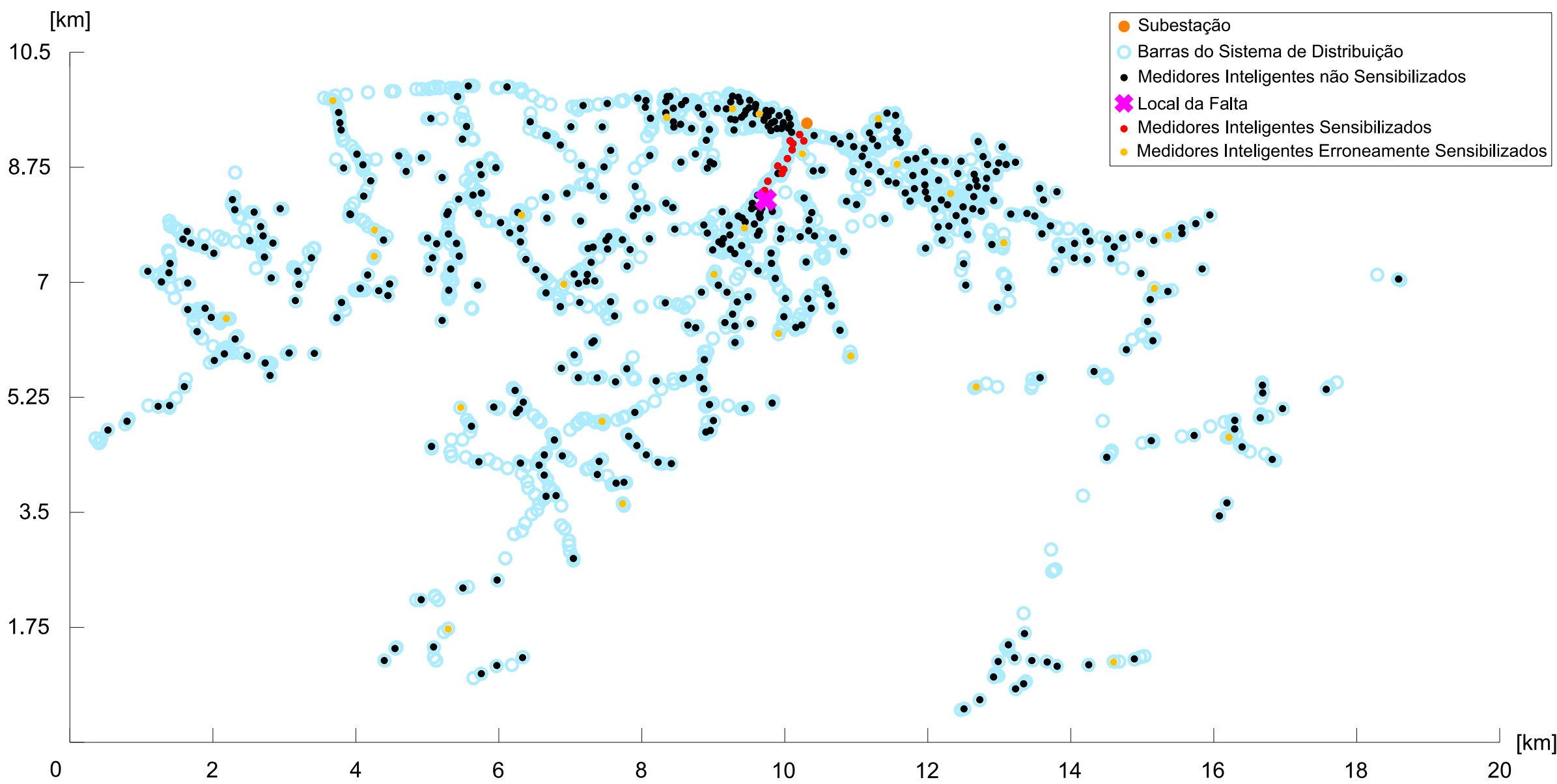

Fonte: autoria própria. 


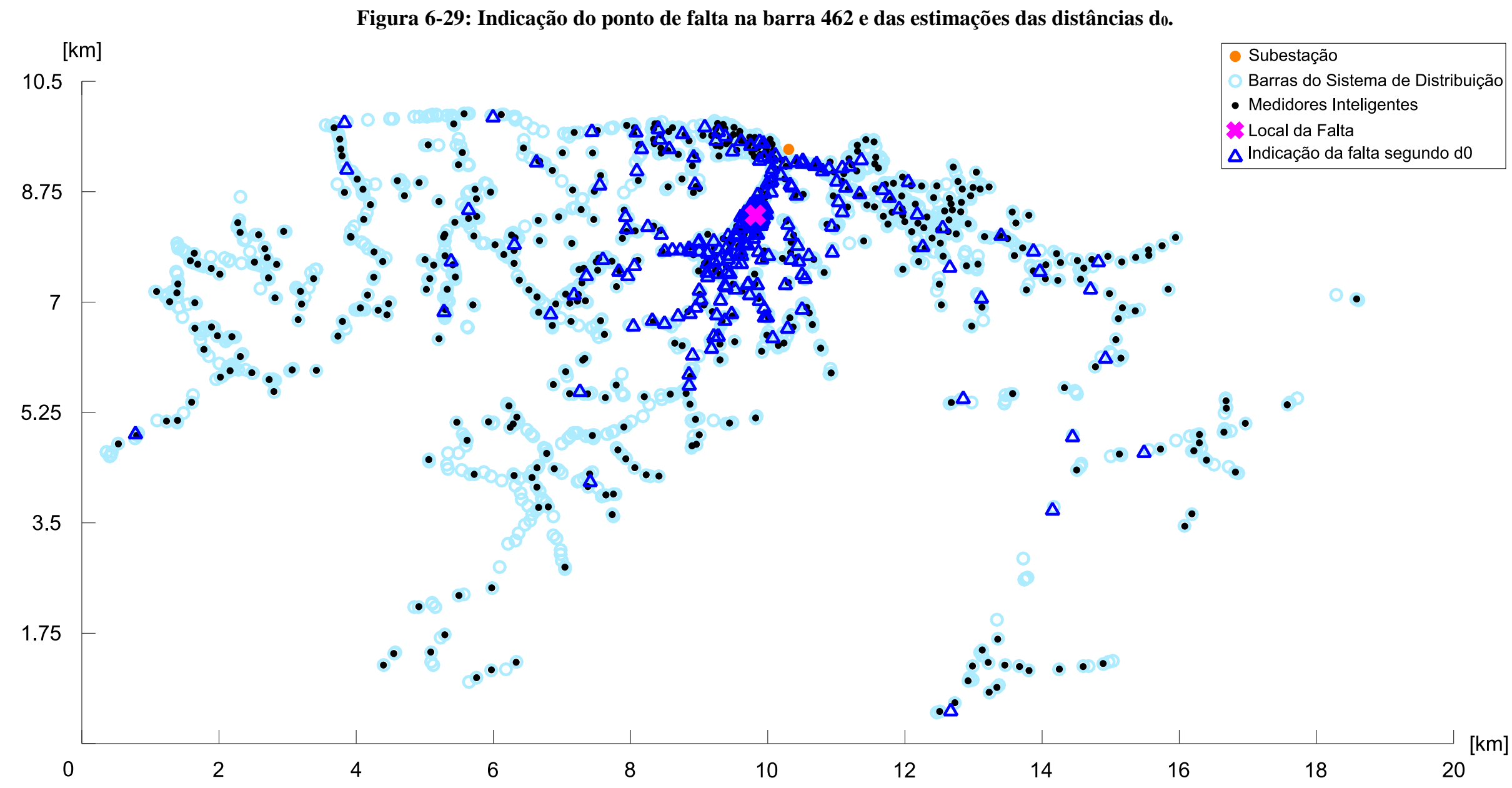

Fonte: autoria própria. 


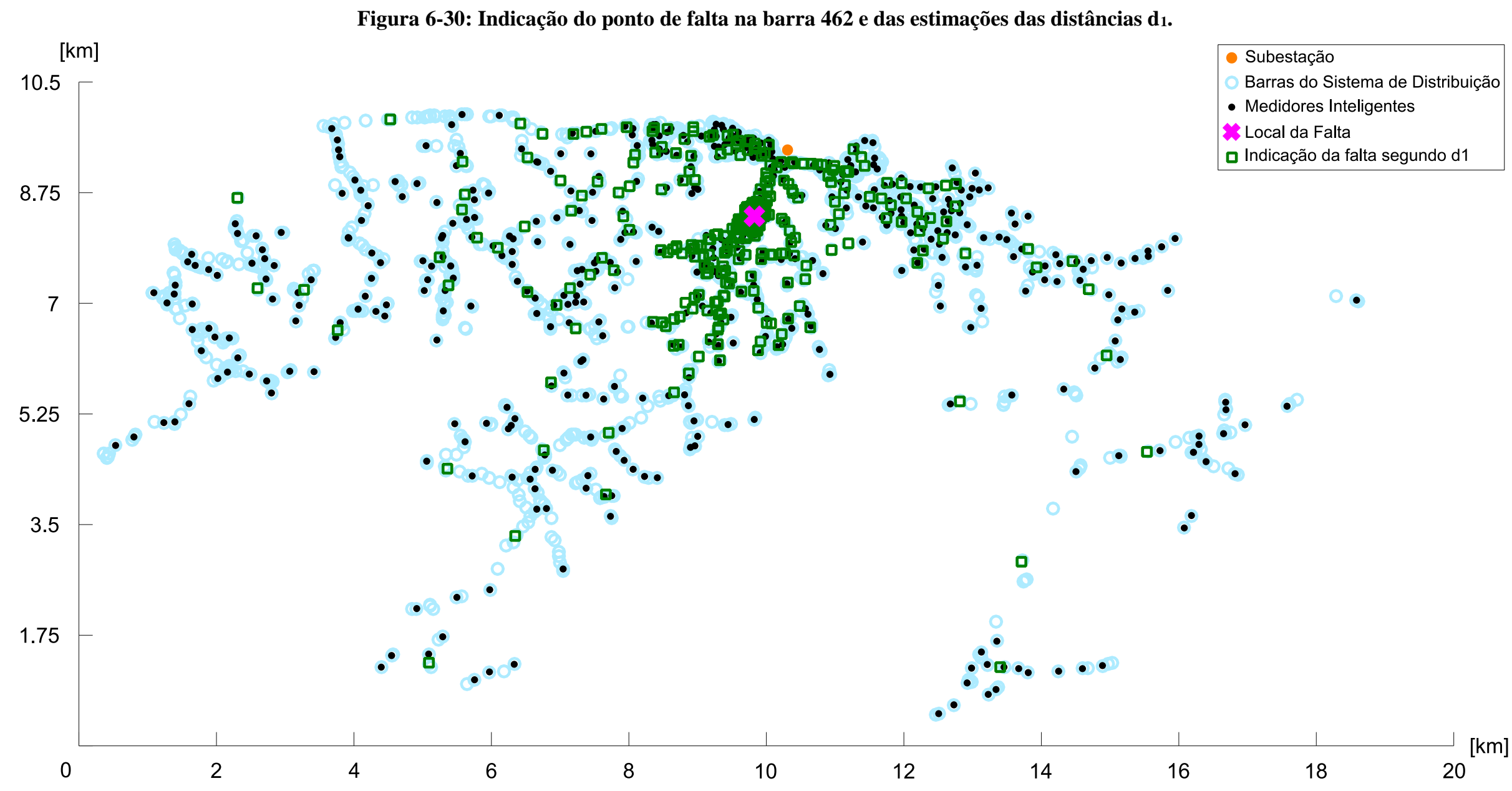

Fonte: autoria própria. 


\subsection{2 - Estudo de caso 2 - falta na barra 1421}

No presente estudo de caso investiga-se a ocorrência de uma falta na barra 1421, conforme representado na Figura 6.31 pelo $X$ na cor magenta, bastante distante da subestação, em uma das extremidades do alimentador e em uma região com poucos medidores inteligentes. Assim como no estudo de caso anterior, por meio desta figura observa-se que os medidores estimados como em estado de sensibilização (representados por círculos em vermelho) se dispersam por todo alimentador, porém trilham um "caminho" entre a subestação e a barra sob falta com alguns pontos falhos. Estes pontos falhos se devem ao erro inerente ao classificador durante o processo de estimação da sensibilização dos medidores e para este caso específico dificultariam a delimitação do local da falta caso apenas esta informação fosse utilizada. Apesar deste contraponto, de forma geral pode-se dizer que os medidores fornecem boa informação sobre o "caminho" da falta para o processo de localização, uma vez que o erro relativo absoluto de estimação neste caso é de $8,51 \%$.

Em seguida, na Figura 6.32 são apresentados os resultados das estimações das distâncias $\mathrm{d}_{0}$, em que os triângulos em azul apontam para o local em que teria acontecido a falta. Nota-se o aumento da distribuição dos pontos de indicação da falta em relação ao estudo de caso anterior, o que se deve a dificuldade de estimação do classificador para faltas em pontos extremos do sistema elétrico, conforme observado nas seções anteriores deste capítulo pelo crescimento do erro de estimação.

Em virtude do maior erro, e consequentemente das distâncias estimadas com menor exatidão, nota-se que o ponto de concentração dos valores estimados para $\mathrm{d}_{0}$ se localiza em uma região que não esta muito próxima do local da falta, como ilustrado na Figura 6.33 pela curva em magenta. Esta região não inclui o local da falta, ao contrário do que ocorreu no estudo de caso anterior, e circunscreve um trecho do alimentador com 592 m de comprimento.

Contudo, retomando a Figura 6.31 verifica-se que esta região não contém as indicações finais do "caminho" de sensibilização dos medidores pela corrente de falta, o qual termina no medidor da barra imediatamente anterior ao ponto sob falta. Logo, realizando o cruzamento dessas informações e delimitando uma nova região de abrangência para os possíveis pontos de ocorrência da falta que inclua a barra subsequente 
a de indicação do último medidor sensibilizado tem-se uma área de $2.277 \mathrm{~m}$ de comprimento.

Analisando a Figura 6.34 visualiza-se a distribuição dos resultados das estimações das distâncias $d_{1}$ entre medidores e local de ocorrência da falta a partir da impedância $Z_{1}$, representadas por quadrados na cor verde que apontam para o local em que teria ocorrido a falta. Novamente, percebe-se que nas estimações para este tipo de distância a região de concentração dos pontos estimados é maior do que para $\mathrm{d}_{0}$, porém para o caso sob avaliação mesmo assim não há a inclusão da barra do local da falta nesta região, conforme destacado na Figura 6.35.

Desse modo, fazendo uso do cruzamento das informações de estimação desta distância com as de sensibilização dos medidores define-se uma nova região de maior abrangência. Esta região abrangendo as indicações do "caminho" de sensibilização dos medidores e a barra subsequente a de indicação do último medidor sensibilizado possui comprimento total de $3.075 \mathrm{~m}$.

Realizando a intersecção das áreas de possível ocorrência da falta, delimitadas cruzando-se as informações obtidas com os três parâmetros avaliados, é possível localizar a falta em um trecho do alimentador de no máximo $2.277 \mathrm{~m}$ que engloba o ponto de ocorrência da falta em sua extremidade mais distante da subestação, ou seja, o erro absoluto máximo da metodologia de localização é de $2.277 \mathrm{~m}$ para o presente caso sob análise. Ademais, esta estimativa fornece uma região com comprimento representando apenas 4,55\% do comprimento total do alimentador sob estudo, o que auxiliaria no processo de localização da falta e deslocamento das equipes de manutenção, porém está acima do usual para bons localizadores de falta.

Todavia, apesar desta estimativa não ser a mais adequada, ela revela que o uso de informações redundantes, conforme proposto pela metodologia desta tese, minimiza os erros de estimação, e a análise de medições dispersas da tensão do sistema elétrico auxilia o processo de localização de faltas. 
Figura 6-31: Indicação do ponto de falta na barra 1421 e da estimação do estado de sensibilização dos medidores inteligentes a passagem de corrente de falta.

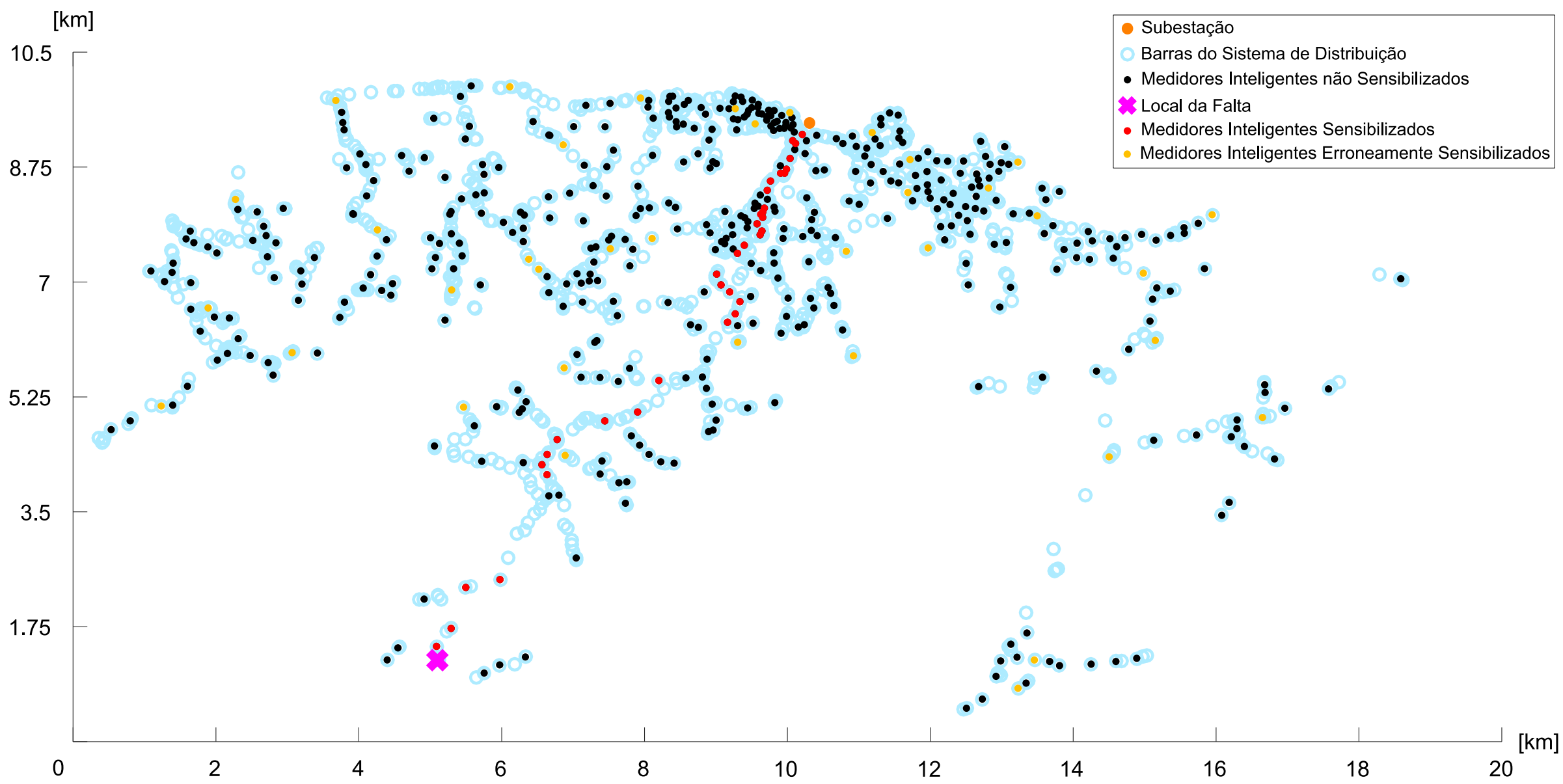

Fonte: autoria própria. 


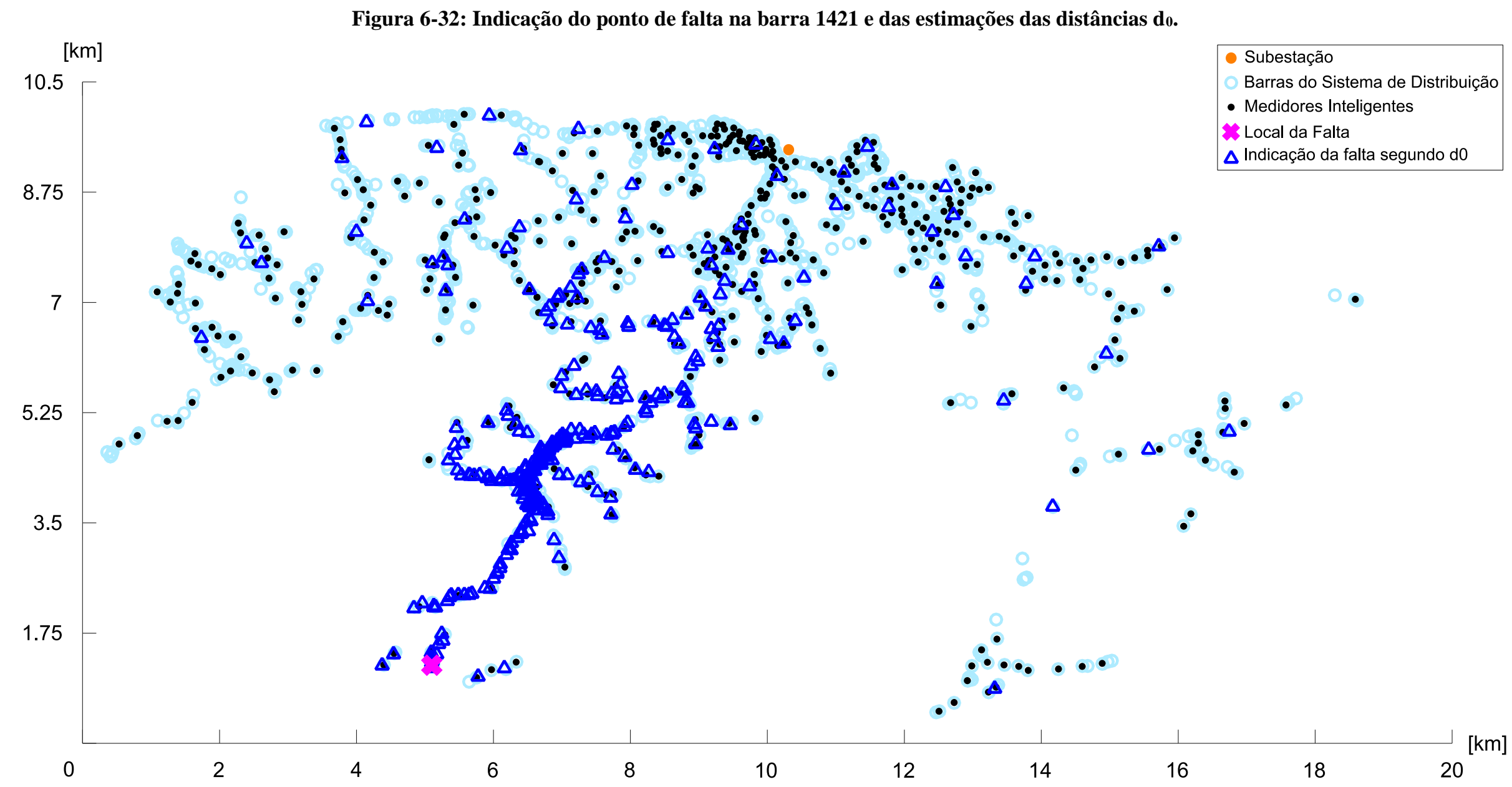

Fonte: autoria própria. 
Figura 6-33: Indicação do ponto de falta na barra 1421, das estimações das distâncias do e da região com maior concentração de estimações.

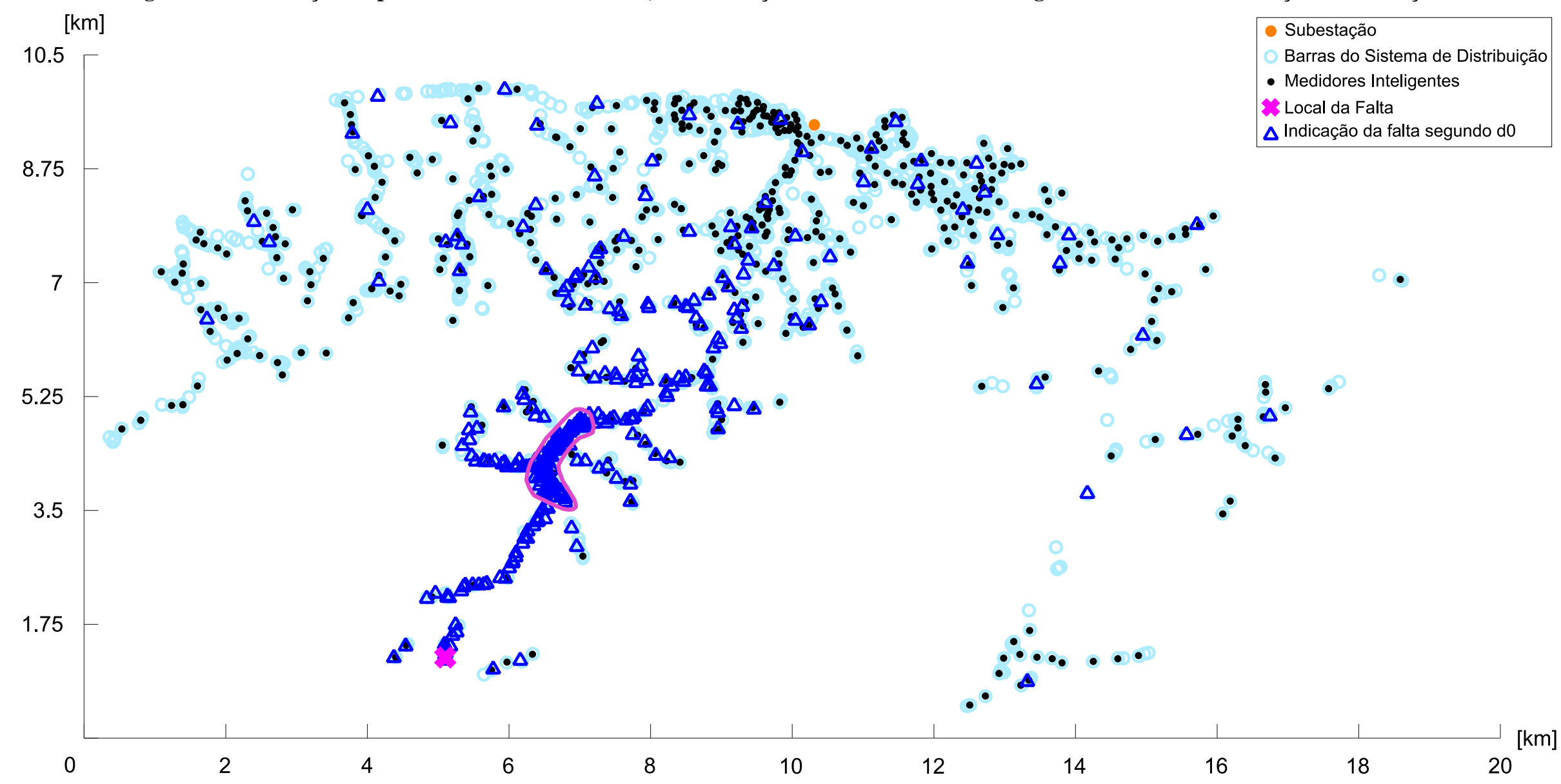

Fonte: autoria própria. 


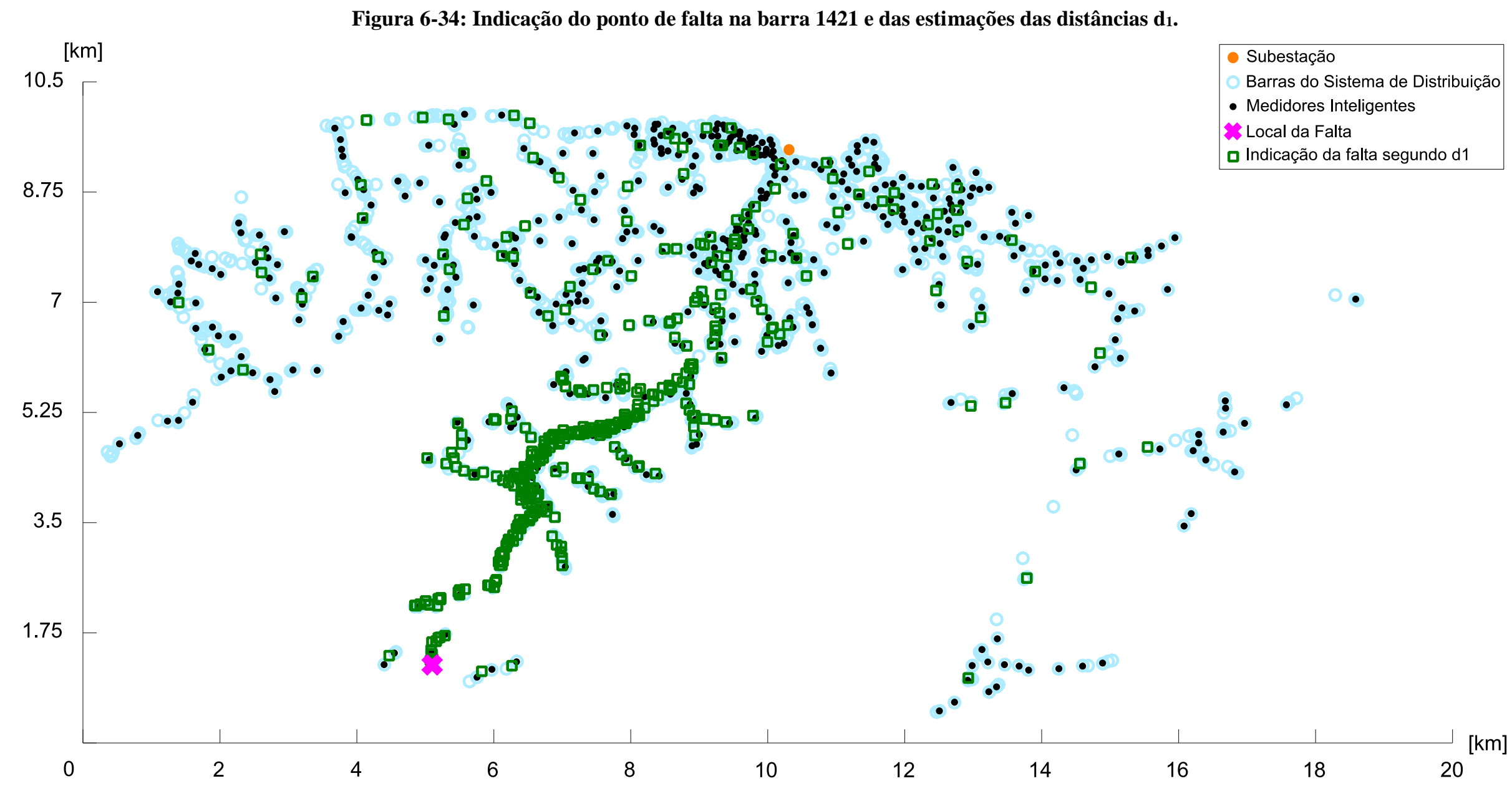

Fonte: autoria própria. 
Figura 6-35: Indicação do ponto de falta na barra 1421, das estimações das distâncias d e da região com maior concentração de estimações.

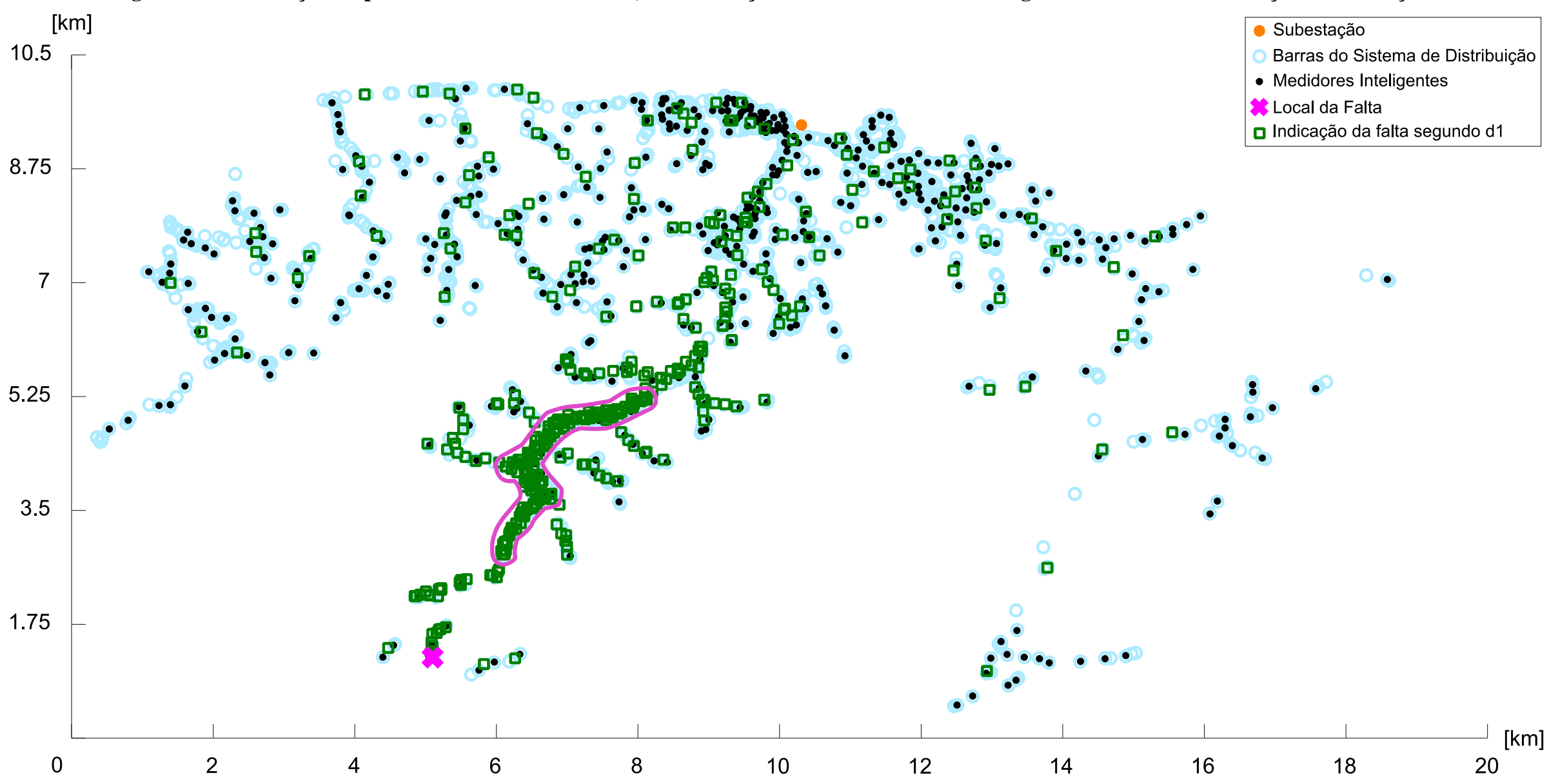

Fonte: autoria própria. 


\subsection{3 - Resultados da Localização de Faltas para os Casos de Validação da Metodologia Proposta}

Fazendo uso da redundância de informações proveniente dos 505 medidores inteligentes e dos três parâmetros estimados pelos sistemas inteligentes, buscou-se definir o local ou região de ocorrência da falta para as 85 simulações do teste de validação seguindo o processo exposto nas seções anteriores.

Como resultado na Tabela 6.8 é apresentado o erro absoluto máximo de localização para cada uma destas simulações, a partir dos quais observa-se que o menor erro é de $87 \mathrm{~m} \mathrm{e}$ ocorre no teste 11, já o maior é de 2854 m e acontece no teste 57.

Tendo em vista os erros apresentados nos treinamentos e testes dos classificadores, bem como nas estimações para o conjunto de validação, pode-se afirmar que no teste 11 a barra sob falta se localiza em uma região do alimentador com muitos medidores próximos dela e entre si, porém não aglomerados exageradamente. Isto se justifica, pois nesta situação os erros de estimação das distâncias tendem a ser menores já que os medidores não estão extremamente próximos entre si e a possibilidade de estimação errônea do estado de sensibilização dos mesmos não compromete o processo de localização por haver muitos medidores próximos ao local da falta.

Já para o teste 57 pode-se dizer que a barra sob falta se localiza em um dos extremos do alimentador distante da subestação e que há poucos medidores próximos a mesma. Esta afirmação se justifica uma vez que com um número reduzido de medidores próximos a barra sob falta a indicação do "caminho" de sensibilização dos medidores é dificultada e porque em estimações para elevadas distâncias os classificadores implementados têm menor número de ocorrências e erro proporcionalmente maior.

Por fim, na Figura 6.36 é apresentado o histograma dos erros da Tabela 6.8, por meio do qual se pode ver a distribuição do número de ocorrências desses erros em função da distância. Verifica-se que há poucas ocorrências com erros muito baixos ou muito altos, e que a maior parte dos erros se concentra entre $200 \mathrm{~m}$ e $1000 \mathrm{~m}$, corroborando com o que fora apresentado nas seções anteriores e era esperado pela metodologia desenvolvida. 
Tabela 6-8: Erros do processo de localização de faltas para as simulações do teste de validação.

\begin{tabular}{|c|c|}
\hline Teste & $\begin{array}{c}\text { Erro } \\
\text { absoluto } \\
\text { máximo }[\mathrm{m}]\end{array}$ \\
\hline 1 & 627 \\
\hline 2 & 1135 \\
\hline 3 & 228 \\
\hline 4 & 737 \\
\hline 5 & 433 \\
\hline 6 & 388 \\
\hline 7 & 1234 \\
\hline 8 & 647 \\
\hline 9 & 545 \\
\hline 10 & 898 \\
\hline 11 & 87 \\
\hline 12 & 1554 \\
\hline 13 & 289 \\
\hline 14 & 735 \\
\hline 15 & 434 \\
\hline 16 & 611 \\
\hline 17 & 922 \\
\hline 18 & 1037 \\
\hline 19 & 2456 \\
\hline 20 & 1942 \\
\hline 21 & 214 \\
\hline 22 & 616 \\
\hline 23 & 749 \\
\hline 24 & 260 \\
\hline 25 & 970 \\
\hline 26 & 749 \\
\hline 27 & 1341 \\
\hline 28 & 238 \\
\hline 29 & 174 \\
\hline
\end{tabular}

\begin{tabular}{c|c}
\hline Teste & $\begin{array}{c}\text { Erro } \\
\text { absoluto } \\
\text { máximo [m] }\end{array}$ \\
\hline 30 & 586 \\
\hline 31 & 898 \\
\hline 32 & 256 \\
\hline 33 & 1485 \\
\hline 34 & 254 \\
\hline 35 & 1027 \\
\hline 36 & 560 \\
\hline 37 & 340 \\
\hline 38 & 2150 \\
\hline 39 & 434 \\
\hline 40 & 198 \\
\hline 41 & 647 \\
\hline 42 & 224 \\
\hline 43 & 852 \\
\hline 44 & 668 \\
\hline 45 & 930 \\
\hline 46 & 435 \\
\hline 47 & 1471 \\
\hline 48 & 2030 \\
\hline 49 & 566 \\
\hline 50 & 282 \\
\hline 51 & 826 \\
\hline 52 & 912 \\
\hline 53 & 1308 \\
\hline 54 & 1911 \\
\hline 55 & 676 \\
\hline 56 & 845 \\
\hline 534 \\
\hline 34
\end{tabular}

\begin{tabular}{|c|c|}
\hline Teste & $\begin{array}{c}\text { Erro } \\
\text { absoluto } \\
\text { máximo }[\mathrm{m}]\end{array}$ \\
\hline 58 & 829 \\
\hline 59 & 310 \\
\hline 60 & 698 \\
\hline 61 & 559 \\
\hline 62 & 717 \\
\hline 63 & 1643 \\
\hline 64 & 2074 \\
\hline 65 & 202 \\
\hline 66 & 604 \\
\hline 67 & 947 \\
\hline 68 & 534 \\
\hline 69 & 450 \\
\hline 70 & 351 \\
\hline 71 & 1891 \\
\hline 72 & 240 \\
\hline 73 & 1630 \\
\hline 74 & 987 \\
\hline 75 & 1002 \\
\hline 76 & 842 \\
\hline 77 & 610 \\
\hline 78 & 727 \\
\hline 79 & 163 \\
\hline 80 & 552 \\
\hline 81 & 873 \\
\hline 82 & 727 \\
\hline 83 & 2277 \\
\hline 84 & 1908 \\
\hline 85 & 578 \\
\hline
\end{tabular}

Fonte: autoria própria. 
Figura 6-36: Erro absoluto máximo de localização para os testes das simulações do conjunto de validação.

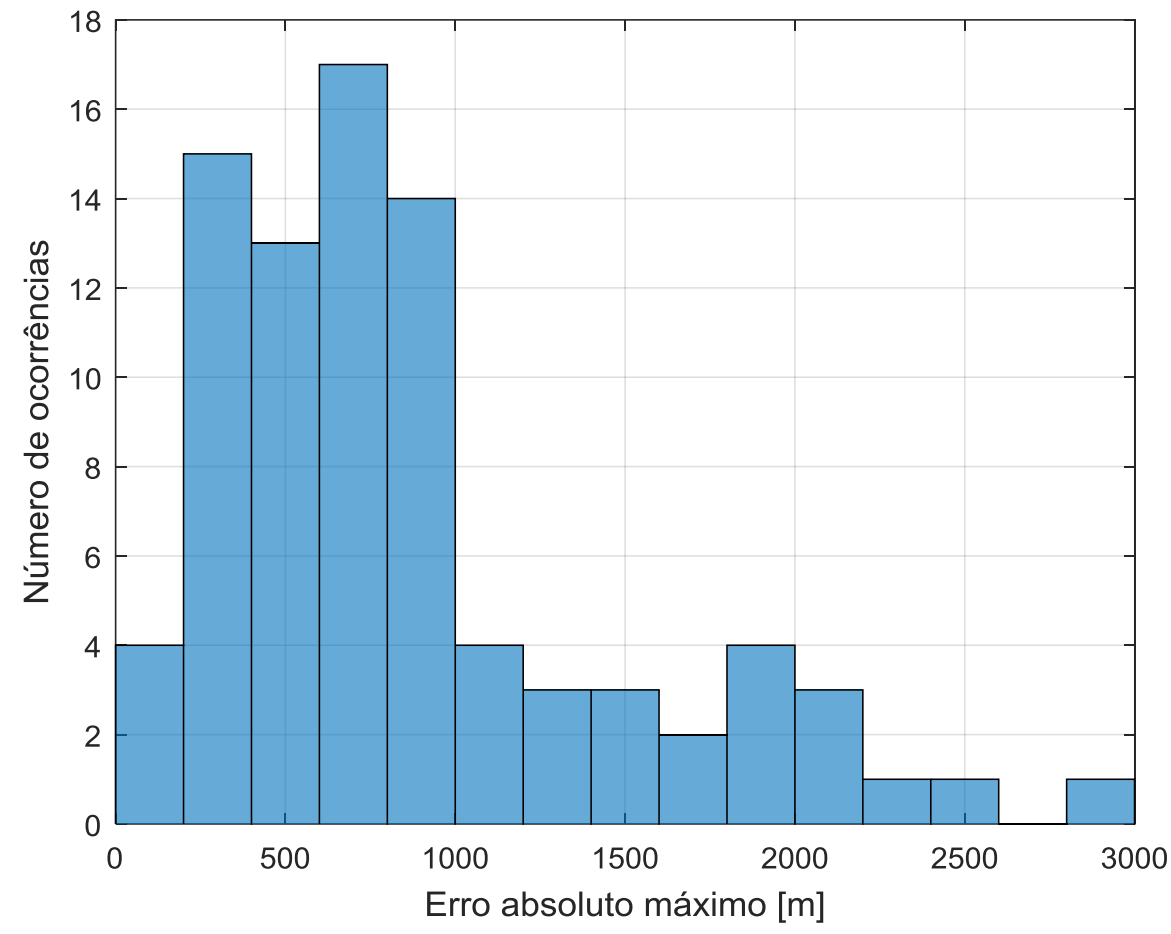

Fonte: autoria própria.

\section{3 - Considerações Parciais sobre a Aplicação da Metodologia para Localização de Faltas em Sistemas de Distribuição}

Ao longo desse capítulo foram apresentados os desenvolvimentos para implementação, por meio do software WEKA, dos 3 sistemas inteligentes da metodologia proposta para localização de faltas dedicados a estimação das distâncias e impedâncias de sequência zero e positiva, e da sensibilização dos medidores inteligentes a passagem da corrente de falta. Para tanto, foi utilizado o algoritmo J48 da técnica de classificação Árvore de Decisão (AD) com validação cruzada (cross-validation) como método de treinamento e teste, tomando-se o cuidado de parametrizá-lo de forma a evitar a especialização e o overfitting do modelo de AD a ser criado.

Com o intuito de extrair o maior conhecimento possível dos dados analisados, reduzir o banco de dados e os esforços computacionais para desenvolvimento dos classificadores, e possibilitar a indução de ADs menores e de maior capacidade de generalização, foi avaliada a 
melhor relação entre o número de divisões de classes e o particionamento e agrupamento das impedâncias em 28 situações distintas. Essa avaliação se deu pela análise das taxas de acerto e quantidade de dados utilizada nas 28 condições estabelecidas, assim como das métricas do software WEKA a respeito do comportamento do processo de indução das ADs e dos resultados de seus classificadores.

Também fora averiguada a resposta dos classificadores frente ao refinamento de dois importantes parâmetros do algoritmo J48. O "confidenceFactor", que representa o fator de confiança de uma regra na predição e define a precisão de cada regra gerada, e o "minNumObj", que está relacionado com o número mínimo de instâncias para uma regra da árvore existir. Após desenvolvimento destas etapas e de suas análises, constatou-se que os melhores classificadores para $Z_{0}$ e $Z_{1}$ obtiveram taxas de acerto de $92,77 \%$ e $87,15 \%$, respectivamente, e para a sensibilização dos medidores de $97,68 \%$, os quais foram aplicados a um conjunto de dados aleatoriamente selecionados com a finalidade de validar a metodologia proposta.

Como resultado do processo de validação observou-se que de forma geral os classificadores das impedâncias $Z_{0}$ e $Z_{1}$ estimam as mesmas para todo o espectro de valores prováveis com boa superposição entre os valores reais e estimados, ocorrendo um número de estimações maior do que o esperado nas faixas centrais do intervalo entre 0 e 1 pu e menor nos demais pontos. Para as distâncias $\mathrm{d}_{0}$ e $\mathrm{d}_{1}$ evidenciou-se a diferença entre seus erros de estimação, uma vez que para $\mathrm{d}_{0} \mathrm{o}$ erro absoluto médio foi de $1,78 \mathrm{~km}$ e o erro relativo absoluto $15,68 \%$, enquanto para $d_{1}$ os mesmos foram respectivamente $2,34 \mathrm{~km}$ e 21,05\%. Já para a estimação do estado de sensibilização dos medidores notou-se o elevado grau de acerto entre o estado real e o estimado cuja taxa de erro relativo absoluto foi de $6,73 \%$.

A partir dos dois estudos de caso apresentados foi salientada a relevância das etapas de cruzamento e análise das informações disponibilizadas por $\mathrm{d}_{0}, \mathrm{~d}_{1}$ e o estado de sensibilização dos medidores no processo de definição do local ou região de ocorrência da falta. Além disso, por meio dos mesmos também se evidenciou a importância do uso de informações redundantes pela presente metodologia, pois a procura por locais com concentração de estimações minimizou a busca em regiões do alimentador com dispersão de estimativas incorretas, auxiliando o processo de localização de faltas. Também ficou evidente a importante colaboração da associação entre a indicação de sensibilização dos medidores e a área de concentração das distâncias estimadas, pois podem haver áreas com muitas indicações de ocorrência da falta sem que o local real da falta esteja contemplado dentro de usa abrangência.

Finalizando, foram expostos os resultados da localização de faltas para os casos de validação da metodologia proposta, nos quais observou-se poucas ocorrências com erros de 
distância até o local da falta muito baixos ou muito altos, e que a maior parte dos erros se concentra entre $200 \mathrm{~m}$ e $1000 \mathrm{~m}$, corroborando com o que fora apresentado durante as etapas de estimação dos parâmetros de saídas dos 3 sistemas inteligentes implementados e que era esperado pela metodologia desenvolvida. 


\section{CAPÍTULO 7}

\section{CONCLUSÕES E TRABALHOS FUTUROS}

Neste capítulo, são apresentadas as conclusões finais obtidas a partir do desenvolvimento da presente investigação cientifica, e são expostas propostas de trabalhos futuros para continuidade da mesma.

\section{1 - Conclusões}

A partir dos resultados obtidos conclui-se que com os estudos bibliográficos e históricos realizados foi possível a construção de uma base sólida sobre os principais aspectos que envolvem a modernização das redes de distribuição no contexto das tecnologias propostas pelas Redes Elétricas Inteligentes (REIs), e a respeito da ocorrência de faltas nos sistemas de distribuição, bem como das principais técnicas para sua localização.

Depreende-se que a aplicação dos conceitos de REI trará novas perspectivas aos SEP, e sobretudo aos sistemas de distribuição, promovendo a modernização da sua infraestrutura e fornecendo meios para integração com novas tecnologias, adoção e inclusão de preceitos sustentáveis, além de prover novas funcionalidades e possibilitando para os sistemas elétricos. $\mathrm{Na}$ conjuntura da presente pesquisa destacam-se, entre as funcionalidades das REIs, as referentes à medição inteligente em virtude de sua capacidade de monitoramento do sistema de distribuição e fornecimento de dados, especificamente sinais de tensão, em tempo real e de forma bidirecional.

O panorama de iniciativas de pesquisa em REIs por diversos países demonstra a relevância deste tema e mostra como seu desenvolvimento e implantação encontra-se em curso de ampliação, apresentando-se um campo bastante vasto para novos estudos e proposição de soluções inovadoras. No Brasil, observa-se entre os maiores motivadores para implantação das REIs a busca por melhorias na confiabilidade e segurança no fornecimento de energia, assim 
como na infraestrutura de medição inteligente, áreas estas em que se insere a proposta desta tese.

Conforme exposto, a variedade de agentes causadores de faltas nos SEPs e sua imprevisibilidade são marcantes, estando os sistemas de distribuição mais propensos a faltas temporárias, decorrentes de falha em equipamentos e contato de animais com a rede elétrica. Devido à inerência das faltas, diversos métodos para localizá-las vêm sendo desenvolvidos nas últimas décadas, porém as dificuldades encontradas pelos mesmos em virtude da variedade de situações e sistemas a que se aplicam, fazem deste um problema ainda sem uma solução fechada.

Evidencia-se que têm sido buscadas metodologias robustas, eficientes e ágeis, e ao mesmo tempo de simples aplicação, pautadas no uso de sistemas inteligentes para tratamento de possíveis incertezas e imprecisões nos dados e informações disponibilizados aos métodos de localização. Também se nota a tendência de exploração da multimedição dos sinais de tensão e corrente pela inserção das tecnologias de REI, orientação esta em que se insere a metodologia proposta pela presente pesquisa, visando a localização de faltas pautada no monitoramento e aquisição de medidas dispersas de tensão da rede elétrica.

Além de todo seu potencial de monitoramento, medição e controle, as REIs trazem consigo a necessidade de armazenamento de um grande volume de dados e de extração de conhecimentos uteis dos mesmos, o que pode ser realizado pelo processo de Descoberta de Conhecimento em Bancos de Dados. Para fins de delimitação da presente pesquisa, a descoberta de conhecimento a partir dos dados de medidas dispersas de tensão e indicação de sensibilização dos medidores inteligentes fora conduzida por um processo de classificação de padrões. Buscou-se a extração de conhecimento pela exploração do espaço de hipóteses baseada no uso da informação presente no conjunto de dados aquisitados empregando ferramentas de Aprendizado de Máquina (AM) voltadas para classificação.

O desenvolvimento e aplicação das ferramentas de AM tem ganho destaque em virtude de sua capacidade de inferir modelos automatizados com baixo esforço computacional para análise de grandes e complexos bancos de dados, fornecendo resultados rápidos e precisos, e por isto foram escolhidas para esta pesquisa. Dentre as ferramentas de AM que incorporam técnicas de classificação, foram selecionadas as Árvores de Decisão (ADs) para estimação dos parâmetros utilizados pela metodologia proposta para a localização de faltas. Esta seleção se deu devido a precisão, velocidade, robustez, escalabilidade e flexibilidade das ADs, além da sua facilidade de interpretação e análise do seu modelo, além do desempenho comprovado por diferentes pesquisas. 
Para implementação das ADs foi escolhido o algoritmo C4.5, implementado em linguagem Java e nomeado como J48 no software WEKA, o qual constrói um modelo de AD baseado em um conjunto de dados de treinamento para posterior classificação de outras instâncias de um conjunto de teste. Sua função de avaliação, utilizada para escolher qual atributo determinará a ramificação da árvore, baseia-se na análise da função do ganho de informação do atributo.

O algoritmo J48 utiliza técnicas de poda para remover da $\mathrm{AD}$ os segmentos que possuem menor ganho de informação, inibindo a ocorrência de overfitting. Além disso, este algoritmo trabalha com atributos categóricos e contínuos, trata valores desconhecidos de maneira diferenciada e não os utiliza nos cálculos do ganho de informação e entropia, gerando árvores mais precisas e menos complexas. Ainda a fim de evitar a especialização e o overfitting do modelo de Árvore de Decisão a ser criado, optou-se pela validação cruzada (crossvalidation) como método de treinamento e teste, pois por meio do mesmo cada um dos exemplos é utilizado tanto para treinamento quanto para teste.

Trabalhando com todo o banco de dados, composto pelos 25 atributos de entrada (tensões) e as impedâncias de sequência zero e positiva como saídas, procurou-se definir a melhor relação entre o número de divisões de classes, o intervalo e agrupamento das impedâncias, e a quantidade de dados utilizada para treinamento dos classificadores das ADs. Destaca-se que este procedimento visava descobrir os dados com maior conhecimento embutido, e teve impacto positivo na redução do banco de dados exigindo menor capacidade de armazenamento e esforços computacionais para desenvolvimento dos classificadores, além de induzir árvores com menos dados e maior capacidade de generalização.

A análise dos resultados das métricas dos classificadores das Árvores de Decisão induzidas revelaram que o melhor classificador para impedância $\mathrm{Z}_{0}$ é o que utiliza os dados referentes às impedâncias do intervalo entre $0 \Omega$ e $30 \Omega$ divididas em 3 classes. Já o melhor classificador para impedância $\mathrm{Z}_{1}$ é o que utiliza os dados referentes às impedâncias do intervalo entre $0 \Omega$ e $9 \Omega$, divididas também em 3 classes. Ressalta-se, que o conjunto de dados relativo a sensibilização dos medidores a passagem de corrente de falta não fora dividido como as impedâncias, pois o mesmo já possuía duas classes de saída pré-definidas, uma referente a sua sensibilização e outra a não sensibilização. As taxas de acertos para os classificadores dos 3 parâmetros mostraram-se elevadas, uma vez que seus valores foram 92,77\%, 87,15\% e 97,68\% para $Z_{0}, Z_{1}$ e a sensibilização dos medidores, respectivamente.

Agora, focando a validação da metodologia, a comparação entre os resultados da estimação da impedância $Z_{0}$ e os valores reais esperados mostraram que o classificador estima 
$Z_{0}$ para todo o espectro de valores prováveis com boa superposição entre os valores reais e estimados e segue seu perfil de distribuição. Pela avaliação da distribuição do erro relativo da estimação desta impedância, verificou-se que a taxa de erro entre os valores esperados e os estimados concentrou-se entre $\pm 0.2 \mathrm{pu}$, indicando que na faixa em que se tem maior número de ocorrências de erro, este é proporcionalmente baixo se comparado com o erro máximo, pois ocorre para impedâncias de menor valor.

Para distância $\mathrm{d}_{0}$ entre o ponto de falta e os medidores inteligentes obtida a partir da impedância de sequência zero foi notória a concentração de valores até próximo de $9 \mathrm{~km}$ devido a concentração dos medidores em barras próximas e as características de topologia do sistema elétrico sob análise. A distribuição do erro relativo entre os valores esperados e os estimados, revelou que a maior parte dos erros se deu na faixa de $\pm 5 \mathrm{~km}$, o que pode dificultar a rápida localização da falta por se tratar de uma faixa com valores não muito baixos em relação ao comprimento total do alimentador, porém até $\pm 2.5 \mathrm{~km}$ o número de ocorrências do erro também possui valor elevado e o processo de cruzamento das informações contribuirá para restringir a área de possível local da falta.

Verificou-se a tendência de crescimento do erro com o aumento da distância de ocorrência da falta, o que já era esperado devido as observações realizadas no processo de definição, treinamento e teste do classificador, porém este fato não compromete a capacidade de generalização do estimador. Ainda avaliando o erro de estimação da distância $\mathrm{d}_{0}$ calculouse seu erro absoluto médio e erro relativo absoluto, os quais para os dados de validação são $1,78 \mathrm{~km}$ e $15,68 \%$, respectivamente. Dado o processo de estimação pelo classificador de $\mathrm{Z}_{0}$ com suas taxas de erros e a diferença de ordem de grandeza entre impedância em ohm e distância em quilômetros, pode-se dizer que ambos os erros calculados para $\mathrm{d}_{0}$ são condizentes, sobretudo o erro relativo absoluto, o qual para o classificador é de aproximadamente $14 \%$.

Já para a estimação da impedância $Z_{1}$, mostrou-se que de forma geral seu classificador a estima para todo o espectro de valores prováveis com boa superposição entre os valores reais e estimados, e segue seu perfil de distribuição. A análise da distribuição do erro relativo evidencia a concentração de erros entre -0.1 e 0.2 pu e assim como ocorre para $Z_{0}$, este fato indica que na faixa em que se tem maior número de ocorrências de erro, este é proporcionalmente baixo se comparado com o erro máximo, pois se dá para impedâncias de menor valor.

Para distância $\mathrm{d}_{1}$ entre o ponto de falta e os medidores inteligentes obtida a partir da impedância de sequência positiva, observou-se uma concentração bastante acentuada de valores até $5 \mathrm{~km}$, reflexo também do agrupamento dos medidores e das características 
topológicas do sistema elétrico sob análise. Contudo, na distribuição do seu erro relativo há um pico menor para o número de ocorrências de erros e a ampliação da faixa de concentração da taxa de erro, que ocorre entre -7.5 e $10 \mathrm{~km}$. Calculando-se o erro absoluto médio e o erro relativo absoluto para a mesma, cujos valores são 2,34 km e 21,05\%, verifica-se a coerência dos mesmos apesar da diferença de $2,95 \%$ entre os erros absolutos relativos, uma vez que para o classificador este dado é de aproximadamente $24 \%$.

Por fim, a validação da estimação do terceiro parâmetro utilizado, ou seja, o estado de sensibilização ou não dos medidores a passagem da corrente de falta, mostrou elevado grau de acerto entre o estado real e o estimado, cuja taxa de erro relativo absoluto foi de $6,73 \%$.

Por meio da apresentação dos dois estudos de caso, selecionados entre as simulações do conjunto de validação, buscou-se mostrar o processo de cruzamento e análise das informações disponibilizadas pelos 3 sistemas inteligentes distintos da metodologia proposta. Foi possível observar que ocorrem estimações de pontos errôneos distribuídos ao longo do sistema elétrico para os três parâmetros avaliados, como era esperado. Todavia, a redundância de informações disponibilizada pelos 505 medidores proporciona uma concentração dos pontos estimados próximos ao local da falta, e fazendo a intersecção entre as regiões de concentração das estimações de distância este problema é contornado. Salienta-se que devido as taxas de acerto dos classificadores da impedância $Z_{0}$, e consequentemente das distâncias $\mathrm{d}_{0}$, serem maiores, a delimitação de uma área maior pela estimação das distâncias $\mathrm{d}_{1}$ é condizente com as outras etapas da metodologia desenvolvida.

Entre os dois estudos de caso também se nota o aumento da distribuição dos pontos de indicação da falta, e consequentemente do erro, para o caso em que a falta ocorre em um dos trechos finais do alimentador, em relação a ocorrência em um ponto próximo a subestação. Isto se deve a dificuldade de estimação do classificador para faltas em pontos extremos do sistema elétrico e com poucos medidores inteligentes próximos ao local da falta.

A análise do erro absoluto máximo de localização para as simulações do conjunto de validação mostrou que o menor erro ocorrido fora de $87 \mathrm{~m}$ entre o local da falta e a região estimada, e o maior de $2854 \mathrm{~m}$. Já pelo histograma do erro absoluto máximo de localização verificou-se que há poucas ocorrências com erros muito baixos ou muito altos, e que a maior parte dos erros se concentra entre $200 \mathrm{~m}$ e $1000 \mathrm{~m}$, corroborando com o que fora apresentado pelos processos de estimação da metodologia desenvolvida.

Todavia, apesar do erro absoluto máximo de localização não ser tão baixo, pode-se concluir que com a estimativa obtida a busca pelo local de ocorrência da falta pelas equipes de manutenção da rede seria consideravelmente reduzida. Depreende-se ainda, que o uso de 
informações redundantes, conforme proposto pela metodologia desta tese, minimiza os erros de estimação, e a análise de medições dispersas da tensão do sistema elétrico auxilia o processo de localização de faltas.

Finalizando, pode-se afirmar que os objetivos delineados para a presente pesquisa foram atingidos e a partir dos resultados obtidos verifica-se a aplicabilidade da metodologia proposta. Posto isto, na próxima seção são mencionadas propostas de trabalhos futuros para sequência das investigações desta pesquisa.

\section{2 - Trabalhos Futuros}

Dentre as propostas de continuidade das pesquisas desenvolvidas e apresentadas nesta tese, pode-se destacar os seguintes trabalhos futuros:

- Composição de uma base de dados de simulações abordando os demais tipos de falta além das fase-terra com o objetivo de estender a técnica para situações de falta mais genéricas.

- Composição de uma base de dados para alimentadores com configurações distintas do utilizado até este momento da pesquisa e com desbalanço de carga e de tensão para estender a validação da metodologia proposta.

- Composição de uma base de dados de simulações que comtemple diferentes tipos de falta e também a inserção de geradores distribuídos ao longo de pontos variados do alimentador de distribuição para avaliação do comportamento da tensão e consequente estimação dos parâmetros da metodologia desenvolvida.

- Aprimoramento do método de partição e agrupamento das variáveis de entrada dos classificadores das Árvores de Decisão induzidas, afim de refinar seu modelo, aumentar os acertos dos classificadores e reduzir o custo computacional do processo de localização de faltas.

- Avaliação das estimações dos parâmetros da metodologia com uso de outras ferramentas de aprendizagem de máquinas, tais como Redes Neurais Artificias, Máquinas de Vetores Suporte e Naive Bayes. 


\section{CAPÍTULO 8}

\section{REFERÊNCIAS BIBLIOGRÁFICAS}

3M. Smart Grid - Energia ligada, eficiente e sustentável. Disponível em: http://solutions.3m.com/wps/portal/3M/pt_PT/PT-Smart-Grid/Smart-Grid/. Acessado em: 05/08/2017.

ABDI - AGÊNCIA BRASILEIRA DE DESENVOLVIMENTO INDUSTRIAL. Mapeamento da Cadeia Fornecedora de TIC e de seus Produtos e Serviços para Redes Elétricas Inteligentes (REI) - Mapeamento Internacional da Cadeia de Produtos e Serviços de TIC para REI. Brasília, DF, Brasil, 2014, 86 p.

ACRA, R.; THAKER, M. Internet Standards Come to the Advanced Metering Infrastructure. Electric Energy T\&D MAGAZINE, pp. 36-39, Sep, 2010.

ANDERSON, P. M. Analysis of Faulted Power Systems: Paul M. Anderson. IEEE Press Power Systems Engineering Series, New York, 1995, p. 513.

ANEEL, Procedimentos de Distribuição de Energia Elétrica no Sistema Elétrico Nacional (PRODIST) - Módulo 8 - Qualidade da Energia Elétrica. Revisão 8 (após realização da AP 082/2015). Resolução Normativa n $n^{\circ}$ 728/2016, vigente a partir de 01/01/2017. Disponível em: http://www.aneel.gov.br/documents/656827/14866914/M\%C3\%B3dulo8_Revisao_8/9c78cfa b-a7d7-4066-b6ba-cfbda3058d19. Acessado em: 19/08/2017.

BAHMANYAR, A.; JAMALI, S.; ESTEBSARI, A.; BOMPARD, E. A comparison framework for distribution system outage and fault location methods. Electric Power Systems Research, vol. 145, pp. 19-34, April, 2017. 
BATISTA, O. E.; FlAUZINO, R. A.; ARAUJO, M. A; MORAES, L. A.; SILVA, I. N. Methodology for information extraction from oscillograms and its application for highimpedance faults analysis. International Journal of Electrical Power \& Energy Systems. vol. 76, pp. 23-34, March, 2016.

BAYINDIR, R.; COLAK, I.; FULLI, G.; DEMIRTAS, K. Smart grid technologies and applications. Renewable and Sustainable Energy Reviews, vol. 66, pp. 499-516, December, 2016.

BELL, J. Machine Learning: Hands-on for developers and technical professionals. 1st Edition, Wiley, 2014, 408 p.

BORGES, F. A. S. Extração de Características Combinadas com Árvore de Decisão para Detecção e Classificação dos Distúrbios de Qualidade da Energia Elétrica. Dissertação de Mestrado apresentada ao Programa de Pós-Graduação em Engenharia Elétrica e de Computação, Escola de Engenharia de São Carlos, Universidade de São Paulo, São Carlos, Brasil, 2013.

BORGHETTI, A.; BOSETTI, M.; SILVESTRO, D.; NUCCI, C. A.; PAOLONE, M. Continuous-wavelet transform for fault location in distribution power networks: Definition of mother wavelets inferred from fault originated transients. IEEE Transactions on Power Systems, vol. 23, nº 2, pp. 380-388, May, 2008.

BORGHETTI, A.; CORSI, S.; NUCCI, C. A.; PAOLONE, M. On the use of continuouswavelet transform for fault location in distribution power systems. International Journal of Electrical Power \& Energy Systems, vol. 28, nº 9, pp. 608-617, Nov. 2006.

BORLASE, S. Smart Grids: Infrastructure, Technology, and Solutions. CRC Press, Taylor \& Francis Group, New York, USA, 2013, 591 p.

BREIMAN, L., FRIEDMAN, J. H., OLSHEN, R. A., \& STONE, C. J. Classification and Regression Trees. Series: Wadsworth Statistics/Probability. 1st Edition, Chapman and Hall/CRC, 1984, 368 p. 
BRETAS; A.; SALIM, R., Fault Location in Unbalanced DG Systems using the Positive Sequence Apparent Impedance. IEEE/PES Transmission \& Distribution Conference and Exposition: Latin America, Caracas, Venezuela, pp. 1-6, Aug. 2006.

CAMINHA, A. C. Introdução a Proteção dos Sistemas Elétricos. $9^{\text {a }}$ Edição. São Paulo, Editora Edgard Blucher, 2004, 224 p.

CGEE - CENTRO DE GESTÃO E ESTUDOS ESTRATÉGICOS. Redes elétricas inteligentes: contexto nacional. Série documentos técnicos. n 16, Brasília, DF, Brasil, 2012, $172 \mathrm{p}$.

COLAK, I.; SAGIROGLU, S.; FULLI, G.; YESILBUDAK, M.; COVRIG, C-F. A survey on the critical issues in smart grid technologies, Renewable and Sustainable Energy Reviews, vol. 54, pp.396-405, February, 2016.

DAS, R.; SACHDEV, M.; SIDHU, T. A Fault Locator for Radial Subtransmission and Distribution Lines. IEEE Power Engineering Society Summer Meeting, Seattle, USA, pp. 443448, Jul. 2000.

DELEN, D.; WALKER, G.; KADAM, A. Predicting breast cancer survivability: a comparison of three data mining methods. Artificial Intelligence in Medicine, vol. 34, n 2, pp. 113-127, 2005.

DEPURE, S.; WANG, L.; DEVABHAKTUNI, V. Smart meters for power grid: Challenges, issues, advantages and status. Renewable and Sustainable Energy Reviews. vol. 15, $\mathrm{n}^{\circ}$ 6, Aug. pp. 2736-2742, 2011.

DOE - U.S. DEPARTAMENT OF ENERGY. “GRID 2030” A National Vision for Electricity's Second 100 Years. Office of Electric Transmission and Distribution, USA, 2003, $44 \mathrm{p}$.

DOE - U.S. DEPARTAMENT OF ENERGY. What is the Smart Grid? Office of Electricity Delivery and Energy Reliability. 2017. Disponível em: https://www.smartgrid.gov/the_smart_grid/. Acessado em: 22/08/2017. 
DUGAN, R. C.; MCGRANAGHAN, M. F.; SANTOSO, S.; BEATY, H. W. Electrical power systems quality. $2^{\mathrm{a}}$ Ed. New York: McGraw-Hill, 2003, 528 p.

DUTRA, J. C.; PINHEIRO, M. C.; LEITE, N. F.; JATOBÁ, P.; MEDEIROS, L. I.; SCHMIDT, M.; PACHECO, L.; MAIA, F.; GUIMARÃES, D. S.; NETO, A. B. Redes Elétricas Inteligentes no Brasil - subsídios para um plano nacional de implantação. $2^{\mathrm{a}}$ Edição, São Paulo, Editora Synergia, 2013, 296 p.

EPRI - ELECTRIC POWER RESEARCH INSTITUTE. Report to NIST on the Smart Grid Interoperability Standards Roadmap. Palo Alto, California, USA, 2009. 184 p.

EPRI - ELECTRIC POWER RESEARCH INSTITUTE. The Green Grid - Energy Savings and Carbon Emissions Reductions Enabled by a Smart Grid. Technical Update Report 1016905, Palo Alto, California, USA, 2008. 64 p.

EUROPEAN COMMISSION. European Technology Platform Smart Grids - Vision and Strategy for Europe's Electricity Networks of the Future. Directorate-General for Research Sustainable Energy Systems. Luxembourg: Office for Official Publications of the European Communities, Printed in Belgium, 2006. 44 p.

FANG, X.; MISRA, S.; XUE, G.; YANG, D. Smart Grid - The New and Improved Power Grid: A Survey. IEEE Communications Surveys \& Tutorials, vol. 14, n 4, Fourth Quarter, 2012.

FAYYAD, U. M.; PIATESKY-SHAPIRO, G.; SMYTH, P. From Data Mining to Knowledge Discovery: An Overview. Advances in Knowledge Discovery and Data Mining, American Association for Artificial Intelligence Menlo Park, CA, USA, 1996.

FRAWLEY, W. J.; PIATETSKY-SHAPIRO, G.; MATHEUS, C. J. Knowledge discovery in databases: an overview. AI Magazine, vol. 13, nº 3, p. 57-70, 1992.

GALIJASEVIC, Z; ABUR, A. Fault Location Using Voltage Measurements. IEEE Transactions on Power Delivery, vol. 17, n² 2, p. 441-445, Apr. 2002. 
GELLINGS, C. W. The smart grid: enabling energy efficiency and demand response. Fairmont Press, Lilburn, USA, 2009, 300 p.

GIRGIS, A. A.; FALLON, C. M.; LUBKEMAN, D. L. A fault location technique for rural distribution feeders. IEEE Transactions on Industry Applications, vol. 29, nº 6, pp. 1170-1175, Nov/Dec. 1993.

GLOVER, J. D.; SARMA, M. S.; OVERBYE, T. J. Power System Analysis and Design, $5^{\mathrm{a}}$ Edição, Editora Cengage Learning, 2011, 848 p.

GOLDSCHIMIDT, R. R. Uma Introdução à Inteligência Computacional: fundamentos, ferramentas e aplicações. $1^{\text {a }}$ Edição, Rio de Janeiro, Editora IST-Rio. 2010, 142 p.

GOLLAPUDI, S. Practical Machine Learning. Packt Publishing, 2016, 468 p.

GONG, Y.; GUZMÁN, A. Integrated Fault Location System for Power Distribution Feeders. IEEE Transaction on Industry Application, vol. 49, n 3, May/June, 2013.

GONZALEZ, R. C.; THOMASON, M. G.: Syntactic pattern recognition: an introduction. Addison-Wesley Publishing Company, 1978, 283 p.

HAN, F.; YU, X.; AL-DABBAGH, M.; WANG, Y. Locating phase-to-ground short-circuit faults on radial distribution lines. IEEE Transactions on Industrial Electronics, vol. 54, $\mathrm{n}^{\mathrm{o}} 3$, pp. 1581-1590, 2007.

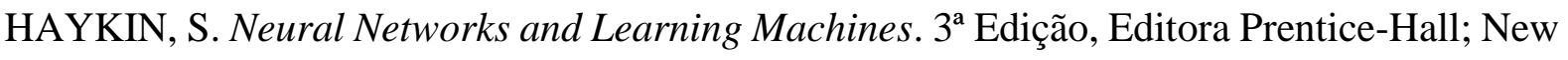
Jersey; 2008, 936 p.

IQTIYANILLHAM, N.; HASANUZZAMAN, M.; HOSENUZZAMAN, M. European smart grid prospects, policies, and challenges. Renewable and Sustainable Energy Reviews, vol. 67, pp. 776-790, January, 2017.

JAMALI, S.; BAHMANYAR, A.; BOMPARD, E. Fault location method for distribution networks using smart meters. Measurement, vol. 102, pp. 150-157, May, 2017. 
JARVENTAUSTA, P.; VERHO, P.; PARTANEN, J. Using fuzzy sets to model the uncertainty in the fault location process of distribution networks. IEEE Transactions on Power Delivery, vol. 9, nº 2, pp. 954-960, Apr. 1994.

JIANG, J.-A.; CHUANG, C.-L.; WANG, Y.-C.; HUNG, C.-H.; WANG, J.-Y.; LEE, C.-H; HSIAO, Y.-T. A Hybrid Framework for Fault Detection, Classification, and Location Part I: Concept, Structure, and Methodology. IEEE Transactions on Power Delivery, vol. 26, $\mathrm{n}^{\mathrm{o}} 3$, pp. 1988-1998, July. 2011.

KABALCI, Y. A survey on smart metering and smart grid communication. Renewable and Sustainable Energy Reviews, vol. 57, pp. 302-318, May, 2016.

KAGAN, N.; GOUVEA, M.; MAIA, F. C.; DUARTE, D.; LABRONICI, J.; GUIMARAES, D. S.; NETO, A. B.; SILVA, J. F. R.; PARTICELLI, F. Redes Elétricas Inteligentes no Brasil - análise de custos e benefícios de um plano nacional de implantação. $1^{\text {a }}$ Edição, Rio de Janeiro, Editora Synergia, 2013, 300 p.

KAGAN, N.; OLIVEIRA, C. C. B.; ROBBA, E. J. Introdução aos Sistemas Distribuição de Energia. 2a Edição, São Paulo, Editora Edgard Blücher, 2010, 328 p.

KAGAN, N.; ROBBA, E. J.; SCHMIDT, H. P. Estimação de Indicadores de Qualidade de Energia Elétrica. $1^{a}$ Edição, São Paulo, Editora Edgard Blücher, 2009, 230 p.

KEZUNOVIC, M. Smart fault location for smart grids. IEEE Transactions on Smart Grids, New York, vol. 2, nº 1, pp. 11-22, March. 2011.

KINDERMANN, G. Curto-Circuito. $5^{\text {a }}$ Edição, Florianópolis, Edição do Autor. UFSC-EELLABPLAN. 2010, 240 p.

KOHAVI, R. A study of cross-validation and bootstrap for accuracy estimation and model selection. In: International Joint Conference on Artificial Intelligence (IJCAI), Montreal, Quebec, Canada, pp. 1137-1143, 1995. 
KRISHNATHEVAR, R.; NGU, E. E. Generalized Impedance-Based Fault Location for Distribution Systems. IEEE Transactions on Power Delivery, vol. 27, $\mathrm{n}^{\circ}$ 1, pp. 449-451, Jan. 2012.

KUNDUR, P. Power System Stability and Control. New York, USA: McGraw-Hill, 1994.

LANDIS, J. R.; KOCH, G. G. The measurement of observer agreement for categorical data. Biometrics. vol. 33, n 1, pp. 159-174, March, 1977.

LEE, S. J.; CHOI, M. S.; KANG, S., H.; JIN, B. G.; LEE, D. S.; AHN, B. S.; YOON, N. S.; KIM, H. Y., WEE, S. B. An intelligent and efficient fault location and diagnosis scheme for radial distribution systems. IEEE Transactions on Power Delivery, vol. 19, n² 2, pp. 524-532, Apr. 2004.

LIN, X.; ZHAO, F.; WU, G.; LI, Z.; WENG, H. Universal wavefront positioning correction method on traveling-wave-based fault-location algorithms. IEEE Transactions on Power Delivery, vol. 27, n 3, pp. 1601-1610, July. 2012.

LOPES, F. V.; SANTOS, W. C.; FERNANDES JR., D.; NEVES, W. L. A.; SOUZA, B. A. An Adaptive Fault Location Method for Smart Distribution and Transmission Grids. IEEE PES Conference on Innovative Smart Grid Technologies (ISGT Latin America), Medelín, Colombia, pp. 1-7, Oct. 2011.

LOPES, F. V.; SILVA, K. M.; COSTA, F. B.; NEVES, W. L. A.; FERNANDES JR., D. RealTime Traveling-Wave-Based Fault Location Using Two-Terminal Unsynchronized Data. IEEE Transactions on Power Delivery, vol. 30, n 3, pp. 1067-1076, June. 2015.

MAMEDE FILHO, J.; MAMEDE, D. R. Proteção de Sistemas Elétricos de Potência. $1^{\mathrm{a}}$ Edição, Rio de Janeiro, Editora LTC, 2011, 620 p.

MCTI - MINISTÉRIO DA CIÊNCIA, TECNOLOGIA E INOVAÇÃO. Redes Elétricas Inteligentes - Diálogo Setorial Brasil-União Europeia (2014). Brasília, DF, Brasil, 2014, 204 p. 
MILARÉ, C. R. Extração de conhecimento de redes neurais artificiais utilizando sistemas de aprendizado simbólico e algoritmos genéticos. Tese de Doutorado apresentada ao Instituto de Ciências Matemáticas e de Computação, ICMC-USP, São Carlos, Brasil, 2003, 174 p.

MOHAMED, E. A.; RAO, N. D. Artificial neural network based fault diagnostic system for Electric power distribution feeders. Electric Power System Research, vol. 35, no 1, pp. 1-10, Oct. 1995.

MORA-FLÓREZ, J. J.; HERRERA-OROZCO, R. A.; BEDOYA-CADENA, A. F. Fault location considering load uncertainty and distributed generation in power distribution systems. IET Generation, Transmission \& Distribution, vol. 9, no 3, pp. 287-295, Feb. 2015.

NOVOSEL, D.; HART, D.; HU, Y.; MYLLYMAKI, J. System for Locating Faults and Estimating Fault Resistance in Distribution Networks with Tapped Loads. US Patent number 5839093. Vaasa, Finlândia: ABB Transmit Oy, 1998.

NTALAMPIRAS, S. Fault Diagnosis for Smart Grids in Pragmatic Conditions, IEEE Transactions on Smart Grid, vol. pp, nº 99, pp. 1-8, August, 2016.

OLIVEIRA, C. C. B.; SCHMIDT, H. P.; KAGAN, N.; ROBBA, E. J. Introdução a Sistemas Elétricos de Potência: Componentes Simétricas. $2^{\mathrm{a}}$ Edição, São Paulo, Editora Edgard Blücher, 2000, 467 p.

PENKOV, D.; RAISON, B.; ANDRIEU, C.; ROGNON, J.-P.; ENACHEANU, B. DG impact on three phase fault location. DG use for fault location purposes? International Conference on Future Power Systems, Amsterdam, Holanda, pp. 6, Nov. 2005.

PEREIRA, R. A. F.; SILVA, L. G. W.; KEZUNOVIC, M.; MANTOVANI, J. R. S. Improved fault location on distribution feeders based on matching during-fault voltage sags. IEEE Transaction on Power Delivery, vol. 24, n 2, pp. 852-862, April. 2009.

PINEDA, J. O. C. A entropia segundo Claude Shannon: o desenvolvimento do conceito fundamental da teoria da informação. Dissertação de Mestrado apresentada ao Programa de 
Pós-Graduação em História da Ciência, Pontifícia Universidade Católica de São Paulo. São Paulo, Brasil, 2006, 126 p.

POURAHMADI-NAKHLI, M.; SAFAVI, A. A. Path Characteristic Frequency-Based Fault Locating in Radial Distribution Systems Using Wavelets and Neural Networks. IEEE Transactions on Power Delivery, vol. 26, nº 2, pp. 772-781, Apr. 2011.

PRATI, R. C. Novas abordagens em Aprendizado de Máquina para Geração de Regras, Classes desbalanceadas e Ordenação de Casos. Tese Doutorado apresentada ao Instituto de Ciências Matemáticas e de Computação, ICMC-USP, São Carlos, Brasil, 2006, 191 p.

QUILICI-GONZALVEZ, J. A.; ZAMPIROLLI, F. A. Sistemas inteligentes e mineração de dados. $1^{\text {a }}$ Edição, Triunfal Gráfica e Editora, Santo André - SP, 2014, 148 p.

QUINLAN, J. R. C4.5: Programs for Machine Learning. Machine Learning, Morgan Kaufmann Publishers Inc., vol. 16, nº 3, pp. 235-240, 1994.

QUINLAN, J. R. Induction of Decision Trees. Machine Learning, vol. 1, n⿳⺈ 1, pp. 81-106, March, 1986.

REZENDE, S. O. Sistemas Inteligentes: Fundamentos e Aplicações. $1^{\mathrm{a}}$ Edição, Barueri, Editora Manole Ltda, 2003, 526 p.

SAHA, M. M.; IZYKOWSKI, J.; ROSOLOWSKI, E. Fault Location on Power Networks, London, Springer, 2010, 425 p.

SALIM R. H.; MEMBER, S.; RESENER, M.; FILOMENA, A. D.; REZENDE, K.; OLIVEIRA, C. DE; BRETAS, A. S. Extended Fault-Location Formulation for Power Distribution Systems. IEEE Transactions on Power Delivery, vol. 24, nº 2, pp. 508-516, Mar. 2009.

SATO, F.; FREITAS, W. Análise de Curto-Circuito e Princípios de Proteção em Sistemas de Energia Elétrica - Fundamentos e Prática. $1^{a}$ Edição, São Paulo, Editora Campus, 2014, 472 p. 
SENGER, E. C.; MANASSERO, G. Jr.; GOLDEMBERG, C.; PELLINI, E. L. Automated fault location system for primary distribution networks. IEEE Transactions on Power Delivery, vol. 20, no 2, pp. 1332-1340, Apr. 2005.

SHARMA, K. and SAINI, L. M. Performance analysis of smart metering for smart grid: An overview. Renewable and Sustainable Energy Reviews, vol. 49, pp. 720-735, September, 2015.

SHORT, T. A. Electric Power Distribution Handbook. CRC Press LLC. 2004. 762 p.

SILVA, M. P. S. Mineração de Dados - Conceitos, Aplicações e Experimentos com Weka. IV Escola Regional de Informática Rio de Janeiro - Espírito Santo, 2004.

SRINIVASAN, K.; ST.-JACQUES, A. A new fault location algorithm for radial transmission lines with loads. IEEE Transactions on Power Delivery. vol. 4, nº 3, pp. 1676-1682, Jul. 1989.

STANGE, R. L. Adaptatividade em aprendizagem de máquina: conceitos e estudo de caso. Dissertação de Mestrado apresentada a Escola Politécnica da Universidade de São Paulo. Departamento de Engenharia de Computação e Sistemas Digitais. São Paulo, 2011. 98 p.

STEVENSON, W. D. Elements of Power System Analysis, 4th edition McGraw Hill Higher Education, 1982, 436 p.

TAKAGI, T.; YAMAKOSHI, Y.; BABA, J.; UEMURA, K.; SAKAGUCHI, T. A new algorithm of an accurate fault location for EHV/UHV transmission lines: Part I - Fourier Transformation Method. IEEE Transactions on Power Apparatus and Systems, vol. PAS-100, nº 3, pp. 1316-1323, Mar. 1981.

TAKAGI, T.; YAMAKOSHI, Y.; BABA, J.; UEMURA, K.; SAKAGUCHI, T. A new algorithm of an accurate fault location for EHV/UHV transmission lines: Part II - Laplace Transform Method. IEEE Transactions on Power Apparatus and Systems, vol. PAS-101, n 3 , p.564-573, Mar. 1982a.

TAKAGI, T.; YAMAKOSHI, Y.; YAMAURA, M.; KONDOW, R.; MATSUSHIMA, T. Development of a new type fault locator using the one-terminal voltage and current data. IEEE 
Transactions on Power Apparatus and Systems, vol. PAS-101, n 8, pp. 2892-2898, Aug. 1982b.

THEODORIDIS, S.; KOUTROUMBAS, K. Pattern Recognition. $4^{\mathrm{a}}$ Edition, Academic Press, 2008, 984 p.

TRINDADE, F. C. L.; FREITAS, W.; VIEIRA, J. C. M. Fault Location in Distribution Systems Based on Smart Feeder Meters. IEEE Transactions on Power Delivery, vol. 29, nº 1, p. 251260, Jul. 2014.

TUBALLA, M. L. and ABUNDO, M. A review of the development of Smart Grid technologies. Renewable and Sustainable Energy Reviews, vol. 59, pp. 710-725, June, 2016.

VON ZUBEN, F. J.; ATTUX, R. R. F. Árvores de Decisão, IA004: Neural Networks II, DCA/FEEC/Unicamp, 2010.

WEKA. The Waikato University. Disponível em: http://www.cs.waikato.ac.nz/ml/weka. Acessado em 03/08/2017.

WITTEN, I. H.; FRANK, E. Data mining: practical machine learning tools and techniques. 2nd Ed. Elsevier, 2005, 558 p.

WONG, W. E.; DEBROY, V.; GOLDEN, R.; XU, X.; THURAISINGHAM, B. Effective Software Fault Localization Using an RBF Neural Network. IEEE Transactions on Reliability, vol. 61, nº 1, pp. 149-169, Mar. 2012.

YAN, Y.; QIAN, Y.; SHARIF, H.; TIPPER, D. A survey on smart grid communication infrastructures: Motivations, requirements and challenges. IEEE Communications Surveys \& Tutorials, vol. 15, nº 1, pp. 5-20, Jan. 2012.

YOLDAS, Y.; ÖNEN, A.; MUYEEN, S. M.; VASILAKOS, A. V.; ALAN, I. Enhancing smart grid with microgrids: Challenges and opportunities. Renewable and Sustainable Energy Reviews, vol. 72, pp. 205-214, May, 2017. 
ZAYANDEHROODI, H.; MOHAMED, A.; SHAREEF, H.; MOHAMMADJAFARI, M. Automated Fault Location in a Power System with Distributed Generations using Radial basis Function Neural Networks. Journal of Applied Sciences, vol. 10, n 23, pp. 3032-3041, 2010.

ZHU, J.; LUBKEMAN, D. L.; GIRGIS, A. A. Automated fault location and diagnosis on electric power distribution feeders. IEEE Transactions on Power Delivery, Piscataway, NJ, vol. 12, nº 2, pp. 801-809, Apr. 1997. 